\title{
Glucagon-like peptide 1 stimulation in relation to body weight
}

Citation for published version (APA):

Adam, T. C. M. (2005). Glucagon-like peptide 1 stimulation in relation to body weight. [Doctoral Thesis, Maastricht University]. Datawyse / Universitaire Pers Maastricht. https://doi.org/10.26481/dis.20050120ta

Document status and date:

Published: 01/01/2005

DOI:

10.26481/dis.20050120ta

Document Version:

Publisher's PDF, also known as Version of record

\section{Please check the document version of this publication:}

- A submitted manuscript is the version of the article upon submission and before peer-review. There can be important differences between the submitted version and the official published version of record.

People interested in the research are advised to contact the author for the final version of the publication, or visit the DOI to the publisher's website.

- The final author version and the galley proof are versions of the publication after peer review.

- The final published version features the final layout of the paper including the volume, issue and page numbers.

Link to publication

\footnotetext{
General rights rights.

- You may freely distribute the URL identifying the publication in the public portal. please follow below link for the End User Agreement:

www.umlib.nl/taverne-license

Take down policy

If you believe that this document breaches copyright please contact us at:

repository@maastrichtuniversity.nl

providing details and we will investigate your claim.
}

Copyright and moral rights for the publications made accessible in the public portal are retained by the authors and/or other copyright owners and it is a condition of accessing publications that users recognise and abide by the legal requirements associated with these

- Users may download and print one copy of any publication from the public portal for the purpose of private study or research.

- You may not further distribute the material or use it for any profit-making activity or commercial gain

If the publication is distributed under the terms of Article $25 \mathrm{fa}$ of the Dutch Copyright Act, indicated by the "Taverne" license above, 
Glucagon-like Peptide 1 Stimulation in Relation to Body Weight 


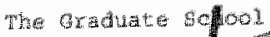

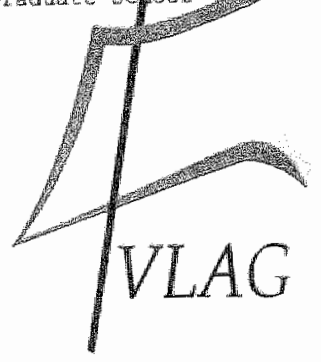

The studies presented in this thesis were performed at the Nutrition and Toxicology Research Institute Maastricht (NUTRIM). which participated in the Graduate School VLAG (Food Technology. Agrobiotechnology, Nutrition and Health Sciences) accredited by the Royal Netherlands Academy of Arts and Sciences.

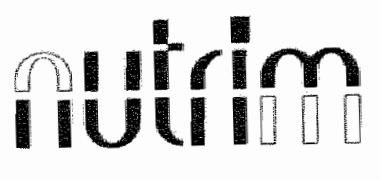

The research described in this thesis was supported by grants from Nowartis consumer Heath Lid., Nyon. Switzerland and Novartis Pharmaceuticals, Basel Switzentand and Sunmmit, USA.

Printing of this thesis was financially supported by Novartis Consumer Health Lid..

Financial support by the Dutch Heart Foundation and the Dutch Diabetes Research Foundation as well as by Nuclilab and Linco Research Inc. for the publication of this thesis is gratefully acknowledged.

Cover design: Tanja Adam

Lay-out: $\quad$ Tanja Adam, Annett Gericke

Printed by: Datawyse, Universitaire Pers Maastricht

(9) Tanja Comelia Maria Adam, Maastricht 2004

ISBN 9052784485 


\title{
Glucagon-like Peptide 1 Stimulation in
}

\author{
Relation to Body Weight
}

\author{
Proefschrift
}

ter verkrijging van de graad van doctor

aan de Universiteit Maastricht,

op gezag van de Rector Magnificus,

Prof. mr. G.P.M.F. Mols"

wolgens het besluit van het College van Decanen.

in het openbaar te verdedigen

op donderdag 20 januari 2005 om 14.00 uur

door

Tanja Cornelia Maria Adam

Geboren te Andernach (Duitsland) op 11 januari 1974

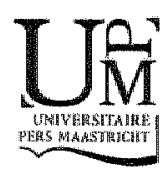




\section{Promotores:}

Prof. dr. K. R. Westerterp

Prof. dr. T.W.A. de Bruin

\section{Co-promotor:}

Dr. M. S. Westerterp-Plantenga

\section{Beoordelingscommissie:}

Prof. dr. ir. R. P. Mensink (voorzitter)

Prof. dr, ir P. A. van den Brandt

Prof. dr. W. Langhans (ETH Zürich, Switzerland)

Prof. dr. M. F. von Meyenfeldt

Prof. dr. A. J. W. Scheurink (Rijksuniversiteit Groningen) 
Es muß das Herz bei jedem Lebensrufe Bereit zum Abschied sein und Neubeginne.

Um sich in Tapferkeit und ohne Trauern In andre, neue Bindungen zu geben. Und jedem Anfang wohnt ein Zauber inne Der uns beschützt und der uns hilift, zu leben 



\section{Contents}

Page

1. General Introduction 9

2. Galactose in combination with guar gum stimulates 27

GLP-1 release in healthy, normal-weight subjects

3. Nutrient-stimulated GLP-1 release in normal-weight men and women

4. Activity-induced GLP-1 release in lean and obese subjects

5. GLP-1 release and satiety after a nutrient challenge in normal-weight and obese subjects

6. Decreased GLP-1 release after weight loss in obese subjects

7. Nutrient stimulated GLP-1 release after body-weight loss and weight maintenance in humans

8. General Discussion

Summary

Samenvatting

Zusammenfassung

Dankwoord

Publications 

Chapter 1

\section{General Introduction}




\section{Body weight regulation}

The way to maintain a stable body weight is to balance the daily energy intake with its expenditure. Whether this balance is achieved through the control of intake or by the control of expenditure has been at issue (1). The control of food intake, reflected in the pattern of eating and overall energy intake, makes a contribution to the maintenance of a healthy weight. It follows that poor regulation can lead to weight gain and obesity (2). In humans, body weight tends to remain within a relatively narrow range, despite a large daymto-day fluctuation in the amount of food consumed. Aithough major changes of energy intake can be induced in humans by restricting energy intake or by overfeeding, body weight returns very close to baseline levels when ad libitum feeding is resumed $(1,3)$.

Short-term and long-term food intake and energy balance are regulated through distinct, but interacting mechanisms. In this context neural and hormonal signals (i.e. gastrointestinal hormones) are involved (Fig. 1). This thesis deals with one particular gastrointestinal homone, glucagon-like peptide 1 (GLP-1), which is believed to play a role depending on body weight status $(3,4)$.

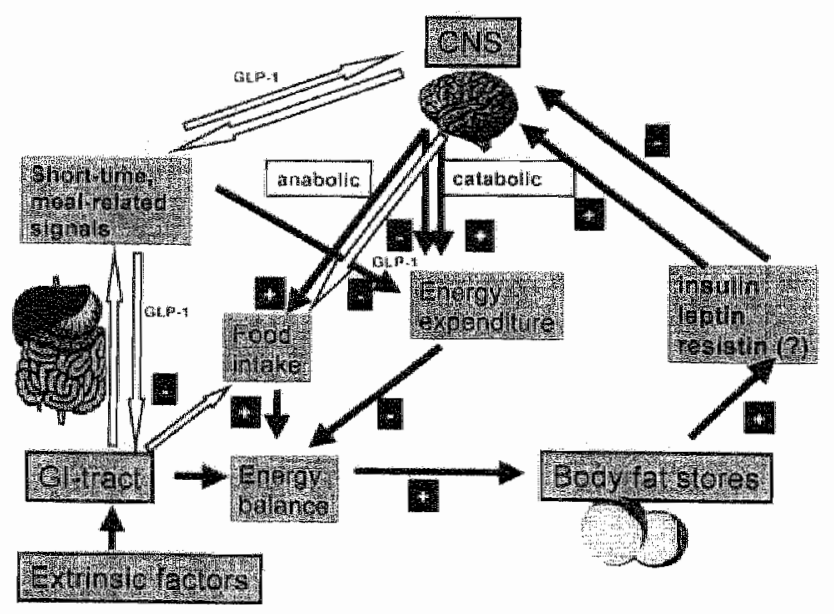

Figure 1 Regulation of energy balance and obesity (4)

Neural systems and homonal signals of energy balance represent major controllers of food intake. Anabolic effector pathways promote feeding and suppress energy expenditure, whereas catabolic effector pathways have the opposite effect. Short-term, meal-related hormonal (i.e. GLP-1) and neuronal (i.e. via distension of the stomach) signals from the gut exert further effects on central nervous regulation of feeding and energy balance. Biological effects of GLP-1 are shown by open
arrows. 


\section{Obesity}

Obesity is defined as an excessive accumulation of body fat. For dassification of overweight and obesity the body mass index (BMI = body weight (kg)/ height (m)2) is commonly used. A classification of normal weight, overweight and obesity based on BMI has been published by the World Health Organization (WHO) (5). For each BMI class the severity of associated health risks have been described (Table 1 ).

Table 1. The WHO classification by BMI in adults (5)

\begin{tabular}{lll} 
BMI $(\mathrm{kg} / \mathrm{m} 2)$ & Classification & Associated health risks \\
\hline$<18.5$ & Underweight & $\begin{array}{l}\text { low (but risk of other clinical } \\
\text { problems increased) } \\
\text { average }\end{array}$ \\
$18.5-24.9$ & Nomal range & increased \\
225.0 & Owerweight & moderately increased \\
$25.0-29.9$ & Obese class I & severely increased \\
$30.0-34.9$ & Obese class II & very severely increased \\
$35.0-39.9$ & Obese class III & \\
240.0 & &
\end{tabular}

The incidence and prevalence of obesity is reaching alarming levels in children (6) as well as adults (7) in and outside the United States (8). Obesity is strongly associated with insulin resistance, dyslipidaemia, hyperinsulinemia, hypertension, cardiovascular disease and non-insulin-dependent diabetes (NIDDM) $(9,10)$. This cluster of metabolic disorders is also known as metabolic syndrom (11). The health risks, that are associated with obesity relate to the amount of fat and to the distribution of fat. Obesity has been found to be a major determinant of health care costs, varying between $1-5 \%$ of total health care expenditure depending on the definition of obesity (12).

Diet-induced obesity is the result of a long-term imbalance of energy expenditure and energy intake. Energy intake, thus food intake regulation is a complex process that involves physiological as well as social and psychological components. It is a form of behaviour that is subject to conscious control although many obese or welght gaining individuals claim that in practice their eating is out of their own control (2).

\section{Satiety}

Satiety can be described as the inhibition of eating and hunger as a consequence of food consumption. It needs to be distinguished from satiation, which is the process that brings a period of eating to a halt. Satiety and satiation act together and determine the pattern of eating behavior (13). For a better understanding of satiely, it is useful to distinguish the different phases of satiety and the different mechanisms that characterize them. Extent and capacity of food to suppress hunger and inhibit further eating is called satiating efficiency of a food $(14,15)$. Food causes this effect by mediating processes 
that can be classified as sensory, cognitive, postingestive and postabsorptive. These processes are operated by the impact of food on physiological and biochemical mechanisms (16) and have been referred to as the satiety cascade. The satiety cascade relates to three levels of operation of the psychobiological system: the behavioural pattern, the peripheral physiology and metabolism and brain activity (Fig. 2) (17). The concept of the satiety cascade implies that foods that vary in nutrient composition will correspond differently with the satiety mediating processes and will therefore exert different effects on satiation and satiety.

The way in which food is sensed and processed by the biological system generates neural and humoral signals, which are used to control appetite.

One part of the system involves signals of body energy reserves. These include insulin and leptin, the long-term signals that contribute to feeding behaviour and body weight regulation (3). Another component of the system is the control of feeding by the gastrointestinal tract. Specific triggers for hunger and satiety, such as gut hormones, that are released in response to nutrient ingestion control frequency of eating meal size and hence total energy intake. GLP-1 is one of those gut hormones. In addition the gut hormones ghrelin (18), Peptide $Y$ (19), pancreatic polypeptide and oxyntomodulin (20) may all play a role.

\section{GLP-1}

\section{Biosynthesis \& Metabolism}

Glucagon-like peptide (GLP) 1 is a 30 amino acid peptide hormone derived from the glucagon precursor proglucagon. The mammalian glucagon precursor is produced both in the a cells of the islets of Langerhans and in the L cells of the intestinall mucosa (21). Proglucagon contains sequences for GLP-1 and glucagon and GLP-2. All three domains are structurally related, whereas GLP-1 and glucagon show a 50\% sequence homalogy by sharing 14 amino acids in identical positions. Pancreatic and intestinal glucagonrelated peptides are encoded by the same single gene, leading to an identical proglucagon RNA transcript, but to different processing in brain, pancreas and gut (Fig. 3). which is probably due to different prohormone convertases $(21,22)$. In the pancreas, glucagon is cleaved from its precursor as the major biologically active hormone, whereas in the gut GLP 1 (7-36 amide) is the major active peptide, due to a different cleavage site. 


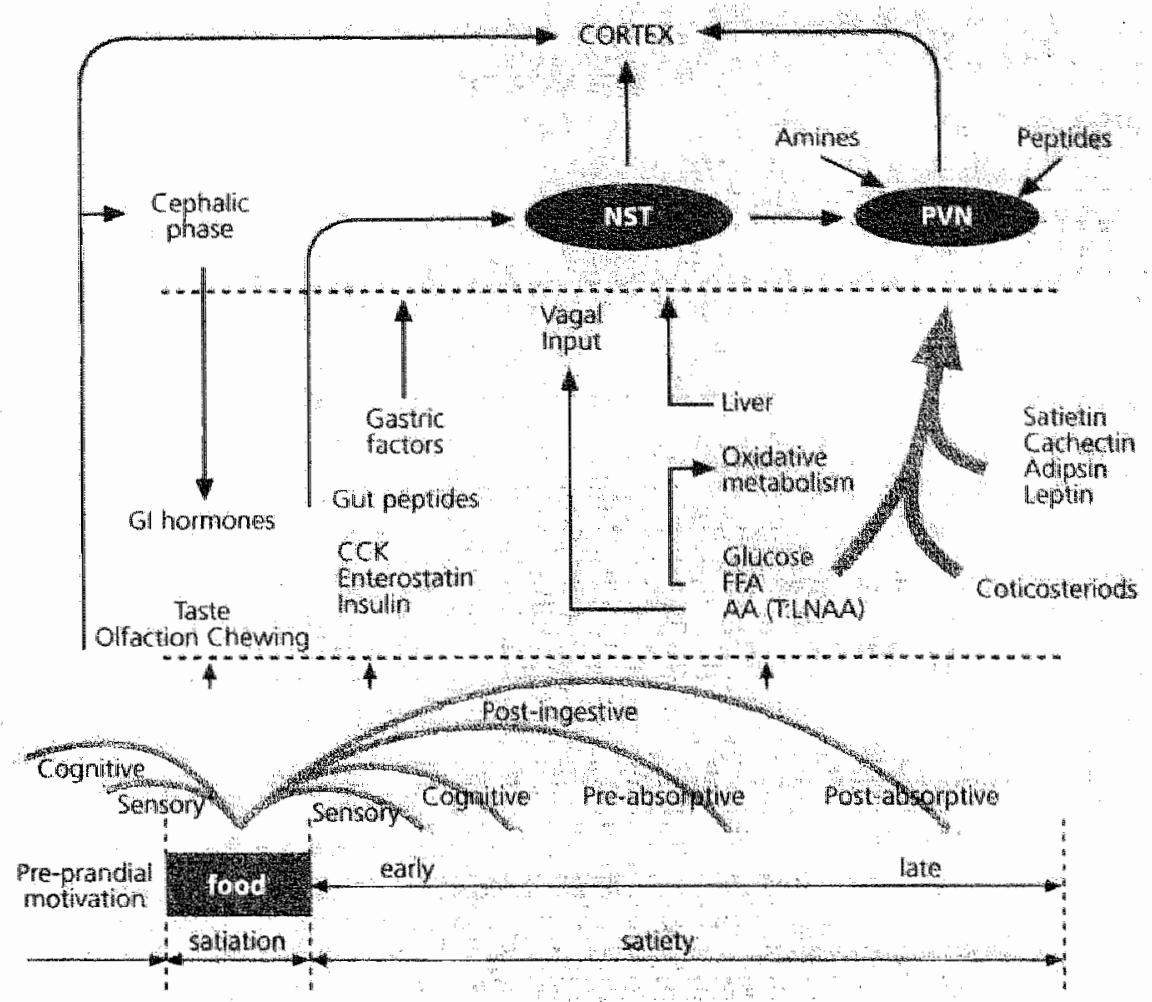

$\mathrm{PVN}=$ paraventricular nucleus, $\mathrm{NST}=$ nucleus of the tractus solitarius, $\mathrm{CCK}=$ cholecystokinin, $\mathrm{AA}=$ amino acids, $\mathrm{T}=$ tryptophan, $\mathrm{LNAA}=$ large neutral amino acids.

Figure 2. The satiety cascade in relation to three levels of operation of the psychophysiological system : The behavioral pattern, peripheral physiology and metabolism and brain activity (17) atter Bundell)

Glucagon-like peptide 1 occurs as a non-amidated form (GLP-1 (7-37amide)), also called insulinotropin, and as an amidated form (GLP-1 (7-36)), which predominantly is produced in the ileum. The latter one is physiologically more important, because $80 \%$ of plasma activity seems to be related to that form of GLP-1 (23). This thesis will deal with GLP-1 (7-36), unless otherwise specified. 


\section{PROGLUCAGON}

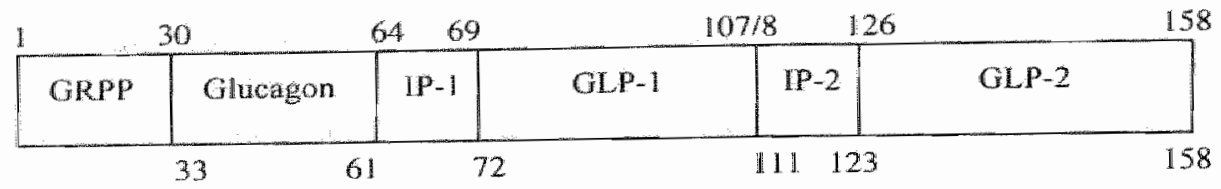

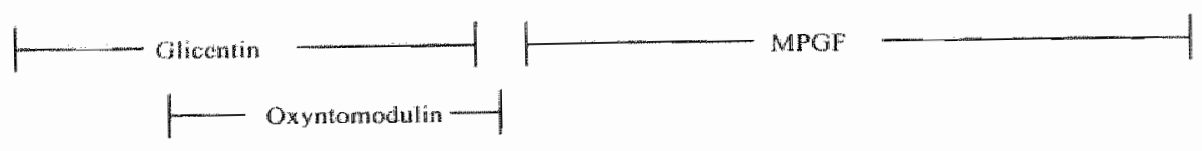

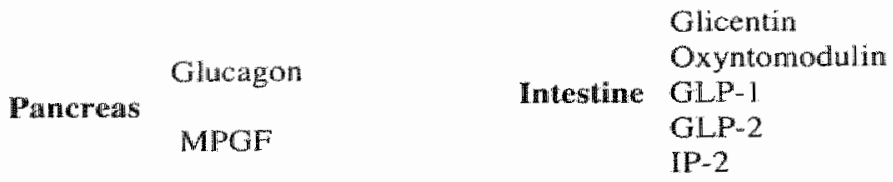

GRPP fragnicat.

Figure 3. Structural organization of mammalian proglucagon (22). The numbers refer to the amino acid sequences in proglucagon. The peptides released by posttranslational processing in the pancreas and intestines are shown.

GLP-1 has a short half wife, due to a rapid degiradation by dipeptidyl-peptidase IV representing the intravascular route of elimination. By remowing two amino acid residues from the Nuterminal of the intact peptide it transforms the biologically active GLP-1 ( 7 36) into an inactive or antagonistic GLP-1 (9-36). This transformation happens very rapidly and leads to a half-life time of less than three minutes (24). In addition to the vascular component there seems to be an organ-related mechanism playing a central role in the degradation of the active GLP-1, a mechanism that probably involves the kidney. Measuring achive GLP-1 requires that the method, which is used, should be clirected to the $N H 2$ terminal of the molecule. If only COOH terminated methods are used, active as well as inactive GLP-1 will be measured. If a C-as well as a N-terminated assay is used, it is possible to make the measurement even more precise and determine $N$-terminally truncated metabolites. The $N$-terminus of the peptide is important for receptor binding, the C-terminus is important for biological activity (25).

Postprandially, the level of GLP-1 (9-36) released, exceeds that of the bioactive 7-36 amide molecule. The inactive form also binds to the GLP-1 receptor but with a lower affinity than the active form (24). 


\section{Secretion and Reception}

GLP 1 releasing $\mathrm{L}$ cells are distributed throughout the intestine but the greatest numbers are found in the jejunum, distal ileum and colon (26). The GLP-1 amino acid sequence is identical across different mammalian species and is highly conserved throughout evolution. Concentrations show a pulsatile pattern and ranges of basal concentrations depend on the assays used. Deacon et al. found fasting active GLP-1 (7-36 amide) levels of $3.3 \pm 0.7 \mathrm{pmol} / \mathrm{L}$ rising up to $9.9 \pm 1.2 \mathrm{pmol} / \mathrm{L}$ in a postprandial state (24).

GLP-1 is released in a biphasic pattern after food intake, with a first peak about $1.5-30$ minutes after nutrient ingestion and a second peak approximately one hour later (27). Elliot et al. (27) reported GLP-1 peaks $30 \mathrm{~min}$ after a carbohydrate and protein meal and 150 min after a fat meal. Results reported by Hermann et al. (28) as well as Orskov et al. (29) confirmed the pattern of GLP-1 response to a meal. Since most of the L cells are localized in the distal small intestine, it seems likely, that the GLP-1 secretion after a meal additionally is induced by signals from the proximal gut, rather than by direct L cell stimulation through luminal nutrients.

Two different systems for the release of GLP-1 have been suggested. The first phase is likely to be caused by a mediated response, whereas the second phase is initiated by nutrient sensation in the distal ileum (30).

One explanation for the early phase of GLP-1 release after the administration of nutrients into the duodenum is the indirect GLP.1 stimulation through a pathway involving the glucose-dependent insulinotropic polypeptide (GIP) secrection by endocrine $\mathrm{K}$ cells, which in turn stimulates the afferent vagus nerve to the central nervous system; thereby activating the efferent vagus to the distal gut (30-33).

These findings underline the possible importance of mediating influences of peptides, endacrine and neural mechanisms in GLP-1 secretion.

Both, GLP-1 secretion and GLP-1 reception have been the focus of recent interest because of their central role in glucose metabolism (34).

Although the sequence homology of amino acids between glucagon and GLP 1 is quite high, they both have specific receptors, which also show an extensive sequence homology, but hardly interact with each other (34). In rats GLP 1 receptors have been identified in thalamic and hypothalamic regions and in the brainstem. Since high concentrations of GLP-1 immunoreactive fibers and cells are localized in arreas where food intake is controlled, like i.e.the periventricular areas, it seems likely that GLP-1 has an influence on food intake and satiety. This has been confirmed by experiments using c-fos as a marker of neuronal activation (35).

GLP-1 receptor mRNA transcripts have been found in human pancreas", lung." kidneym, stomach-, heart- and brain tissues. GLP-1 exerts its actiwity through binding to a Gprotein-linked receptor, which is expressed on the islet b-cells (22). A 90\% homology has been detected between the human and rat receptors. The possibility of cloning the 
receptor allows the investigation of specific structure functions and signal transduction studies (36).

\section{Biological activities of GLP-1}

Pathways, loops or mechanisms by which GLP-1 exerts its effects on insulin, glucagon, glucose, possibly in relation to hunger, satiety or energy intake are still unclear for a large part. The question whether GLP-1 affects food intake regulation via a direct effect on the brain by crossing the blood-brain barrier or an indirect effect by slowing gastric emptying or neural signaling, is still under discussion. There is evidence that the peptide is able to reach the brain by gaining access to subfornical organs and the area postrema $(37,38)$. These areas lack a perivascular blood-brain barrier and allow free exchange of molecules between blood and cerebrospinal fluid.

There are several ways to manipulate active GLP-1 concentrations experimentally. One is to prevent degradation of active GLP-1 by applying a peptidase inhibitor (DPP-IV inhibitor) to avoid truncation of the peptide. Secondly, many studies have applied GLP-1 exogenously, mostly intravenously (iv) or intracerebroventricular (icv).

In line with the suggestion that peripheral GLP-1 might not have fully access to receptors in the brain are the results of rat experiments, in which effects on food and water intake were only obtained by centrally administered GLP-1 and not by peripherally given GLP 1 (39).

In healthy humans, peripheral GLP 1 tumed out to have an effect on satiety and appetite sensations as well as on glucagon, insulin and blood glucose levels (40). The same results for appetite and energy intake have been reported for subjects with obesity as well as those with NIDDM, in whom energy intake was reduced by $27 \%$ by GLP-1 compared to saline infusion (41). Actions of GLP-1 are summarized in Fig. 4.

\section{The incretin effect}

According to Creutzfeldt (42) an incretin is defined as an endocrine transmitter produced in the gastrointestinal tract, that is released after stimulation by nutrients (especially carbohydrates), and that stimulates insulin release at physiological concentrations. Incretins work through a sensitization of beta cells to glucose stimulation, thereby leading to an augmented insulin response to absorbed glucose (42) and contribute to postprandial control of substrate concentrations, especially glucose. Many peptides were discussed as incretings. The two peptide hormones that qualify as incretins, are glucagon-like peptide 1 (GLP-1) and gastric inhibitory polypeptide (GIP) (43).

Their effects on insulin secretion is additive and the effect of both of them seem to account for the whole incretin effect in humans. When GLP-1 (7-36) and GIP are infused at physiologicai doses, GLP-1 tums out to be more powerful than GIP conceming insulin stimulation (44). 
Studies using exendin (9-39 amide), a GLP-1 receptor antagonist, provide ewidence for GLP-1 as an important physiological incretin by attenuating insulin response and elicting increased plasma glucose levels after intraduodenal glucose infusion (22).

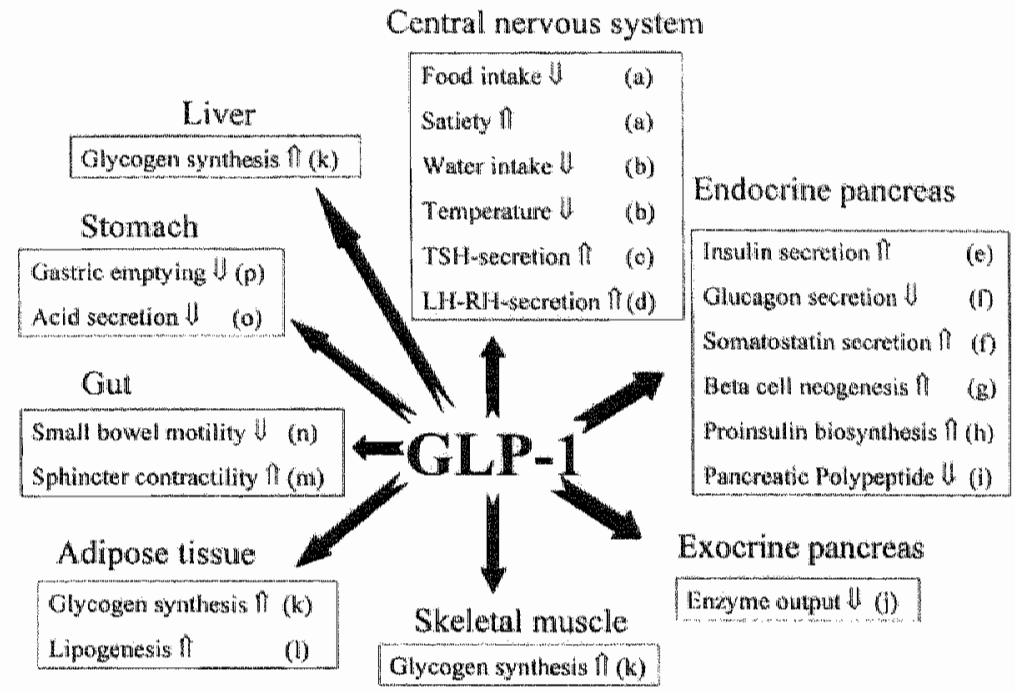

Figure 4. Actions of GLP-1 in various organs and tissues in vivo (4 (modified according to (80)). Small letters indicate references documenting the quoted effect:

(a) (40); (b) (81); (c) (82); (d) (83); (e) (84); (f) (46); (g) (85); (h) (86); (i) (87); (b) (61); (k) $(88) ;(1)(89) ;(m)(90) ;(n)(91) ;(0)(59) ;(p)(61)$.

\section{Glucagon suppression}

It has been reported that GLP-1 in physiological doses inhibits glucagon secretion in animals as well as in humans (45). Furthermore, the peptide stimulates somatostatin secretion. This has been shown by experiments in the perfused pig pancreas (46). Somatostatin in turn has been proposed, like GLP-1, to lower or moreover inhibit glucagon secretion. Additionally, it prolongs the absorption of nutrients by decreasing the motility of the small intestine (42). To answer the question whether glucagon suppression is primarily due to the influence of GLP-1 or is mediated by its influence on somatostatin, we may look at experiments which have shown, that GLP-1 induces inhibition of glucagon release from isolated human cells, but not from a culture of pancreatic islets (47). This suggests that the effect on glucagon-producing cells is indirect (23). 


\section{Glucose-tolerance improvement}

The prevalence of insulin resistance, a decreased ability of insulin to stimulate glucose uptake in peripheral tissues is increased in obese individuals. Although the majority of individuals in the general population that can be considered insulin resistant are also obese, not all obese individualls are insulin resistant $(48,49)$. A failure of b-cells to compensate for the insulin resistance then leads to both, fasting and postprandial hyperglyceamia or glucose intolerance. Criteria for the diagnosis of various forms of hyperglycemia, such as impaired glucose tolerance, impaired fasting glucose, and finally diabetes have been developed by the WHO (50).

An improvement of glucose tolerance through i.e. exogenous administration of GLP-1 has been reported in animal as well as in human studies, in healthy subjects as well as in obese subjects and subjects suffering from NIDDM (51-55).

An explanation for the improved glucose tolerance caused by GLP-1 is, that GLP-1 might accelerate glucose elimination through its insulinotropic effect $(51,56)$.

Experiments in humans with the GLP 1 receptor antagonist exendin (9-39) have shown a significant deterioration in postprandial glycemic control, which suggests, that GLP-1 is an important factor in mediating the physiological regulation of postprandial glucose concentrations (54).

\section{Gastric actions}

Glucagon and related peptides, such as GLP-1 are potent pharmacological inhibitors of gastric acid secretion in humans (57-59). GLP-1 stimulates CAMP production in gastric cells as well as adenylate cyclase activity, the corresponding enzyme that is localized in the cell membrane. This suggests that GLP-1 plays a pivotal role in the enteric control of gastric acid secretion.

Schjoldjager et al (59) were able to support this suggestion by finding an inhibition of gastric acid secretion in humans by truncated GLP-1. It aiso has been shown, that gastric acid output during a GLP-1 (7-36) infusion close to postprandial levels (44) decreased pentagastrin stimulated acid output in man by $47-49 \%$ (57).

Effects on gastric emptying are controversial $(43,60)$. The inhibitory action of GLP-1 on gastric emptying has been described in normal subjects and in type 2 diabetic subjects (61). Using paracetamol as a marker, Balkan et al. (43) did not find any effect of GLP-1 on gastric emptying in rats.

\section{Effects on satiety and food intake}

GLP- 1 is supposed to affect hunger, satiety and appetite. Although findings concerning the reduction of sensations of hunger and satiety are controversial (62), most studies found a significant reduction of energy intake in healthy (40), as well as in diabetic (41) and obese subjects (63). For an owerview see Table 2 . 
The role of the vagus nerve in signal transduction, suggests, that GLP-1 affects satiety in terms of an inter-meal interval related satiety rather than by satiation (62).

GLP-1 receptors are localized in brain areas, which are strongly involved in the control of feeding (40). With the administration of exendin (9-39), the GLP-1 receptor antagonist, humans increase their food intake when having access to an ad libitum meal (35). These results contribute to the suggestion of a role for GLP-1 in the control of hunger and satiety. The mechanisms by which GLP-1 leads to a regulation of appetite and food intake are not clear yet. One of the current explanations is, that the effect of GLP-1 on satiety might be due to its inhibition of gastric emptying and thereby leading to a prolonged period of gastric distension (64). This again leads to a prolonged period of release of various other gastrointestinal hormones and a longer simulation of gastrointestinal vagal receptors that are involved in the control of food intake (62).

\section{GLP-1 and obesity}

The role of GLP-1 in relation to obesity is not clear yet. One study has been reporting hypersecretion of GLP-1 in obese subjects. Others have found lower basal as well as attenuated responses to carbohydrate stimulation in the obese $(65,66)$.

According to latter it can be speculated that the lower postprandial GLP-1 level in obese subjects may lead to a shorter inter-meal interval related satiety and thereby leading to a more frequent food intake to reach appropriate individual satiety levels (20). Several studies have shown that GLP-1 administration prolongs postprandial satiety and improves glycaemic control in the obese (63). Observations concerning stimulated GLP-1 release in obesity seem to be strongly related to the class of obesity (63), the health status (67) that is being investigated and the kind of macronutrient that is used as a stimulus (65). Studies investigating GLP-1 release in relation to obesity have been assessing subjects with an BMI of 38 or higher concerning the postprandial GLP-1 release $(65,66)$. With respect to treatment and prevention it is important though that pre-obese and class I obesity are being investigated as well. Studies investigating the effect of GLP-1 on appetite parameters mostly have been assessing the effect of pharmacological dosages of GLP-1 $(35,63)$. When physiological concentrations were used, only hunger and prospective food consumption were affected, all other ratings and ad libitum energy intake were not different compared to a placebo condition (68). Assessment of the effect of weight loss on GLP-1 led to ambivalent results. Strong improvement of GLP-1 concentrations was shown after jejunoileal bypass surgery, when subjects were investigated twenty years after surgery (69). Short-term effects of surgery on GLP-1 concentrations could not be observed (70). Only very few studies have been investigating the effect of diet-induced weight loss on GLP-1 concentrations. Results in the study from Verdich et al. show differences in GLP-1 concentrations between obese and lean subjects, but no improvement due to weight loss in the obese subjects (71). Others report a decrease in GLP-1 concentrations after weight loss (72). 


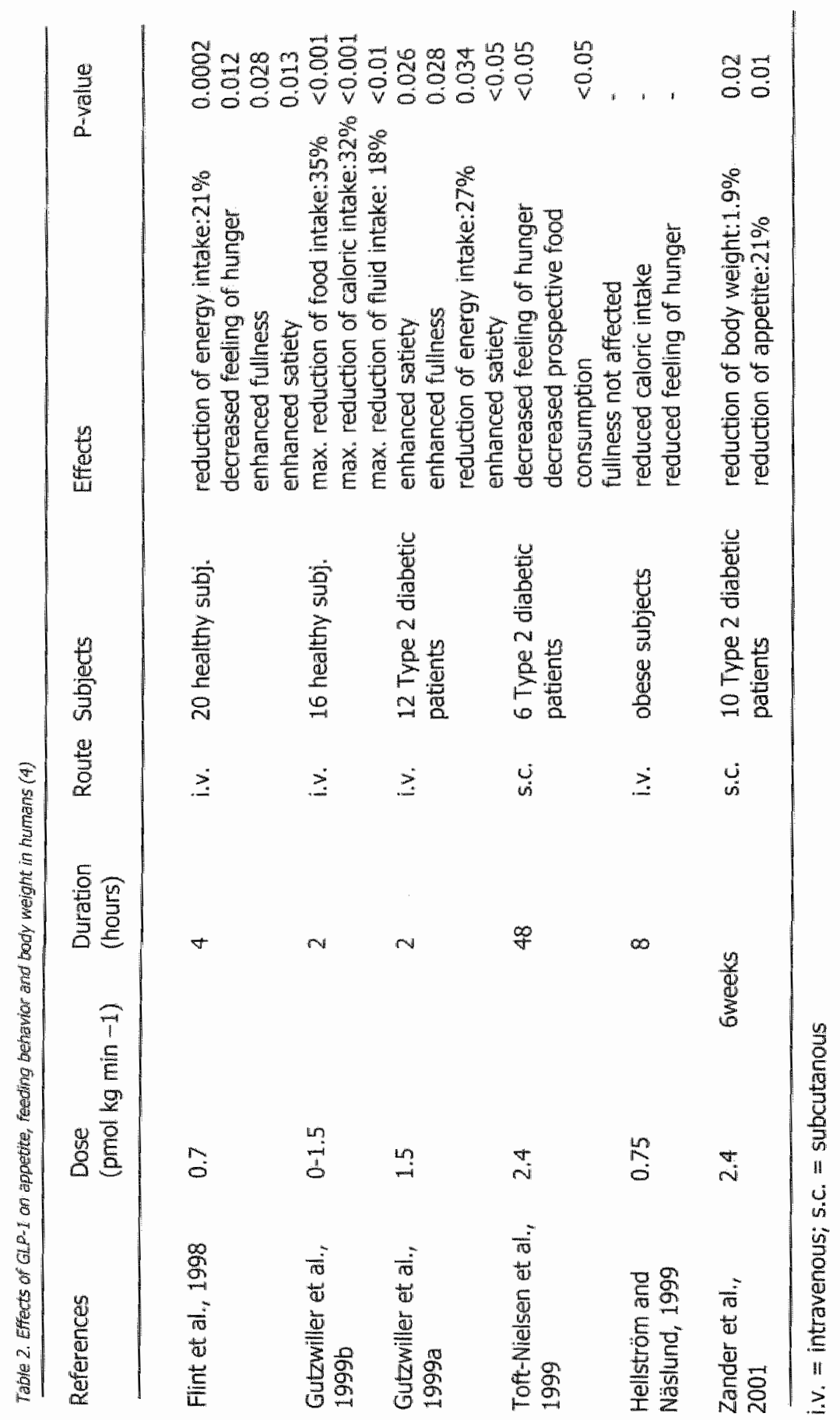




\section{Outline of the thesis}

Many questions remain unanswered concerning the role of GLP-1 in obesity and the potential role of GLP-1 for prevention and treatment of obesity. This thesis describes a series of experiments that aim to study nutrient and physical activity stimulated GLP-1 release in relation to body weight and to which extent GLP-1 can be considered a metabolic target for the treatment of obesity.

In order to answer these questions we firstly assessed whether basal and postprandial GLP-1 concentrations are related to body weight and thus are different between lean and overweight/ obese subjects (Chapter $2,3,5$ ). Second we explored ways in which GLP-1 release can be stimulated in normal-weight subjects (Chapter $2,3,4$ ). It is known that glucose is a potent stimulus for GLP-1 release (73). With respect to glyceamic index and treatment or prevention of obesity (74), it seems reasonable to test non-glucose carbohydrates as well, like galactose $(28,75,76)$ and dietary fiber and their potential to stimulate GLP-1 release. Dietary fiber, such as guar gum have been suggested to act on satiety by stimulating gastrointestinal peptides (77) and fermentable dietary fiber has been shown to increase GLP-1 release in animals (78),

After investigating ways of stimulating GLP-1 release in normal-weight subjects, we assessed, whether stimulation of GLP-1 release observed in normal-weight subjects also appeared in obese subjects (Chapter 4, 5).

Since the autonomic nervous system has been suggested to be involved in the release of GLP-1 as well $(28,79)$ we have been investigating the effect of physilcal exercise on GLP-1 secretion in obese and normal-weight subjects (Chapter 4).

Not much is known yet about the influence of weight loss on GLP-1 release. Increased concentrations of GLP-1 have been found (69), while other studies observed decreased GLP-1 concentrations after weight loss (72). These results might depend on the amount of weight loss or the way weight was lost and need further investigation (Chapter 4,6 ).

Finally it is important not only to look at the effect of weight loss on GLP-1 release, but also to investigate how GLP-1 concentrations change after weight loss, during a weight maintenance period (Chapter 7). Time of investigation after weight loss, seems to play an important role for the conclusion concerning GLP-1 concentrations $(69,70,72)$.

The results of the studies described above are dliscussed (Chapter 8) with the purpose of coming to a general conclusion on the role of GLP-1 as a metabolic target for the treatment of obesity. 


\section{References}

1. Keesey RE, Hirvonen MO. Body weight set-points: determination and adjustment. J Nutr 1997;127:18755-18835.

2. Blundell JE, Gillett A. Control of food intake in the obese. Obes Res 2001;9 Suppl $4: 2635-2705$.

3. Havel P]. Peripheral signals conweying metabolic information to the brain: short-term and long-term regulation of food intake and energy homeostasis. Exp Biol Med (Maywood) 2001;226:963-77.

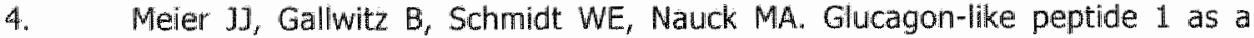
regulator of food intake and body weight: therapeutic perspectives. Eur $I$ Pharmacol 2002;440:269-79.

5. WHO. Obesity: preventing and managing the global epidemic. Geneva: WHO, 1998.

6. Ogden CL, Flegal KM, Carroll MD, Johnson CL. Prevalence and trends in overweight among US children and adolescents, 1999-2000. Jama 2002;288:1728-32.

7. Flegal KM, Carroll MD, Ogden CL, Johnson CL. Prevalence and trends in obesity among US adults, 1999-2000. Jama 2002;288:1723-7.

8. Seidell JC. Obesity, insulin resistance and diabetes--a worldwide epidemic. Br J Nutr 2000;83 Suppl 1:55-8.

9. Pi-Sunyer FX. Medical hazards of obesity. Ann Intern Med 1993;119:655-60.

10. Pi-Sunyer FX. The obesity epidemic: pathophysiology and consequences of obesity. Obes Res 2002;10 Suppl 2:975-1045.

11. Bosello 0 , Zamboni M. Visceral obesity and metabolic syndrome. Obes Rev $2000 ; 1: 47-56$.

12. Seidell IC. The impact of obesity on health status: some implications for health care cost5. Int I Obes Relat Metab Disord 1995;19 Suppl 6:513-6.

13. Blundell JE, Lawton CL, Hill AJ. Mechanisms of appetite control and their abnormalities in obese patients. Horm Res 1993;39 Supp 3:72-6.

14. Kissilleff HR, GruSs LP, Thomton J, Jordan HA. The satiating efficiency of foods. Physiol Behav 1984; 32:319-32.

15. Porrini $M$, Crovetti $R$, Riso $P$, Santangelo $A$, Testolin $G$. Effects of physical and chemical characteristics of food on specific and general satiety. Physiol Behav $1995 ; 57: 461-8$.

16. Blundell JE, Hill $A J$, Rogers PJ. Hunger and the satiety cascade - their importance for food acceptance in the late 20th century. In: Thompson DMH, ed. Food acceptability. London: Elsevier, 1988:233-250.

17. Hetherington MM, Blundell JE. Eating disorders. In: Westerterp-Plantenga MS, Steffens $A B$, Tremblay $A_{v}$ eds. Regulation of Food Intake and Energy Expenditure. Milano: EDRA, 1999:185-199. 
18. Wren AM, Seal $\amalg$, Cohen MA, et al. Ghrelin enhances appetite and increases food intake in humans. J Clin Endocrinol Metab 2001;86:5992.

19. Batterham RL, Cowley MA, small CJ, et al. Gut hormone PYY(3-36) physiologically inhibits food intake. Nature 2002; 418:650-4.

20. Blundell $\mathrm{JE}$, Näslund E. Glucagon-like peptide-1, satiety and appetite control. $\mathrm{Br}$ Jutr 1999;81:259-60.

21. Holst J1. Glucagonlike peptide 1: a newly discovered gastrointestinal hormone. Gastroenterology 1994; 107:1848-55.

22. Drucker DJ. Glucagon-like peptides. Diabetes 1998;47:159-69.

23. Gutniak M. Treatment of Diabetes - GLP-1: a new kid in town. International Diabetes Monitor 1997:9:1-12.

24. Deacon CF, Nauck MA, Toft-Nielsen M, Pridal L, Willms B, Holst J]. Both subcutaneously and intravenously administered glucagon-like peptide I are rapidly degraded from the $\mathrm{NH2}$-terminus in type II diabetic patients and in healthy subjects. Diabetes 1995;44:1126-31.

25. Deacon CF, Johnsen AH, Holst Jj. Degradation of glucagon-like peptide-1 by human plasma in vitro yields an $N$-terminally truncated peptide that is a major endogenous metabolite in vivo. I Clin Endocrinol Metab 1995;80:952-7.

26. Eissele R, Göke $R$, Willemer $S$, et al. Glucagon-like peptide-1 cells in the gastrointestinal tract and pancreas of rat, pig and man. Eur I Clin Invest $1992 ; 22: 283-91$.

27. Elliott RM, Morgan LM, Tredger JA, Deacon S, Wright J, Marks V. Glucagon-like peptide-1 (7-36)amide and glucose-dependent insulinotropic polypeptide secretion in response to nutrient ingestion in man: acute post-prandial and $24-\mathrm{h}$ secretion patterns. J Endocrinol 1993;138:159-66.

28. Hermann $C_{*}$ Göke $R$, Richter $G_{y}$ Fehmann $H_{\text {, }}$ Arnold $R$, Göke B. Glucagon-like peptide- 1 and glucose-dependent insulin-releasing polypeptide plasma levels in response to nutrients. Digestion 1995;56:117-26.

29. Drskov C, Wettergren A, Holst Jj. Secretion of the incretin hormones glucagonlike peptide-1 and gastric inhibitory polypeptide correlates with insulin secretion in normal man throughout the day. Scand J Gastroenterol 1996;31:665-70.

30. Roberge JN, Brubaker PL. Regulation of intestinal proglucagon-derived peptide secretion by glucose-dependent insulinotropic peptide in a novel enteroendocrine loop. Endocrinology 1993;133:233-40.

31. Brubaker PL. Regulation of intestinal proglucagon-derived peptide secretion by intestinal regulatory peptides. Endocrinology 1991;128:3175-82.

32. Aziz A, Anderson GH. Exendin-4, a GLP-1 receptor agonist, interacts with proteins and their products of digestion to suppress food intake in rats. J Nutr $2003 ; 133: 2326-30$.

33. Rocca AS, Brubaker PL. Role of the vagus nerve in mediating proximal nutrientinduced glucagon-like peptide-1 secretion. Endocrinology 1999;140" 1687-94. 
34. Holst 1y. Glucagon, glucagon-like peptide-1 and their receptors: an introduction. Acta Physiol Scand 1996;157:309-15.

35. Nåslund $E$, Gutniak M, Skogàr $S$, Rössner $S$, Hellström PM. Glucagon-like peptide 1 increases the period of postprandial satiety and slows gastric emplying in obese men. Am J Clin Nutr 1998;68:525-30.

36. Dillon JS, Tanizawa $Y$, Wheeler MB, et al. Cloning and functional expression of the human glucagon-like peptide-1 (GLP-1) receptor. Endocrinology $1993 ; 133: 1907-10$.

37. Kastin AJ, Akerstrom W, Pan W. Interactions of glucagon-like peptide-1 (GLP-1) with the biood-brain barrier. J Mol Neurosci $2002 ; 18: 7-14$.

38. Yamamoto $H$, Kishi $T$, Lee $C E$, et al. Glucagon-like peptide-1-responsive catecholamine neurons in the area postrema link peripheral glucagon-like peptide-1 with central autonomic control sites. I Neurosci $2003 ; 23: 2939-46$.

39. Turton MD, O'Shea D, Gunn I, et al. A role for glucagon-like peptide-1 in the central regulation of feeding. Nature $1996 ; 379: 69-72$.

40. Fint A, Raben A, Astrup A, Holst J1. Glucagon-like peptide 1 promotes satiety and suppresses energy intake in humans. J Clin Invest 1998;101:515-20.

41. Gutzwiller JP, Drewe J, Göke B, et al. Glucagon-like peptide-1 promotes satiety and reduces food intake in patients with diabetes mellitus type 2. Am I Physiol $1999 ; 276:$ R $1541-4$

42. Creutzfeldt $W$. The incretin concept today. Diabetologia 1979;16:75-85.

43. Bakian B, Kwasnik $L$, Miserendino $R_{,}$, Holst $J 3$, Li X. Inhibition of dipeptidyl peptidase IV with NVP-DPP728 increases plasma GLP-1 (7-36 amide) concentrations and improves oral glucose tolerance in obese Zucker rats. Diabetologia $1999 ; 42: 1324-31$.

44. Kreymann B, Williams G, Ghatei MA, Bloom SR. Glucagon-like peptide-1 7-36: a physiological incretin in man. Lancet 1987;2:1300-4.

45. Meier JJ, Weyhe D, Michaely M, et al. Intravenous glucagon-like peptide 1 normalizes blood glucose after major surgery in patients with type 2 diabetes. Crit Care Med 2004;32:848-51.

46. Drskow C, Holst J], Nielsen OW. Effect of truncated glucagon-like peptide-1 [proglucagon-(78-107) amide] on endocrine secretion from pig pancreas,
antrum, and nonantral stomach. Endocrinology 1988,123:2009-13.

47. D'Alessio DA, Fujmoto WY, Ensinck JW. Effects of glucagonlike peptide $[-(7-36)$ on release of insulin, glucagon, and somatostatin by rat pancreatic islet cell monolayer cultures. Diabetes 1989;38:1534-8. 48. Chan JM, Rimm EB, Colditz GA, Stampfer M], willett WC. Obesity, fat
distribution, and weight gain as risk factors for clinical diabetes in men.
Diabetes Care 1994; 17:961-9. 49. Reaven $G$, Abbasi F, Mclaughlin T. Obesity, insulin resistance, and
Cardiovascular disease. Recent Prog Horm Res 2004;59:207-23. 
50. WHO. Definition, diagnosis and classification of diabetes mellitus. Report of a WHO Consultation. Part 1: Diagnosis and Classification of Diabetes Mellitus. Geneva, Switzerland, 1999.

51. Ahren B, Pacini G. Dose-related effects of GLP-1 on insulin secretion, insulim sensitivity, and glucose effectiveness in mice. Am J Physiol 1999;277:E996E1004.

52. DAlessio DA, Kahn SE, Leusner CR, Ensinck JW. Glucagon-like peptide I enhances glucose tolerance both by stimulation of insulin release and by increasing insulin-independent glucose disposal. J Clin Invest 1994;93:2263-6.

53. D'Alessio DA, Vogel $R$, Prigeon $R$, et al. Elimination of the action of glucagonlike peptide 1 causes an impairment of glucose tolerance after nutrient ingestion by healthy baboons. J Clin Invest 1996;97:133-8.

54. Edwards CM, Todd JF, Mahmoudi M, et al. Glucagon-like peptide 1 has a physiologicall role in the control of postprandial glucose in humans: studies with the antagonist exendin 9-39. Diabetes 1999;48:86-93.

55. Wang $Y$, Perfetti $R$, Greig NH, et all. Glucagon-like peptide-1 can reverse the age-related decline in glucose tolerance in rats. J Cin Invest 1997;99:2883-9.

56. Gutniak M, Ørskov C, Holst J], Ahren B, Efendic S. Antidiabetogenic effect of glucagon-like peptide-1 (7-36)amide in normal subjects and patients with diabetes mellitus. $N$ Engl I Med 1992;326:1316-22.

57. Laver P, Holst $1 \mathrm{~J}$, Grandt D, Goebell $\mathrm{H}$. Ileal release of glucagon-like peptide-1 (GLP-1). Association with inhibition of gastric acid secretion in humans. Dig Dis Sci 1995;40:1074-82.

58. O'Halloran DJ, Nikou GC, Kreymann B, Ghatei MA, Bloom SR. Glucagon-like peptide-1 (7-36)-NH2: a physiological inhibitor of gastric acid secretion in man. J Endacrinol 1990;126:169-73.

59. Schjoldager BT, Mortensen PE, Christiansen 1, Ørskov C, Holst j]. GLP-1 (glucagon-like peptide 1) and truncated GLP-1, fragments of human proglucagon, inhibit gastric acid secretion in humans. Dig Dis SCi 1989;34:703-8.

60. Delgado-Aros S, Kim DY, Burton DD, et al. Effect of GLP-1 on gastric volume, emptying, maximum volume ingested, and postprandial symptoms in humans. Am J Physiol Gastrointest Liver Physiol 2002;282:G424-31.

61. Wettergren A, Schjoldager B, Mortensen PE, Myhre J, Christiansen J, Holst J]. Truncated GLP-1 (proglucagon 78-107-amide) inhibits gastric and pancreatic functions in man. Dig Dis Sci 1993;38:665-73.

62. Long S1, Sutton JA, Amaee WB, et al. No effect of glucagon-like peptide-1 on short-term satiety and energy intake in man. Br J Nutr 1999;81:273-9.

63. Näslund $\mathbb{E}$, Barkeling $B$, King $\mathbb{N}$, et al. Energy intake and appetite are suppressed by glucagon-like peptide-1 (GLP-1) in obese men. Int 1 Obes Relat Metab Disord 1999;23:304-11.

64. Hellström PM, Näslund E. Interactions between gastric emptying and satiety, with special reference to glucagon-like peptide-1. Physiol Behav 2001;74:735-41. 
65. Ranganath LR, Beety JM, Morgan LM, Wright JW, Howland R, Marks V. Attenuated GLP-1 secretion in obesity: cause or consequence? Gut $1996 ; 38.916-9$.

66. Ranganath $L$, Norris $F$, Morgan $L$, Wright J, Marks $V$. Inhibition of carbohydratemediated glucagon-like peptide-1 (7-36)amide secretion by circulating nonesterified fatty acids. Cin Sci (Lond) 1999;96:335-42.

67. Vilsboll $T$, Krarup $T$, sonne $J$, et al. Incretin secretion in relation to meal size and body weight in healthy subjects and people with type 1 and type 2 diabetes mellitus. J Clin Endocrinol Metab 2003;88:2706-13.

68. Flint A, Raben A, Ersboll AK, Holst JJ, Astrup A. The effect of physiological levels of glucagon-like peptide-1 on appetite, gastric emptying, energy and substrate metabolism in obesity. Int J Obes Relat Metab Disond 2001:25:781-92.

69. Näslund E, Gryback P, Hellström PM, et al. Gastrointestinal hormones and gastric emptying 20 vears after jejunoileal bypass for massive obesity. Int $J$ Obes Relat Metab Disord 1997;21:387-92.

70. Clements RH, Gonzalez QH, Long CI, Wittert G, Laws HL. Hormonal changes after Roux-en Y gastric bypass for morbid obesity and the control of type-II diabetes mellitus. Am Surg 2004; 70:1-4; discussion 4-5.

71. Verdich C, Toubro S, Buemann B, Lysgard Madsen J, Juul Holst J, Astrup A. The role of postprandial releases of insulin and incretin hormones in meal-induced satiety-effect of obesity and weight reduction. Int 1 Obes Relat Metab Disord 2001;25:1206-14.

72. Cigaina V, Hirschberg AL. Gastric pacing for morbid obesity: plasma levels of gastrointestinal peptides and leptin. Obes Res 2003;11:1456-62.

73. Kong MF, Chapman 1 , Goble $E$, et al. Effects of oral fructose and glucose on plasma GLP-1 and appetite in normal subjects. Peptides 1999;20:545-51.

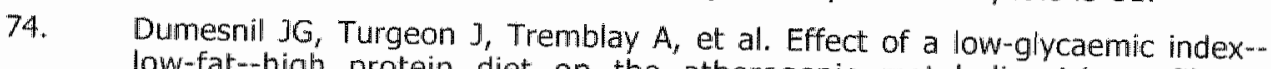
low-fat--high protein diet on the atherogenic metabolic risk profile of
abdominally obese men. Br J Nutr 2001;86:557-68.

75. Shima $K$, suda $T$, Nishimoto $K$, Yoshimoto $S$. Relationship between molecular structures of sugars and their ability to stimulate the release of glucagon-like peptide-1 from canine lleal loops. Acta Endocrinol (Copent) 1990;123:464-70.

76. Ritzel $U$, Fromme A, Otteben M, Leonhardt U, Ramadori G. Release of glucagon-like peptide-1. (GLP-1) by carbohydrates in the perfused rat ileum.
Acta Diabeto/ $1997 ; 34: 18-21$.

77. Lavin $\mathrm{JH}$, Read NW. The effect on hunger and satiety of slowing the absorption of glucose: relationship with gastric emptying and postprandial blood glucose
and insulin responses. Appetite 1995:25:89-96.

78. Massimino SP, McBurney MI, Field CJ, et al. Fermentable dietary fiber increases GLP-1 secretion and improves glucose homeostasis despite increased intestinal
glucose transport capacity in healthy dogs. I Nutr 1998;128:1786-93.

79. Claustre J, Brechet S, Plaisancie P, Chayvialle JA, Cuber JC. Stimulatory effect of beta-adrenergic agonists on ileal $L$ cell secretion and modulation by alpha-
adrenergic activation. J Endocrino $1999 ; 162: 271-8$. 


\section{Chapter 2}

\section{Galactose in combination with guar gum stimulates GLP-1 release in healthy, normal-weight subjects}

Tanja C.M. Adam, Tjerk W.A. de Bruin, Paul P.C.A. Menheere and Margriet S.Westerterp-Plantenga 


\section{Abstract}

The stimulation of gut hormones like glucagon-like peptide $\mathbb{1}$ (GLP.1) seems to play a major role in triggering satiety, but seems to differ between different monosaccharides. Guar gum is known for its effects on satiety as well. The present study investigates whether galactose or galactose in combination with guar gum is sufficient for stimulation of GLP-1 compared to glucose and glucose with guar gum.

20 subjects (12 women and 8 men) were investigated in a randomized, cross-over design with five different test conditions. Subjects received either $75 \mathrm{~g}$ glucose, $75 \mathrm{~g}$ glucose in combination with $2.5 \mathrm{~g}$ guar gum, $50 \mathrm{~g}$ galactose, $50 \mathrm{~g}$ galactose with $2.5 \mathrm{~g}$ guar gum or $250 \mathrm{ml}$ water. Blood samples were taken for determining GLP-1, insulin, ghucose and free fatty acids. The appetite profile was obtained with wisual analogue scales.

Galactose in combination with guar gum was sufficient in stimulating GLP-1 release different from galactose at $60(P=0.03)$ and 90 minutes $(P=0.03)$. The area under the curve of GLP-1 release for galactose/guar gum was not different from glucose/guar gum. Plasma insulin and glucose concentrations were significantly lower in the galactose conditions compared to the glucose conditions $(P<0.01)$.

Satiety ratings were higher in both guar gum conditions compared to no guar gum ( $P=$ 0.01). Galactose in combination with guar gum was a trigger for GLP-1 release and satiety similar to glucose in combination with guar gum in healthy, nomal-weight subjects, but accompanied by lower glucose and insulin concentrations. 


\section{Introduction}

Glucagon-like peptide 1 (GLP-1) is a 30 amino acid peptide hormone secreted from intestinal $L$ cells after ingestion of glucose or mixed meals (1-3). Secretion of GLP-1 in response to food intake is known to stimulate insullin secretion in pancreatic beta-cells $(4,5)$ and intravenous GLP-1 administration reduced energy intake in normal-weight subjects (6). There is evidence that the peptide reaches the brain by areas lacking a perivascular blood-brain area, like subfornical organs and the area postrema, which allow free exchange of molecules between blood and cerebrospinal fluid (7). The area postrema as well as the subfornical organ are known to be involved in the regulation of feeding and drinking by projecting to the hypothalamus (8). The stimulation of gut hormone release by oral carbohydrates seems to play a major role in triggering satiation, but may differ between different monosaccarides (9).

Galactose has been shown to stimulate GLP-1 secretion $(8,10,11)$ with a committant increase in plasma insulin secretion $(12)$, but a lower glycaemic index (GI $=20$ ) compared to glucose. There is evidence that foods with higher glycaemic indices are assaciated with less subjective satiety $(13,14)$ although results are contradictory $(15$, 16). Furthermore, guar gum, a soluble fiber, has been shown to prolong satiety by slowing the absorption of glucose from the small intestine, and thereby possibly leading to a prolonged stimulation of gut hormones $(17,18)$. Fermentable fiber has been shown to increase GLP-1 secretion in dogs (19). The aim of the present study was to investigate the effects of galactose and guar gum together on GLP-1 release and satiety compared to glucose in combination with guar gum.

We hypothesize that galactose in combination with guar gum leads to profound GLP-1 stimulation, with prolonged satiety compared to glucose and guar gum, due to lower glycaemic impact.

\section{Materials and Methods}

First, a dose-response study (study A) was done in eight subjects (5 women and 3 men). Four loads were tested in randomized order on different test days, with at least three days between trials. $2,5 \mathrm{~g}$ guar gum (20), $12 \mathrm{~g}$ galactose $+2,5 \mathrm{~g}$ guar gum ( $200 \mathrm{~kJ}$ or 48 $\mathrm{kcal}), 25 \mathrm{~g}$ galactose $+2,5 \mathrm{~g}$ guar gum $(418 \mathrm{~kJ}$ or $101 \mathrm{kcal})$, or $50 \mathrm{~g}$ galactose $+2,5 \mathrm{~g}$ guar gum $(836 \mathrm{~kJ}$ or $202 \mathrm{kcal})$. All ingredients were dissolved in $250 \mathrm{ml}$ water. $50 \mathrm{~g}$ of galactose was the maximum amount that could be dissolved in $250 \mathrm{ml}$ water without being perceived as unpleasant by the subjects.

After the dose-response study, a randomized, crossover design was applied (study B) to twenty subjects. ( 12 women and 8 men). Five conditions were applied single blind and in random order one week apart from each other. Subjects received either $75 \mathrm{gg}$ glucose $(1254 \mathrm{~kJ}) ; 75 \mathrm{~g}$ glucose $+2.5 \mathrm{~g}$ guar gum; $50 \mathrm{~g}$ galactose $(836 \mathrm{~kJ}) ; 50 \mathrm{~g}$ galactose $+2.5 \mathrm{~g}$ guar gum, dissolved in $250 \mathrm{ml}$ water, or water alone. $75 \mathrm{~g}$ glucose was chosen since this is a standard solution in similar tests (21). The addition of guar gum did not increase 
caloric content of the glucose or galactose loads. Since the energy content of the galactose and glucose loads was different, data were controlled for energy content. Procedures were the same for study $A$ and $B$.

\section{Subjects}

Subjects were recruited by means of advertisements in local newspapers. Informed consent was obtained from all subjects. For study A subjects underwent a medical screening, including a medical history, and a two-hour oral glucose tolerance test, conducted according to the guidelines of the World Health Organization $(1999)(22)$. Body weight was measured on a digital balance (Seca, model 707, Hamburg, Germany). Height was measured using a wall mounted stadiometer (Seca, model 220, Hamburg, Germany). Body mass index (BMI) was calculated as weight (in $\mathrm{kg}$ ) / height (in meters squared). Body composition was determined by underwater weighing using the method of Siri (23). Dietary habits were assessed using a validated Dutch translation of the Three Factor Eating Questionnaire (TFEQ) $(24,25)$. The study was approved by the Maastricht University Medical Ethics Committee.

Subject characteristics are shown in table 1.

Table 1. Subject characteristics

\begin{tabular}{lll}
\hline & Women $(\mathrm{n}=12)$ & Men $(\mathrm{n}=8)$ \\
\hline Age $(\mathrm{y})$ & $41 \pm 14$ & $39 \pm 12$ \\
Weight $(\mathrm{kg})$ & $62 \pm 8.8$ & $76 \pm 8.6$ \\
Height $(\mathrm{cm})$ & $167 \pm 10$ & $178 \pm 8$ \\
BMI $\left(\mathrm{kg} / \mathrm{m}^{2}\right)$ & $22 \pm 2$ & $24 \pm 1$ \\
Bodyfat $(\%)$ & $28.5 \pm 7$ & $18.7 \pm 7$ \\
\hline values shown as means \pm sd & &
\end{tabular}

\section{Procedure}

After arrival in the morning, a catheter (Baxter BV, Utrecht, The Netherlands) was inserted in an antecubital vein. Subjects were recumbent during trials.

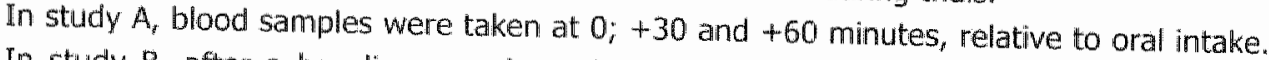
In study $B$, after a baseline sample at 0 minutes, blood samples were taken at +30 , $+60,+90,+120$ and +240 minutes relative to oral intake, for determining GLP-1, insulin, and glucose concentrations. Free fatty acids were measured in samples taken at time points $0,+30,+60$ and +120 minutes. Prior to blood sampling, subjects rated their feelings of hunger, fulliness, satiety and desire to eat on $100-\mathrm{mm}$ visual analogue scales (VAS) (26). Subjects were instructed to report discomfort or nausea at any time during the trial. Resting metabolic rate (RMR) was measured ten minutes after the subject 
arrived, using a ventilated hood system (Oxycon b, Mijnhardt, Bunnik, The Netherlands) (27). Diet-induced thermogenesis was measured using the same apparatus four times after treatment and was expressed as percentage energy intake (Table 2 ). $\mathrm{O}_{2}$ consumption and $\mathrm{CO}_{2}$ production were measured and energy expenditure was calculated according to Weir (28). At the end of each test day, subjects were offered an ad-libitum meal on a plate placed on the Universal eating monitor $(29,30)$ consisting of pasta peas, green beans, corn and cheese with a vinegar dressing. Energy density was 10,8 kl per gram.

\section{Analytical methods}

Blood samples for free fatty acids and glucose analysis were mixed with EDTA to prevent clotting. Samples for GLP-1 analysis were collected into chilled syringes and mixed with EDTA and $40 \mu$ of a DPP-IV (DPP-IV403: EC 3.4.14.5) inhibitor (Linco Research, St. Charles, USA) to prevent degradation. The plasma samples were centrifuged at $2500 \times \mathrm{g}$ at $4{ }^{\circ} \mathrm{C}$ for 10 minutes. To blood samples for insulin no anticoagulant was added and samples were allowed to clot for 30 minutes, then centrifugled at $2000 \times \mathrm{g}$ at $4{ }^{\circ} \mathrm{C}$ for 10 minutes. Aliquots of plasma and serum were frozen immediately in liquid nitrogen and stored at $-20^{\circ} \mathrm{C}$. Plasma glucose concentrations were determined using the hexokinase method (Glucose HK 125 kit; ABX diagnostics, Montepellier, France). The WAKO NEFA Ckit (Wako Chemicals, Neuss, Germany) was used to determine free fatty acid (FFA) concentrations. GLP-1 concentrations were measured using an ELISA kit (EGLP-35K; Linco Research Inc., St Charles, MO, USA) for non-radioactive quantification of biologically active forms of glucagon-like peptide. The assay has an intra-assay coefficient of variation (CV) of $8 \%$ or less and an inter CV of $12 \%$ or less and sensitivity is $2 \mathrm{pmol} / \mathrm{l}$ (31). Insulin was measured using a fluoroimmunometric sandwich assay (AutoDELFIATM assay; Perkin Elmer, Finlland).

\section{Statistical Analyses}

In the dose response study, GLP-1 release was compared among four conditions using a repeated measurement analysis of variance (ANOVA) and Sheffe-F or Fisher PLSD posthoc test. In study B, GLP-1, insulin, glucose, free fatty acids as well as hunger, satiety, desire to eat, fullness and RMR were compared among conditions using a repeated measurement analysis of variance (ANOVA) and Sheffe- F or Fisher PLSD post-hoc test with a condition $x$ time interaction. Diet-induced thermogenesis was expressed as percentage of energy intake. It was compared among the four nutrient conditions in a repeated measurement analysis of variance (ANOVA) and a Sheffe -.F post-hoc test. 
Regression analysis was used to study the relationship between satiety ratings and GLP1 increase. STATVIEW+GRAPHICS software (Abacus Concepts Inc, Berkeley, CA) was used for statistical analysis. Significance was defined as $\mathrm{P}<0.05$

\section{Results}

\section{Dose-response study}

The effect of $12 \mathrm{~g}$ galactose as well as $25 \mathrm{~g}$ galactose in combination with guar on GLP-1 release was not different from guar gum alone. Only $50 \mathrm{~g}$ galactose in combination with 2,59 guar gum evoked a significantly different GLP-1 increase at 30 (F 3,21 = 15.81; $P=$ $0.0001)$ and 60 ( F $3.21=5.68 ; P=0.005)$ minutes compared to all other conditions (Fig. 1)

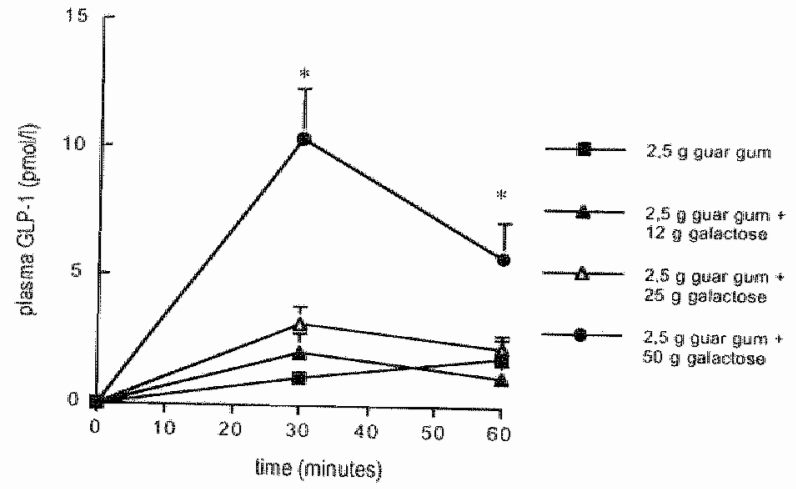

Figure. 1. Plasma GLP'1 concentrations expressed as means ( 1 SEM) after ingestion of $2,5 \mathrm{~g}$ guar gum alone (filled squares) or in combination with $12 \mathrm{~g}$ galactose (filled triangles), $25 \mathrm{~g}$ galactose (open triangles) or $50 \mathrm{~g}$ galactose (Tilled circles).

* significanty different compared to all other dosages at $P<0.05$. 


\section{Plasma GLP-1 levels and insulin concentrations (study B)}

Compared to water, maximum plasma GLP-1 concentrations were reached at 30 minutes in the glucose as well as in the galactose conditions $(\mathrm{F} 4,76=11.27 ; \mathrm{P}<0.05 ; \mathrm{Fig}$. 2A). $\triangle$-GLP-1 plasma concentrations were significantly higher in the galactose/ guar gum condition compared to galactose alone at $60(\mathrm{~F} 1,19=5.19 ; \mathrm{P}=0.03$ ) and 90 minutes $(F 1,19=4.78 ; P=0.03) . \Delta-G L P-1$ concentrations between glucose conditions were not different at any time. Calculating the area under the curve, there was no significant difference between the glucose+guar gum or galactose+guar gum treatment (Fig. 2B). Serum insulin concentrations peaked at 30 minutes in the galactose conditions and at 60 minutes in the glucose conditions (Fig. 3). Insulin concentrations in the galactose/ guar gum condition were not different from galactose alone, but both galactose conditions lead to significantly lower insulin concentrations at $30(\mathrm{~F} 3,57=26.43 ; \mathrm{P}<0.01)$; 60 ( $\mathrm{F}$ $3,57=34.37 ; P<0.01), 90(F 3,57=16.21 ; P<0.01)$ and 120 minutes $(F 3,57=$ 16.98; $\mathrm{P}<0.01)$ compared to both glucose conditions.

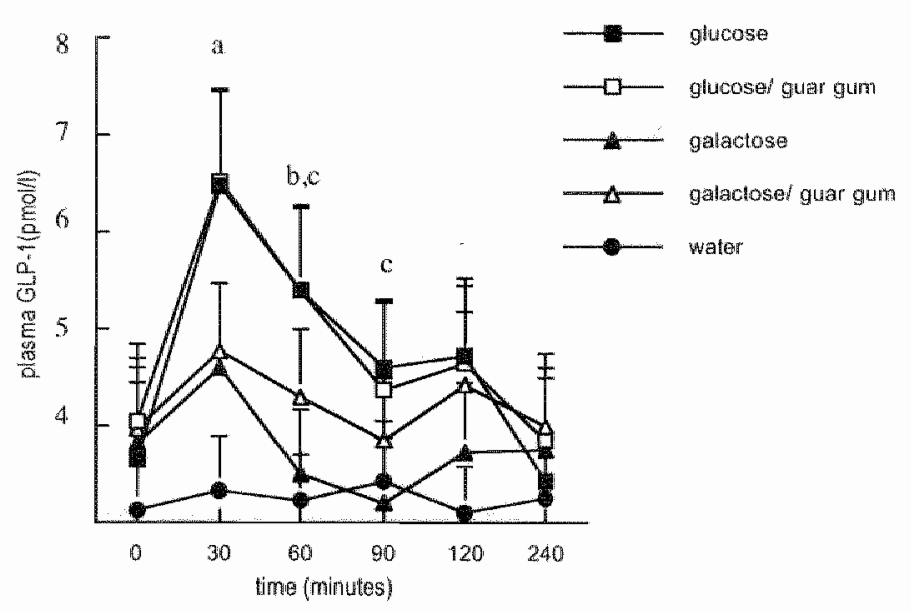

Figure 2A. Plasma GLP-1 concentrations expressed as means ( \pm SEM) after ingestion of glucose (filled squares), glucose/ guar gum (open squares), galactose (filled triangles), galactose/ guar gum (open triangles) or water (filled circles).

a: glucose, glucose/ guar gum, galactose and galactosel guar gum are significantly different from water at $P<0.05$.

b: glucose, glucose/ guar gum and galactose/ guar gum are significantly different from water at $P$ \& 0.05 .

c: $\triangle$ - GLP-1 (compared to baseline) after galactose/ guar gum is significantly different from galactose at $P<0.05$. 


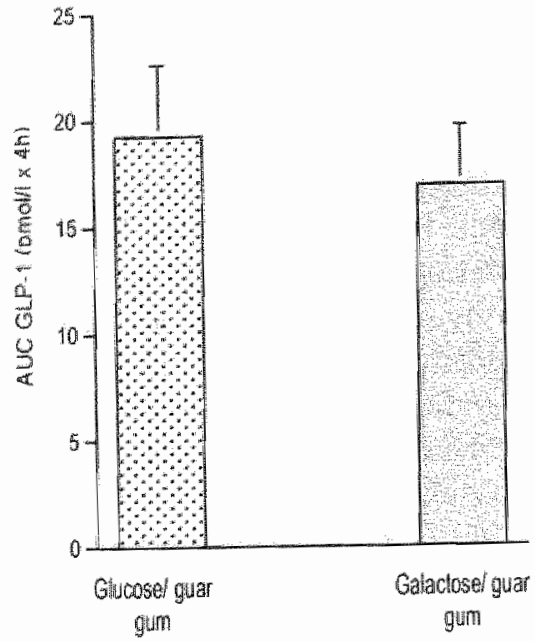

Figure. 2B. AUC (pmol/ $\times$ 4h) for GLP-1 release after ingestion of glucosed guar gum or galactose/guar gum (n.s.)

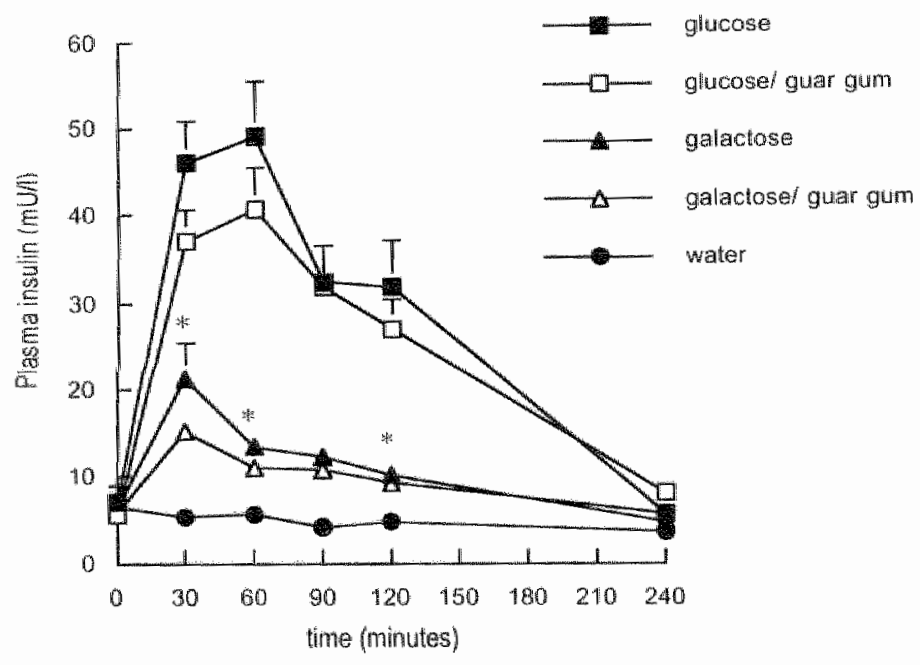

Figure 3. Serum insuh concentration (mU/1) expressed as means ( 1 SEM)after ingestion of glucose (filed squares), gucose/ guar gum (open squares), galactose (filled triangles), galactose/ guar gum (open triangles) or water.

* both galactose conditions are significantly different from both glucose conditions at $P<0.01$. 


\section{Plasma glucose and free fatty acid concentrations (study B)}

Plasma glucose peaked at 30 minutes in all conditions compared to water (Fig. 4). Glucose concentrations were not different between the galactose conditions. Both galactose conditions lead to significantly lower glucose concentrations at $30(\mathbb{F} 3,57=$ $26.61 ; P<0.01), 60(F 3,57=30.41 ; P<0.01), 90(F 3,57=14.45 ; P<0.01)$ and 120 minutes $(F 3,57=17.09 ; P<0.01)$ compared to both the glucose conditions.

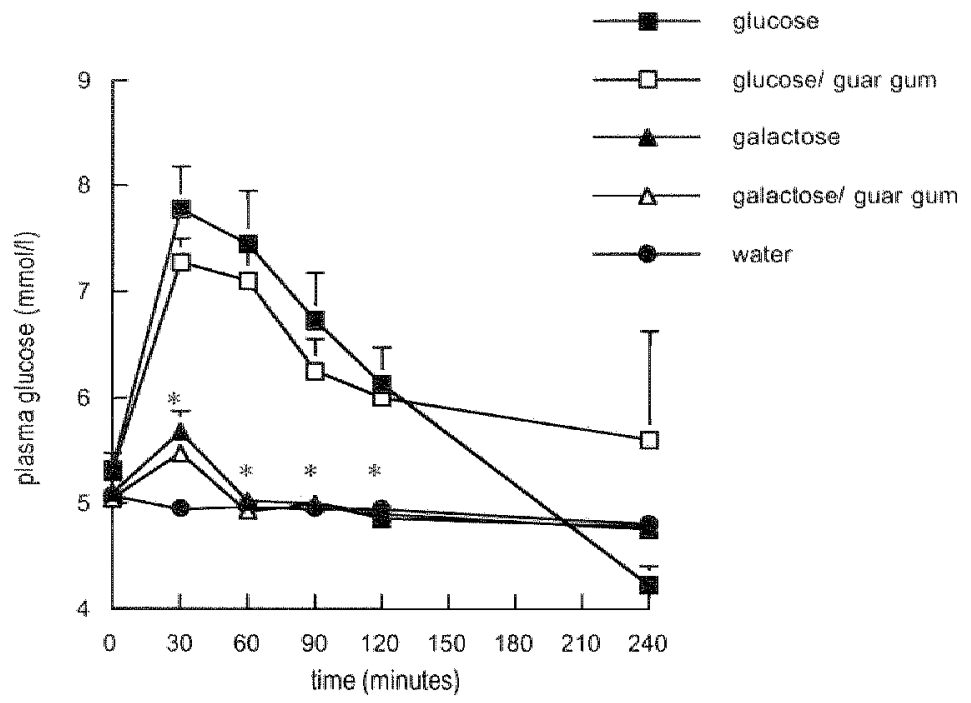

Figure 4. Plasma glucose concentrations (mmol/1) expressed as means ( $\pm S E M$ ) after ingestian of glucose (filled squares), glucose/ guar gum (open squares), galactose (filled triangles), galactosef guar gum (open triangles) or water.

* both galactose and galactose/ guar gum are significantly different from both glucose conditions at $p<0.05$.

Plasma free fatty acids decreased over time in all nuttrient conditions except for water (Fig. 5). After ingestion of galactose/ guar gum, free fatty acid concentrations were significantly higher compared to both glucose conditions at 60 minutes $(F 3,57=6.59 ; P$ $<0.01$ ). Both galactose conditions had higher free fatty acid concentrations at 120 minutes compared to both glucose conditions $(F 3,57=11.72 ; \mathrm{P}<0.01)$. 


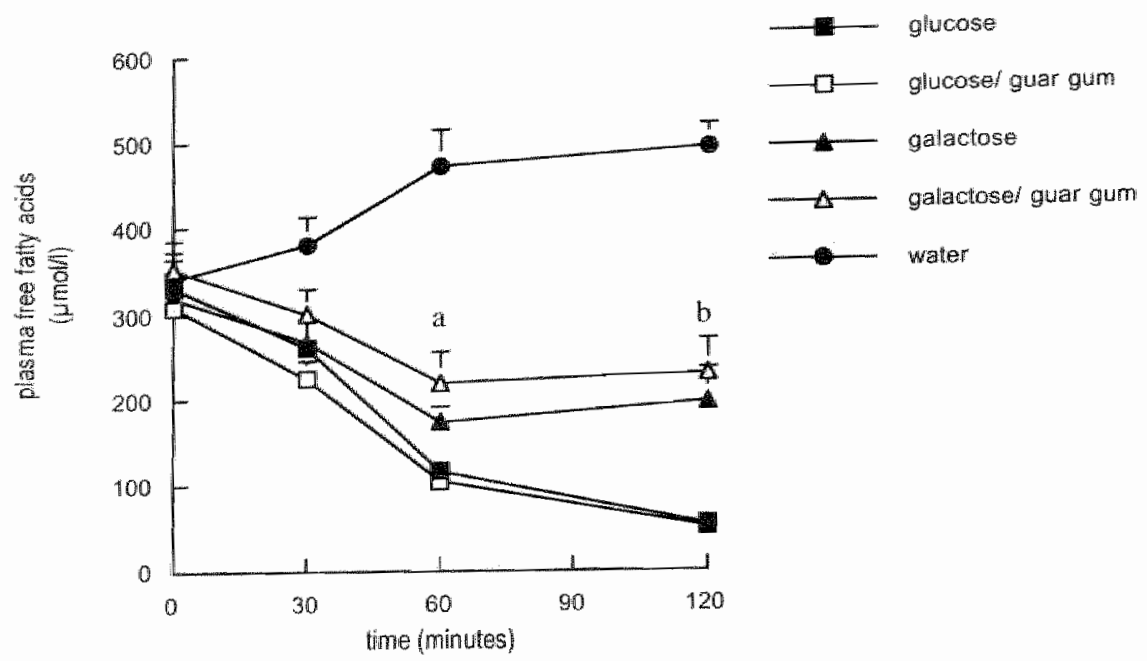

Figure 5. Plasma free fatty acid concentration ( 1 mol/l)) expressed as means ( 1 SEM)after ingestion of glucose (filled squares), glucosef guar gum (open squares), galactose (filled triangles), galactose/ guar gum (open triangles) or water.

a. galactose/ guar gum is different from both givcose conditions at $p<0.01$

b: both galactose conditions are different from both glucose conditions at $p<0.01$

Appetite sensations, resting metabolic rate and diet-induced thermogenesis (study B)

$\Delta$-satiety ratings (compared to baseline) were higher in both the guar gum/ nutrient conditions (Fig. $6 \mathrm{~A}, \mathrm{~B}$ ), with significantly higher ratings after ingestion of glucose/ guar gum compared to glucose alone at 60 minutes $\left(F 1,19=7.48 ; P^{\prime}=0.01\right)$. Fulliness ratings were similar to the satiety ratings (data not shown). Hunger ratings were similar to the desire to eat ratings (data not shown). Average (mean value of each point of measurement) satiety was related to GLP-1 release at $30(r 2=.23 ; P=0.03)$ and 120 minutes after ingestion of the loads $(r 2=.22 ; p=0.03)$, independent of condition, excluding the water condition. 


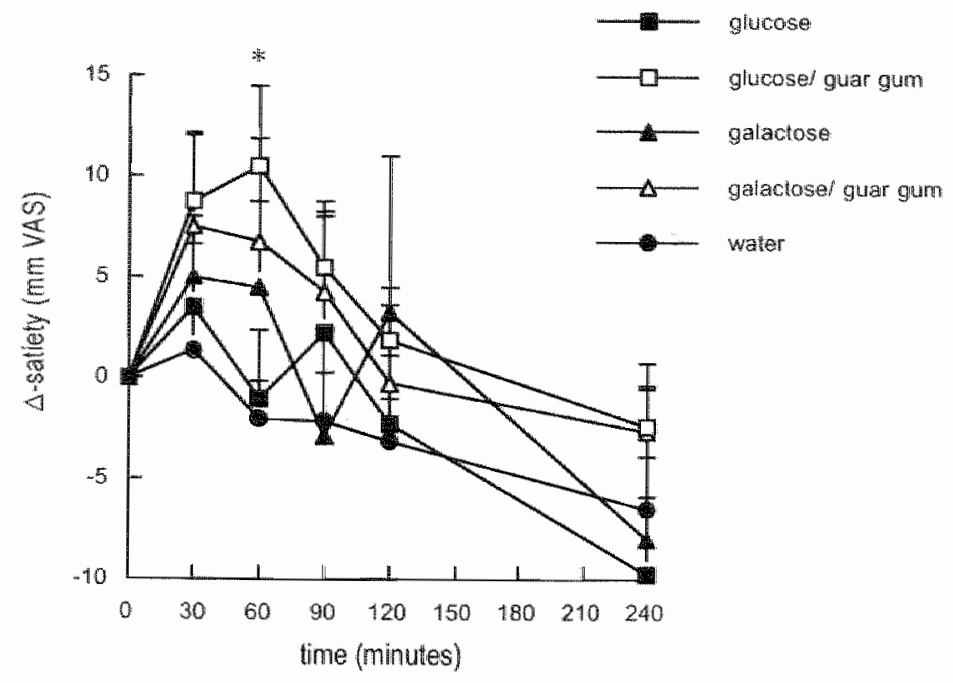

Figure 6A. $\triangle$ satiety (nm VAS) relative to baseline, expressed as means (ISEM) after ingestion of gucose (filled squares), glucose/ guar gum (open squares), galactose (filled triangles), galactose/ guar gum (open triangles) or water (filled circles).

* gilucose/ guar gum is different from glucose at $P=0.01$.

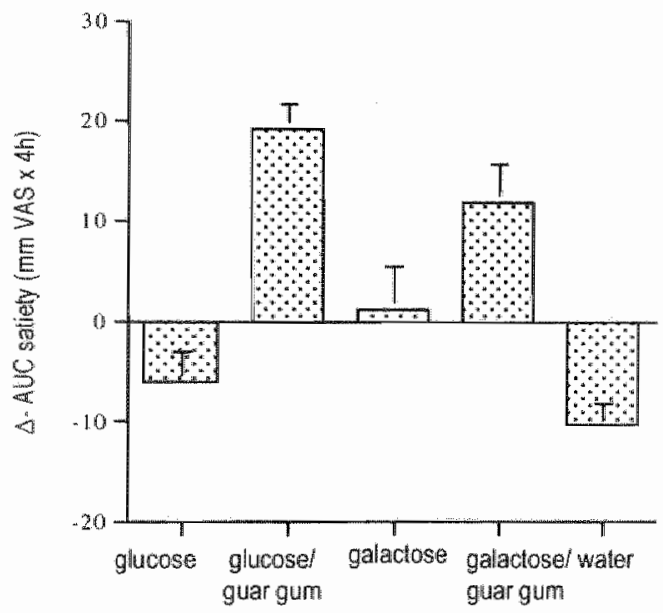

Figure 6B. $\triangle$-Area under the curve (compared to baseline, average 0-240 minutes) of satiety ratings (mm VAS) after ingestion of glucose $(75 \mathrm{~g})$, glucose/ guar gum $(75 \mathrm{~g} / 2.5 \mathrm{~g})$, galactose $(50 \mathrm{~g})$, galactose/ guar gum $(50 \mathrm{~g} / 2.5 \mathrm{~g})$ or water ( $250 \mathrm{mi})$.

No subject discomfort was reported during the trials. Resting metabolic rate was not significantly different among conditions. Diet-induced thermogenesis (as a percentage of total energy intake) was not significantly different among the conditions (Table 2). The 
subjects consumed an average of $3.5 \pm 1.3 \mathrm{M}$ in the test meal, with no difference among the treatment groups ( $\mathrm{F} 4,36=1.65$; ns.)

Table 2. Diet induced thermagenesis (OIT) and resting metabolic rate (RMR) for 20 subjects (12 women, 8 men); values are meansts.d.

\begin{tabular}{lcccccc} 
Condition & \multicolumn{2}{c}{ DITf\% of energy intake) } & \multicolumn{2}{c}{ RMR } \\
\hline Gucose & 6.2 & \pm & 5.6 & 6.33 & \pm 1.1 \\
Gucose/ guar gum & 4.7 & \pm & 4.7 & $6.48 \pm \pm 1$ \\
Galactose & 9.1 & \pm & 13.5 & $6.33 \pm 1.1$ \\
Galactose/ guar gum & 6.4 & \pm & 8.1 & $6.33 \pm 1.1$ \\
\hline
\end{tabular}

\section{Discussion}

In healthy, normal-weight subjects, glucose and galactose, with or without guar gum showed maximum GLP-1 stimulation 30 minutes after ingestion. Galactose in combination with guar gum appeared to be more sufficient in stimulating GLP-1 than galactose allone. Surprisingly, the area under the curve for GLP-1 release in the galactose/ guar gum combination was not different from glucose with guar gum, despite of a higher caloric content in the glucose conditions. Like glucose, galactose is absorbed by the liver and converted to glucose. Subsequently it is stored as glycogen or released into the circulation. Compared to lower dosages only the dosage of $50 \mathrm{~g}$ of galactose in combination with guar gum had a stimulating effect on GLP-1 release (Fig. 1).

Guar gum, a soluble viscous fiber, has been suggested to decrease the rate of gastric emptying and transit time through the small intestine $(32,33)$. A decrease in the rate of gastric emptying might delay nutrient absorption and thus lead to prolonged stimulation of GLP-1 release (34). In the dose response study we found that the amount guar gum used did not affect GLP-1 release. Previously we have shown that the dosage of guar gum we used did not affect gastrointestinal transit, or gastric emptying rate (35), but did affect satiety (36). If gastric emptying was affected it is likely that it has been by the effect of GLP-1 itself on gastric emptying (37-39). Similar to previous observations $(6$, 40) GLP-1 appeared to be related to satiety. The effect on satiety in this study seems to be influenced by the addition of guar gum rather than glycaemic index (Fig. 6B).

Stimulation of insulin release is blunted in both glucose and galactose conditions, when guar gum is added. This effect has been found in other studies about the effect of fiber on insulin release as well and has been suggested as probably due to the slowed absorption of nutrients by fiber $(17,41)$. The effects of guar gum on insulin and satiety seem likely to be explained by the increased contact of the carbohydrates with receptors in the small intestine $(17,18)$.

Since galactose, as well as fiber such as guar gum are known for their low glycaemic index compared to glucose (42), it seems relevant to investigate the nutrient composition with respect to obesity. 
We did not find any differences among treatments in the amount of food eaten after the treatments, or any differences in eating rate. The satiety effect was expressed in mm VAS during four hours after the load. After four hours, when the test-meal was given, it was obvious that the difference in satiety had disappeared.

There was no significant difference in diet-induced thermogenesis. (DIT) between the fiber and non fiber conditions. This result is not necessarily contradictory to other findings that found a reduction in diet-induced thermogenesis after consumption of a high-fiber meal (43), possibly due to the low energy content of the nutrients compared to the time subjects were fasted during the trial.

In conclusion, $50 \mathrm{~g}$ galactose in combination with $2.5 \mathrm{~g}$ guar gum dissolved in $250 \mathrm{ml}$ water, was a trigger for GLP-1 release and satiety similar to GLP-1 release caused by glucose with guar gum, but was accompanied by lower glucose and insulin concentrations in healthy, normal-weight subjects. The question remains, whether this can be seen in obese subjects as well.

\section{Acknowledgements}

Supported by Novartis Consumer Health Ltd, Nyon, Switzerland \& Novartis Pharmaceuticals, Basel, Switzerland and Summit, USA.

Part of the results is published as patent:

Hughes, TE, Westerterp-Plantenga MS, Adam TCM.

"Nutritional compositions comprising a non-glucose carbohydrate or pectine and soluble fiber". WO 2004/022074 A1, 2004 


\section{References}

1. Elliott RM, Morgan LM, Tredger JA, Deacon S, Wright J, Marks V. Glucagon-like peptide-1 (7-36)amide and glucose-dependent insulinotropic polypeptide secretion in response to nutrient ingestion in man: acute post-prandial and $24-\mathrm{h}$ secretion patterns. I Endocrinol 1993;138:159-66.

2. Gutniak M. Treatment of diabetes - GLP-1: a new kid in town. International Diabetes Monitor 1997;9:1-12.

3. Kreymann $B$, Williams $G$, Ghatei MA, Bloom SR. Glucagon-like peptide-1 7-36: a physiological ncretin in man. Lancet $1987 ; 2: 1300-4$.

4. Thorens B, Porret A, Buhler $L_{*}$ Deng SP, Morel $P$, Widmann $C$. Claning and functional expression of the human islet GLP-1 receptor. Demonstration that exendin-4 is an agonist and exendin-(9-39) an antagonist of the receptor. Diabetes 1993,42:1678-82.

5. Tillil H, Shapiro ET, Miller MA, et al. Dose-dependent effects of oral and intravenous glucose on insulin secretion and clearance in normal humans. Am J Physiol 1988;254:E349-57.

6. Flint $A_{s}$ Raben A, Astrup $A$, Holst 1]. Glucagon-like peptide 1 promotes satiety and suppresses energy intake in humans. J Clin Inwest 1998;101:515-20.

7. Drucker D.1. Glucagon-like peptides. Diabetes 1998;47:159-69.

8. Shapiro RE, Miselis RR. The central neural connections of the area posturema of the rat. I Comp Neurol 1985;234:344-64.

9. Kong MF, Chapman I, Goble E, et al. Effects of oral fructose and glucose on plasma GLP-1 and appetite in normal subjects. Peptides 1999;20:545-51.

10. Herrmann $C$, Göke R, Richter $G$, Fehmann $H C$, Arnold $R$, Göke B. Glucagon-like peptide-1 and glucose-dependent insulin-releasing polypeptide plasma levels in response to nutrients. Digestion $1995 ; 56: 117-26$.

11. Ritzel $U$, Fromme $A$, Qttleben $M$, Leonhardt $U$, Ramadori $G$. Release of glucagon-like peptide-1 (GLP-1) by carbohydrates in the perfused rat ileum. Acta Diabetol 1997; 34:18-21.

12. Ercan N, Nuttall FQ, Gannon MC, Redmon JB, Sheridan KJ. Effects of glucose, galactose, and lactose ingestion on the plasma glucose and insulin response in persons with non-insulin-dependent diabetes mellitus. Metabolism $1993 ; 42: 1560-7$.

13. Holt $S_{j}$ Brand 1 , Soveny $C$, Hansky 1. Relationship of satiety to postprandial glycaemic, insulin and cholecystokinin responses. Appetite 1992;18:129-41.

14. Leathwood $P$, Pollet P. Effects of slow release carbohydrates in the form of bean flakes on the evolution of hunger and satiety in man. Appetite

15. Rodin $J_{,}$Wack $]_{\text {, Ferrannini }} E_{r}$ DeFronzo RA. Effect of insulin and glucose on feeding behavior. Metabolism 1985;34:826-31. 
16. Vozzo $\mathrm{R}$, Baker $\mathrm{B}$, Wittert $\mathrm{GA}$, et al. Glycemic, homone and appette responses to monosaccharide ingestion in patients with type 2 diabetes. Metabolsm 2002; $51: 949-57$.

17. Lavin $\mathrm{JH}_{s}$ Read NW. The effect on hunger and satiety of slowing the absorption of glucose: relationship with gastric emptying and postprandial biood glucose and insulin responses. Appetite 1995;25:89-96.

18. Blackburn $N A_{\text {, }}$ Redfern $\mathrm{JS}$, Jarjis $\mathrm{H}$, et al. The mechanism of action of guar gum in improving glucose tolerance in man. Cin Sc (Lond) 1984,66:329-36.

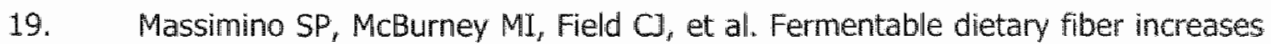
GLP-1 secretion and improves glucose homeostasis despite increased intestinal glucose transport capacity in healthy dogs. J Nutr 1998; 128:1786-93.

20. Kovacs EM, Westerterp-Plantenga MS, Saris WH, Goossens I, Geurten P, Brouns $F$. The effect of addition of modified guar gum to a low-energy semisolid meal on appetite and body weight loss. Int J Obes Relat Metab Disord 2001:25:307-15.

21. Djurhuus $C_{B}$, Hansen $T K$, Gravholt $C_{*}$ et al. Circulating levels of ghrelin and GLP-1 are inwersely related during glucose ingestion. Horm Metab Res $2002 ; 34: 411-3$.

22. Dixon $\mathrm{JB}$, Dixon $\mathrm{AF}, \mathrm{O} B$ rien $\mathrm{PE}$. Improvements in insulin sensitivity and betacell function (HOMA) with weight loss in the severely obese. Homeostatic model assessment. Diabet Med 2003;20:127-34.

23. Siri. The cross composition of the body. Adv Biol Med Physiol 1956;4:239-280.

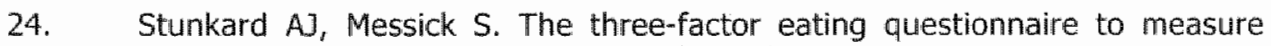
dietary restraint, disinhibition and hunger. J Psychosom Res 1985;29:71-83.

25. Westerterp-Plantenga MS, Rolland $V$, Wilson SA, Westerterp KR. Satiety related to $24 \mathrm{~h}$ diet-induced thermogenesis during high protein/carbohydrate ws high fat diets measured in a respiration chamber. Eur I Clin Nutr 1999;53:495-502.

26. Raben A, Tagliabue A, Astrup A. The reproducibility of subjective appetite scores. Br J Nutr 1995:73:517-30.

27. Fredrix EW, Soeters PB, Deerenberg IM, Kester AD, wan Meyenfeldt MF, Saris WH. Resting and sleeping energy expenditure in the elderly. Eur 1 Clin Nutr $1990 ; 44: 741-7$.

28. Weir 3B. New methods for calculating metabolic rate with special reference to. protein metabolism. Nutrition [classilcal article] 1949;6:213-221.

29. Kissileff $H R$, Klingsberg $G$, Van Itallie TB. Universal eating monitor for continuous recording of solid or liquid consumption in man. Am I Physiol $1980 ; 238: R 14-22$.

30. Westerterp-Plantenga MS, Westerterp KR, Nicalson NA, Mordant A, Schoffelen PF, ten Hoor $F$. The shape of the cumulative food intake curve in humans, during basic and manipulated meals. Physiol Behav 1990;47:569-76.

31. Nathan DM, Schreiber E, Fogel H, Mojsov S, Habener JF. Insulinotropic action of glucagonlike peptide-I-(7-37) in diabetic and nondiabetic subjects. Diabetes Care 1992;15:270-6. 
32. French S1, Read NW. Effect of guar gum on hunger and satiety after meals of differing fat content: relationship with gastric emptying. Am J Clin Nutr $1994 ; 59: 87-91$.

33. Harju E. Increases in meal viscosity caused by addition of guar gum decrease postprandiale acidity and rate of emptying of gastric contents in healthy subjects. Panminerva Med 1985;27:125-8.

34. Banerji MA, Chaiken RL, Gordon D, Kral JG, Lebovitz HE. Does intra-abdominal adipose tissue in black men determine whether NIDDM is insulin-resistant or insulin-sensitive? Diabetes $1995 ; 44: 141-6$.

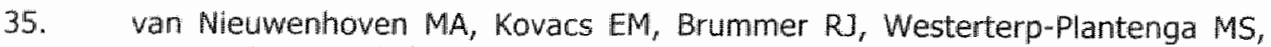
Brouns $F$. The effect of different dosages of guar gum on gastric emptying and small intestinal transit of a consumed semisolid meal. I Am Coll Nutr $2001 ; 20: 87-91$.

36. Kowacs EM, Westerterp-Plantenga MS, Saris WH, et al. The effect of guar gum addition to a semisolid meal on appetite related to blood glucose, in dieting men. Eur J Clin Nutr 2002;56:771-8.

37. Nauck MA, Niedereichholz $U$, Ettler $R$, et al. Glucagon-like peptide 1 inhibition of gastric emptying outweighs its insulinotropic effects in healthy humans. Am $J$ Physiol 1997;273:E981-8.

38. Willms B, Wemer J, Holst 11, Ørskov C, Creutzfeldt W, Nauck MA. Gastric emptying, glucose responses, and insulin secretion after a liquid test meal: effects of exogenous glucagon-like peptide-1 (GLP-1)- (7-36) amide in type 2 (noninsulin-dependent) diabetic patients. I Clin Endocrinol Metab 1996;81:32732.

39. Long SJ, Sutton JA, Amaee WB, et al. No effect of glucagon-like peptide-1 on short-term satiely and energy intake in man. Br J Nutr 1999;81:273-9.

40. Gutzwiller JP, Drewe J, Göke B, et al. Glucagon-like peptide-1 promotes satiety and reduces food intake in patients with diabetes mellitus type 2 . Am J Physiol 1999;276:R1541-4.

41. Giacco $\mathrm{R}$, Clemente $\mathrm{G}$, Riccardi $\mathrm{G}$. Dietary fibre in treatment of diabetes: myth or reality? Dig Liver Dis. 2002; Sep; 34 Suppl $2: 140-4$. 42. Jenkins DJ, Jenkins AL. Dietary fiber and the glycemic response. Proc Soc Exp
Biol Med 1985;180:422-31.

43. Raben A, Christensen NJ, Madsen 1, Holst 1J, Astrup A. Decreased postprandial thermogenesis and fat oxidation but increased fullness after a high-fiber meal compared with a low-fiber meal. Am I Clin Nutr 1994;59:1386-94. 
Chapter 3

\section{Nutrient-stimulated GLP-1 release in normal-weight men and women}

Tanja CM Adam \& Margriet Westerterp-Plantenga

Hormone and Metabolic Research (in press) 


\section{Abstract}

Aim of the present study was to investigate the effect of a monosaccharide/ fiber preload (galactose/ guar gum) in combination with a standard breakfast (GG) on plasma GLP-1, insulin, glucose, free fatty acid concentrations and appetite ratings (satiety, hunger, fuilness and desire to eat) in 30 normal-weight subjects. GG was compared to water in combination with the standard breakfast (W). Furthermore we assessed whether GLP-1 release in the described conditions is different in relation to gender.

In the women postprandial plasma GLP-1 concentrations after GG were significantly increased compared to $W(P<0.05)$. The $\triangle$ GLP-1 area under the curve (AUC) for GG was related to body fat ( $\% \mathrm{BF})$ in women $(r=.48 ; P=0.02)$, but not in men. The rise in plasma insulin was delayed and plasma glucose concentration was blunted with GG. $\Delta$ - satiety was significantly related to $\Delta-G L P-1(W)$.

In conclusion galactose with guar gum increased and extended the GLP-I release due to breakfast in women, but not in men. This may be partly explained by $\% \mathrm{BF}_{\text {, which is }}$ larger in women than in men, since GLP-1 release appeared to be related to \%BF. 


\section{Introduction}

Glucagon-like peptide 1 (GLP-1) is a 30 amino acid peptide hormone, secreted from $L$ cells in the intestinal mucosa after ingestion of carbohydrates and after mixed meals in humans (1-3). Peripheral GLP-1 probably gains access to the subfornical organs and the area postrema, two of the circumventricular organs in the brain that may communicate to appetite regulating centers in the hypothalamus (4). The stimulation of gut hormone release, such as GLP-1 by oral carbohydrate seems to play a major role in triggering satiety, but may differ among different monosaccharides. Not much is known about the effect of galactose on GLP-1 release yet. Carbohydrates with a low glyceamic index (GI), thus with low postprandial glucose and insulin responses are considered beneficial for health $(5,6)$. Galactose is one of the major monosaccharides $(G I=20)(7)$. In the liver it: is rapidly converted to glucose-1-phosphate and is subsequently stored as glucose in glycogen. It also may be converted to glucose with subsequent release into the circulation (8). A few studies demonstrated a stimulating effect of galactose on GLP- 1 . release, but without evaluating concomitant effects on satiety (9-11).

Guar gum, a viscous polysaccharide, was found to prolong satiety by slowing the absorption of carbohydrates from the small intestine, extending the period of contact between nutrients and small intestinal epithelium, thereby possibly leading to a prolonged stimulation of gut hormones $(12,13)$. Results about the effect of fiber on GLP-1 release are inconsistent. Some studies found stimulating effects on GLP-1 release (14-16), others showed that the effect of fiber on GLP-1 release might rather be related to the form and botanical structure of food (17).

In a former experiment we found a dose of $50 \mathrm{~g}$ galactose in combination with $2.5 \mathrm{~g}$ guar gum effective in stimulating GLP-1 release in normal weight subjects in a manner similar to glucose in combination with guar gum (18). Recent work has been showing that leptin is able to stimulate GLP-1 secretion (19). Gender differences have been described for leptin and other peptides so far (20-22). Nothing is known yet whether stimulated GLP-1 concentrations are different in relation to gender.

Therefore we investigated the effect of galactose in combination with guar gum in combination with a standard breakfast on GLP-1 secretion, and satiety in healthy, normal- weight subjects and second, whether this is related to gender. 


\section{Materials and Methods}

\section{Subjects}

36 normal-weight subjects were recruited by means of advertisements in local newspapers. After they had given their written, informed consent, subjects underwent a medical screening. The study was approved by the Medical Ethics Committee of the Maastricht University. The screening included a medical history and a two-hour oral glucose tolerance test, conducted according to the guidelines of the World Health Organization. Systolic and diastolic blood pressures were measured during screening by an automatic blood pressure monitor (Omron $705 \mathrm{CP}$, Omron Healthcare GmbH, Hamburg, Germany). After screening, 30 healthy subjects, with a normal glucose tolerance (23) and normal blood pressure (24) (15 women, 15 men) were selected. Subject characteristics are depicted in Table 1.

Table 1. Basic characteristics of subjects $(n=30 ; 15$ men, 15 women) (means $\pm 5 d$ )

\begin{tabular}{|c|c|c|c|c|c|c|c|}
\hline & \multicolumn{3}{|c|}{ Womern $(n=15)$} & \multicolumn{3}{|c|}{$\operatorname{Men}(n=15)$} & $P$ \\
\hline Age $(y)$ & 34.6 & $\#$ & 13.5 & 27.3 & \pm & 11.1 & n.S. \\
\hline Weight (kg) & 65.2 & \pm & 6.5 & 74.2 & 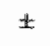 & 3.9 & $<0.05$ \\
\hline Height (cm) & 169 & \pm & 1 & 182 & \pm & 1 & $<0,05$ \\
\hline$B M I^{1}\left(\mathrm{~kg}^{\prime} / \mathrm{m}^{2}\right)$ & 23 & \pm & 1,6 & 22 & \pm & 1.3 & n.s. \\
\hline Bodyfat $(\%)$ & 27.1 & \pm & 7 & 15 & \pm & 6.8 & $<0.05$ \\
\hline TFEQ I (restraint) & 7 & $\#$ & 3.3 & 4 & \pm & 2 & $<0.05$ \\
\hline TFEQ ${ }^{2}$ I (disinhibition) & 4.1 & \pm & 2.5 & 3.7 & \pm & 1.4 & r.s. \\
\hline TFEQ $Q^{2}$ III (huinger) & 4.5 & 止 & 3.2 & 3.6 & \pm & 2.4 & n.s. \\
\hline
\end{tabular}

\section{Anthropometry}

Body weight was measured on a digital balance (Seca, model 707, Hamburg, Germany: weighing accuracy of $0.1 \mathrm{~kg}$ ) with subjects in underwear, in a fasted state. Height was measured using a wallmounted stadiometer (Seca, model 220, Hamburg, Germany), The body mass index was calculated as $B W /$ height ${ }^{2}\left(\mathrm{~kg} / \mathrm{m}^{2}\right)$.

Whole body composition was determined by underwater-weighing with simultaneous assessment of residual lung volume with the helium dilution technique using a spirometer (Volugraph 2000, Mijnhardt, the Netherlands). Measurements were performed in triplicate and the average was used to calculate body density. Body composition was calculated according to Siri (25). 


\section{Eating behavior}

Eating behavior was analyzed during screening using a validated Dutch translation of the Three Factor Eating Questionnaire (TFEQ) (26, 27). Cognitive restrained and unrestrained eating behavior (factor 1), emotional eating and disinhibition (factor 2) and the subjective feeling of hunger (factor 3) were scored.

\section{Study design and protocol}

A crossover, randomized design was applied in 15 women and 15 men on two test days that were at least one week apart. After arriving at the laboratory in a fasted state, a catheter (Baxter BV, Utrecht, The Netherlands) was placed for blood sampling in an antecubital vein. Subjects stayed in a supine position for the rest of the test day. After the catheter was placed, subjects were allowed to rest for 30 minutes before the baseline blood sample was taken. Subjects then received a preload of $50 \mathrm{~g}$ galactose $+2.5 \mathrm{~g}$ guar gum $(836 \mathrm{~kJ})$ ) dissolved in $250 \mathrm{ml}$ water and a standard breakfast (28) (GG) or the same breakfast with $250 \mathrm{ml}$ water as preload (W). The two test conditions were applied in random order. Subjects were asked to drink the preload in less than five minutes. Subjects received the standard breakfast 15 minutes after the preload. Then they had 15 minutes again for finishing the breakfast. The breakfast (1.9 MJ) had an energy density of $3.9 \mathrm{~kJ} / \mathrm{g}$ and consisted of two slices of brown bread $(100 \mathrm{~g})$, baked $\mathrm{egg}(85 \mathrm{~g})$ and $300 \mathrm{ml} \mathrm{skim} \mathrm{milk.} \mathrm{The} \mathrm{distribution} \mathrm{of} \mathrm{energy}(\mathrm{ED}=3.9 \mathrm{~kJ} / \mathrm{g})$ was 48.8 energy-percent ( $\mathrm{E} \%$ ) from carbohydrates, $28.5 \mathrm{E} \%$ from protein and $22.6 \mathrm{E} \%$ from fat. All subjects reported that the breakfast size is more than what they habitually have as a breakfast.

Total available energy content of the breakfast was calculated (29) to be $20 \%$ of energy requirements for men and $22 \%$ of energy requirements for women, adjusted to the nearest $0.5 \mathrm{MJ}$.

After a fasted blood sample, samples were taken five times during 2 hours, to determine plasma GLP-1, insulin, glucose and free fatty acid concentrations at 30,45, 60, 90 and 120 minutes relative to completion of the preload (thus immediately after breakfast, 15 , 30,60 and 90 minutes after breakfast). Prior to blood sampling subjects were instructed to rate their feeling of hunger, fullness, sensations of satiety and desire to eat on 100 mm visual analogue scales (VAS) with anchors expressing the most positive and the most negative rating at each end (30). Furthermore subjects were instructed to report possible discomfort or nausea at any time during the trial immediately.

\section{Laboratory analyses}

Blood samples for GLP-1. were taken in iced syringes and mixed with EDTA and $40 \mu$ of DPP-IV inhibitor to prevent degradation (Linco Research, St. Charles, USA). Blood samples for other blood parameters were mixed with EDTA to prevent clotting. Plasma 
was obtained by centrifugation for 10 minutes at $2800 \mathrm{~g}$ at $4{ }^{\circ} \mathrm{C}$. Plasma was collected, frozen in liquid nitrogen and stored at $-20^{\circ} \mathrm{C}$ for analysis.

GLP-1 concentrations were measured using an ELISA Kit (EGLP -35K; Linco Research Inc., St Charles, MO, USA) for non-ractioactive quantification of biologically active forms of glucagon-like peptide. The assay has an intra-assay coefficient of variation (CV) of $8 \%$ or less and an inter CW of $12 \%$ or less and sensitivity is 2 pmol// (31).

Plasma glucose concentrations were determined using the hexokinase method (Glucose HK 125 kit; ABX diagnostics, Montepellier, France). The WAKO NEFA C-kit (Wako Chemicals, Neuss, Germany) was used to determine free fatty acid (FFA) concentrations. Insulin concentrations were measured using a radioimmunoassay kit (Insulin RIA-100; Pharmacia, Uppsala, Sweden).

\section{Statistics}

Data are presented as means \pm standard error of the means (SEM). Differences between the treatments were determined by analysis of variance for repeated measures (ANOVA) and Sheffe $F$ post-hoc test (Statview SE graphics TM). Gender differences were analyzed with factorial analysis of variance (ANOVA) and Sheffe-F post-hoc test (Statview SE graphics TM).

Pearson correlation coefficients, $r$, were calculated to determine the relationship between GLP-1, anthropometrical data and appetite ratings.

The level of significance was set at $P<0.05$.

\section{Results}

\section{Blood parameters}

Blood parameters are given as means \pm SEM. $\triangle$ was calculated as difference from fasted concentrations at 0 mirutes. To control GLP-1 release for the difference in energy content of the preloads, $\triangle$ GLP- 1 release has been calculated per $M J$.

Baseline plasma GLP-1 concentrations were not different between conditions $(P=0.31)$. Plasma $\Delta$ - GLP-1 concentration (compared to baseline) after ingestion of GG was significantly increased compared to $W$ at 30 minutes $(F 1 ; 29=32.5 ; P=0.0001), 45$ minutes (F 1;29 = 8.85; $\mathrm{P}=0.006)$ and 60 minutes $(F 1 ; 29=6.19 ; \mathrm{P}=0.01)$ (Fig. $1 \mathrm{~A})$. The addition of GG to breakfast increased the AUC ( $x$ h) for plasma GLP-1 concentrations by $57 \%$ compared to the AUC for $W$, white the energy content was increased by $40 \%$.

The $\triangle$-AUC (increase in GLP-1 compared to baseline $x h$ ) for GG (9.41.66) and breakfast was significantly higher compared to $W(6.32 \pm .57 ; P=0.008)$. 


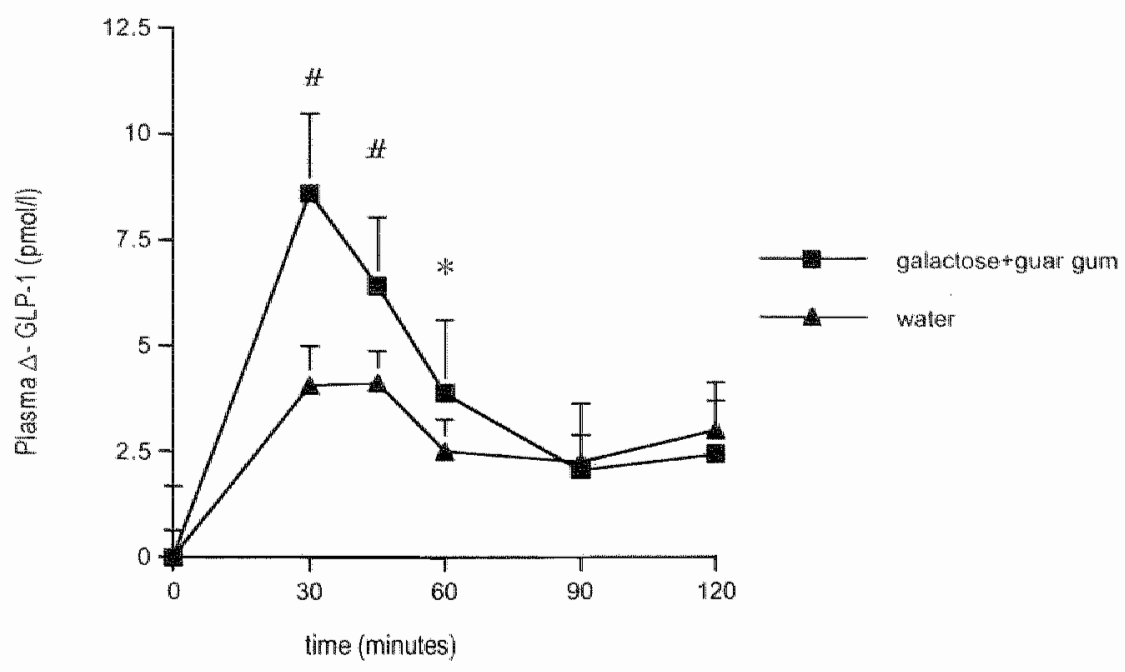

Figure 1A. $\triangle$ - GLP-1(change from fasted concentrations) plasma concentrations expressed as means \pm SEM after ingestion of galactose/ guar gum and a standard breakfast (GG) (squares), or the same breakfast with water as a preload (W) (triangles).

* Significant difference at $P=0.01$ comparing $G G$ and $W$

\# Significant difference at $P<0.01$ comparing $G G$ and $W$

$\Delta$ - GLP-1 release (compared to baseline) after GG was significantly higher for women compared to men at $30\left(F_{1} ; 28=4.77 ; P^{\prime}=0.03\right), 45(F 1 ; 27=19.99 ; P=0.0001), 60$ $(F 1 ; 28=8.86 ; P=0.005), 90(F 1 ; 28=11.07 ; P=0.002)$ and 120 minutes $(F 1 ; 27=$ $3.9 ; P=0.05$ ). This was not seen in the $W$ condition ( $F i g 1 B$ ). This can be seen in the AUC for $\triangle$-GLP-1 release as well (Fig 1C). Fasted GLP-1 concentrations were not different between men and women. Gender only affected plasma GLP-1 concentrations. None of the other blood parameters differed between men and women.

Plasma insulin concentrations were not different between conditions in the fasted state or after 30 minutes (Table 2). Ingestion of GG before breakfast led to significantly lower insulin concentrations at $45\left(F_{1} 1 ; 25=5.20 ; \mathrm{P}=0.02\right)$ and $60(\mathrm{~F} 1 ; 25=12.54 ; \mathrm{P}=$ 0.002) minutes compared to $W$ and breakfast. At 90 minutes ( $F 1 ; 25=5.50 ; P=0.03)$ and 120 minutes ( $F 1 ; 25=18.55 ; P=0.0004$ ) plasma insulin concentrations were increased in the GG condition compared to $W$.

Plasma glucose concentrations were not different between conditions in the fasted state or at 30 minutes (Table 2). At 45 minutes ( $F 1 ; 28=10.44 ; P=0.003$ ) as well as 60 minutes $(F 1 ; 29=11.64 ; P=0.001)$ glucose was significantly elevated after $W$ compared to GG. Glucose concentrations in the GG condition were not significantly different from baseline concentration at any time.

Free fatty acids decreased continuously over time in both conditions. No differences were observed between conditions (Table 2). 


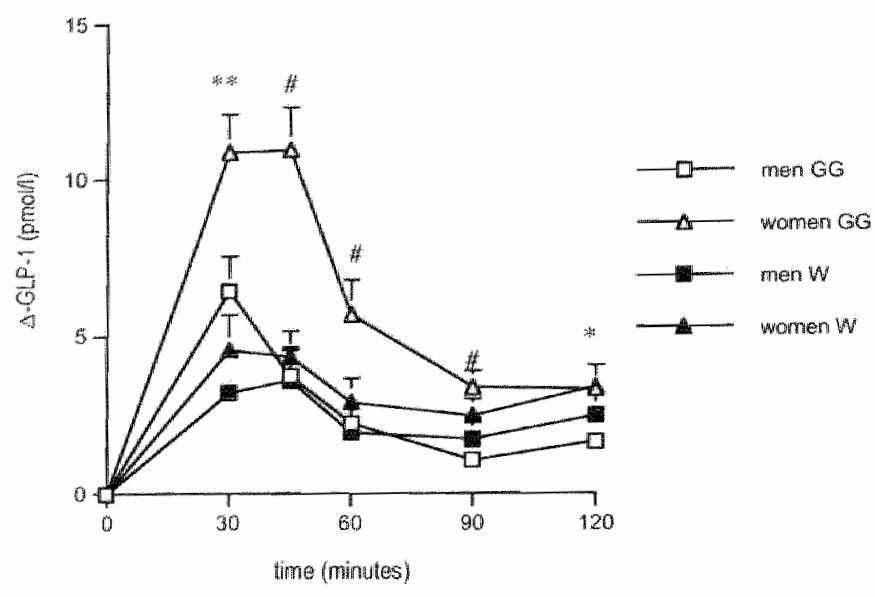

Figure 1B. A-GLP-1 (change from fasted concentrations) expressed as means 1 SEM separately for men (squares) and women (triangles) after ingestion of GG (open squares and triangles) or W (filled squares and triangles).

* Significant difference at $P=0.05$ comparing $G G$ and Wh women

* Significant difference at $P<0.05$ comparing GG and W in women

* Significant diference at $P<0.01$ comparing $G G$ and W in women

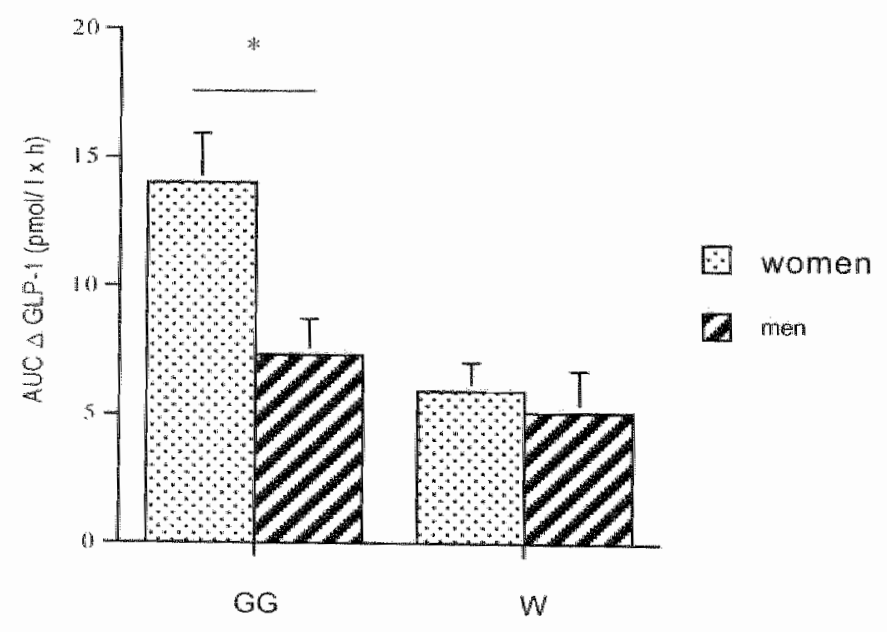

Figure $1 C$. ALC (omol/ $x h$ ) for $\triangle$-GLP-l release (change from fasted concentrations) for men $(n=15)$ and women $(n=15)$, after ingestion of galactose/ guar gum and breakfast (GG) or water and breakfast (W).

* = significant difference after GG between men and women at $P=0.003$ 


\section{Appetite ratings}

$\Delta$ - satiety ratings were significantly related to $\Delta$-GLP-1 release in the $W$ condition at 60 $(r=.42 ; P=0.02)$ and $90(r=.39 ; P=0.03)$ minutes ( $F i g .2)$. Appetite ratings were not different between $W$ and $G G$ in the men or in the women (data not shown). That subjects were able do distinguish between the preloads did not lead to differences in appetite ratings.

\section{Anthropometry}

AUC $\left(x_{2} 2 h\right)$ of $\Delta-$ GLP-1 (increase from fasted concentrations), was positively related to bodyfat $(\%),(r=.71 ; P=0.02)$. Looking at the effect separately for men and women, it becomes obvious that only women contributed to that effect $(r=.48 ; P=0.02)$. No relationship between the AUC for $\Delta-$ GLP-1 and bodyfat was found for men $(r=.08$; n.s.), (Fig. 3).

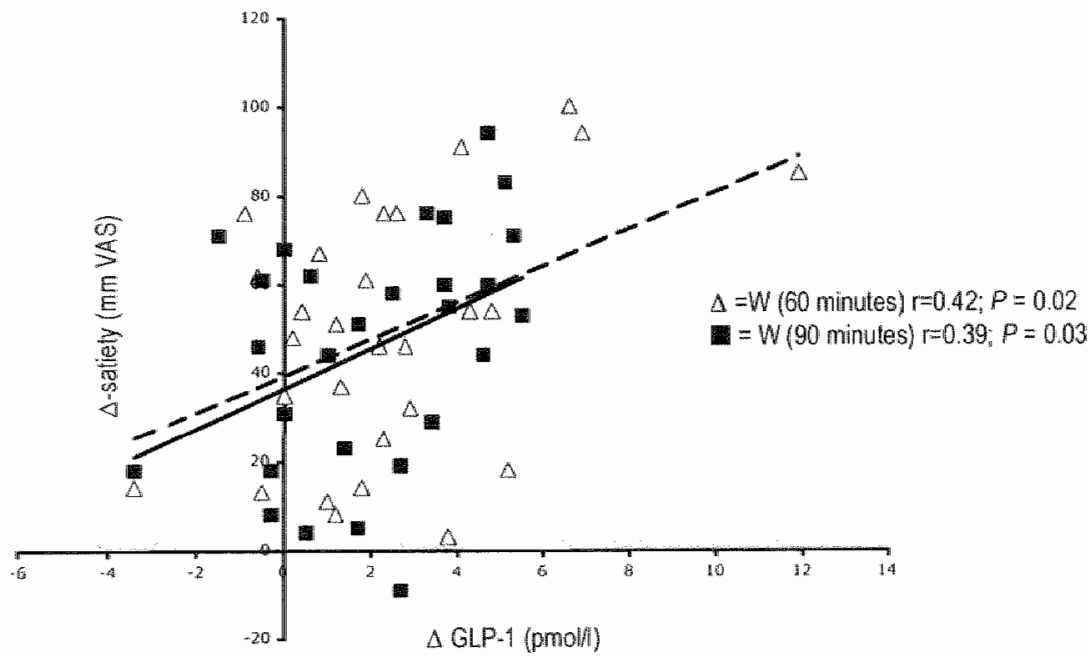

Figure 2. 4 - GLP-1 (change from fasted concentrations) is significantly related to 4 - satiety (change from fasted ratings) after ingestion of water and breakfast (W) at 60 minutes (open triangles, dashed line: $y=4.14 x+39.4 ; r=0.42 ; p=0.02$ ) and 90 minutes (filled squares, solid line: $y=4.55 x+36.5 ; r=0.39 ; P=0.03)$. 


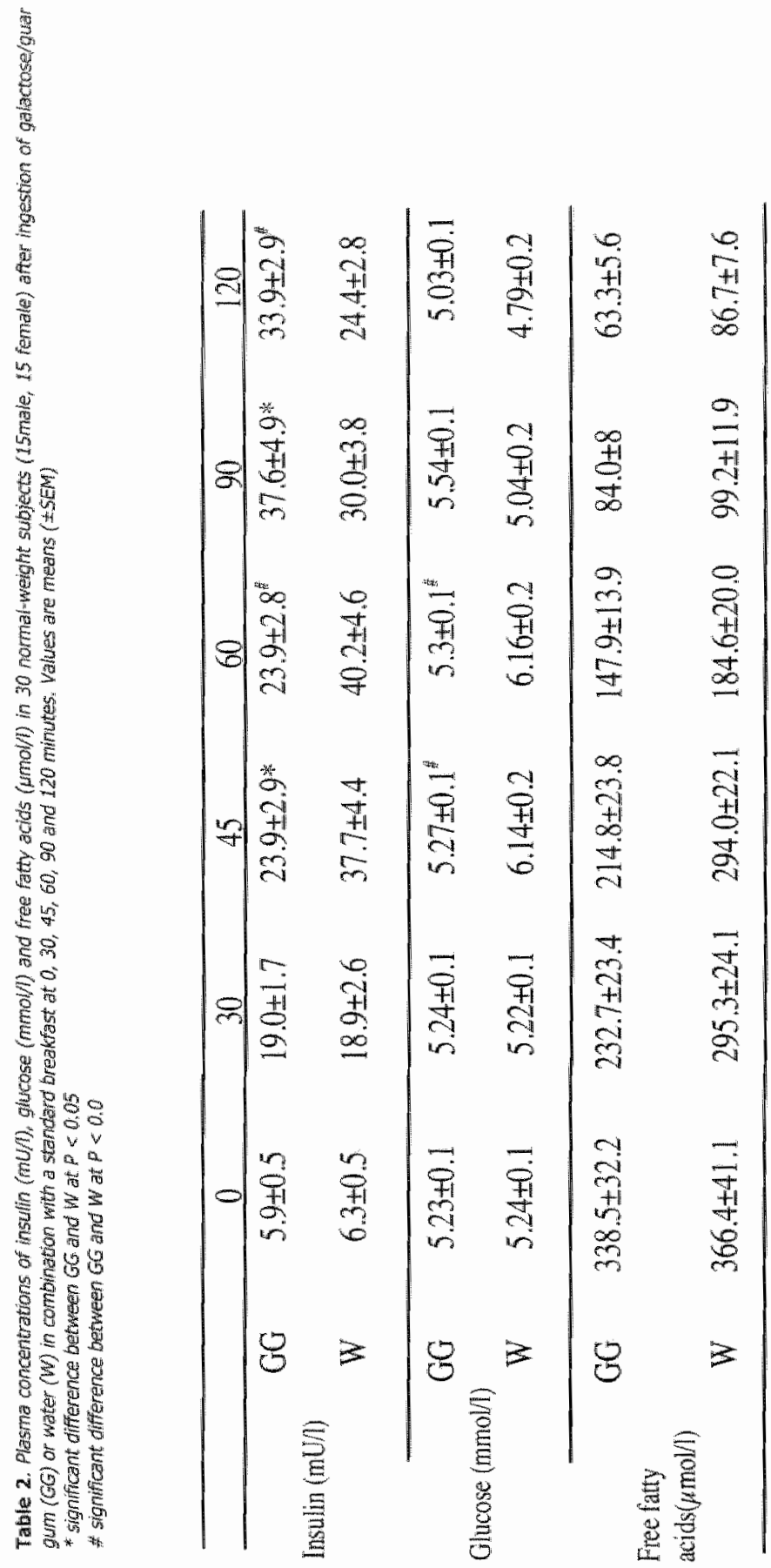




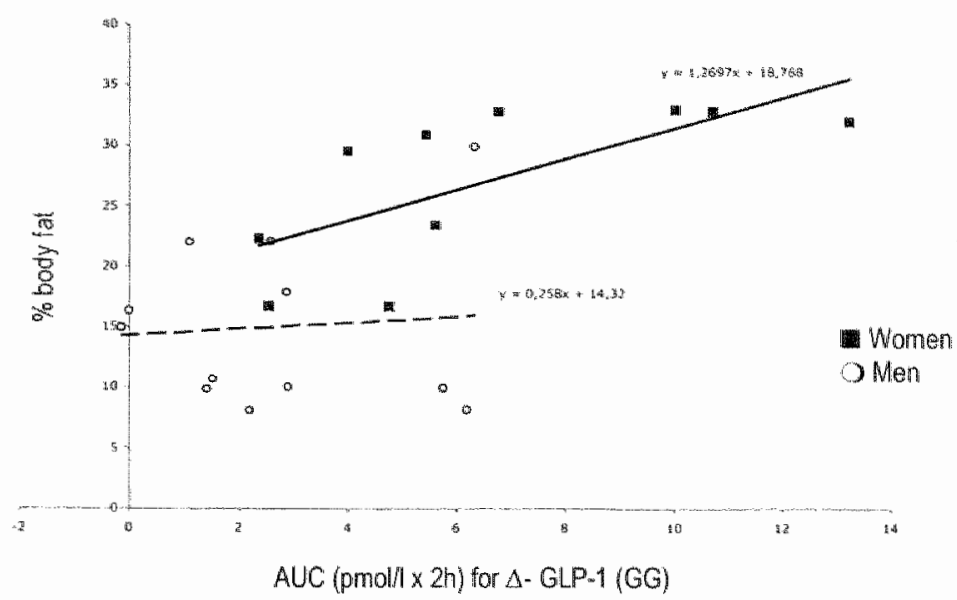

Figure 3. AUC (Pmol// $x h$ ) for $\triangle$ - GLP-1 (change from fasted concentrations) in the GG condition related to \% body fat separately for men (open circles, dashed line) and women (filled squares, solid line).

\section{Discussion}

The addition of a galactose/ guar gum preload to a standard breakfast led to a $57 \%$ increase of the GLP-1 release compared to breakfast alone. The GLP-1 response to the breakfast was also extended to 90 minutes in the women by the addition of the GG load. These observations confirm results of a former study which showed, that the galactose/ guar gum combination stimulates GLP-1 release in a manner similar to glucose/ guar gum (18). Different from glucose, which has been shown to stimulate GLP-1 release sufficiently before $(2,32)$, not much is known about galactose and GLP-1 secretion yet. Compared to glucose galactose has a lower glycaemic index (7), that might be beneficial and relevant for prevention and treatment of obesity (33), diabetes (34) and cardiovascular disease.

Insulin and glucose concentrations are lower in the GG condition, although the ingestion of galactose beside the breakfast adds up on the total carbohydrate intake. It has been shown though, that the amount galactose used as a preload in the present study results in a mean increase of the peripheral circulating glucose of only $1 \mathrm{mmol} / \mathrm{L}$ or less in healthy as well as in type 2 diabetic subjects $(35,36)$.

The potential role of gastric emptying on the increase and extension of GLP-1 release (37) in the present study is not clear. Carbohydrates as well as fiber have been shown to 
affect gastric emptying $(13,38)$. However, it has been found that the amount of guar gum used in the current study does not seem to affect gastric emptying (39).

From the results of the present study no final conclusions can be drawn about the role of fiber or galactose on GLP-1 release alone, since fiber always is presented in combination with galactose. However, in a pilot experiment, preceding the present study, the dosage of galactose and guar gum used have been tested separately and did not evoke GLP-1 release differently from water. Only the combination of both was effective (18).

Not much is known about the relationship of gender and GLP-1 release yet.

GG led to a significant increase and extended GLP-1 release compared to $W$. In the current study this effect was primarily present in women and appeared to be partly explained by the relationship of GLP-1 and body-fat mass. Gender has been reported as the major independent covariate for incremental GLP-1 response (40), yet clear gender differences in stimulated GLP-1 release have not been shown before. Gender differences have been described so far for other peptides, i.e. resistin, adiponectin $(41,42)$, CCK $(20,21)$ and for leptim $(21,22)$. The gender difference for CCK is somehow related to sex steroids $(20,43)$. As far as GLP-1 concentrations, it still needs to be determined whether sex steroids might play a direct or indirect role in the gender related differences.

DPP-IV hyperactivity leading to an accelerated degradation of GLP-1 was found in obese subjects compared to normal controls (44). Nothing is known about potential gender differences in DPP-IV activity, but should be a topic for future research, since that might contribute to the interpretation of the present results.

Physiological concentrations of leptin stimulated GLP $\mathbb{1}$ release from mouse, rat and human $L$ cells in a dose-dependent manner (19). The authors found the leptin receptor to be present on the membrane of all cells of the epithelium, including all rodent and hurnan $L$ cells. They suggested leptin as a physiological regulator of GLP-1 secretion under both basal and stimulated conditions (19). Since leptin has been reported to play a more important role in food intake regulation in women than in men (45), a stronger stimulation of GLP-1 in women in the present study may be due to leptin. This explanation seems to be at odds with the reports on lower GLP-1 concentrations and decreased GLP-1 release in obese compared to normal-weight subjects (46), since leptin is produced in direct proportion to the amount of fat stored in the adipocytes (47). However, it has been stated before, that the leptin resistance in particular present in obesity might account for lower GLP-1 secretion (19).

It is unlikely that the size of the breakfast was the cause for a difference in GLP-1 release in the men and women. Due to the small non-significant difference in BMI the energy requirements of these men and women differed on average by $1 \mathrm{MJ}$. The intake at breakfast was more than all subjects consumed habitually and the difference in the percentage of total energy requirements covered was only $2 \%$. 
The caloric content of the two preloads differ. Therefore $\Delta$ - GLP-1 release has been calculated per MJ (3.15 pmol/MJ after GG compared to $1.84 \mathrm{pmol} / \mathrm{MJ}$ after $W(\mathrm{p}=$ 0.003 ) at 30 minutes). The increase in GLP-1 stayed significant when adjusted for caloric content, suggesting that the difference in caloric content is not is nat the only possible explanation for differences in GLP-1 release between conditions.

Due to the difference in texture it was not possible to blind this study. However, appetite ratings between conditions were not different.

In accordance with ather work, we found a reduced rise in postprandial plasma glucose concentrations following the guar gum condition compared to the condition without guar gum (48-50). Due to lower glucose concentrations, insulin requirements were lower in the GG condition compared to $W$. The increase in GLP-1 was significantly related to satiety ratings in the $W$ condition, this observation reinforces the possible role of GLP-1 as a short-term satiety hormone (51).

In conclusion the addition of galactose and guar gum to a standard breakfast increased and extended plasma GLP-1 release compared to water and a standard breakfast to a greater extent than expected based upon the increase in energy intake. This increase in GLP-1 release was observed in particular in women. Since the $\triangle$ - AUC (GG) for GLP-1 was significantly related to percent body fat in women, and since percent body fat is the most discriminating variable between men and women in the present study, it seems likely, that body fat is a crucial variable for GLP-1 release in normal-weight subjects. Possible relationships of GLP-1 with leptin and other peptides as well as with sex steroids need to be further elucidated. A significant relationship between the increase in satiety and the increase in GLP-1 concentrations supports the view of GLP-1 as a short-term satiety regulating peptide.

\section{Acknowledgements}

Supported by Nowartis Consumer Health Ltd, Nyon, Switzerland 8 . Novartis Pharmaceuticals, Basel, Switzerland and Summit, USA. 


\section{References}

1. Elliott RM, Morgan LM, Tredger JA, Deacon S, Wright J, Marks V. Glucagon-ilke peptide-1 $(7-36)$ amide and glucose-dependent insulinotropic polypeptide secretion in response to nutrient ingestion in man: acute post-prandial and 24-h secretion patterns. J Endocrinol 1993;138:159-66.

2. Kreymann B, Williams G, Ghatei MA, Bloom SR. Glucagon-like peptide-1 7-36: a physiological incretin in man. Lancet $1987 ; 2: 1300-4$.

3. Lugari $R$, DellAnna $C$, Ugolotti $D$, et al. Effect of nutrient ingestion on glucagonlike peptide 1 (7-36 amide) secretion in human type 1 and type 2 diabetes. Horm Metab Res 2000;32:424-8.

4. Orskov C, Poulsen SS, Moller M, Holst J]. Glucagon-like peptide I receptors in the subfornical organ and the area postrema are accessible to circulating glucagonlike peptide 1. Diabetes 1996;45:832-5.

5. Jenkins DJ, Kendall CW, Augustin LS, et al. Glycemic index: overview of implications in health and disease. Am J Clin Nutr 2002;76:2665-735.

6. Jenkins D], Wolever TM, Taylor RH, et al. Glycemic index of foods: a physiological basis for carbohydrate exchange. Am I Cin Nutr 1981;34:362-6.

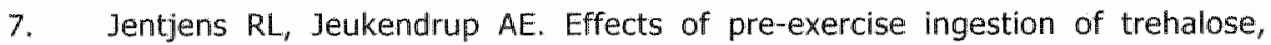
galactose and glucose on subsequent metabolism and cycling performance. Eur $J$ Appl Physiol 2003;88:459-65.

8. Gannon MC, Khan MA, Nuttall FO. Glucose appearance rate after ingestion of galactose. Metabolism 2001;50:93-98.

9. Shima $K$, Suda $T$, Nishimato $K$, Yoshimato $S$. Relationship between molecular structures of sugars and their ability to stimulate the release of glucagon-like peptide-1 from canine ileal loops. Acta Endacrinol (Copenh) 1990;123:464-70.

10. Hermann $C$, Göke $R$, Richter G, Fehmann HC, Arnold R, Göke B. Glucagon-like peptide- 1 and glucose-dependent insulin-releasing polypeptide plasma levels in response to nutrients. Digestion 1995;56:117-26.

11. Ritzel $U_{t}$ Fromme $A$, Ottleben $M_{r}$ Leonhardt $U_{s}$ Ramadori $G$. Release of glucagon-like peptide-1 (GLP-1) by carbohydrates in the perfused rat ileum. Acta Diabetol $1997,34: 18-21$.

12. Blackburn NA, Redfern 15 , Jarjis $H_{3}$, et all. The mechanism of action of guar gum in improving glucose tolerance in mam. Clin SCI (Lond) 1984;66:329-36.

13. Lawin JH, Read NW. The effect on hunger and satiety of slowing the absorption of glucose: relationship with gastric emptying and postprandiall blood glucose and insulin responses. Appetite 1995;25:89-96.

14. Massimino SP, McBurney MI, Field CJ, et al. Fermentable dietary fiber increases GLP.1 secretion and improves glucose homeostasis despite increased intestinal glucose transport capacity in healthy dogs. J Nutr 1998; 128:1786-93. 
15. Reimer RA, McBurney MI. Dietary fiber modulates intestinal proglucagon messenger ribonucleic acid and postprandial secretion of glucagon-like peptide-1 and insulin in rats. Endocrinology 1996;137:3948-56.

16. Reimer RA, Thomson AB, Rajotte RV, Basu TK, Ooraikul B, McBurney MI. A physiological level of rhubarb fiber increases proglucagon gene expression and modulates intestinal glucose uptake in rats. J Nutr 1997;127:1923-8.

17. Juntunen KS, Niskanen LK, Liukkonen KH, Poutanen KS, Holst J], Mykkanen HM. Postprandial glucose, insulin, and incretin responses to grain products in healthy subjects. Am I Clin Nutr 2002;75:254-62.

18. Hughes TE, Westerterp-Plantenga MS, Adam TCM. Nutritional compositions comprising a non-glucose carbohydrate or pectine and soluble fiber. Wo $2004 / 022074 \mathrm{Al}, 2004$.

19. Anini $Y$, Brubaker PL. Role of leptin in the regulation of glucagon-like peptide-1 secretion. Diabetes 2003; $52: 252-9$.

20. Geary N. Estradiol, CCK and satiation. Peptides 2001;22:1251-63.

21. Hickey MS, Israel RG, Gardiner SN, et al. Gender differences in serum leptin levels in humans. Biochem Mol Med 1996;59:1-6.

22. Plasqui $G$, Kester $A D$, Westerterp KR. Seasonal variation in sleeping metabolic rate, thyroid activity, and leptin. Am I Physiol Endocrinol Metab 2003;285:E338-43.

23. WHO. Definition, diagnosis and classification of diabetes mellitus. Report of a WHO Consultation. Part 1: Diagnosis and Classification of Diabetes Mellitus. Geneva, Switzerland, 1999.

24. Marieb EN. Human Anatomy \& Physiology. 5th ed. San Francisco Boston New York: Benjamin Cummings, 2001.

25. Siri. The cross composition of the body. Adv Biol Med Physiol 1956;4:239-280.

26. Stunkard AJ, Messick S. The three-factor eating questionnaire to measure dietary restraint, disinhibition and hunger. I Psychosom Res 1985;29:71-83.

27. Westerterp-Plantenga MS, Westerterp KR, Nicolson NA, Mordant A, Schoffelen PF, ten Hoor $F$. The shape of the cumulative food intake curve in humans, during basic and manipulated meals. Physiol Behav 1990;47:569-76.

28. Lugari R, Dei Cas A, Ugolotti D, et al. Evidence for early impairment of glucagonlike peptide 1 -induced insulin secretion in human type 2 (non insulin-dependent) diabetes. Horm Metab Res 2002;34:150-4.

29. Harris JA, Benedict FG. A biometric strudy of basal metabolism in men. Washington: Carnegie Institution, 1919.

30. Raben A, Tagliabue A, Astrup A. The reproducibility of subjective appetite scores. Br I Nutr 1995;73:517-30.

31. Nathan DM, Schreiber E, Fogel H, Mojsov S, Habener JF. Insulinotropic action of glucagonlike peptide-I-(7-37) in diabetic and nondiabetic subjects. Diabetes Care $1992 ; 15: 270-6$. 
32. Mannucci $E$, Ognibene $A_{r}$ Cremasco $F$, et al. Glucagon-like peptide (GLP)-1 and leptin concentrations in obese patients with Type 2 diabetes mellitus. Diabet Med $2000 ; 17: 713=9$.

33. Slabber M, Barnard $H C$, Kuyl JM, Dannhauser $A_{r}$ Schall R. Effects of a low-insulinresponse, energy-restricted diet on weight loss and plasma insulin concentrations in hyperinsulinemic obese females. Am 7 Clin Nutr 1994;60:48-53.

34. Frost $G$, willing $J_{f}$ Beecham $J$. Dietary advice based on the glycaemic index improves dietary profile and metabolic control in type 2 diabetic patients. Diabet Med 1994;11:397-401.

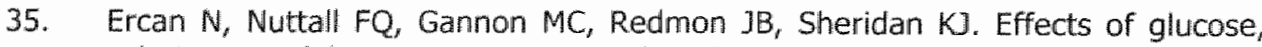
galactose, and lactose ingestion on the plasma glucose and insulin response in persons with non-insulin-dependent diabetes mellitus. Metabolism 1993;42:1560-7.

36. Gannon MC, Khan MA, Nuttall FQ. Glucose appearance rate after the ingestion of galactose. Metabolism 2001,50:93-8.

37. Nauck $M A$, Niedereichholz $U$, Ettler $R$, et al. Glucagon-like peptide 1 inhibition of gastric emptying outweighs its insulinotropic effects in healthy humans. Am $J$ Physiol 1997;273:E981-8.

38. Murray $R$, Bartoli $W$, Stofan J, Horn $M_{x}$ Eddy D. A comparison of the gastric emptying characteristics of selected sports drinks, Int J Sport Nutr 1999:9:263-74.

39. van Nieuwenhoven MA, Kovacs EM, Brummer RJ, Westerterp-Plantenga MS, Brouns $F$. The effect of different dosages of guar gum on gastric emptying and small intestinal transit of a consumed semisolid meal. J Am Coll Nutr 2001;20:87-91.

40. Vaag AA, Holst J], Volund A, Beck-Nielsen HB. Gut incretin hormones in identical twins discordant for non-insulin-dependent diabetes mellitus (NIDDM)-mevidence for decreased glucagon-like peptide 1 secretion during oral glucose ingestion in NIDDM twins. Eur J Endocrinol 1996;135:425-32.

41. Silha JV, Krsek M, Skrha JV, Sucharda P, Nyomba BL, Murphy LJ. Plasma resistin, adiponectin and leptin levels in lean and obese subjects: correlations with insulin resistance. Eur J Endocrinol 2003;149:331-5.

42. Yannakoulia M, Yiannakouris $\mathbb{N}$, Bluher $S$, Matalas AL, Klimis-Zacas D, Mantzoros CS. Body fat mass and macronutrient intake in relation to circulating soluble leptin receptor, free leptin index, adiponectin, and resistin concentrations in healthy humans. I Cinn Endocrinol Metab 2003;88:1730-6.

43. Geary N. Estradiol and appetite. Appetite 2000;35:273-4.

44. Lugari R, Dei Cas A, Ugolotti $D_{r}$ et al. Glucagon-like peptide 1 (GLP-1) secretion and plasma dipeptidyl peptidase IV (DPP-IV) activity in morbidlly obese patients undergoing billopancreatic diversion. Horm Metab Res 2004;36:111-5.

45. Woods SC, Gotoh $\mathrm{K}$, Clegg DJ. Gender differences in the control of energy homeostasis. Exp Biol Med (Maywood) 2003;228:1175-80.

46. Ranganath LR, Beety JM, Morgan LM, Wright JW, Howland $R$, Marks V. Attenuated GLP 1 secretion in obesity: Cause or consequence? Gut 1996;38:916-9. 
47. Woods SC, Schwartz MW, Baskin DG, Seeley RJ. Food intake and the regulation of body weight. Annu Rev Psychol 2000;51:255-77.

48. Fairchild RM, Ellis PR, Byrne AJ, Luzio SD, Mir MA. A new breakfast cereal containing guar gum reduces postprandial plasma glucose and insulin concentrations in normal-weight human subjects. Br I Nutr 1996;76:63-73.

49. Sierra M, Garcia 1J, Fernandez N, Diez MJ, Calle AP, Sahagun AM. Effects of ispaghula husk and guar gum on postprandial glucose and insulin concentrations in healthy subjects. Eur J Cin Nutr 2001;55:235-43.

50. Torsdottir I, Alpsten $M_{*}$ Andersson $H$, Einarsson S. Dietary guar gum effects on postprandial blood glucose, insulin and hydroxyproline in humans. $J$ Nutr 1989;119:1925-31.

51. Havel PJ. Peripheral signals conveying metabolic information to the brain: shortterm and long-term regulation of food intake and energy homeostasis. Exp Biol Med (Maywood) 2001:226:963-77. 



\section{Chapter 4}

\section{Activity-induced GLP-1 release in lean and obese subjects}

Tanja CM Adam \& Margriet S Westerterp-Plantenga

Physiology \& Behavior (in press) 


\section{Abstract}

Aim of the study was to determine whether physical activity stimulates GLP-1 release on the short-term in normal-weight and in obese subjects compared to rest and furthermore, whether modest weight loss affects GLP-1 release or sensitivity in the obese.

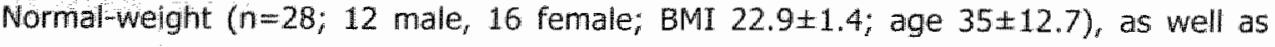

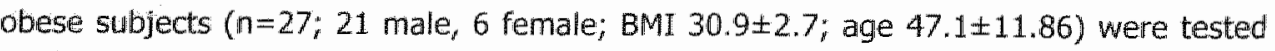
in a resting and a physical activity condition. Obese subjects were matched over two groups for a weight loss period of three months. After weight loss the tests were repeated.

The area under the curve (AUC pmol// $\times$ min) for GLP-1 concentrations was significantly increased in the physical activity condition compared to rest in lean subjects $(p=0.05)$ as well as in the obese subjects after weight loss $(p<0.05)$, but not in the obese subjects before weight loss.

Physical activity stimulated GLP-1 release in lean and obese subjects after a weight loss period supports the idea of a neuroendocrine loop in addition to distal-intestinal stimulation of GLP-1 release. Modest weight loss might be effective for increasing GLP-1 sensitivity to acute stimulation. 


\section{Introduction}

Glucagon-like peptide 1 (GLP-1) is a physiological incretin hormone, secreted by intestinal $L$ cells in response to nutrient ingestion $(1,2)$. GLP. 1 has been shown to increase postprandial satiety sensations in lean $(3,4)$ as well as in obese subjects $(5,6)$. The GLP-1 secretion in response to nutrient ingestion seems attenuated as well as delayed in abese subjects compared to lean, healthy controls (7). Since diminished GLP1 release in obese subjects may be an effect of obesity (7) body weight loss might affect GLP-1 concentrations. There is evidence that weight loss, whether dietary induced or after surgery, improves GLP-1 concentrations in obese subjects $(8,9)$.

Secretion of the peptide is biphasic with levels rising quickly (15-30 min) after ingestion of a mixed meal before nutrients can reach the lleum (10), where the GLP-1 producing $L$ cells are predominantly located. These observations make it unlikely that GLP $\mathbb{L}$ rellease is stimulated only by direct action of nutrients on $L$ cells (11). Several peptides and neurotransmitters -in line with the idea of a neuroendocrine loop- have been suggested to act as triggers for GLP-1 secretion as well. Gastrointestinal polypeptide (GIP) i.e. was shown to be a potent stimulus for GLP-1 seciretion, GIP is released when nutrients are present in the upper intestine (11). Furthermore it is believed that GLP-1 release is triggered by the autonomic nervous system $(11,12)$. For peptide $Y$ (PY $Y$, which is cosynthezised with GLP-1 from intestinal L cells, it has been shown, that the sympathetic nervous system affects its release (13). The modulation of GLP-1 secretion by the nervous system has been poorly investiglated in humans. Meal-induced activation of the sympathetic nervous system has been mentioned as a factor to account for the early secretion of GLP-1 (14). Cholinergic agonists enhanced GLP-1 secretion, when arterially infused (15), and epinephrine has been shown to induce GLP-1 release in the isolated perfused rat ileum (11).

One way to stimulate the sympathetic nervous system is physical activity (16). GLP-1. was shown to be increased in marathon runners after a race (17).

With respect to the treatment of obesity and the metabolic syndrome, increased physical activity is one of the first-line treatments next to weight reduction (18). Although a body of literature has shown that exercise as such has little effect on weight loss, its effect on fat loss and preservation of fat free mass makes is a major component in weight-loss programs (19). There is a two- to sixfold increase in norepinephrine levels during light to maximal exercise. Epinephrine output from the adrenal medulla increases with exercise as well, and the magnitude of increase is directly related to the intensity and duration of effort (16).

The present study aims to assess, whether there is an acute GLP-1 release following physical activity of low intensity in normal weight subjects. Secondly, we assessed whether this would occur in overweight/ obese subjects. If, as expected, GLP-1 release differs between lean and obese subjects $(7,8)$, we aimed to assess GLP-1 release in the overweight/ obese subjects after modest weight loss. 


\section{Materials and methods}

\section{Subjects}

Subjects $(n=65)$ were recruited by means of advertisements in local newspapers or by advertisements in the university. 55 subjects were selected following the criteria of being in good health, not taking any medications, and no history of diabetes, eating disorders or any chronic disease. 28 (12 male, 16 female) normal-weight (BMI 19-25) volunteers (Caucasian) and 27 ( 21 maie, 6 female) visceral overweight/obese subjects (Caucasian) as defined by a BMI between 25 and 30 , and by a waist-hip ratio above $.85(20,21)$, were selected. Informed written consent was obtained. The study was approved by the Medical Ethics Committee of the Maastricht University. Subject characteristics are depicted in Table 1.

\section{Screening}

Before participating in the study all subjects underwent a medical screening, and performed an oral glucose tolerance test, conducted according to the guidelines of the World Health Organization (22).

\section{Anthropometry}

For all participants body weight was measured on a digital balance (Seca, model 707, Hamburg, Germany; weighing accurancy of $0.1 \mathrm{~kg}$ ) with subjects in underwear, in a fasted state. Height was measured using a wall-mounted stadiometer (Seca, model 220, Hamburg, Germany). Body mass index was calculated as BW/height ${ }^{2}\left(\mathrm{~kg} / \mathrm{m}^{2}\right)$.

\section{Physical fitness}

For investigating the individual appropriate power for the moderate physical exercise condition lean, as well as overweight/obese subjects had to perform an incremental exercise test on an electromagnetically braked cycle ergometer (Lode, Groningen, The Netherlands) with open-circuit indirect calorimetry (Oxycon b, Mijnhardt, Bunnik, The Netherlands) and heart rate monitoring (Polar, Kempele, Finland). After an initial warm up period of $7.5 \mathrm{~min}(5 \mathrm{~min}$ at $50 \mathrm{~W}$ and $2.5 \mathrm{~min} 100 \mathrm{~W}$ ), the workload was increased every two and a half minutes with $25 \mathrm{~W}$ until exhaustion. The maximal power output was calculated using the total time cycled at the exercise test. The highest workload completed for 2.5 minutes (Wcompleted) and the number of seconds $(X)$ that the final increase of $25 \mathrm{~W}$ was maintained, were added, according to the following formula: Wmax $=$ Wcompleted $+((x / 150) * 25$ (23). On the test day, subjects cycled on $25 \%$ of their maximal power output for 60 minutes. The reason for applying a bout of $25 \%$ of maximum power output to subjects during the test was that metabolic rate with that 
workload is increased by approximately 3 - to 4-fold above rest, which is a requirement that is primarily met by an increase in uptake and oxidation of plasma fatty acids and is reflected in the results on free fatty acids ( 24$)$.

\section{Blood sample collection and processing}

At the test day subjects arrived at the laboratory in a fasted state. An indwelling cannulae (Baxter BV, Utrecht, The Netherlands) was inserted in an antecubital vein for blood sampling. At every time point of blood sampling plasma concentrations were measured for: GLP-1, insulin, free fatty acids and glucose. All subject were in a supined position for thirty minutes after placing the cannula and before a fasted blood sample was taken. After the first blood sample subjects either continued resting or started cycling on the same electromagnetically braked cycle ergometer on which they performed the maximal power output test. They cycled for one hour on $25 \%$ of their maximal power output. Blood samples were taken immediately after 60 minutes of physical activity and 30 minutes after cycling. After 60 minutes on the ergometer subjects stayed in a supine position again for the rest of the trial. In the resting condition blood samples were taken at the same time-points, while subjects stayed in a supined position. In between blood sample 0 and 60 all subjects got $250 \mathrm{~m} /$ of water to drink to prevent dehydration.

GLP-1 plasma ( $4 \mathrm{ml}$ ) was collected into iced vacutainer tubes (Becton Dickinson, UK) prepared with EDTA and $40 \mu$ of DPP-IV inhibitor (Linco Research, St. Charles, USA) for preventing active GLP-1 (7-36 amide) degradation into truncated, inactive GLP-1 ( $9-36$ amide). Dipeptidyl peptidase IV (DPP-IV: EC3.4.14.5) is an amino peptidase present in serum, which causes degradation resulting in the formation of an inactive metabolite of the former active hormone.

Insulin and free fatty acids were measured in plasma from a $4 \mathrm{ml}$ blood sample collected into EDTA vacutainer tubes (Becton Dickinson, UK). Blood for glucose was collected into vacutainers prepared with potassium (Becton Dickinson, UK).

\section{Analytical methods}

Plasma glucose concentrations were determined using the hexokinase method (Glucose HK $125 \mathrm{kit}$; ABX diagnostics, Montepellier, France) and free fatty acid concentrations were analyzed with the WAKO NEFA C-kit (Wako Chemicals, Neuss, Germany). GLP-1 samples were analyzed by LINCO (USA) using ELISA (EGLP-35K; Linco Research Inc., St Charles, MO, USA) for non-radioactive quantification of biologically active forms of glucagon-like peptide. It is highly specific for the immunological measurement of active GLP- 1 and does not detect other forms of GLP-1.

The assay has an intra assay coefficient of variation (CV) of $8 \%$ or less and an inter $\mathrm{CV}$ of $1.2 \%$ or less and sensitivity is $2 \mathrm{pmol} / 1(25)$.

Insulin was measured using RIA for quantitative measurement of insulin from serum, EDTA-plasma and heparin plasma (Insulin RIA-100; Pharmacia, Uppsala, Sweden). 


\section{Adverse events}

Adverse events during treatment were recorded and severity and outcome specified. Subjects were instructed to report discomfort or nausea at any time during trials immediately.

\section{Weight loss period}

To investigate whether weight loss affects the results obtained in overweight/obese subjects at the first test session and based on reported improvement of GLP-1 concentrations after weight loss $(8,9)$, a weight loss period of three months was executed.

Based on physical activity levels, maximum power output and subject characteristics, the obese subjects were matched over two groups for the weight loss period of three months.

One group was instructed to increase their daily physical activity level in order to lose weight, the other group was instructed to keep their habitual daily activity pattern. All subjects were told not to change their habitual diet. Monthly subjects received instructions on how to increase their physical activity, e.g. thirty minutes of walking every day, working in the garden, cycling, or walking the dog. Once a month subjects came to the lab to have their body weight determined and for receiving new activity instructions. At the same time subjects reported their activities during the last month.

After the three months weight loss period, all overweight/obese subjects repeated the two test trials of rest and physical activity, which have been described above.

\section{Basal metabolic rate and energy expenditure}

Basal metabolic rate (BMR) was estimated according to the Harris-Benedict equation (26):

BMR women $(\mathrm{MJ} / \mathrm{d})=2.74+(0.774 \times$ height $(\mathrm{m}))+(0.04 \times$ bodyweight $(\mathrm{kg}))$ $-(0.02 \times$ age (years)) .

BMR men $(\mathrm{Ml} / \mathrm{d})=0.28+(2.093 \times$ height $(\mathrm{m}))+(0.058 \times$ bodyweight $(\mathrm{kg}))$ $-(0.028 \times$ age $($ years $))$.

Estimation of energy expenditure (EE) in obese subjects was based upon the equation of Harris \& Benedict (26) and the physical activity level (PAL), calculated as:

Total energy expenditure (TEE) $=$ BMR $\times$ PAL. 


\section{Physical activity}

Daily Physical activity level of the obese subjects was measured before and after weight loss with either tri-axial accelerometers (Tracmor) (27) or uni-axial accelerometers (computer science and application monitor, CSA) $(28,29)$ and the Baecke questionnaire (30). Subjects wore the CSA or Tracmor during waking hours on a belt at the back of the waist for one week before and after the weight loss period.

Physical activity level was calculated using the following equation for the CSA (29):

$$
\text { physical activity level }=(0.000001379 \times(\text { counts }(\text { in }) \text { per day } \times 5))+1.113
$$

and the following equation for the Tracmor (27):

$$
\text { total } \mathrm{EE}=-1.259+(1.552 \times \text { resting } \mathrm{EE})+(0.076 \times \text { counts }(n) \text { per min }) \text {, }
$$

and then:

physical activity level $(P A L)=$ total $E E(M J / d) /$ resting $E E(M J / d)$.

The accelerometers were randomized over the two groups. Subjects received the same accelerometers for measurements before and after weight loss.

\section{Statistical Analyses}

The data in text and figures are presented as means \pm SEM. Data in the table are presented as mean \pm standard deviation (s.d.). AUC is calculated as $\mathrm{pmol} / 1 \times 90$ minutes. All statistics were calculated with STATVIEW+GRAPHICS (Abacus Concepts Inc, Berkeley, CA). GLP-1, insulin, glucose and free fatty acids were compared between conditions with factorial analyses of variance (ANOVA) and Sheffe-F or Fisher PLSD as a post hoc test. The area under the curve between conditions was compared with Student's t test for paired data. A value of $p<0.05$ was considered significant.

\section{Results}

Since it appeared that weight loss did not differ between the two groups (one group with the activity instructions, the other one with the instruction to keep their habitual daily activity levell), both groups were taken together for further analysis.

Also, no difference between men and women was observed, therefore they were taken together for further analysis as well. 


\section{OGTT}

Glucose plasma concentrations during the OGTT were significantly different between lean and overweight/obese subject at $0(P=0.0001), 30(P=0.0002), 60(P=0.0001)$ and 120 minutes $(P=0.0001)$ with increased glucose concentrations in obese subjects compared to lean subjects (Table 1). Overweight/obese subjects did not match the criteria for impaired glucose tolerance (22).

The OGTT in overweight/obese subjects was not different after the weight loss period compared to before weight loss (Table 1).

Tabje 1. Subject characteristics of lean subjects $(n=28)$ and overweight/obese subjects $(n=27)$ before and after weight loss

\begin{tabular}{|c|c|c|c|c|c|c|c|c|c|c|}
\hline \multirow[b]{3}{*}{ Wehght (kg) } & \multicolumn{3}{|c|}{$\begin{array}{l}\text { Lean subjects } \\
\text { (12 male, } 16 \\
\text { female }\end{array}$} & \multicolumn{6}{|c|}{$\begin{array}{l}\text { Obese subjects } \\
\text { (21male, } 6 \text { frmale) }\end{array}$} & \multirow{3}{*}{0.02} \\
\hline & & & & \multicolumn{3}{|c|}{ before weight loss } & \multicolumn{3}{|c|}{ after weight loss } & \\
\hline & 69.34 & \pm & 7.09 & 98 & \pm & 5.11 & 94.5 & t & $4.5 *$ & \\
\hline $\mathrm{BM} 1(\mathrm{~kg} / \mathrm{m} 2)$ & 22.9 & $t$ & 1.4 & 30.9 & \pm & 2.74 & 29.3 & \pm & $2,5^{*}$ & 0.01 \\
\hline Writade & 187.7 & \pm & 48.3 & 205.6 & \# & 10 & 220 & \pm & 40 & 0.49 \\
\hline Waist $(\mathrm{cm})$ & & & & 103.9 & 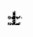 & 1.7 & 101 & \pm & $1.2^{\text {*4 }}$ & 0.02 \\
\hline Baecke & & & & 8.03 & \pm & 2.4 & 8.37 & \pm & 1.2 & 0.39 \\
\hline $\begin{array}{l}\text { PAL (phlysical } \\
\text { activily level) }\end{array}$ & & & & 1.5 & & & 1.5 & & & 0.17 \\
\hline $\begin{array}{l}\text { BMR (MO/d) } \\
\text { (basal metabolic } \\
\text { rate, calculated) }\end{array}$ & & & & 7.89 & \pm & 1 & 7.7 & \pm & 1 & 0.04 \\
\hline $\begin{array}{l}\text { [EE (MU/d) } \\
\text { (energy } \\
\text { expenditume) }\end{array}$ & & & & 112.13 & & & $11.6^{*}$ & & & 0.05 \\
\hline $\begin{array}{l}\text { OGT } 0 \\
(\mathrm{mmol} / \mathrm{l})\end{array}$ & 5.12 & \pm & 0,07 & 6.06 & \pm & $0.16 \#$ & 5.89 & \pm & 0.15 & 0.0001 \\
\hline $\begin{array}{l}\text { aGT } 30 \\
(\text { mmolil) }\end{array}$ & 7.43 & stst & 0.23 & 9.13 & \pm & 0.39 & 9.41 & \pm & 0.26 新 & 0.0002 \\
\hline $\begin{array}{l}\text { OGTT } 50 \\
(\mathrm{~mm} a \mathrm{l} / \mathrm{l})\end{array}$ & 6.52 & \pm & 0.30 & 9.54 & \pm & 0.58 .78 & 9.96 & \pm & 0.41 & 0.0001 \\
\hline $\begin{array}{l}0671120 \\
(\text { minoly) }\end{array}$ & 5.24 & ty & 0.19 & 7.29 & \pm & 0.46 滦 & 7.02 & $\star$ & 0.36 & 0.0002 \\
\hline
\end{tabular}

\section{Results for lean subjects and overweight/obese subjects before weight loss}

First, in lean subjects the physicail activity condition was compared to the resting condition. The concentration of basal plasma GLP-1 (7-36) amide in lean subjects was $4.5 \pm 0.6 \mathrm{pmol} / /$ (mean \pm SEM). With physical activity, GLP-1 release was significantly increased at 60 minutes $(5.9 \pm 1.08 \mathrm{pmol} / \mathrm{l})$ compared to rest $(3.62 \pm .56 \mathrm{pmol} / \mathrm{l})$, $(F 1 ; 26=5.50 ; \mathrm{P}<0.05)$, as well as compared to baseline $(F 1 ; 26=5.26 ; \mathrm{P}=0.03)$. Immediately after the cycling period GLP-1 levels went back to almost basal concentrations $(4.2 \pm .81 \mathrm{pmol} / \mathrm{I})$, comparable to $4.8 \pm 1.02 \mathrm{pmol} / \mathrm{l}$ at rest. 
The AUC (pmoll/1 $\times$ minutes) for GLP-1 was different between activity and rest (F 1;26 = 5.52; $\mathrm{P}=0.05$ ) (Figure 1 ).

Before weight loss, in the overweight/obese subjects, the AUC (pmol// $x$ minutes) for GLP-1 concentrations was not different between the resting and the activity condition. (Figure 2A).

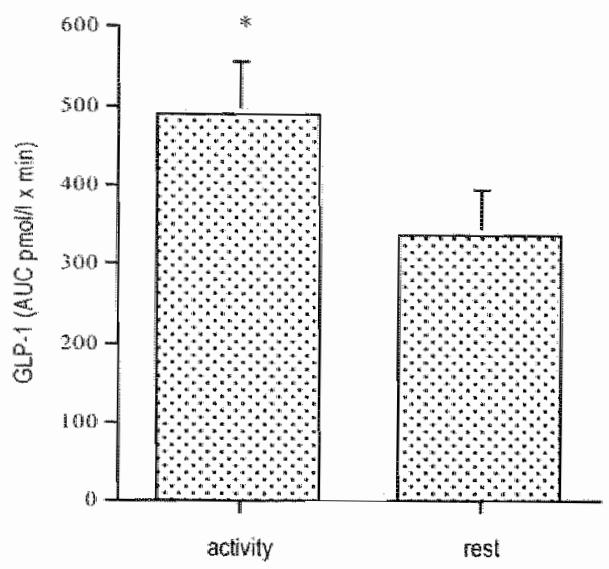

Figure 1. Comparison between AUC (pmol/l $x$ min) of GLP-1 release in normal-weight subjects $(n=28)$ during rest and activity

* different at $p=0.05$

In the lean subjects insulin concentrations after physicall activity were significantly increased compared to rest at 90 minutes ( $F 1 ; 24=7.55 ; \mathrm{P}=0.01$ ) (Table 2).

For the obese group insulin concentrations were not different between the resting condition and the activity condition before weight loss.

Glucose concentrations in lean subjects were elevated during physical activity compared to rest at 60 minutes $(F 1 ; 24=10.16 ; P=0.003$ ). (Table 2$)$.

Giucose concentrations in the obese group were not different between the two conditions before weight loss.

Free fatty acids significantly increased in the lean subjects during physical activity and peaked at 60 minutes ( $F 1 ; 26=4.97 ; P=0.03$ ). After activity, free fatty acids declined rapidly and approached resting concentrations (Table 2 ).

Before weight loss, free fatty acid concentrations were significantly increased in obese subjects during physical activity compared to rest at $60(F 1 ; 25=10.98 ; P=0.002)$ and 90 minutes $\left(F_{1} ; 21=8.48 ; \mathrm{P}=0.008\right.$ ) (Table 2).

Baseline concentrations between physical activity and rest for insulin, glucose and free fatty acids were not different in obese subjects. 
Resuits for overweight obese subjects after weight loss

After three months all overweight/obese subjects had reduced their weight and their waist circumference significantly, without any differences between the two groups that recelved different activity instructions (Table 1).

In all overweight/obese subjects physical activity indicated by the Baecke score, Wmax or PAL remained unchanged. Since no difference was abserved between the two overweight/obese sub-groups, these groups were taken together for further analysis.

After weight loss the AUC (pmol/I $\times 90$ minutes) for GLP-1 release was significantly different between physical activity and rest $(375.2 \mathrm{pmol} / 1 \pm 75.2$ compared to 267.2 pmoll $1 \pm 30.9 ; \mathrm{P}=0.03$ ), (Figure $2 \mathrm{~B}$ ).
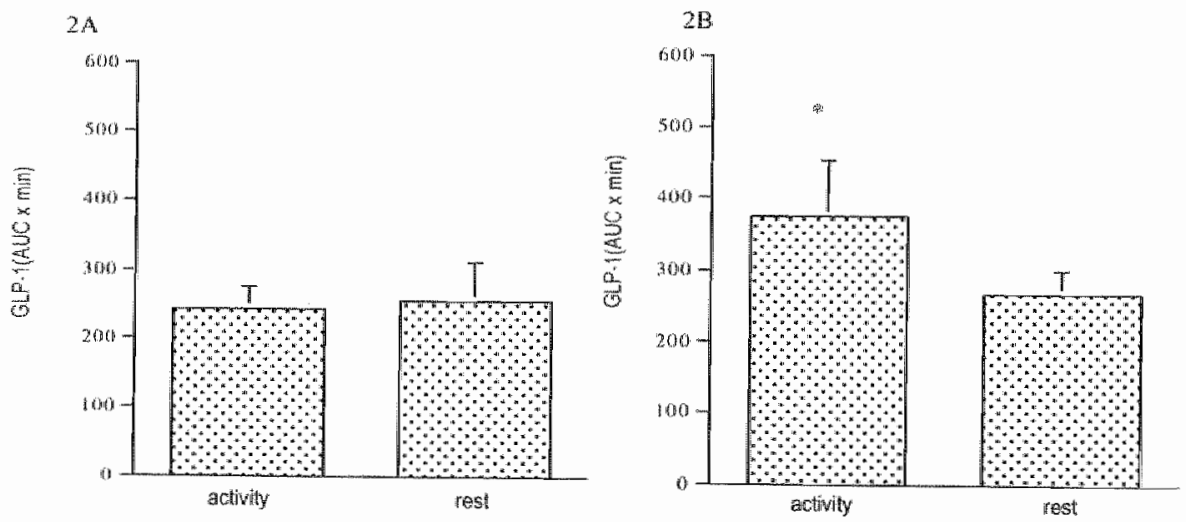

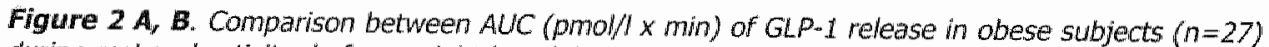
during rest and activity, before weight loss ( $A$ ) and after madest weight loss (B).

* different at $p<0.05$

Baseline concentrations for insulin, glucose and free fatty acids between physical activity and rest were not different in obese subjects.

In the obese group after weight loss no difference in plasma insulin or glucose concentrations was observed between the resting and the activity condition (Table 2 ).

Free fatty acid concentrations were different between activity and rest at 60 ( $F 1 ; 20=$ $15.2 ; P=0.0009)$ and 90 minutes $(F 1 ; 13=21.9 ; P=0.0004)$. 


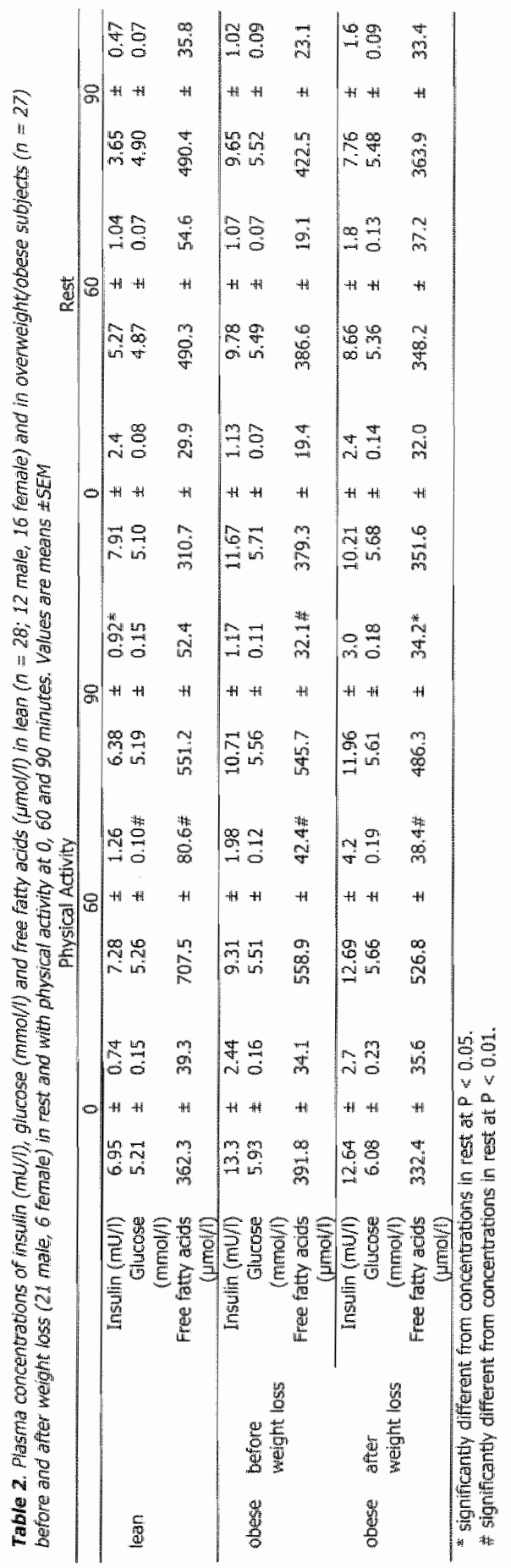




\section{Discussion}

Whereas the effects of nutrients on GLP-1 secretion have been studied extensively, modulation of this secretion by physical activity or by the nervous system has been poorly investigated in humans.

On the short term, after 60 minutes of low intensity activity, GLP-1 release was significantly increased in fasted, normal-weight subjects, but not in overweight/obese subjects. The area under the curve in a physical activity condition was significantly different from a resting condition in lean subjects. However, this phenomenon of increased GLP-1 concentration during activity compared to rest appeared as well in the overweight/obese subjects after weight loss.

We speculate, that the short-term stimulation of GLP-1 secretion in these subjects is due to the stimulation of the sympathetic nervous system during exercise. GLP-1 induces inhibition of gastrointestinal motor activity (31). Colonic sympathetic afferents that control the gastroduodenal area have been described (32) and GLP-1 action on these fibers has been suggested to activate an ileal brake mechanism $(32,33)$.

With respect to the intended physical activity induced weight-loss, it is umlikely that weight-loss was activity-induced, since the scores on the Baecke questionnaire remained unchanged after the weight loss period compared to before weight loss. The same holds for the Wmax. Although the lack of increase in PAL is partly due to the weight-loss induced decrease in BMR, and a small increase in activity induced energy expenditure, the achieved weight loss seems not to be completely attributable to increased physical acitivity. It has been shown before that other factors may be responsible for the actua! weight lloss, such as an increase in dietary restraint $(34,35)$.

Epinephrine (11) and isoproterenol (36) were shown to stimulate GLP-1 release in the isolated rat ileum. Together with other studies that show a blockade of the effect of GLP-1 on gastric intestinal motor artivity by phentolamine and propranolol, the present data suggest a possible involvement of adrenergic pathways in GLP-1 actions (32). The stimulation of the sympathetic nervous system during exercise leads to epinephrine as well as norepinephrine release, possibly triggering GLP-1 release in lean as well as postobese subjects. Exercise stimulates b-adrenergic receptors (37). There is evidence from animal studies, that stimulation of b-adrenergic receptors stimulates ileal $L$ cell secretion (38, 39). Epinephrine has not been measured in this experiment. The quick but rather short stimulation of GLP-1 release is in line with experiments showing transient peptide release in response to adrenergic agonists and support the hypothesis that neurotransmitters modulate intestinal endocrine cell secretion for brief time periods ( 36 , $39,40)$.

There is evidence for attenuated postprandial GLP-1 release in obese subjects $(7,8)$. It might be possible that obese subjects are less sensitive to any kind of GLP-1 stimulation in line with other metabolic changes and disturbances caused by obesity $(21,41)$, and that diminished GLP-1 concentrations in the obese may indeed be an effect of obesity, 
and may be reversible after weight loss. The difference in GLP-1 concentrations after physical activity was not obserwed in obese subjects before weight loss, following the same protocol as lean subjects, suggesting that weight loss contributes to an improvement of metabolic fitness $(42,43)$ and to an improvement of GLP-1 sensitivity. A gradual postprandial normalization of GLP-1 response has been reported in abese subjects after weight loss (8).

Leptin, an adiposity signal that is secreted in proportion to the amount of fat stored in the adipocytes, was shown to stimulate GLP-1 secretion from rat, mouse and human L cells dose dependently and to contribute to the improvement of GLP-1 release after weight loss (44). Leptin resistance is common in obese humans (45) and leptin sensitivity improves with weight loss (46). In a murine model leptin resistance impaired GLP-1 release. These results give support to the idea of leptin as a causative factor for impaired GLP-1 release in obese humans (44). Although leptin was not measured in the present study, improved leptin sensitivity due to weight loss might be one possible mechanism underlying improved GLP-1 release following weight loss.

Based on the present study it seems that even modest weight loss affects GLP-1 release. Further studies are necessary for investigating effects of severe weight loss on GLP $\mathbb{1}$ release. Insulin concentrations appeared as expected (47).

Free fatty acids are a major oxidative fuel during rest and activity. Sub-threshold power output physical activity increases the proportion of free fatty acid oxidation. As expected, this is reflected in the results, comparing activity induced increase in free fatty acids to rest.

Taken together, GLP-1 release is stimulated by physical activity of $25 \%$ Wmax after one hour in normal weight subjects, suggesting a role of a neuroendocrine loop in the regulation of the entero-insular axis and GLP-1 release, that may be mediated by the sympathetic nervous system. A significant difference between the activity condition and rest after weight loss was observed in overweight/obese subjects. That difference was not seen before weight loss, indicating a diminished acute GLP-1 response due to abesity rellated insensitivity.

From the tendency of improved GLP-1 concentrations in the post-weight loss vs. the preweight loss state, we conclude that the diminished GLP- 1 concentrations in the obese may be reversible, and therefore may be rather an effect than a cause of obesity. 


\section{References}

1. Creutzfeldt $W$. The incretin concept today. Diabetologia 1979;16:75-85.

2. Kreymann B, williams $G_{3}$, Ghatei MA, Bloom SR. Glucagon-like peptide-1 7-36: a physiological incretin in man. Lancet $1987 ; 2: 1300-4$.

3. Flint A, Raben A, Astrup A, Holst j]. Glucagon-like peptide 1 promotes satiety and suppresses energy intake in humans. J Clin Invest 1998:101:515-20.

4. Turton MD, O'Shea D, Gunn I, et al. A role for glucagon-like peptide-1 in the central regulation of feeding. Nature 1996;379:69-72.

5. Näslund $E$, Barkeling $B$, King $N$, et al. Energy intake and appetite are suppressed by glucagon-like peptide-1 (GLP-1) in obese men. Int 1 Obes Relat Metab Disord 1999;23:304-11.

6. Näslund $E$, Gutniak M, Skogar $S$, Rössner $S$, Hellström PM. Glucagon-like peptide 1 increases the period of postprandial satiety and slows gastric emptying in obese men. Am J Clin Nutr 1998;68:525-30.

7. Ranganath LR, Beety JM, Morgan LM, Wright JW, Howland R, Marks V. Attenuated GLP-1 secretion in obesity: cause or consequence? Gut $1996 ; 38: 916-9$.

8. Verdich $C$, Tioubro $S$, Buemann $B$, Lysgard Madsen J, Juul Holst J, Astrup A. The role of postprandial releases of insulin and incretin hormones in meal-induced satiety-effect of obesity and weight reduction. Int I Obes Relat Metab Disord $2001 ; 25: 1206-14$.

9. Näslund E, Gryback P, Hellstrom PM, et al. Gastrointestinal hormones and gastric emptying 20 years after jejunoileal bypass for massive obesity. Int $]$ Obes Relat Metab Disord 1997;21:387-92.

10. Anini Y, Hansotia T, Brubaker PL. Muscarinic receptors control postprandial release of glucagon-like peptide-1: in vivo and in vitro studies in rats. Endocrinology 2002;143:2420-6.

11. Herrmann-Rinke $C$, Vöge $A$, Hess $M$, Göke B. Regulation of glucagon-like peptide-1 secretion from rat ileum by neurotransmitters and peptides. $J$ Endocrinol 1995;147:25-31.

12. Herrmann-Rinke $C$, Horsch D, McGregor GP, Göke B. Galanin is a potent inhibitor of glucagon-like peptide-1 secretion from rat lleum. Peptides $1996,17: 571-6$.

13. Zhang $T$, Uchica $T$, Gomez $G$, Luis $F$, Thompson JC, Greeley GH, Jr. Neural regulation of peptide $Y Y$ secretion. Regul Pept 1993;48:321-8.

14. Plaisancie P, Bernard $C$, Chayvialle JA, Cuber JC. Regulation of glucagon-like peptide-1-(7-36) amide secretion by intestinal neurotransmitters and homones in the isolated vascularly perfused rat colon. Endocrinology 1994;135:2398-403.

15. Abello J, Ye F, Bosshard A, Bernard C, Cuber JC, Chayvialle JA. Stimulation of glucagon-like peptide-1 secretion by muscarinic agonist in a murine intestinal endocrine cell line. Endocrinology 1994;134:2011-7. 
16. McArdle WD, Katch FI, Katch VI. Exercise Physiology. 4 ed ed. Baltimore, Maryland: Williams \& Wilkins, 1996.

17. O'Connor AM, Johnston CF, Buchanan KD, Boreham $C_{*}$ Trinick TR, Riddoch CJ. Circulating gastrointestinal hormone changes in marathon running. Int $J$ Sports Med 1995; 16:283-7.

18. Ginsberg HN. Treatment for patients with the metabolic syndrome. Am I Cardiol 2003; $91: 29 \mathrm{E}-39 \mathrm{E}$.

19. Votruba SB, Horvitz MA, Schoeller DA. The role of exercise in the treatment of abesity. Nutrition 2000;16:179-88.

20. Davy BM, Melby $\mathrm{CL}$. The effect of fiber-rich carbohydrates on features of Syndrome X. J Am Diet Assoc 2003;103:86-96.

21. Bosello $O$, Zamboni M. Visceral obesity and metabolic syndrome. Obes Rev $2000 ; 1: 47-56$.

22. WHO. Definition, diagnosis and classification of diabetes mellitus. Report of a WHO Consultation. Part 1: Diagnosis and Classification of Diabetes Mellitus. Geneva, Switzerland, 1999.

23. Bovens $A M$, van Baak MA, Vrencken $J G_{*}$ Wijnen $I A$, Saris WH, Verstappen FT. Maximal aerobic power in cycle ergometry in middle-aged men and women. active in sports, in relation to age and physical activity. Int 3 sports Med $1993 ; 14: 66-71$.

24. Romijn JA, Coyle EF, Sidossis LS, et al. Regulation of endogenous fat and carbohydrate metabolism in relation to exercise intensity and duration. Am $J$ Physiol 1993;265:E380-91.

25. Nathan DM, Schreiber E, Fogel H, Mojsov S, Habener JF. Insulinotropic action of glucagonlike peptide-I-(7-37) in diabetic and nondiabetic subjects. Diabetes Care $1992 ; 15: 270-6$.

26. Harris 1, Benedict F. A biometric study of basal metabolism in man. Washington, Carnegie Institution, 1919.

27. Goris AH, Meijer EP, Kester A, Westerterp KR. Use of a triaxial accelerometer to validate reported food intakes. Am J Clin Nutr 2001;73:549-53.

28. Melanson EL, Jr., Freedson PS. Validity of the Computer Science and Applications, Inc. (CSA) activity monitor. Med Sci Sports Exerc 1995;27:934-40.

29. Ekelund $U$, Yngve A, Sjostrom M, Westerterp K. Field evaluation of the Computer Science and Application's Inc. Activity monitor during running and skating training in adolescent athletes. Int J Sports Med 2000;21:586-92.

30. Baecke JA, Burema J, Frijters JE. A short questionnaire for the measurement of habitual physical activity in epidemiological studies. Am I Clim Nutr $1982 ; 36: 936-42$.

31. Schïrra J, Houck P, Wank U, Arnold $R$, Göke B, Katschinski M. Effects of glucagon-like peptide-1(7-36) amide on antro-pyloro-duodenal motility in the interdigestive state and with duodenal lipid perfusion in humans. Gut $2000 ; 46: 622-31$. 
32. Giralt M, Vergara P. Sympathetic pathways mediate GLP-1 actions in the gastrointestinal tract of the rat. Regul Pept 1998;74:19-25.

33. Giralt M, Vergara P. Glucagonlike peptide-1 (GLP-1) participation in ileal brake induced by intraluminal peptones in rat. Dig Dis 5ci 1999;44:322-9.

34. Stunkard AJ, Messick S. The three-factor eating questionnaire to measure dietary restraint, disinhibition and hunger. I Psychosom Res 1985;29:71-83.

35. Lejeune MP, Van Aggel-Leijssen DP, Van Baak MA, Westerterp-Plantenga MS. Effects of dietary restraint $v$ s exercise during weight maintenance in obese men. Eur J Clin Nutr 2003;57:1338-44.

36. Dumoulin $V_{*}$ Dakka $T$, Plaisancie $P$, Chayvialle $\mathrm{JA}_{*}$ Cuber $\mathrm{JC}$. Regulation of glucagon-like peptide-1-(7-36) amide, peptide $Y Y$, and neurotensin secretion by neurotransmitters and gut hormones in the isolated vascularly perfused rat ileum. Endocrinology 1995;136:5182 -8.

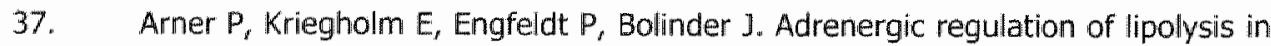
situ at rest and during exercise. I Chin Invest 1990;85:893-8.

38. Chap $Z$, Okuda $Y$, Pena J, Field JB. Beta-adrenergic stimulation contributes to incretin effect in conscious dogs. Am I Physiol 1991;261:E58-65.

39. Claustre 3, Brechet S, Plaisancie P, Chayvialle JA, Cuber JC. Stimulatory effect of beta-adrenergic agonists on ileal $L$ cell secretion and modulation by alphaadrenergic activation. J Endocrinal 1999;162:271-8.

40. Chrousos GP, Gold PW. The concepts of stress and stress system disorders. Overview of physical and behavioral homeostasis. Jama 1992:267:1244-52.

41. Bloomgarden ZT. Obesity, hypertension, and insulin resistance. Diabetes Care $2002 ; 25: 2088-97$.

42. Bond Brill J, Perry AC, Parker L, Robinson A, Burnett $K$. Dose-response effect of walking exercise on weight loss. How much is enough? Int $J$ Obes Relat Metab Disord 2002;26:1484-93.

43. Poirier $P$, Despres JP. Exercise in weight management of obesity. Cardiol Clin 2001;19:459-70.

44. Anini $Y$, Brubaker PL. Role of leptin in the regulation of glucagon-like peptide-1 secretion. Diabetes 2003;52:252-9.

45. Kolacaynski JW, Ohannesian JP, Considine RV, Marco CC, Caro JF. Response of leptin to short-term and prolonged overfeeding in humans. J Clin Endocrinol Metab 1996;81:4162-5.

46. Lustig RH, Sen S, Soberman JE, Velasquez-Miever PA. Obesity, leptin resistance, and the effects of insulin reduction. Int $J$ Obes Relat Metab Disord 2004.

47. Marliss $E B$, Vranic M. Intense exercise has unique effects on both insullin release and its roles in glucoregulation: implications for diabetes. Diabetes $2002 ; 51$ Suppl 1:5271-83. 
Chapter 5

\section{GLP-1 release and satiety after a nutrient challenge in normal- weight and obese subjects}

Tanja CM Adam \& Margriet S Westerterp-Plantenga

British Journal of Nutrition (In Press) 


\section{Abstract}

The present study was conducted to assess whether Glucagon-like peptide (GLP)-1 release and appetite after a breakfast with or without an additional gallactose/guar gum stimulation is different in normal-weight as compared to overweight/obese subjects. 28 overweight/obese (BMI: $30.3 \pm 2.7 \mathrm{~kg} / \mathrm{m}^{2}$; age: $44.3 \pm 9.7 \mathrm{y}$ ) and 30 normal-weight subjects (BMI: 22.8 $\pm 1.4 ;$ age: $31.5 \pm 12.8 y$ l participated in a crossover study. Fasting and postprandial plasma GLP-1, insulin, glucose and free fatty acid concentrations were measured in response to either a galactose $(50 \mathrm{~g}) / \mathrm{guar}$ gum $(2,5 \mathrm{~g}) \mathrm{load}(836 \mathrm{~kJ})$, and a standard breakfast (1,9 MJ) (GG), or water $(250 \mathrm{ml})$ and the standard breakfast (W) every 30 minutes relative to the ingestion for 120 minutes. Appetite was assessed using $100 \mathrm{~mm}$ visual analogue scales.

GLP-1 concentrations were significantly increased after GG at 30 and 60 minutes compared to $W$ in both groups.

Plasma GLP-1 concentrations in the $W$ condition were higher in normal-weight as compared to overweight/obese subjects $(p=0.03)$. No difference was observed in the $G G$ condition between groups. Satiety was increased in normal-weight subjects compared to the overweight/obese in the GG condition at $30(p=0.02)$ and 60 minutes $(p=0.04)$. We conclude, that after a standard breakfast with water, GLP-1 release was lower in the overweight/obese compared to normal-weight subjects. However, postprandial GLP-1 release in overweight/obese subjects was not different from normal-weight subjects, when galactose/guar gum was added to the breakfast. The latter was not mirrored by subjective feelings of satiety. Disturbed perception of physiological feedback of a satiety hormone rather than disturbed feedback itself might contribute to obesity. 


\section{Introduction}

Food intake regulation is a complex process that involves physiological as well as social and psychological components. The way food is sensed and processed by the biological system generates and activates meural and humoral signals that control appetite. Glucagon-like peptide 1 (7-36) amide (GLP-1) is believed to be one of the gut peptides that are involved in satiety signaling in addition to other signals that operate via gastric and small-intestinal vagal afferent nerve fibers (1-3).

GLP-1 is a 30 amino acid peptide hormone that is released from intestinal L-cells of the intestinal mucosa in response to nutrients and mixed meals $(4,5)$. It increases satiety and suppresses appetite in normal weight subjects $(6,7)$. GLP-1 release in response to nutrient sensing is known to stimulate insulin release in pancreatic beta-cells (6-9). Findings on basal GLP-1 concentration and the effect of food intake on GLP-1 release and satiety in obese subjects are contradictory. While one study reports hypersecretion of truncated GLP-1 in obese subjects in response to a glucose load (10), others find attenuated release of GLP-1 in response to a meal (11). Peripheral administration of GLP-1 in obese subjects decreased hunger ratings and reduced energy intake (12).

Although dietary fiber such as guar gum was found to effectively increase satiety and fullness ratings and reduce hunger and desire to eat in obese as well as normal weight subjects in the short-term $(13,14)$, the evidence for effects on weight loss is poor (15), The effect of fiber on GLP-1 release seems not clear yet and has been found to be a matter of amount $(16,17)$, but also has been suggested to depend on structural food properties rather than the amount of fiber

ingested (18). In an earlier study we found that galactose in combination with guar gum before breakfast increased GLP-1 release in normal-weight subjects (19). The aim of the present study was to investigate whether GLP-1 release will be increased postprandially in response to galactose with guar gum consumed before a standard breakfast (GG) in obese subjects compared to normal- weight subjects. Furthermore we examined whether this is reflected in appetite ratings.

\section{Subjects and Methods}

\section{Subjects}

70 subjects between the ages of 20 and 60 years were recruited by means of advertisements in local newspapers. Of the 58 included subjects, 28 subjects were overweight/ obese ( 9 male and 19 female) according to the classification of the World Health Organization (WHO) (20). Thirty subjects were normal weight controls (15 male and 15 female), (Table 1). Subjects were used to a laboratory environment, since they participate frequently in experiments that are executed at the Maastricht University. Selection criteria included being in good health, not taking any medications, and no history of diabetes or chronic disease and no participation in other ongoing studies or former studies that would influence the outcome of the present study. 
The power calculation for the present study is based on former results that are assumed as a scientifically important difference (19) and has been calculated for a sensitivity of 0.90 and a two-sided significance level of 0.05 according to the standard equations (21). Based on a difference between conditions of $8.6 \mathrm{pmol} / \mathrm{l}$ and a standard deviation of 10 we calculated 26 subjects. If a Mann-Whitney $U$ test is applied, the $\mathbb{N}$ needs to be increased by $5 \%$, which added up to 28 subjects.

Informed written consent was obtained and the study was approved by the Medical Ethics Committee of the Mastricht University.

\section{Body weight and BMI}

For all subjects body weight (BW) was measured on a digital balance (Seca, model 707, Hamburg, Germany; weighing accuracy of $0.1 \mathrm{~kg}$ ) and height was measured using a wall-mounted stadiometer (Seca, modei 220, Hamburg, Germany). Body mass index was calculated as BW/ height ${ }^{2}\left(\mathrm{~kg} / \mathrm{m}^{2}\right)$ (Table 1$)$.

Table 1. Subject characteristics are expressed as means \pm sd.

* significant difference between normal-weight $(n=30)$ and overweight/ obese subjects $(n=28)$, (factorial ANOWA).

Nomal weight $(n=30) \quad$ Obese $(n=28) \quad p$

\begin{tabular}{|c|c|c|c|}
\hline Age (vears) & $31.58+12.84$ & $44.38 \pm 9.76$ & $0.0002^{*}$ \\
\hline Heght (m) & $1.75 \pm 0.09$ & $1.71 \pm 0.06$ & 0.10 \\
\hline Weight (kg) & $69.34 \pm 7.09$ & $89.32 \pm 8.92$ & $0.0001 *$ \\
\hline $\mathrm{B} M \mathrm{Mi}\left(\mathrm{kg}_{\mathrm{m}} / \mathrm{m}^{-2)}\right.$ & $22.89 \pm 1.49$ & $30.35 \pm 2.70$ & 0.0001 \\
\hline Whatody fat & $20.49 \pm 9.02$ & $38.15 \pm 6.13$ & $0.0001^{*}$ \\
\hline
\end{tabular}

\section{Body composition}

Total body water was measured using the ${ }^{2} \mathrm{H}\left({ }^{2} \mathrm{H}_{2} \mathrm{O}\right)$ - dillution technique $(22,23)$. The evening prior to the first test day subjects drank a deuterium dilution (70g water with an enrichment of 5 atom\% excess ${ }^{2} \mathrm{H}$ ) after voiding. Deuterium enrichment was measured in urine from the second voiding of the following morning. ${ }^{2} \mathrm{H}$ cancentrations in the urine samples were measured using an isotope ratio MS (Micromass Optima, Manchester, UK). Total body water was determined by dividing the measured ${ }^{2} \mathrm{H}$ dilution space by 1.04 (23). Fat-firee mass (FFM) was calculated by dividing the total body water by the hydration factor 0.73 . By subtracting FFM from body weight, fat mass (FM) was obtained. Body fat (\%) was calculated as FM expressed as \% body weight (Table 1). 


\section{Study protocol and meal}

Subjects came to the laboratory for two visits, separated by at least one week. The subjects were instructed to fast from $10 \mathrm{pm}$ the night prior to each visit. After arrival at 8:00 in the moming, an indwelling cannulae (Baxter BV, Utrecht, The Netherlands) was inserted in an antecubital vein. After a baseline blood sample was collected, subjects consumed a nutrient load $(836 \mathrm{~kJ})$ that consisted of either $50 \mathrm{~g}$ galactose $(\mathrm{D}-(+)-$ galactose; Fagron Farmaceuticals, The Netherlands) and $2.5 \mathrm{~g}$ guar gum (Meyprofin, Switzerland), dissolved in $250 \mathrm{ml}$ water, or they drank $250 \mathrm{ml}$ water alone, in randomized order. After drinking the load subjects had to eat a standard breakfast. Subjects were given fifteen minutes to finish the meal. The breakfast (1.9 MJ) had an energy density of $3.9 \mathrm{~kJ} / \mathrm{g}$ and consisted of two slices of brown bread (100 g), baked egg $(85 \mathrm{~g}$ ) and $300 \mathrm{~m} /$ skim milk. The distribution of energy was 48.8 energy-percent ( $E$ $\%$ ) carbohydrates, $28.5 \mathrm{E} \%$ protein and $22.6 \mathrm{E} \%$ fat. All subjects reported the breakfast as much bigger than what they habitually would eat for breakfast.

Blood samples were taken for a total of two hours, every half hour relative to ingestion.

\section{Pre- and post-absarptive appetite profile}

To determine the appetite profile, satiety and desire to eat were rated on anchored 100 $\mathrm{mm}$ visual analogue scales before the meal (timepoint 0 ), immediately after the meal (timepoint 30) and during the rest of the test day every 30 minutes relative to the measurement after the meal for two hours. For the increase in satiety due to the meal delta-satiety was calculated as increase from the fasted rating at timepoint 0 .

\section{Blood sample collection and processing}

Blood samples were taken to measure plasma GLP- $1_{r}$ insulin and glucose concentrations. Blood samples for GLP-1 were taken in iced syringes and mixed with EDTA and $40 \mu \mathrm{l}$ of DPP-IV inhibitor to prevent degradation (Linco Research, St. Charles, USA). Blood samples for other blood parameters were mixed with EDTA to prevent clotting. Plasma was obtained by centrifugation for 10 minutes at $2800 \mathrm{~g}$ at $4{ }^{\circ} \mathrm{C}$. Plasma was collected, frozen in liquid nitrogen and stored at $-20^{\circ} \mathrm{C}$ for analysis.

GLP-1 concentrations were measured using an ELISA kit (EGLP $-35 K_{\text {; }}$ Linco Research Inc., St Charles, MO, USA) for non-radioactive quantification of biologically active forms of glucagon-like peptide. The assay has an intra-assay coefficient of variation (CV) of $8 \%$ or less and an inter $\mathrm{CV}$ of $12 \%$ or less. Sensitivity of the analysis is $2 \mathrm{pmol} / \mathrm{l}(24)$.

Plasma glucose concentrations were determined using the hexokinase method (Glucose HK 125 kit; ABX diagnostics, Montepellier, France). The WAKO NEFA C-kit (Wako Chemicals, Neuss, Germany) was used to determine free fatty acid (FFA) concentrations. Insulin concentrations were measured using a radioimmunoassay method (Insulin RIA100; Pharmacia, Uppsala, Sweden). 


\section{Statistical analysis}

For test of normality, data were tested with the Shapiro-Wilk test of nomality.

A one-way repeated-measures ANOVA was carried out to determine the hormonal and appetite differences between GG and water per group. Hormonal parameters and area under the curve (AUC) were tested with a non-parametric Mann-Whitney $U$ test for differences between groups. AUC was calculated as incremental area under the curve over time (2h). Appetite differences in $G G$ and $W$ between obese and lean subjects were tested with factorial ANOVA.

The relationship between age and blood parameters such as GLP-1, insulin, glucose and free falty acids was tested with a multiple regression analysis.

Results are presented as mean values and standard error of the means (SEM) or medians and ranges as appropriate. Statistical procedures were performed by using Statview SE+Graphics (1988; Abacus Concepts, Berkely, CA, USA).

For all statistical tesits the level of significance was set to $p<0.05$.

\section{Results}

\section{Differences between the conditions $G G$ and $W$}

Fasting GLP-1 concentrations were not different between conditions, neither in the normal-weight group, nor in the obese group. In the normal-weight group plasma GLP-1 was significantly increased in the GG condition compared to $W$ at 30 min $(F 1,28=$ $30.09 ; p=0.0001)$ and $60 \mathrm{~min}(F 1,28=6.10 ; p=0.02)$ after ingestion of the load.

Similarly, in the overweight/ obese group, GLP-1 concentration in response to GG was higher at 30 min $(F 1,27=20.94 ; p=0.0001), 60$ min $(F 1,27=4.38 ; p=0.045)$ and 90 $\min (\mathbb{F} 1,28=6.39 ; p=0.017)$, compared to W (Figure 1 ).

In lean as well as in the overweight/ obese subjects $\Delta$-plasma insulin concentrations peaked at 60 minutes in the $W$ condition. In lean subjects $\Delta$-insulin concentrations were significantly higher in the $W$ condition compared to $G G$ at 60 minutes ( $F 1,25=9.51$; $p$ $<0.05)$ and were lower compared to $G G$ at $90(F 1,24=5.48 ; p<0.05)$ and 120 minutes $(\mathrm{FL}, 23=\mathbb{1 5 . 8 7} ; \mathrm{p}<0.05)$. 


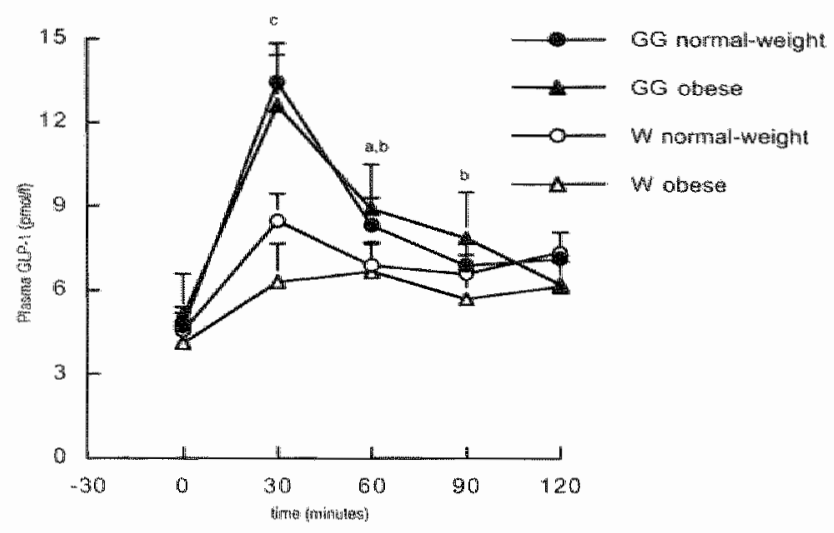

Figure 1. GLP-1 plasma concentrations after ingestion of galactose/guar gum (GG) or water (W) and a standard breakfast in normal-weight and obese subjects. Values are means ( \pm SEM).

a: GG normal-weight different from Whorma'-weight at $p<0.05$

b: GG obese different from W abese at $p<0.05$

c: GG different from water in obese and nomal-weight subjects at $p=0.0001$

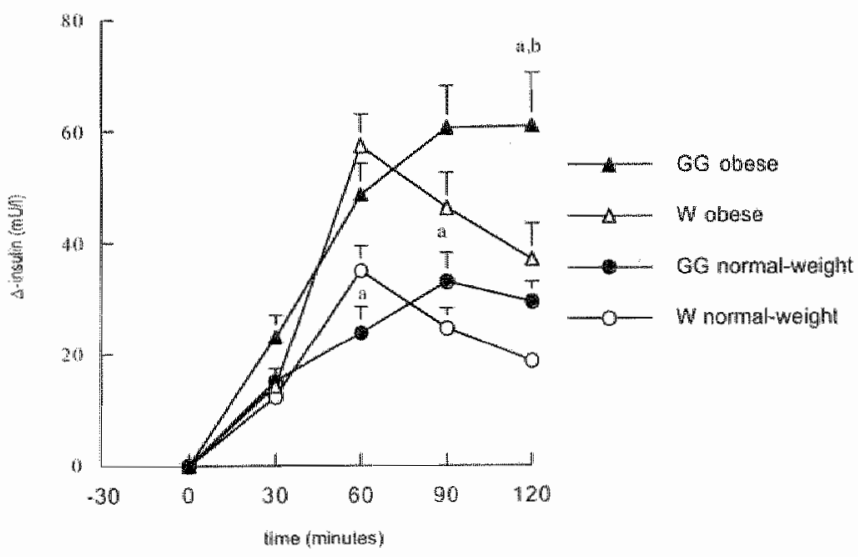

Figure 2. $\Delta$-insulin plasma concentrations ( $m U / 1)$ after ingestion of galactose/guar gum (GG) or water (W) and a standard breakfast in normal-weight and obese subjects. Values are means $( \pm S E M)$

a: GG normal-weight different from $W$ normal-weight at $p<0.05$

b: GG obese different from W obese at $p<0.05$ 
In overweight/ obese subjects insulin concentrations were significantly different at 120 minutes $(F 1,17=5.46 ; p<0.05$ ) with lower plasma insulin concentrations in the $W$ condition compared to GG (Figure 2).

In normal-weight subjects, plasma glucose concentrations (Figure 3) were significantly higher after ingestion of water compared to $G G$ at $60 \mathrm{~min}(F 1,28=10.3 ; p=0.003$ ). Glucose concentration in the overweight/ obese group did not differ between GG and W at any point of measurement.

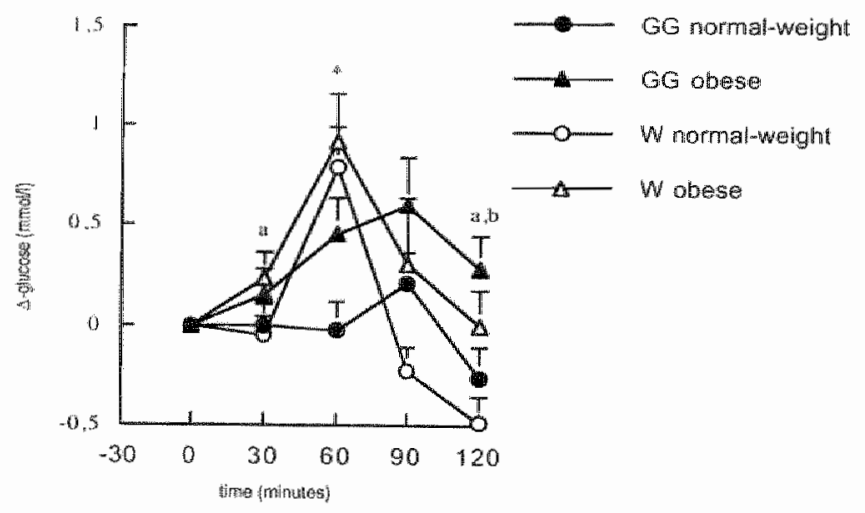

Figure 3. A-plasma glucose concentration (change from fasted concentrations) after ingestion of galactose/guar gum and breakfast in normal-weight (filled circles) and obese subjects (filled triangles), compared to water and breakfast in normal-weight (open circles) and obese subjects (open triangles).

* GG normal weight different from W normal weight at $p=0.003$

a: Median difference of $W$ obese is significantly different from $W$ normal weight at $30(p=0.04)$ and 120 minutes ( $\rho=0.05$; Mann-Whitney U test for two groups).

$b$ : Median difference of $G G$ obese is significantly different from $G G$ normal weight at $60(p=0.02)$ and 120 minutes ( $p=0.04$; Mann-Whitney $U$ test for two groups).

values are means ( 5 SEM).

Plasma free fatty acid concentration (Figure 4) was higher in the normal-weight group at $30 \min (F 1,25=5.90 ; p=0.02$ ) during $W$ compared to $G G$. There were no differences between $W$ and $G G$ at any other point of measurement. No differences were found in free fatty acid concentration in the overweight/ obese group comparing $W$ and $G G$. 


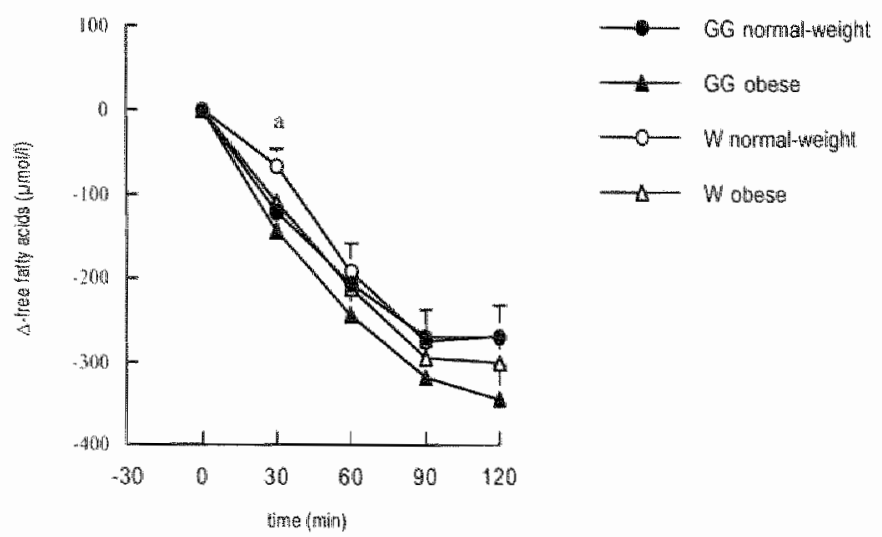

Figure 4. A-plasma free fatty acid concentration (change from fasted concentrations) after ingestion of galactose/guar gum and breakfast in narmal-weight (filled circles) and obese subjects (filled triangies), compared to water and breakfast in normal-weight (open circles) and obese subjects (open triangles).

a: Median difference of $W$ obese is significantly different from W normal weight at $30(p=0.03$; Mann-Whitney U test for two groups).

\section{Differences between normal-weight and obese subjects}

The overweight/ obese subjects were on average older than the lean subjects. However, as tested none of the blood parameters assessed were related to age.

Fasted GLP-1 concentrations were not different between the groups, neither in the GG nor in the $W$ condition. Normal-weight subjects had significantly higher GLP-1 concentrations after $W$ at 30 min compared to the overweight/ abese group $(p=0.02)$ (Table 2). The area under the curve $(\mathrm{pmol} / \mathrm{l} \times \mathrm{h}$ ) for GLP-1 concentrations (Figure 5A) after $W$ was significantly different in the normal-weight group compared to the overweight/ obese group [6.42 pmol/ $/ \times \mathrm{h}(4.52-9.13)$ compared to $4.2 \mathrm{pmol} / \mathrm{l} \times \mathrm{h}(2.2-$ 6.8)]; $(p=0.03)$.

The area under the curve $(\mathrm{pmol} / \mathrm{l} \times \mathrm{h})$ for $\mathrm{GLP}-\mathbb{1}$ concentrations after $\mathrm{GG}$ was not different between groups (Figure 5B).

Median fasted insulin concentrations were significantly different for GG as well as for $W$ between lean and overweight/ obese subjects with overweight/ obese subjects having significantly higher fasted insulin concentrations in the $W$ and in the GG condition ( $p=$ 0.0001) (Table 2). 

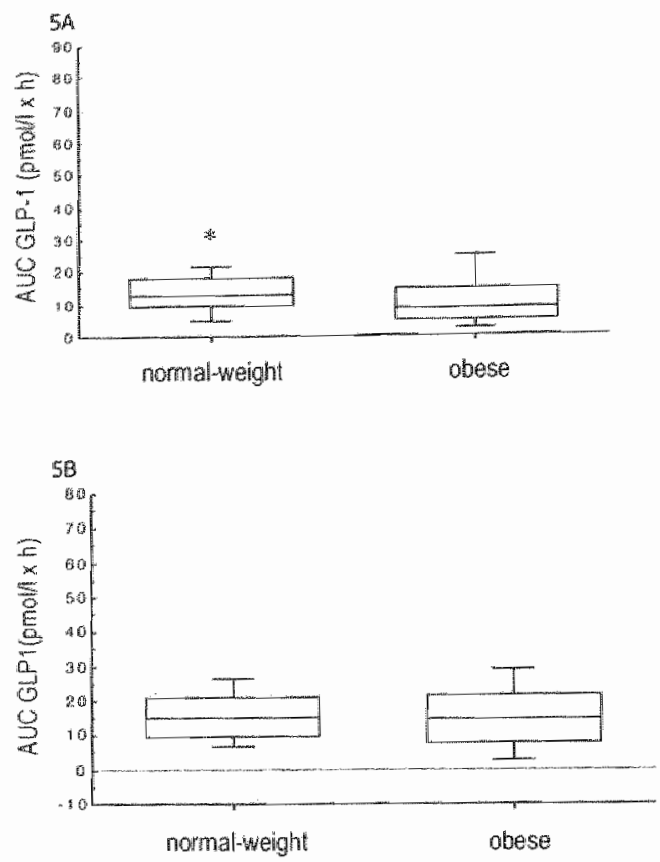

Figure 5A, B. Median (horizontal bar within box) of AUC (pmol/l $x$ h) for GLP-1 concentrations in normal-weight and obese subjects after ingestion of $W ;(A)$, or $G G ;(B)$. The median difference for GLP-1 concentrations was significanty higher for normal-weight subjects compared to the obese after $W(p=0.03$, Mann-Whitney $U$ test for two groups). This was not the case for ingestion of galactose/guar gum and breakfast. 75 th percentile, upper limit of box: 25 th percentile, lower limit of box; 90 th percentile, edge of upper limit; 10 th percentile, edge of lower limit.

Median differences between the overweight obese and normal weight group for $\Delta$ glucose concentrations were significant at $30 \mathrm{~min}(\mathrm{P}=0.04)$ and $120 \mathrm{~min}$ in the $W$ condition $(p=0.05$ ) (Table 3). Values were different in the sense that overweight/ obese subjects had significantly higher glucose concentrations compared to the normalweight group after ingestion of $W$. Median differences for $\Delta$-glucose concentrations were significant at $60 \mathrm{~min}(p=0.02)$ and $120 \mathrm{~min}(p=0.04)$ between groups in the GG condition, with significantly higher glucose concentrations in the overweight/ obese group compared to the nomal-weight group (Table 3 ).

In the $W$ condition $\Delta$-free fatty acid concentrations in the normal-weight group were significantly less decreased compared to the overweight/ obese at 30 minutes $(p=0.03)$ (Table 3). There were no differences between groups in $\Delta$-free fatty acid concentrations in the GG condition. 


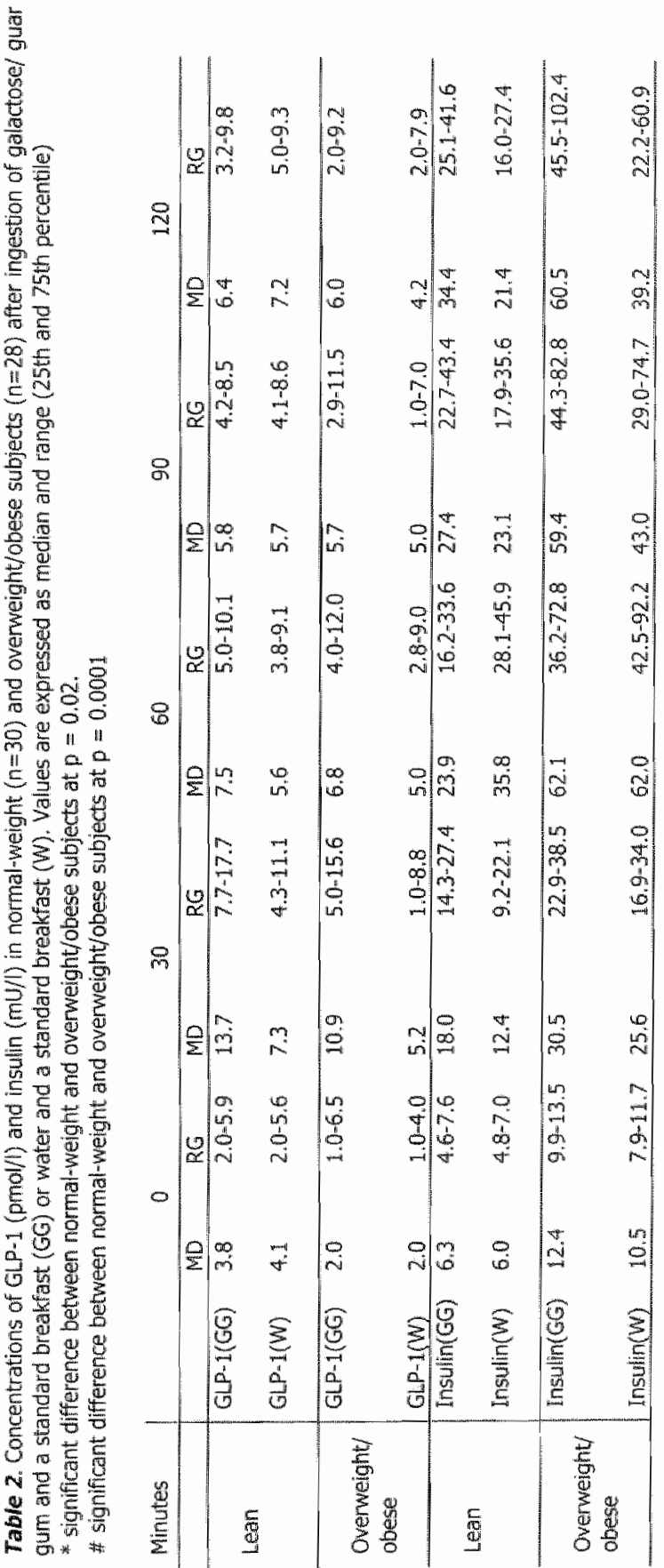




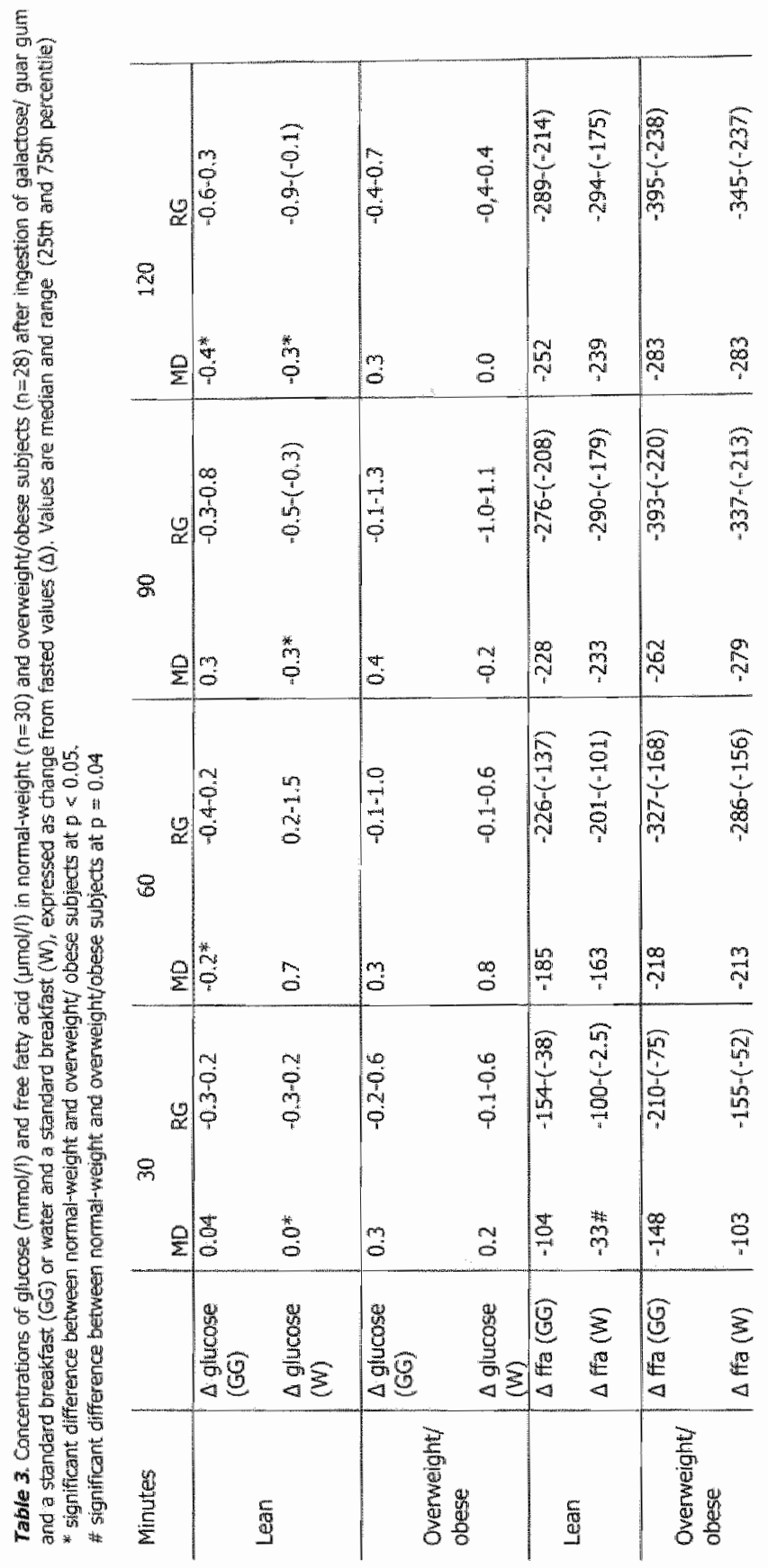


Ratings of satiety (AUC) were related to GLP-1 concentrations (AUC) in the nomalw weight group after ingestion of $G G(r=0.20 ; p=0.01)$, but not in the overweight/ obese group $(r=.07 ; p=0.74)$.

Ratings of satiety and desire to eat were not different between groups in the $W$ condition. After ingestion of GG the increase in feelings of satiety were significantly higher in normal-weight subjects at $30 \mathrm{~min}(\mathrm{~F} 1,53=5.28 ; \mathrm{p}=0.02)$ and $60 \mathrm{~min}$ ( $F 1$, $52=4.21 ; p=0.04$ ) compared to the overweight/ obese group (Figure 6 ).

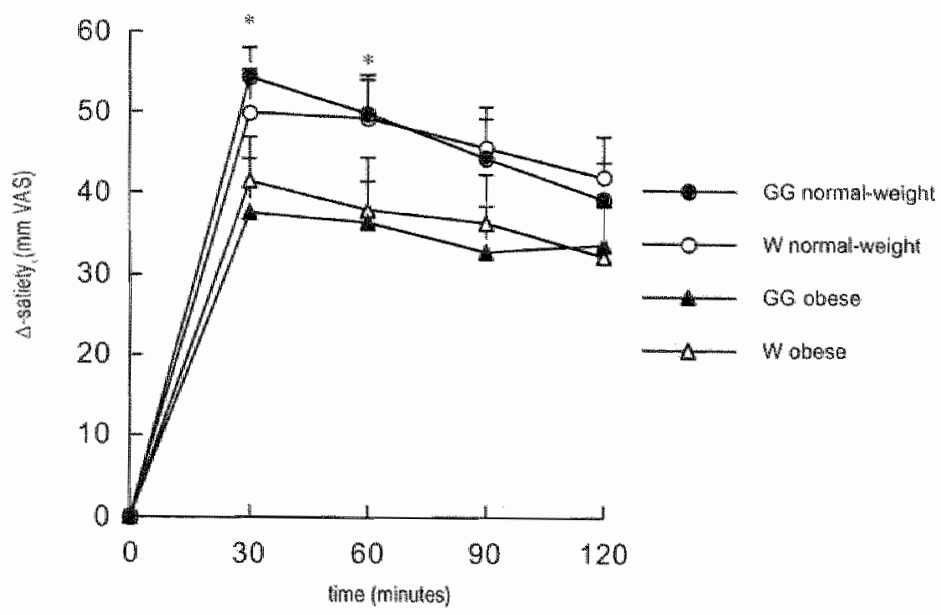

Figure 6. A-satiety (mm VAS) in normal weight (circles) and obese (triangles) subjects after ingestion of galactose/guar gum and a standard breakfast (filled circles; filled triangles) or water and a standard breakfast (open circles; open triangles).

* significantly different at $p<0.05$ from obese subjects in the GG condition.

\section{Discussion}

The results of the current study show a significant difference in postprandial GLP-1 stimulation in nomal-weight subjects compared to overweight/ obese subjects after ingestion of water and a standard breakfast. Ingestion of a galactose/ guar gum load seems to outweigh this difference. Galactose in combination with guar gum has been shown to sufficiently stimulate GLP-1 release in normal weight subjects. The area under the curve for Glip-1 release stimulated by galactose/ guar gum was similar to the area under the curve for stimulation by glucose/guar gum (19). The question remained whether this could be seen in overweight/ obese subjects as well.

The sensitivity for a GLP-1 response seems slightly higher in the normal-weight compared to the overweight/ obese subjects, as shown by the difference in the GLP-1 response to water and breakfast. However, baseline GLP-1 appeared not to be different between the subjects, nor the increase in GLP-1 release due to a stronger trigger such as GG. With the GG load, the effect of additional energy intake also may have stimulated GLP-1 release in the overweight/ obese subjects. It has to be taken into consideration 
that a decreased $L$ cell stimulation in the overweight/ obese due to a relatively lower $k$ stimulation per $\mathrm{kg}$ body weight might possibly contribute to the difference in GLP-1 release in normal-weight and overweight/ obese subjects. However, a between as well as a within subject design has been applied in the present study. The difference between overweight/ obese and normal-weight subjects, when subtracting GLP-1 release after W from GLP-1 release after GG was not significant, suggesting a lower sensitivity rather than a decreased $L$ cell stimulation.

The present findings are different from observations by Ranganath et al. $(11,25)$ and Verdich et al. (27) who reported a pronounced attenuation of postprandial GLP-1 response in obese subjects $(11,25,26)$ In those studies abese subjects with a higher BMI were assessed $\left(38-40 \mathrm{~kg} / \mathrm{m}^{2}\right)(11,25,26)$, in which the GLP-1 release may be lower than in our obese subjects with a BMI of $30 \mathrm{~kg} / \mathrm{m}^{2}$. It was suggested before that GLP-1 response to a nutrient trigger normalizes gradually with weight loss (27). According to the WHO classification the subjects investigated in the present study can be classified as overweight// obese class I compared to obese class II subjects in the other studies.

GLP-1 has been shown to reduce energy intake, enhance sensations of fullness and decrease feelings of hunger in lean (6), as well as in obese subjects $(12,27)$. Therefore one would expect that higher GLP-1 concentrations in the GG condition compared to W in both groups would be mirrored in appetite ratings being related to GLP-1 concentration.

This only is the case in normal-weight subjects, where we found a weak relationship between satiety and GLP-1 rellease. Also the almost similar GLP-1 concentrations in normal- weight and obese subjects in the GG condition would be expected to be reflected in similar appetite ratings. But, despite no difference in GLP-1 stimulation with galactose/ guar gum and breakfast between the obese and the normal weight, perceived satiety was increased only in the normal weight, and not in the obese. This could be an example of an inappropriate feedback in a situation of energy imbalance (28).

Two groups with significantly different body weight status were investigated in the present study. Leptin is considered an important adiposity signal and is secreted in direct proportion to the amount of fat stored in individual adipocytes (29). Leptin was shown to stimulate GLP-1 release and it has been suggested that leptin resistance may account for decreased GLP-1 concentrations in obese humans (30). Leptin was not measured in this experiment, yet no difference in GLP-1 release after GG between overweight/ obese and normal-weight subjects suggests, that the subjects are probably not leptin resistant. The difference in GLP-1 release between the groups after W though might indicate a starting development of leptin resistance. A stronger trigger, such as GG still seems to be able to compensate for that.

Insulin release parallels glucose release. Higher plasma insulin concentrations in both groups at 90 and 120 minutes in the GG condition compared to $W$ are probably due to a reduced rate of glucose absorption, which will lead to a prolonged influence on insulin concentrations (31). 
As has been shown before (14) the addition of guar gum decreased insulin and glucose release compared to the condition without guar gum in both the normal-weight as well as the overweight/ obese group. Insulin is an important adiposity signal (29) and has been reported to produce anorexic responses, including reduced food intake and body weight $(32,33)$. Higher scores of satiety in the normal-weight group are corresponding with lower insulin release compared to the owerweight/ obese group. In the present study, no differences between the GG and W condition have been observed that would support the idea of increased insulin concentrations contribute to increased satiety in the short term. However, unlike other hormones, such as Cholecystokinin where hypophagia has a rapid onset and lasts for only a few minutes after administration, the hypophagia following insulin develops much more slowly and has been shown to last hours to days (34), in line with the view of insulin as a long-term adiposity and satiety signal (35).

In conclusion, obese subjects seem to have a slightly lower sensitivity for GLP-1 release in response to a standard nutrient challenge like a standard breakfast compared to normal-weight subjects. The sensitivity can be improved to a level comparable to normal-weight subjects by addition of a stronger challenge like a galactose/guar gum nutrient load. However, since the improvement is not reflected in subjective sensations of satiety, it seems likely that in obese subjects, disturbance of appropriate perception of the feedback rather than primarily the physiological feedback disturbance may contribute to obesity.

\section{Acknowledgements}

Supported by Novartis Consumer Health Ltd, Nyon, Switzerland \& Novartis Pharmaceuticals, Basel, Switzerland and Summit, USA. 


\section{References}

1. Blundell JE, Lawton CL, Hill AJ. Mechanisms of appetite control and their abnormalities in obese patients. Horm Res 1993;39:72-6.

2. Morley JE. Appetite regulation by gut peptides. Annu Rev Nutr 1990;10:383-95.

3. Näslund $E$, Gutniak $M$, Skogar $S$, Rössner $S$, Hellström PM. Glucagon-like peptide 1 increases the period of postprandial satiety and slows gastric emptying in obese men. Am J Clin Nutr 1998;68:525-30.

4. Elliott RM, Morgan LM, Tredger JA, Deacon 5, Wright J, Marks V. Glucagon-like peptide-1 (7-36)amide and glucose-dependent insulinotropic polypeptide secretion in response to nutrient ingestion in man: acute post-prandial and 24-h secretion patterns. J Endocrinol 1993;138:159-66.

5. Kreymann B, Williams G, Ghatei MA, Bloom SR. Glucagon-like peptide-1 7-36: a physiological incretin in man. Lancet 1987;2:1300-4.

6. Flint A, Raben A, Astrup A, Holst J]. Glucagon-like peptide 1 promotes satiety and suppresses energy intake in humans. J Clin Invest 1998;101:515-20.

7. Gutzwiller JP, Drewe J, Göke $B$, et al. Glucagon-like peptide-1 promotes satiety and reduces food intake in patients with diabetes mellitus type 2. Am J Physiol 1999;276:R1541-4.

8. Thorens $B$, Porret $A$, Buhler $L$, Deng SP, Morel P, Widmann C. Cloning and functional expression of the human islet GLP-1 receptor. Demonstration that exendin-4 is an agonist and exendin-(9-39) an antagonist of the receptor. Diabetes 1993;42;1678-82.

9. Tillil $H_{*}$ Shapiro ET, Miller MA, et al. Dose-dependent effects of oral and intravenous glucose on insulin secretion and clearance in normal humans. $\mathrm{Am} J$ Physiol 1988;254:E349-57.

10. Fukase $\mathbb{N}$, Igarashi $M$, Takahashi $H$, et al. Hypersecretion of truncated glucagon-like peptide-1 and gastric inhibitory polypeptide in obese patients. Diabet Med 1993;10:44-9.

11. Ranganath LR, Beety JM, Morgan LM, Wright JW, Howland R, Marks V. Attenuated GLP-1 secretion in abesity: cause or consequence? Gut $1996 ; 38: 916-9$.

12. Näslund $E_{*}$ Barkeling $B$, King $N$, et al. Energy intake and appetite are suppressed by glucagon-like peptide-1 (GLP-1) in obese men. Int 1 Obes Relat Metab Disord 1999;23:304-11.

13. Pasman WJ, Saris WH, Wauters MA, Westerterp-Plantenga MS. Effect of one week of fibre supplementation on hunger and satiety ratings and energy intake. Appetite 1997;29:77-87.

14. Lavin JH, Read NW. The effect on hunger and satiety of slowing the absorption of glucose: relationship with gastric emptying and postprandial blood glucose and insulin responses. Appetite 1995;25:89-96. 


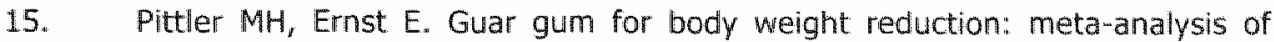
randomized trials. Am J Med 2001;110:724-30.

16. Massimino SP, McBurney MI, Field $\mathrm{CJ}_{\text {, }}$ et al. Fermentable dietary fiber increases GLP-1 secretion and improves glucose homeostasis despite increased intestinal glucose transport capacity in healthy dogs. J Nutr 1998;128:1786-93.

17. Gee JM, Lee-Finglas W, Wortley GW, Johnson IT. Fermentable carbohydrates elevate plasma enteroglucagon but high viscosity is also necessary to stimulate small bowel mucosal cell proliferation in rats. I Nutr 1996;126:373-9.

18. Juntunen KS, Niskanen LK, Liukkonen KH, Poutanen KS, Holst. J], Mykkanen HM. Postprandial glucose, insulin, and incretin responses to grain products in healthy subjects. Am J Clin Nutr 2002;75:254-62.

19. Hughes TE, Westerterp-Plantenga MS, Adam TCM. Nutritional compositions comprising a non-glucose carbohydrate or pectine and soluble fiber. WO $2004 / 022074 \mathrm{A1}, 2004$.

20. WHO. Obesity: preventing and managing the global epidemic. Geneva: WHO, 1998.

21. Bortz J. Statistik fuer Sozialwissenschaftler. 3rd ed. Berlin, Heidelberg: Springer, 1993.

22. van Marken Lichtenbelt WD, Westerterp $K R$, Wouters L. Deuterium dilution as a method for determining total body water: effect of test protocol and sampling time. Br J Nutr 1994;72:491-7.

23. Schoeller DA, van Santen E, Peterson DW, Dietz W, Jaspan J, Klein PD. Total body water measurement in humans with 180 and $2 \mathrm{H}$ labeled water. Am J Clin Nutr 1980;33:2686-93.

24. Nathan DM, Schreiber E, Fogel H, Mojsov S, Habener JF. Insulinotropic action of glucagonlike peptide-I-(7-37) in diabetic and nondiabetic subjects. Diabetes Care 1992;15:270-6.

25. Ranganath $L$, Norris $F$, Morgan L, Wright J, Marks $V$. Inhibition of carbohydratemediated glucagon-like peptide-1 (7-36)amide secretion by circulating nonesteriffed fatty acids. Clin Sci (Lond) 1999;96:335-42.

26. Verdich C, Toubro S, Buemann B, Lysgard-Madsen J, Holst 1], Astrup A. The role of postiprandial releases of insulin and incretin hormones in meal-induced satiety-effect of obesity and weight reduction. Int I Obes Relat Metab Disord 2001;25:1206-14.

27. Flint A, Raben A, Ersbgll AK, Holst J], Astrup A. The effecti of physiological levels of glucagon-like peptide- 1 on appetite, gastric emptying, energy and substrate metabolism in obesity. Int $J$ Obes Relat Metab Disord 2001.;25:781-92.

28. French SJ, Cecil JE. Oral, gastric and intestinal influences on human feeding. Physiol Behav 2001;74:729-34.

29. Woods SC, Schwartz MW, Baskin DG, Seeley RJ. Food intake and the regulation of body weight. Annu Rev PSychol 2000;51:255-77. 
30. Anini $Y$, Brubaker PL. Role of leptin in the regulation of glucagon-like peptide- 1 secretion. Diabetes 2003;52:252-9.

31. van Nieuwenhoven MA, Kovacs EM, Brummer RJ, Westerterp-Plantenga MS, Brouns $F$. The effect of different dosages of guar gum on gastric emptying and small intestinal transit of a consumed semisolid meal. I Am Coll Nutr $2001 ; 20: 87-91$.

32. Air EL, Benoit SC, Clegg DJ, Seeley R], Woods SC. Insulin and leptin combine additively to reduce food intake and body weight in rats. Endocrinology 2002; $143: 2449-52$.

33. Baskin DG, Figlewilcz Lattemann D, Seeley RJ, Woods SC, Porte D, Ir., Schwartz MW. Insulin and leptin: dual adiposity signals to the brain for the regulation of food intake and body weight. Brain Res 1999;848:114-23.

34. Woods SC. Lessons in the interactions of hormones and ingestive behavior. Physiol Behav 2004;82:187-90.

35. Havel PJ. Peripheral signals conveying metabolic information to the brain: short-term and long-term regulation of food intake and energy homeostasis. Exp Biol Med (Maywood) 2001;226:963-77. 


\section{Chapter 6}

\section{Decreased GLP-1 release after weight loss in obese subjects}

Tanja C M Adam, Johan Jocken and Margriet S Westerterp-Plantenga 


\section{Abstract}

Objective: Postprandial GLP-1 release seems to be attenuated in obese subjects. Results on whether weight loss improves GLP-1 release are contradictory.

Aim of the present study was to further clarify the effect of weight loss on basal and postprandial GLP-1 release in obese subjects.

Research methods and procedures: 32 obese subjects participated in a repeated measurement design before $\left[B M I\left(\mathrm{~kg} / \mathrm{m}^{2}\right) ; 30.3 \pm 2.8\right.$; waist circumference $(\mathrm{cm})$ : 92.6 17.8 ; hip circumference $(\mathrm{cm}): 111.1 \pm 7.4]$ and after a weight loss period of six weeks [BMI $\left(\mathrm{kg} / \mathrm{m}^{2}\right): 28.2 \pm 2.7$; waist circumference $(\mathrm{cm}): 85.5 \pm 8.5$; hip circumference (cm): 1.02.1.9.2].

During weight loss subjects received a wery low energy diet (Optifast) in order to replace three meals/ day. Subjects came to the laboratory fasted and after a baseline blood sample they received a standard breakfast (1.9 MJ). Postprandially, blood samples were taken every half hour relative to intake for 120 minutes, in order to determine GLP-1, insulin, glucose and free fatty acids from plasma. Appetite ratings were abtained with visual analogue scales.

Results: After weight loss, posttprandial GLP-1 concentrations at 30 and 60 minutes were significantly lower than before weight loss $(P<0.05)$. Glucose concentrations were also lower and free fatty acids were higher compared to before weight loss.

Ratings of satiety were increased and hunger scores were decreased after weight loss ( $p$ $<0.05$ ).

Discussion: In obese subjects GLP-1 concentrations after weight loss were decreased compared to before weight loss and nutrient related stimulation was abolished. This might be a response to a proceeding negative energy balance. Satiety and GLP-1 seem to be unrelated on the long term. 


\section{Introduction}

Obesity is associated with increased risks of cardiovascular diseases, impaired glucose tolerance and insulin resistance (1, 2).

Two of the factors that are suggested to be related to the development of obesity are increased energy intake and decreased energy expenditure $(3,4)$.

Energy intake is partly controlled by neural and humoral signals that are generated by al biological system that senses and processes food (5). There is evidence that glucagonlike peptide 1 (GLP-1) is one of the mediators that is involved in the post-meal satiety response (6). Together with glucose-dependent insulinotropic polypeptide (GIP) GLP-1 acts as an incretin and has synergistic effects on insulin release after food ingestion.

GLP-1 is a 30 amino acid peptide hormone that is secreted from intestinal L-cells after intake of a mixed meal $(7,8)$ and has been shown to affect appetite ratings and food intake. Peripheral GLP-1 administration reduced food intake and suppressed appetite in normal-weight subjects (9). Intravenous GLP 1 infusion in obese subjects led to significantly lower hunger ratings compared to a saline infusion and reduced ad libitum energy intake ( 8 ).

Basal GLP-1 concentrations and postprandial GLP-1 release seem to be attenuated in obese subjects, although statistical significance is unclear $(10,11)$. It has been suggested that this is related to increased concentrations of non-esterified fatty acids, which are associated with obesity (12). Not much is known yet about the effect of weight loss on GLP-1 release. Only few studies have been investigating the effect of weight reduction on GLP-1 concentrations and found an increase of GLP-1 response to a level between that of obese and lean subjects (11).

The purpose of the present study was to further investigate and clarify the effect of weight loss on GLP-1 release in abese subjects.

\section{Methods and Procedures}

\section{Subjects}

Forty subjects were recruited by means of advertisements in local newspapers.

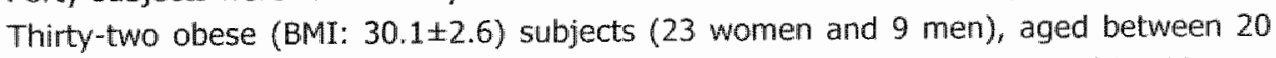
and 60 participated in the study. Selection criteria included being in good health, not taking any medications, and no history of diabetes or chronic disease.

Informed written consent was obtained and the study was approved by the Medical Ethics Conmittee of Maastricht University. 


\section{Experimental design}

A repeated measurement design (two visits $T 1$ and $T 2$ ) was applied to the 32 selected subjects before (T1) and after a six week weight loss period (T2) with a very-lowenergy-diet (VLED). Subjects came to the laboratory in the morning in a fasted state. They were instructed to fast from $10 \mathrm{pm}$ the night prior to the test day. After filling in the questionnaires, collecting urine samples and measurement of resting energy expenditure, an indwelling cannulae (Baxter BV, Utrecht, The Netherlands) was inserted in an antecubital vein. After 20 minutes of rest, subjects received a standard breakfast. The breakfast $(1.9 \mathrm{MJ})$ had an energy density of $3.9 \mathrm{~kJ} / \mathrm{g}$ and consisted of two slices of brown bread $(100 \mathrm{~g})$, baked egg $(85 \mathrm{~g})$ and $300 \mathrm{ml} \mathrm{skim} \mathrm{milk.} \mathrm{The} \mathrm{distribution} \mathrm{of} \mathrm{energy}$ was 48.8 energy-percent ( $\mathrm{E} \%$ ) carbohydrates, $28.5 \mathrm{E} \%$ protein and $22.6 \mathrm{E} \%$ fat.

Blood samples were taken for a total of two hours, every half hour after ingestion of the breakfast, for determining GLP-1, insulin, glucose and free fatty acids.

To determine the appetite profile, subjects rated their subjective feelings of hunger and satiety on anchored $100 \mathrm{~mm}$ visual analog scales prior to each blood sample (13).

After the baselline measurements, a VLED intervention followed for 6 weeks in order to praduce weight loss in the subjects. The VLED (Optifast (R); Novartis Consumer Health, Osthofen, The Netherlands) was supplied in three sachets per day, dissolved in water to obtain a milk shake, pudding or soup. Three sachets provided $2540 \mathrm{~kJ} / \mathrm{d}$, consisting of $52.5 \mathrm{~g}$ protein $(35 \mathrm{E} \%), 13.5 \mathrm{~g}$ fat $(20 \mathrm{E} \%)$ and $67.5 \mathrm{~g}$ carbohydrate $(45 \mathrm{E} \%) .200 \mathrm{~g}$ of vegetable or fruit were allowed in addition to the VLED.

After the six weeks of the VLED, all measurements were repeated.

\section{Anthropometry}

For all subjects, body weight (BW) was measured on a digital balance (Seca, Hamburg, Germany), with subjects in underwear, in a fasted state, and after voiding their bladder. Height was measured using a wall-mounted stadiometer (Seca, Hamburg, Germany). The body mass index (BMI) was calculated as BW/ height ${ }^{2}\left(\mathrm{~kg} / \mathrm{m}^{2}\right)$. Systolic and diastolic blood pressures were measured by an automatic blood pressure monitor (Omron 705 $\mathrm{CP}$, Omron Healthcare GmbH, Hamburg, Germany).

The distribution of fat was determined by measuring the waist and hip circumferences and calculation of the waist-hip ratio (WHR). The waist circumference was measured at the site of the smallest circumference between the rib cage and the ileac crest, with the subjects in sitanding position. The hip circumference was measured at the side of the largest circumference between the waist and the thighs. The WHR was calculated by dividing the waist circumference by the hip circumference.

Body composition was measured by using the deuterium $\left({ }^{2} \mathrm{H}_{2} \mathrm{O}\right)$ dilution technique (14). The dilution of the deuterium isotope is a measure for total body water (TBW) (15). The evening prior to the two test days, subjects drank a deuterium dilution ( $70 \mathrm{~g}$ water with an enrichment of 5 atom $\%$ excess ${ }^{2} \mathrm{H}$ ) after voiding. Deuterium enrichment was 
measured in urine from the second woiding of the following morning. ${ }^{2} \mathrm{H}$ concentrations in the urine samples were measured using an isotope ratio mass spectrometer (Micromass Optima, Manchester, UK). Total body water was determined by dividing the measured ${ }^{2} \mathrm{H}$ dilution space by 1.04 (14).

Fat-free mass (FFM) was calculated by dividing the total body water by the hydration factor 0.73. By subtracting FFM from body weight, fat mass (FM) was obtained. Percentage of body fat (\%BF) was calculated according to the equation of Siri (16).

\section{Resting Energy Expenditure and substrate oxidation}

Resting energy expenditure (REE) was measured by means of an open-circuit ventilated hood system. Subjects came to the laboratory in the morning by car or by bus to mimimize the amount of physical activity before the test. REE was measured at the beginning of each of the two test days with subjects in a fasted state while lying supine for 30 minutes. Gas analyses were performed by a paramagnetic $\mathrm{O}_{2}$ analyzer (Servomex type 500A; Servomex Controls Ltd, Crowborough, Sussex, UKI and an IR CO2 analyzer (Servomex type 500A), similar to the analysis system described by Schoffelen et al. (17). Calculation of REE was based upon Weir's formula (18). Respiratory quotient (RQ) was calculated as $\mathrm{CO}_{2}$ produced/ $\mathrm{O}_{2}$ consumed.

Fat oxidation was calculated using the following equation (19):

Fat oxidation $(\mathrm{g} / \mathrm{h})=\left(1.695 \times \mathrm{VO}_{2}(\mathrm{l} / \mathrm{min})-1.701 \times \mathrm{VCO}_{2}(\mathrm{l} / \mathrm{min}) \times 60\right.$.

\section{Insulin resistance}

Measures for insulin resistance were obtained from fasting plasma insulin and glucose concentrations using the 'homeostasis model assessment' (HOMA). It is assumed that normal-weight subjects with an age under 35 years have an insulin resistance of 1 . Based on that assumption resistance can be calculated according to the following equation (20):

$$
\text { resistance }=\text { insulin/ }(22.5 e-\text { ln glucose) }
$$

\section{Attitude towards eating}

Eating behavior was analyzed at the beginning of each test day using a validated Dutch translation of the Three-Factor Eating Questionnaire (TFEQ) $(21,22)$. Cognitive restrained and unrestrained eating behavior (factor 1 ), emotional eating and disinhibition (factor 2) and the subjective feeling of hunger (factor 3) were scored.

\section{Blood parameters}

Blood samples for GLP-1 were taken in iced syringles and mixed with EDTA and $40 \mu$ il of DPP-IV inhibitor to prevent degradation (Linco Research, St. Charles, USA). Blood samples for other blood parameters were mixed with EDTA to prevent clotting. Plasma 
was obtained by centrifugation for 10 minutes at $2800 \mathrm{~g}$ at $4{ }^{\circ} \mathrm{C}$. Plasma was collected, frozen in liquid nitrogen and sitored at $-20^{\circ} \mathrm{C}$ for analysis.

GLP-1. concentrations were measured using an ELISA kit (EGLP - 35K; Linco Research Inc., St Charles, MO, USA) for non-radioactive quantification of biologically active forms of glucagon-like peptide. The assay has an intra-assay coefficient of variation (CV) of $8 \%$ or less and an inter CV of $12 \%$ or less. Sensitivity of the analysis is $2 p m o l / l(23)$.

Plasma glucose concentrations were determined using the hexokinase method (Glucose HK 125 kit; ABX diagnostics, Montepellier, France). The WAKO NEFA C-kit (Wako Chemicals, Neuss, Germany) was used to determine free fatty acid (FFA) concentrations. Insulin concentrations were measured using a radioimmunoassay kit (Insulin RIA-100; Pharmacia, Uppsala, Sweden).

\section{Statistical procedures}

Data are presented as mean \pm standard error of the mean (SEM) or as mean \pm standard deviation (sd). Differences for blood parameters, appetite profile and anthropometric data between $T 1$ and $T 2$ were determined by analysis of variance for repeated measures (ANOVA) and Sheffe-F post-hoc tests (Statwiew SE Graphics TM). Area under the curve (AUC) was calculated as incremental area under the curve over time (2h). Pearson correlation coefficients, $r$, were calculated to determine the relationship between fat free mass (FFM) and resting energy expenditure (REE).

The level of significance was set at $p<0.05$.

\section{Results}

Anthropometrical data for T1 and T2 are shown in Table 1.

During the six-week weight loss period subjects lost a significant amount of weight, reducing their BMI as well as waist and hip circumferences.

Table 1. Subject characteristics $(n=32$ ) before and after wejgit loss (means $\pm s d$ )

\begin{tabular}{|c|c|c|c|}
\hline & before weight loss & after weight loss & $\rho$ \\
\hline Boty waight (kg) & $85.59 \pm 9.8$ & $79.50 \pm 10.2$ & $<0.05$ \\
\hline$B M L\left(\mathrm{~kg} / \mathrm{m}^{2}\right)$ & $30.3 \pm 2.8$ & $28.2 \pm 27$ & $<0.05$ \\
\hline Woust choumference (cm) & $92.6 \pm 7.8$ & $85.5 \pm 2.5$ & $<0.05$ \\
\hline Hip circumference (cm) & $111.1 \pm 7.4$ & $102.1 \pm 9.2$ & $<0.05$ \\
\hline Waist-hip ratio & $.83 \pm 05$ & $.84 \pm, 08$ & ns \\
\hline \% body fat & $37.8 \pm 6.4$ & $33.4 \pm 7.7$ & $<0.05$ \\
\hline $\mathrm{FWM}(\mathrm{kg})$ & $55.0 \pm 8.5$ & $54.1 \pm 8.3$ & ns \\
\hline $\mathrm{RQ}$ & $.83 \pm .04$ & $.78 \pm .05$ & $<0.05$ \\
\hline REE (MU/d) & $7.0 \pm .8$ & $6.9 \pm .9$ & $n s$ \\
\hline F1 (cognitive restraint) & $6.5 \pm 4.3$ & $11.2 \pm 4.4$ & $<0.05$ \\
\hline 3 (hunger) & $5.3+3.9$ & $3.6 \pm 2.7$ & $<0.05$ \\
\hline
\end{tabular}


Cognitive restraint (factor 1, TFEQ) was significantly increased after weight loss and general hunger scores (factor 3, TFEQ) were decreased (Table 1).

Respiratory quotient was significantly lower after weight loss compared to before weight loss, due to increased fat oxidation $(4.16 \mathrm{~g} / \mathrm{h}(\mathrm{sd}=1.31$ ) before weight loss compared to $5.49 \mathrm{~g} / \mathrm{h}$ ( $\mathrm{sd}=1.73$ ) after weight loss; $p<0.05$. REE (MJ/d) was a function of FFM (kg) before weight loss $(r=.81 ; p<0.05)$ and after weight loss $(r=.43 ; p<0.05)$ $\left(\right.$ Fig $\left._{1}, 1\right)$.

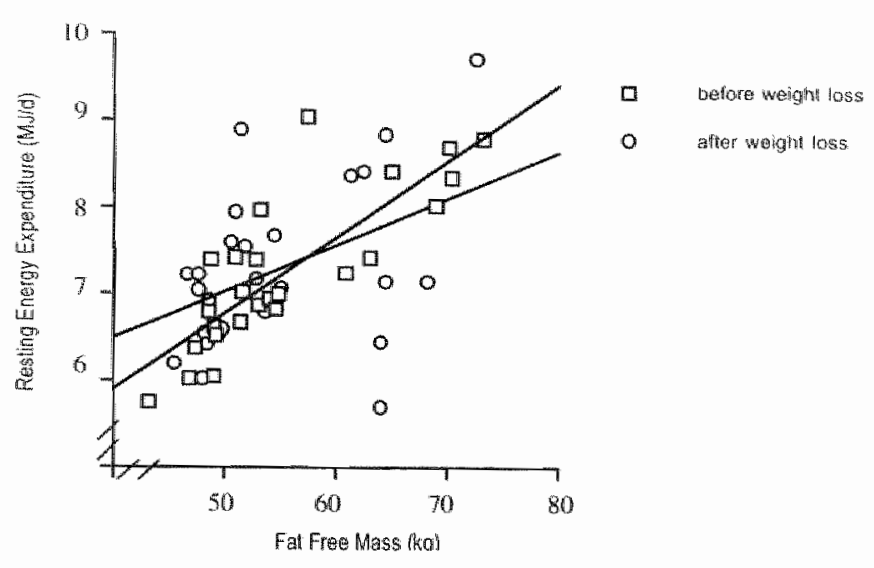

Figure 1. Resting energy expenditure before (squares) and after (circles) weight loss as a function of fat-free mass. Regression equation before weight loss is: resting energy expenditure $(\mathrm{MJ} / \mathrm{d})=$ $0.08 \times$ fat-free mass $(\mathrm{kg})+2.3(p<0.05 ; \mathrm{r}=.81)$.

Regression equation after weight loss is: resting energy expenditure (MI/d) $=0.05 \times$ fat-free mass (kg) $+4.3(p<0.05 ; r=.43)$.

Comparison of GLP-1 concentrations before (T1) and after (T2) weight loss showed the following. Although only approaching significance, fasting GLP-1 concentrations at T2 tended to be lower compared to $T_{1}(p=0.07)$.

After weight loss, stimulated GLP-1 concentrations were on a level below that of T1. GLP-1 concentrations were significantly different between $T 1$ and $T 2$ at 30 minutes ( $F 1$, $31=5.39 ; p<0.05$ ) and 60 minutes $(F 1,31=8.27 ; p<0.05$ ). The area under the curve for GLP-1 concentration at T1 was significantly higher compared to T2 (Fig. 2 A). While at T1 stimulated GLP-1 release was significantly different from fasting concentrations at $30(F 1,31=10.19 ; p<0.05), 60(F 1,31=23.05 ; p<0.05)$ and 120 minutes $(F 1,31=16.07 ; p<0.05)$, the stimulated GLP-1 concentrations measured at T2 did not differ significantly from fasting concentrations at T2 any time (Fig 2 A). 

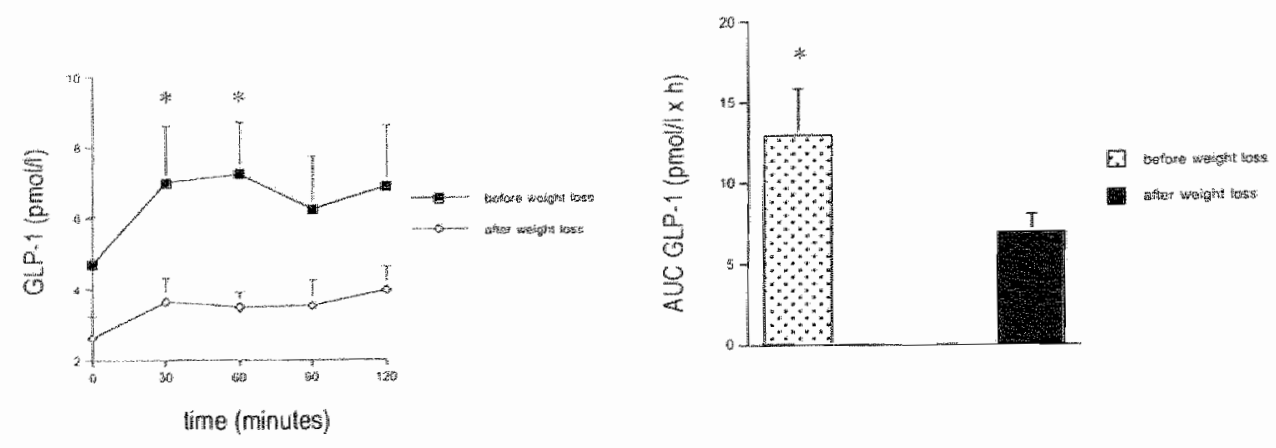

Figure 2 A. Plasma GLP-1 concentrations at baseline and postprandially after ingestion of a standard breakfast before and after a six-week weight loss period. Data are presented as means ( \pm SEM).

Left panel: plasma concentrations before weight loss (filled squares) and after weight loss (open diamonds).

* significant difference between $T 1$ and $T 2$ at $p<0.05$ (ANOWA for repeated measurement).

Right panel: AUC (average $x 2 h$ ) before (left bar) and after (right bar) weight loss.

* significantly different at $p<0.05$ (ANOVA for repeated measurement).

After ingestion of the breakfast, insulin concentrations increased, peaking at 60 minutes at $\mathrm{T} 1$ and $\mathrm{T2}$. There were no differences in baseline or postprandial insulin concentrations between $T 1$ and $T 2$ (Fig. 2 B). Insulin resistance, calculated using the homeostasis model assessment (HOMA), was not different between T1 and T2 (mean $T 1: 2.54 \pm .25$ compared to $2.53 \pm .26$ at T2).

Glucose concentrations increased after ingestion of the breakfast and peaked at 60 minutes at: $T 1$ and $T 2$. In contrast to the insulin results, glucose concentrations at $T 2$ were always below the concentrations at T1 with significant differences between T1 and T2 at baseline $(F 1,27=14.44 ; p<0.05)$ and 30 minutes $(F 1,26=9.46 ; p<0.05)$ (Fig. 2C). 

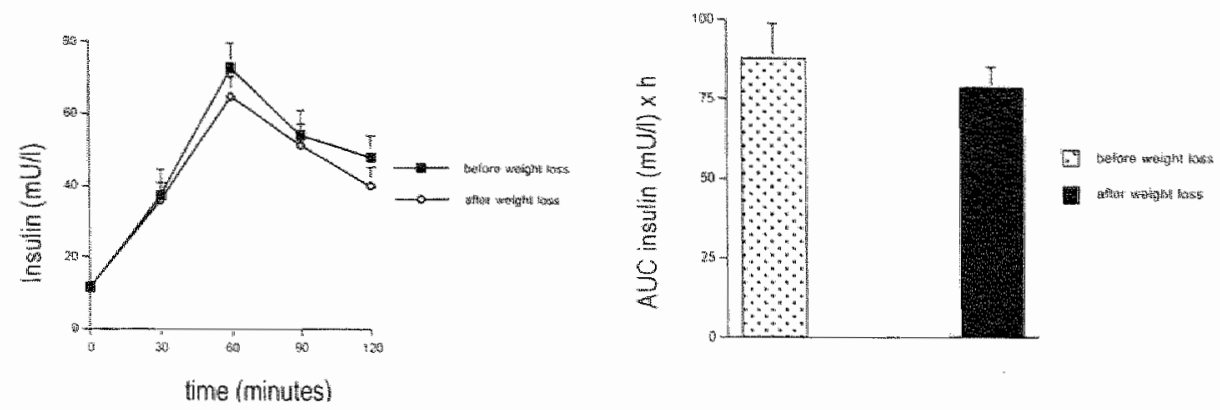

Figure 2 B. Plasma insulin concentrations at baseline and postprandially after ingestion of a standard breakfast before and after a six-week weight loss period. Data are presented as means ( $\$$ SEM).

Left panel: plasma concentrations before weight loss (filled squares) and after weight loss (open diamonds).

Right panel: AUC (average $\times 2 h$ ) before (left bar) and after (right bar) weight loss.
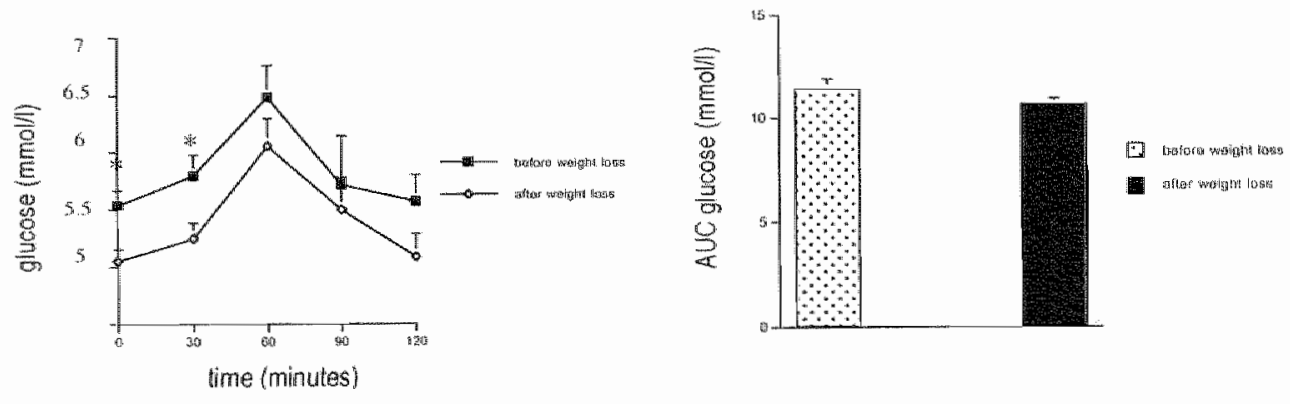

Figure 2 C. Plasma glucose concentrations at baseline and postprandially after ingestion of a standard breakfast before and after a six-week weight loss period. Data are presented as means (t. SEM).

Left panel: plasma concentrations before weight loss (filled squares) and after weight loss (open diamonds).

* significant difference between T1 and 72 at $p<0.05$ (ANOVA for repeated measurement).

Right panel: AUC (average $\times 2 h$ ) before (left bar) and after (right bar) weight loss. 
Free fatty acid concentrations decreased over time after breakfast. At every blood draw, concentrations were increased after weight loss compared to before weight loss. Differences between $T 1$ and $T 2$ were significant at baseline ( $F 1,26=5.24 ; p<0.05$ ) and postprandially at $30(F 1,26=6.07 ; p<0.05), 60(F 1,26=11.22 ; p<0.05), 90$ $(F 1,26=6.27 ; \mathrm{p}<0.05)$ and 120 mimutes $(\mathrm{F} 1,26=9.87 ; \mathrm{p}<0.05)$ (Fig. $2 \mathrm{D})$.
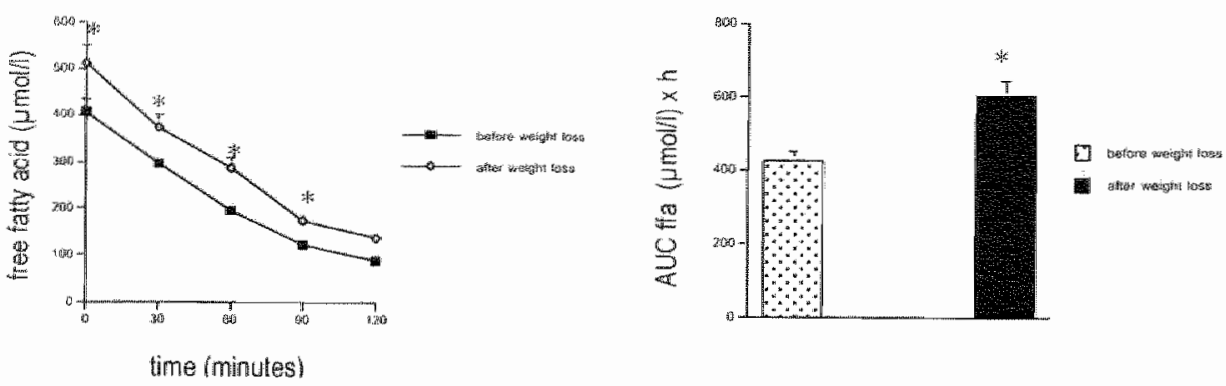

Figure $2 \mathrm{D}$. Plasma free fatty acid concentrations at baseline and postprandially after ingestion of a standard breakfast before and after a six-week weight loss period. Data are presented as means ( $t$ SEM).

Left panel: plasma concentrations before weight loss (filled squares) and after weight loss (open diamonds).

* significant difference between 71 and T2 at $p<0.05$ (ANOVA for repeated measurement). Right panel: ALC (average $\times 2 h$ ) before (left bar) and after (right bar) weight loss.

* significantly different at $p<0.05$ (ANOVA for repeated measurement).

Baseline satiety ratings were not different between T1 and T2. Postprandial satiety ratings were significantly increased after the weight loss period compared to T1 att 120 minutes ( $F 1,22=5 ; p<0.05$ ) (Fig $3 \mathrm{~A}$ ). Hunger ratings were not different at baseline comparing $T 1$ and $T 2$, but were decreased after weight loss compared to before weight loss at 90 minutes $(F 1,21=4.52 ; p<0.05)$ and 120 minutes $(F 1,22=4.64 ; p<0.05)$

(Filg 3 B). Satiety- or hunger ratings were not related to the increase in GLP-1 release. 

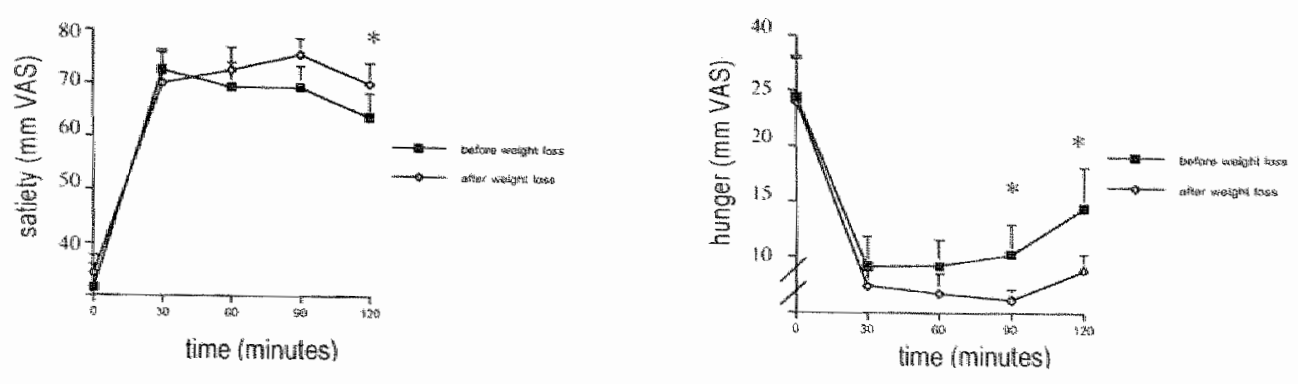

Figure $3 \mathrm{~A}-\mathrm{B}$.

Subjective satiety ( 3 A) and hunger ( 3 B) ratings before (filled squares) and after (open diamonds) a 6 week weight lass period. Data are presented as means ( \pm SEM).

* significant difference between $T 1$ and $T 2$ at $p<0.05$ (ANOVA for repeated measurement).

\section{Discussion}

The current study shows decreased GLP- 1 concentrations with weight loss in a group of obese subjects. Not only were fasting GLP-1 concentrations decreased, but it appears that secretion due to mutrient ingestion is abolished after weight loss as well. This result is similar to a study reporting decreased levels of GLP-1 after weight loss in severely obese subjects (24) but partly different from a study showing a marginal increase in GLP-1 concentrations after weight loss in obese subjects. However, incremental GLP-1. concentrations were not improved after weight loss $(11,25)$. In contrast to these studies, the present study has been investigating subjects with a BMI of $30 \pm 2.68$, compared to an average BMI of 38 (11) or an average BMI of 44 (25) in the other studies. This may partly explain the inconsistent results. Since in the current study subjects lost less weight than in other studies $(11,24,25)$ and the weight loss period was shorter, our results rather should be described as effects of the first phase of weight loss on GLP-1 concentrations, likely being induced by a strong negative energy balance. Free fatty acid concentrations were increased during weight loss, as has been shown before (26).

GLP-1 secretion may be inhibited by circulating non-esteriffed-fatty acids $(10,12,27)$, especially during the first phase of weight loss, when energy baiance is strongly negative. It has been suggested that the postprandial fall in plasma non-esterified-fatty acids is an important mechanism by which GLP-1 release is stimulated and that an impaired postprandial suppression of non-esterified-fatty acids may in part be responsible for the impaired GLP-1 secretion in obesity (12) This mechanism might have played a role in this study. An alternative explanation for decreased GLP-1 concentrations with weight loss may be an alteration in the autonomic nervous system 
(ANS) due to obesity or weight loss. There is no consensus yet on how the ANS is changed and/or possibly contributes to obesity (28). Findings of decreased levels of vagally mediated gastrointestinal hormones after weight loss suggest that the effect of weight loss on vagal tone in the sense of either depression or hyperstimulation might play an important role in decreased GLP-1 concentrations after weight loss (24).

The decrease of GLP-1 concentrations during weight loss might be a response to a proceeding negative energy balance, thereby playing a role as a neuroendocrine factor signaling energy deficiency.

After weight loss satiety ratings were increased and hunger ratings were decreased compared to before weight loss. After two hours subjects fett more satiated and less hungry, which may be explained by less energy requirements due to weight loss, although the test meal provided the same energy contents as before weight loss. No relationship was found between GLP-1 and satiety ratings before, nor after weight loss. Previously, a positive relationship between satiety and GLP-1 release in normal-weight subjects was shown by Flint et al. (9). Näslund et al. showed a relationship between satiety and GLP-1 in obese men, when GLP-1 was infused $(8,29)$. In a previous study we showed an increase in GLP-1 release in obese subjects, when stimulated with a galactose and guar gum solution. However, a corresponding increase in satiety did not occur. We suggest, given the results of the present study, that GLP-1 is a satiety regulator in the short term, and that a possible relationship between satiety and GLP-1 release is weaker in obese subjects compared to normal weight subjects.

It has been suggested that GLP-1 secretion normalizes gradually when overweight is reduced, as concluded based upon increased fasting concentrations after weight loss. However, incremental ALC does not seem to be normalized after weight loss (11). More research needs to be done to clarify how the reduced GLP-1 concentrations after weight loss change during weight maintenamce and regain. It is likely that during the first phase of weight loss, when energy balance is very negative, GLP-1 decreases, and that it normalizes subsequently. Similar changes in other hormones during different phases of weight loss have been shown before (24).

As expected, fasting and postprandial glucose concentrations were lower and free fatty acid concentrations were increased after weight loss $(26,30)$. Insulin sensitivity did not change, which was not surprising, since subjects were normally insulin sensitive before as well as after weight loss.

REE as a function of FFM decreased due to weight loss and restraint score increased significantly during weight loss as expected. Subjects lost a little less weight than expected based on the three sachets a day. Weight loss was six kilograms on average. This means that subjects consumed an average energy of $4.2 \mathrm{MJ} / \mathrm{day}$, providing evidence for a very negative energy balance, but also showing that subjects did not stick to the VLED completely. The difference of $1.6 \mathrm{MJ} /$ day cannot be explained by the additional intake of 200 grams of fruit or vegetables. 
In conclusion the present study shows that in the presence of a very negative energy balance, fasting GLP-1 release decreases in modestly obese subjects. Even the ability of nutrients to stimulate GLP-1 release seems to be abolished. The question remains how GLP-1 concentrations develop when subjects are back in energy balance.

\section{Acknowledgements}

Supported by Novartis Consumer Health Ltd, Nyon, Switzerland \& Novartis Pharmaceuticals, Basel, Switzerland and Summit, USA. 


\section{References}

1. Rennent NJ, Charney P. Preventing cardiovascular disease in diabetes and glucose intolerance: evidence and implications for care. Prim Care $2003 ; 30: 569-92$.

2. Sowers IR. Obesity as a cardiovascular risk factor. Am J Med 2003;115 Suppl $8 \mathrm{~A}: 37 \mathrm{~S}-415$.

3. Westerterp-Plantenga MS. Analysis of energy density of food in relation to energy intake regulation in human subjects. $\mathrm{Br}$ I Nutr 2001;85:351-61.

4. Westerterp KR. Pattern and intensity of physical activity. Nature 2001;410:539.

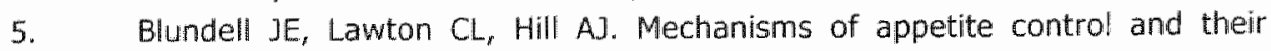
abnormalities in obese patients. Horm Res 1993;39:72-6.

6. Blundell JE, Näslund E. Glucagon-like peptide-1, satiety and appetite control. $B r$ J Nutr $1999 ; 81: 259-60$.

7. Holst 11. Glucagonlike peptide 1: a newly discovered gastrointestinal hormone. Gastroenterology 1994; 107: 1848-55.

8. Näslund $E$, Barkeling B, King $N$, et al. Energy intake and appetite are suppressed by glucagon-like peptide-1 (GLP-1) in obese men. Int I Obes Relat Metab Disord 1999;23:304-11.

9. Flint A, Raben A, Astrup A, Holst 1]. Glucagon-like peptide 1 promotes satiety and suppresses energy intake in humans. J Cin Invest 1998;101:515-20.

10. Ranganath LR, Beety JM, Morgan LM, Wright JW, Howland R, Marks $V$. Attenuated GLP-1 secretion in obesity: cause or consequence? Gut $1996 ; 38: 916-9$.

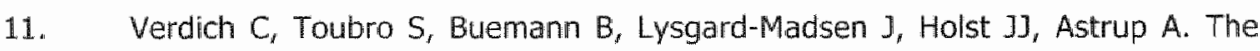
role of postprandial releases of insulin and incretin hormones in meal-induced satiety-effect of obesity and weight reduction. Int J Obes Relat Metab Disord 2001:25:1206-14.

12. Ranganath $L_{\text {, }}$ Norris $F_{f}$ Morgan $L$, Wright $J$, Marks $V$. Inhibition of carbohydratemediated glucagon-like peptide-1 (7-36) amide secretion by circulating nonesterified fatty acids. Clin Sci (Lond) 1999;96:335-42.

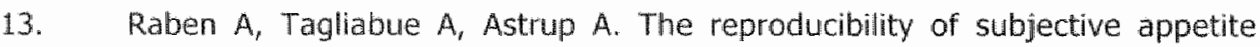
scores. Br J Nutr 1995;73:517-30.

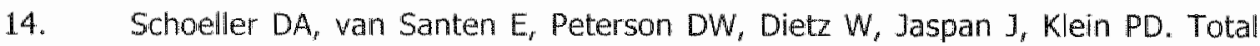
body water measurement in humans with 180 and $2 \mathrm{H}$ labeled water. Am I Clin Nutr $1980 ; 33: 2686-93$.

15. van Marken Lichtenbelt WD, Westerterp KR, Wouters L. Deuterium dilution as a method for determining total body water: effect of test protocol and sampling time. Br J Nutr 1994;72:491-7.

16. Siri. The cross composition of the body. Adv Biol Med Physiol 1956;4:239*280.

17. Schoffelen PF, Westerterp KR, Saris WH, Ten Hoor F. A dual-respiration chamber system with automated calibration. J Appl Physiof 1997;83:2064-72. 
18. Weir IB. New methods for calculating metabolic rate with special reference to protein metabolism. Nutrition [classical article] 1949;6:213-221.

19. Peronnet $F$, Massicotte $D$. Table of nonprotein respiratory quotient: an update. Can J Sport Sci 1991; 16:23-9.

20. Matthews DR, Hosker JP, Rudenski AS, Naylor BA, Treacher DF, Turner RC. Homeostasis model assessment: insulin resistance and beta-cell function from fasting plasma glucose and insulin concentrations in man. Diabetologia $1985 ; 28: 412-9$.

21. Stunkard AJ, Messick S. The three-factor eating questionnaire to measure dietary restraint, disinhibition and hunger. J Psychosom Res 1985;29:71-83.

22. Westerterp-Plantenga MS, Rolland V, Wilson SA, Westerterp KR. Satiety related to $24 \mathrm{~h}$ diet-induced thermogenesis during high protein/carbohydrate vs high fat diets measured in a respiration chamber. Eur J Clin Nutr 1999;53:495-502.

23. Nathan DM, Schreiber $E_{r}$ Fogel $H$, Mojsov $S$, Habener JF. Insulinotropic action of giucagonlike peptide-1-(7-37) in diabetic and nondiabetic subjects. Diabetes Care $1992 ; 15: 270-6$.

24. Cigaina V, Hirschberg AL. Gastric pacing for morbid obesity: plasma levels of gastrointestinal peptides and leptin. Obes Res 2003;11:1456-62.

25. Näslund $E$, Gryback $P_{s}$ Hellstróm $P M$, et al. Gastrointestinal hormones and gastric emptying 20 years after jejunoileal bypass for massive obesity. Int $j$ Obes Relat Metab Disond 1997;21:387-92.

26. Westerterp-Plantenga MS, Lejeune MP, Nijs I, van Ooijen M, Kovacs EM. High protein intake sustains weight maintenance after body weight loss in humans. Int I Obes Relat Metab Disord 2004;28:57-64.

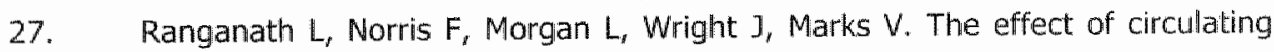
non-esterified fatty acids on the entero-insular axis. Eur $J$ Clin Invest $1999 ; 29: 27-32$.

28. Rissanen $P$, Franssila-Kallunki $A$, Rissanen $A$. Cardiac parasympathetic activity is increased by weight loss in healthy obese women. Obes Res 2001;9:637-43.

29. Näslund $E$, Gutniak $M$, Skogar $S$, Rössner $S$, Hellström PM. Glucagon-like peptide 1 increases the period of postpraindial satiety and slows gastric emptying in obese men. Am I Cin Nutr 1998;68:525 -30.

30. Anderson JW, Konz EC. Obesity and disease management: effects of weight loss on comorbid conditions. Obes Res 2001; 9 Suppl 4:3265-3345. 
Chapter 7

\section{Nutrient stimulated GLP-1 release after body-weight loss and weight maintenance in humans}

Tanja C M Adam, Manuela P G M Lejeune and Margriet S Westerterp-Plantenga

submitted for publication 


\section{Abstract}

Background: Glucagon-like peptide $\mathbb{1}$ (GLP-1) is a peptide hormone, which is released in response to nutrient ingestion. Postprandial GLP-1 release has been reported as being attenuated in obese subjects. Reports on the effect of weight loss on GLP-1 are conflicting.

Objective: The aim of the current study was to clarify the effect of a weight loss period and a consecutive weight maintenance period on nutrient stimulated GLP-1 release in obese subjects.

Design: Nutrient stimulated (standard breakfast, 1.9 MJ) GLP 1 release was investigated in 32 obese subjects at three occasions: before weight loss (T1) [BMI $\left.\left(\mathrm{kg} / \mathrm{m}^{2}\right): 30.0 \pm 2.5\right]$,

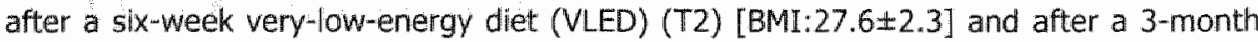
weight maintenance period (T3) [BMI:27.912.3]. At each of these occasions, following a fasting blood sample the test meal was fed and blood was drawn every 30 minutes for two hour's relative to ingestion in order to determine plasma GLP-1, insulin, glucose and free fatty acid concentrations.

Results: Subjects lost $7 \pm 3.4 \mathrm{~kg}$ during the VEED $(p<0.0001)$ and regained $1 \pm 3.2 \mathrm{~kg}$ during the weight maintenance period (ns). The area under the curve (AUC) for nutrientstimulated plasma GLP -1 (pmol// $x$ h) was significantly decreased $(P=0.01)$ at $T 2(6.8 \pm 1)$ compared to $T \mathbb{1}(12.8 \pm 2.9 ;)$ and $T 3(11.1 \pm 1.5)$.

Conclusions: Nutrient-stimulated plasma GLP-1 concentrations decreased after weight loss. Since we found a rebound of concentrations after a weight maintenance period, decrease after weight loss seems to be transient and more due to a very negative energy balance. 


\section{Introduction}

The increasing incidence of obesity is a recognized medical problem in developed countries (1). Obesity is associated with insulin resistance and hyperinsulinemia, hypertension, dyslipidaemia, cardiovascular disease, type 2 diabetes mellitus, and gallbladder disease $(2,3)$. Cancer mortality thas been shown to increase with increasing BMI among women (4).

The treatment of obesity is beneficial, since modest weight loss of 5 to $10 \%$ of the initial body weight is associated with a marked health improvement (5). Factors suggested as being related to the development of obesity are decreased physical activity and/or increased energy intake. Weight loss can thus be achieved by reducing energy intake and/ or increasing energy expenditure.

Energy intake is partly controlled by neural and humoral signals that are generated by a biological system that senses and processes food and that has impact on the satiating efficiency of food (6). One of the supposed mediators that is involved in the development of post-meal satiety and possibly contributes to satiation, is glucagon-like peptide 1 (GLP-1) (7).

GLP-1 is a thirty amino acid peptide hormone that is released from intestinal $L$ cells into the circulation after a mixed meal $(8,9)$. Peripheral GLP-1 administration compared to saline infusions reduced food intake and suppressed appetite in normal weight-subjects (10) and led to lower hunger ratings and decreased energy intake during an ad libitum meal in obese subjects (9). The role of GLP-1 and its possible contribution to obesity is not clear yet. One study has been reporting hypersecretion of GLP-1 in obese subjects (11). However, there also is evidence that postprandial GLP-1 release in response to carbohydrate and mixed meal ingestion seems to be attenuated in abese subjects (12, 13). Results about the effect of weight loss on GLP-1 concentrations in obese subjects are ambivalent. While increased concentrations have been found after weight loss (12, 13), others report decreased concentrations of appetite related peptides after weight loss (14). The aim of the present study is to clarify the effect of diet-induced weight loss on GLP-1 concentrations in obese subjects and in particular the development of GLP-1 concentrations during consecutive weight maintenance following weight loss.

\section{Subjects and Methods}

\section{Subjects}

Forty subjects were recruited by means of advertisements in local newspapers.

Thirty-two overweight/ obese class1 (BMI: 30.1 22.6) subjects with and average age of $44 \pm 9$ years ( 23 women; mean age $43 \pm 8$ years, ranging between 20 and 59 , and 9 men; mean age $46 \pm 12$ years, ranging between 28 and 60 ) according to the classification of the World Health Organization (BMI $\geq 25$ and $\left.<34.9\left(\mathrm{~kg} / \mathrm{m}^{2}\right)\right)$ (15) "participated in the study. Selection criteria included being in good health, not taking any medications, and no history of diabetes or chronic disease. 
Informed written consent was abtained and the study was approved by the Medicall Ethics Committee of the Maastricht University

\section{Experimental design}

A repeated measurement design was applied to the 32 selected subjects including three visits: before weight loss (T1), after a six week weight loss period (T2) with a very-lowenergy-diet (VLED) and after a 12 week weight maintenance period (T3). Each time subjects came to the laboratory in the morning in a fasted state. They were instructed to fast from $10 \mathrm{pm}$ the night prior to the test day. After the questionnaires were completed, urine samples collected, resting energy expenditure measured, an indwelling cannulale (Baxter BV, Utrecht, The Netherlands) was inserted in an antecubital vein. After 20 minutes of rest, subjects received a standard breakfast. The breakfast (1.9 MJ) had an energy density of $3.9 \mathrm{~kJ} / \mathrm{g}$ and consisted of two slices of brown bread $(100 \mathrm{~g})$, baked egg $(85 \mathrm{~g}$ ) and $300 \mathrm{ml}$ skim milk. The distribution of energy was 48.8 energy-percent ( $E$ $\%$ ) carbohydrates, $28.5 \mathrm{E} \%$ protein and $22.6 \mathrm{E} \%$ fat.

Blood samples were taken for a total of two hours, every half hour relative to ingestion of the breakfast for determining plasma GLP.1, insulin, glucose and free fatty acid concentrations.

To determine the appetite profile, subjects rated their subjective feeling of hunger and satiety an anchored $100 \mathrm{~mm}$ visual analog scales 15 minutes before the meal (timepoint 0 ), immediately after the meal (timepoint 30), and during the rest of the test day every 30 minutes relative to the measurement after the meal for a total of 120 minutes (16).

After the baseline measurements at the first appointment, a VLED intervention followed for 6 weeks in order to let the subjects lose weight. The VLED (Optifast ${ }^{\circledR}$; Novartis Consumer Health, Osthofen, Germany) was supplied in three sachets per day, dissolved in water to obtain a milk shake, pudding or soup. Three sachets provided $2540 \mathrm{~kJ} / \mathrm{d}$, consisting of $52.5 \mathrm{~g}$ protein $(35 \mathrm{E} \%), 13.5 \mathrm{~g}$ fat $(20 \mathrm{E} \%$ ) and $67.5 \mathrm{~g}$ carbohydrate (45 E\%). A maximum of $200 \mathrm{~g}$ of vegetable or fruit were allowed in addition to the VLED.

After the six weeks of the VLED all measurements were repeated. The last appointment followed after a 12 -week weight mantenance period. During the weight maintenance period subjects had no specific instructions about diet or physical activity.

\section{Anthropometry}

All anthropometrical data were obtained three times, before and after weight loss and after weight maintenance. Subject characteristics are depicted in Table 1.

For all subjects, body weight (BW) was measured on a digital balance (Seca, Hamburg, Germany), with subjects in underwear, in a fasted state, and after voiding their bladder. Height was measured using a wall-mounted stadiometer (Seca, Hamburg, Germany). The body mass index (BMI) was calculated as BW/ height ${ }^{2}\left(\mathrm{~kg} / \mathrm{m}^{2}\right)$. 
Table 1. Subject $(n=32 ; 23$ women, 9 men) characteristics (Data are presented as means $\pm 5 . d$. Statistical significance was determined by ANOVA for repeated measures

\begin{tabular}{|c|c|c|c|c|c|c|c|c|c|c|}
\hline \multirow[b]{2}{*}{ Body weght ( $\mathrm{kg}$ ) } & \multicolumn{3}{|c|}{$\begin{array}{c}\text { before weight loss } \\
\text { (T1) }\end{array}$} & \multicolumn{3}{|c|}{$\begin{array}{c}\text { after weight loss } \\
(\pi 2)\end{array}$} & \multicolumn{3}{|c|}{$\begin{array}{c}\text { after weight naintremance } \\
\text { (T3) }\end{array}$} & \multirow{2}{*}{$\frac{P}{0.0001}$} \\
\hline & 85.7 & \pm & 8.8 & 79.7 & \pm & $8.4^{18}$ & 80.7 & \pm & $9.6^{9}$ & \\
\hline $\mathrm{EMI}\left(\mathrm{kg} / \mathrm{m}^{2}\right)$ & 30.0 & \pm & 2.5 & 27.6 & \pm & $2.3^{3}$ & 279 & 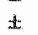 & $2.3^{2}$ & 0.0001 \\
\hline obotily fat & 38.1 & \pm & 6.1 & 33.8 & 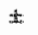 & $7.7^{a}$ & 39.6 & \pm & $7.6 \%$ & $0.000:$ \\
\hline FFM (kg) & 54.3 & $\#$ & 7.9 & 53.4 & \pm & 7.7 & 53.9 & 泣 & 8.8 & ns \\
\hline $\mathbb{R Q}$ & .83 & $\#$ & .04 & 0.78 & 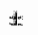 & $0,05^{*}$ & 0.86 & it & $0.06^{b}$ & 0.0001 \\
\hline Fat oxidation $(\mathrm{g} / \mathrm{h})$ & 40 & \pm & 11.3 & 5.4 & \pm & $1.8^{2}$ & 3.3 & 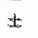 & $2.0^{61}$ & 0.0001 \\
\hline $\operatorname{REE}$ (MIMd) & 7.3 & \pm & 0.9 & 7.1 & $\Phi$ & 1 & 6.9 & \pm & 0.88 & $n$ \\
\hline $\begin{array}{l}\text { F1 (cognitive } \\
\text { restraint) }\end{array}$ & 6.5 & \pm & 4.3 & 11.2 & \pm & $4.4^{9}$ & 10.5 & t & $4.3^{\mathrm{gi}}$ & 0.0001 \\
\hline 12 (distnhibition) & 6.1 & \pm & 3.1 & 4.9 & \pm & $2.5^{2}$ & 4.8 & \pm & $2.9^{a}$ & 0.005 \\
\hline F3 (hunger)" & 5.3 & \pm & 3.9 & 3.6 & \pm & $2.7 \mathrm{~m}$ & 3.1 & $\#$ & $27^{a}$ & 0.0004 \\
\hline
\end{tabular}

The distribution of fat was determined by measuring the waist and hip circumferences. and calculation of the waist-hip ratio (WHR). The waist circumference was measured at the site of the smallest circumference between the rib cage and the ileac crest, with the subjects in standing position. The hip circumference was measured at the side of the largest circumference between the waist and the thighs. The WHR was calculated by dividing the waist circumference by the hip circumference.

Body composition was measured by using the deuterium $\left({ }^{2} \mathrm{H}_{2} \mathrm{O}\right)$ dilution techniquie (17). The dilution of the deuterium isotope is a measure for total body water (TBW) (18). The evening prior to the three test days subjects drank a deuterium dilution ( 70 g water with an enrichment of 5 atom\% excess ${ }^{2} \mathrm{H}$ ) after voiding. Deuterium enrichment was measured in urine from the second voiding of the following morning. ${ }^{2} \mathrm{H}$ concentrations in the urine samples were measured using an isotope ratio MS (Micromass Optima, Manchester, UK). Total body water was determined by dividing the measured ${ }^{2} \mathrm{H}$ dilution space by $1.04(17)$.

Fat-free mass (FFM) was calcullated by dividing the total body water by the hydration factor 0.73 . By subtracting FFM from body weight, fat mass (FM) was obtained. Percentage of body fat (\%BF) was calculated according to the equation of Siri (19).

\section{Resting Energy Expenditure and substrate oxidation}

Resting energy expenditure (REE) was measured by means of an open-circuit ventilated hood system. Subjects came to the laboratory in the morning by car or by bus to minimize the amount of physical activity before the test. REE was measured at the beginning of each of the test days with subjects in a fasted state while lying supine for 30 minutes. Gas analyses were performed by a paramagnetic $\mathrm{O}_{2}$ analyser (Servomex type 500A; Servomex Dontrols L.td, Crowborough, Sussex, UK) and an i.r. CO, analyser 
(Servomex type 500A), similar to the anallysis system described by Schoffelen et al. (20). Calculation of REE was based upon Weir's formula (21). Respiratory quotient (RQ) was calculated as $\mathrm{CO}_{2}$ produced/ $\mathrm{O}_{2}$ consumed.

Fat oxidation was calculated using the following equation (22):

Fat oxidation $(\mathrm{g} / \mathrm{h})=1.695 \times \mathrm{VO}_{2}(1 / \mathrm{min})-1.701 \times \mathrm{V} \mathrm{CO}_{2}(\mathrm{l} / \mathrm{min}) \times 60$.

\section{Ambient temperature}

Data on 24-h average ambient temperature were supplied by the Royal Dutch Meteorological Institute and were collected at a location near the university (Maastricht, Beek: $51^{\circ}$ North, $6^{\circ}$ East).

\section{Attitude towards eating}

Eating behavior was analyzed at the beginning of each test day using a vallidated Dutch translation of the Three-Factor Eating Questionnaire (TFEQ) (23, 24). Cognitive restrained and unrestrained eating behavior (factor 1), emotional eating and disinhibition (factor 2) and the subjective feeling of hunger (factor 3) were scored.

\section{Blood parameters}

Blood samples for GLP-1 were taken in iced syringes and mixed with EDTA and $40 \mu 1$ of DPP-IV inhibitor to prevent degradation (Linco Research, St. Charles, USA). Blood samples for other blood parameters were mixed with EDTA to prevent clotting. Plasma was obtained by centrifugation for 10 minutes at $2800 \mathrm{~g}$ at $4{ }^{\circ} \mathrm{C}$. Plasma was collected, frozen in liquid nitrogen and stored at $-20^{\circ} \mathrm{C}$ for analysis.

GLP 1 concentrations were measured using an ELISA (EGLP -35K; Linco Research Inc. St Charles, MO, USA) for non radioactive quantification of biologically active forms of glucagon-like peptide. The assay has an intra-assay coefficient of variation (CV) of $8 \%$ or less and an inter $\mathrm{CV}$ of $12 \%$ or less. Sensitivity of the analysis is 2 pmol/ $/ 25)$.

Plasma glucose concentrations were determined using the hexokinase method (Glucose HK 125 kit; ABX diagnostics, Montepelier, France). The WAKO NEFA C-kit (Wako Chemicals, Neuss, Germany) was used to determine free fatty acid (FFA) concentrations. Insulin concentrations were measured using a radioimmunoassay kit (Insulin RIA-100; Pharmacia, Uppsala, Sweden).

\section{Statistical procedures}

Data are presented as means ( \pm standard error of the mean, SEM) or as means \pm standard deviation (s.d.) All figures show changes from fasting plasma concentrations at each time of blood sampling $(\Delta)$ at the three testing occasions T1, T2 and T3 or area under the curve. Differences for blood parameters, appetite profile and anthropometrical data between T1, T2 and T3 were determined by analysis of variance for repeated 
measures (ANOVA) and Sheffe-F post-hoc test (Statview SE Graphics TM). Area under the curve (AUC) was calculated as incremental area under the curve over time ( $2 \mathrm{~h}$ ), using the trapezoidal method. Pearson correlation coefficients, $r$, were calculated to determine the relationship between resting energy expenditure (REE) and fat free mass (FFM).

The relationship between anthropometrical data such as age, sex and $\Delta$ body weight with the $\Delta$ of GLP-1 release and other blood parameters was tested with a multiple regression analysis. The decrease in GLP-1 release after weight loss compared to before weight loss was related to $\Delta$ body fat, $\Delta$ body weight, sex and age with the same method.

The level of significance was set at $P<0.05$.

\section{Results}

\section{Anthropometrical results}

Anthropometrical data are shown in Table 1 and are expressed as means $( \pm s . d$.$) .$

During the six-week VLED subjects had lost $8 \%$ (range $1 \%-14.8 \%$ ) of their weight. This was followed by a not statistically significant1. $2 \%$ regain during the twelve-week weight maintenance period. All anthropometrical results were compared between men and women. There was no gender effect with respect to age $(r=0.15 ; n . s),. F 1(r=$ 0.11 ; n.s.), $\mathrm{F} 2(r=0.31$; n.s. $), F 3(r=0.02 ; n .5$. $)$ and $R Q(0.04 ;$ n.s. $)$. Women and men lost a significantly different amount of weight (women $-5.8 \pm 2.7$ vs. men: $-9.8 \pm 2.8 ; \mathrm{P}=$ 0.001 ). Subjects mainly lost fat mass during the VLED (Figure 1).

Body-weight status after weight loss as well as after weight maintenance both were significantly lower compared to body-weight before weight loss ( $P=0.0001)$,

Percentage body fat was significantly reduced after weight loss as well as after weight maintenance compared to before weight loss $(P=0.0001)$. Fat free mass decreased slightly, but not statistically significant over time. Factor one of the three-factor eating questionnaire (restraint scores) was significantly increased at $\mathrm{T} 2$ and $\mathrm{T} 3$ compared to $\mathrm{T} 1$ $(P=0.0001)$, while factor two (disinhibition) and three (hunger) were significantly reduced $(P<0.05)$.

Respiratory quotient (RQ) was significantly decreased at $T 2$ compared to $T 1$, yet significantly increased at $T 3$ compared to $T 2(P=0.0001)$. Resting energy expenditure was significantly related to fat free mass before weight loss $(r=.81 ; \mathrm{P}<0.0001)$, after weight loss $(r=.43 ; P<0.05)$ and after weight maintenance $(r=.65 ; P<0.05)$ (Figure 2). 


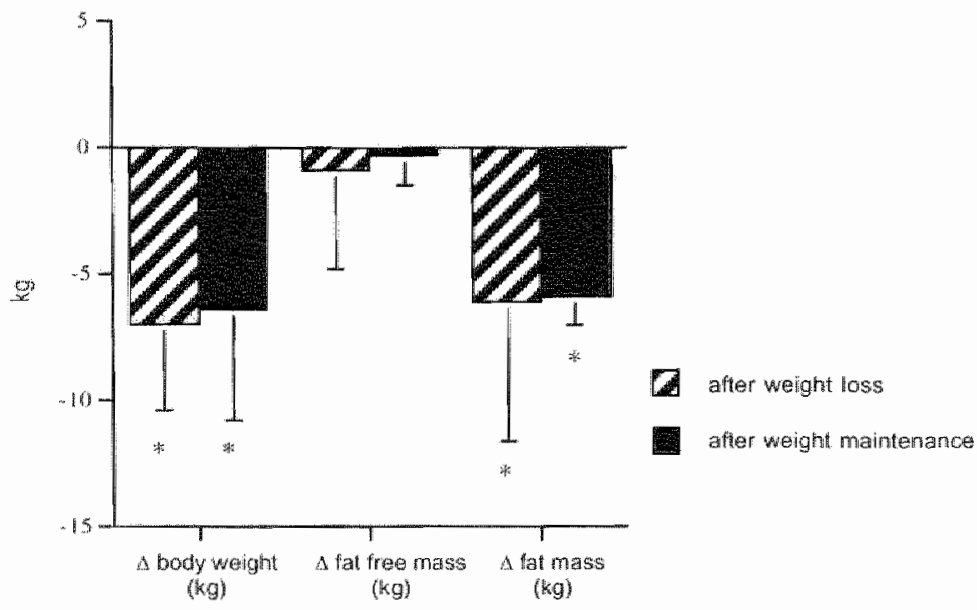

Figure 1. Changes in body weight(average for 32 subjects), FFM and FM (kg \pm s.d.) after a six-week weight loss period (striped bars) and a consecutive three months weight maintenance period (black bars) expressed as change from before weight loss( $(\Delta)$.

* significantly different from before weight loss at $P=0.0001$

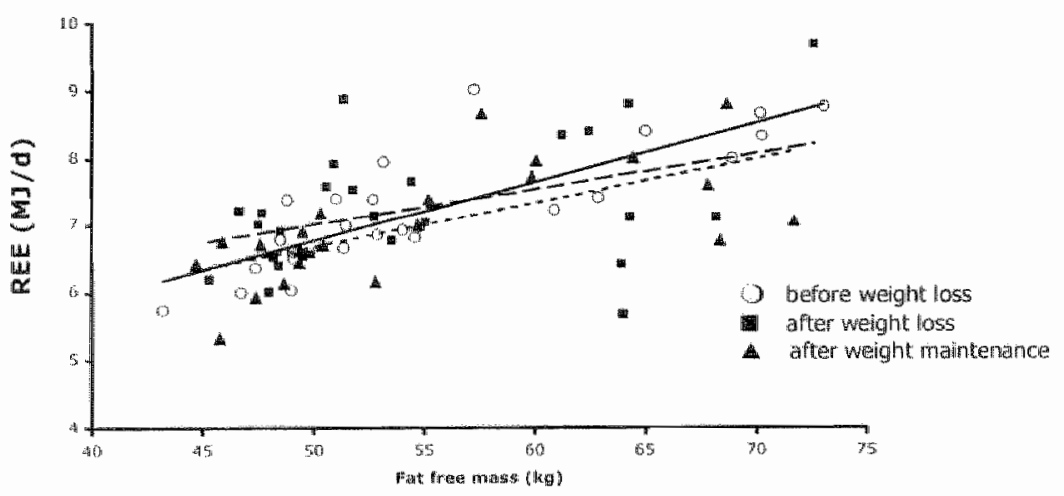

Figure 2. Resting energy expenditure (REE) as a function of fat free mass $(n=32 ; 23$ women, 9 men) berore weight loss (circles, solid line, $y=0.09 x+2.38 ; P=0.0001$ ), after weight loss (squares, dashed line, $y=0.05 x+4.33, P=0.02$ ) and after weight maintenance (triangles, dotted line, $y=0.07 x+3.37 ; P=0.001$. 


\section{Blood parameters}

Since men and women lost a different amount of weight all blood parameters were investigated for men and women separately first. Since no differences for sex were observed, results on blood parameters are given for the whole group.

The decrease in GLP-1 after weight loss compared to before weight loss was not related to the decrease in body weight ( $r=0.12 ; n . s$.$) , the decrease in body weight ( r=0.15$; n.s.), gender $(r=0.11 ; n . s$.$) or age (r=0.06 ; n . s$.$) .$

After weight loss, mean plasma GLP- $\mathbb{1}(\mathrm{pmol} / \mathrm{l})$ concentration in the fasting blood sample tended to be lower compared to before weight loss (2.6 (SEM 0.61) vs. 4.7 (SEM 1.3), approaching significance $(P=0.06)$.

Plasma GLP-1 concentrations expressed as change from the fasting blood sample ( $\Delta$ ) were significantly increased after ingestion of the breakfast before weight loss (T1) and after weight maintenance ( $(T 3)$. Post hoc testing revealed a significant increase $(P<0.05)$ at $30,60,90$ and 120 minutes at both accasions. After weight loss (T2), plasma GLP-1 concentrations were not significantly different from fasting plasma concentrations after breakfast.
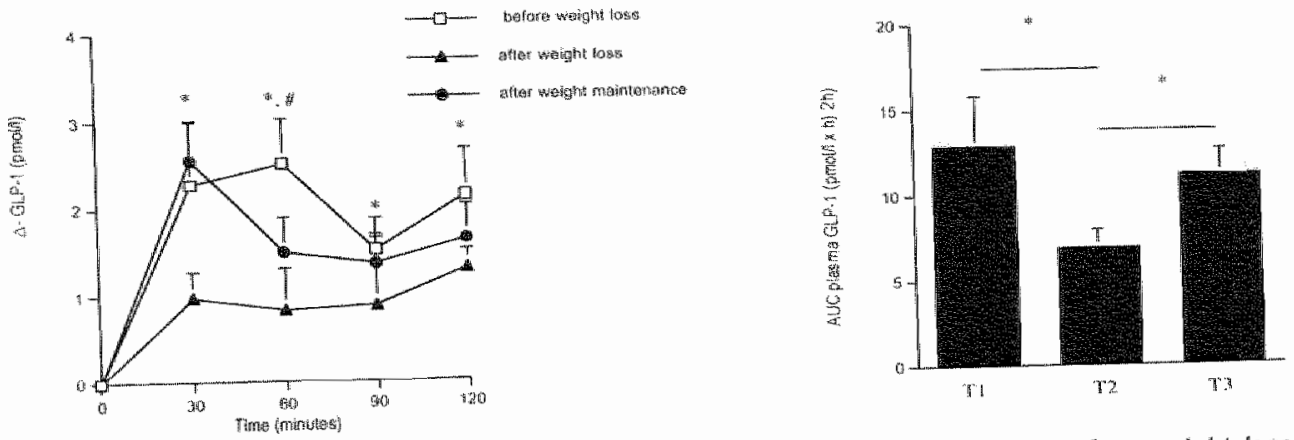

Figure 3 A. Plasma GLP-1 concentrations in response to a standard breakfast before weight loss, after weight loss and after weight maintenance. Data are presented as mean's 1 SEM.

a concentrations expressed as change from the fasted sample at time point $O(\Delta)$ wert pan before weight loss (squares), aftations compared to fasting concentrations before weight loss and * significantly different concentration maintenance. $p<0.05$ * significant difference between plasma concentrations before weight loss and after weight loss. $P$ $<0.05$ Right panel: Area under the curve (AUC) calculated as incremental AUC $\times 2$ h before weight loss (T1), after weight loss (T2) and after weight maintenance (T3).

* significantly different at $P<0.05$ 
A- plasma GLP.1 concentrations were significantly lower after weight loss compared to before weight loss at 60 minutes after breakfast (.83 (SEM 0.48) wS. 2.5 (SEM 0.52), $(P=0.003)$.

The AUC (pmol/I $\times 2 h$ ) for T1,T2 and T3, the AUC for plasma GLP-1 concentrations before weight loss (12.8 (SEM 2.9)) and after weight maintenance (11.1 (SEM 1.5) were significantiy higher compared to after weight loss $(6.8($ SEM 1.0)) $(P=0.01)$ (Figure $3 A)$.

Plasma insulin concentrations were significantly increased compared to fasting concentrations after breakfast at $T 1, T 2$ and $T 3(P<0.05)$. No differences were observed between $\mathrm{T}_{1}, \mathrm{~T} 2$ and $\mathrm{T} 3$ in insulin concentrations expressed as change from fasting concentrations or comparing the AUC (mU// $\times 2 h$ ) (Figure 3B).

Plasma glucose concentrations were significantly increased compared to fasting concentrations after ingestion of the breakfast at 60 minutes $(P<0.05)$ at T1 $(5.52$ (SEM 0.12) vs. 6.44 (SEM 0.26), T2 (5.07 (SEM 0.10) vs. 6.08 (SEM 0.23) and T3 (5.36 (SEM 0.12) vs. 6.61 (SEM 0.32). No differences were observed between T1, T2 and T3. Change from fasting concentrations for glucose $(\Delta)$ are shown in Figure $3 C$.

Plasma free fatty acid concentrations decreased over time at $T 1, T 2$ and $T 3$. The decrease compared to fasting concentrations $(\Delta)$ was significant before weight loss and after weight loss at every time point except for 30 minutes after weight maintenance ( $P$ $<0.05$ ). The AUC for free fatty acid concentrations ( $\mu$ mol/ $1 \times 2 \mathrm{~h}$ ) was significantly higher

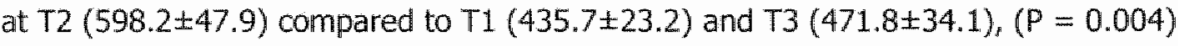

(Figure 3D)
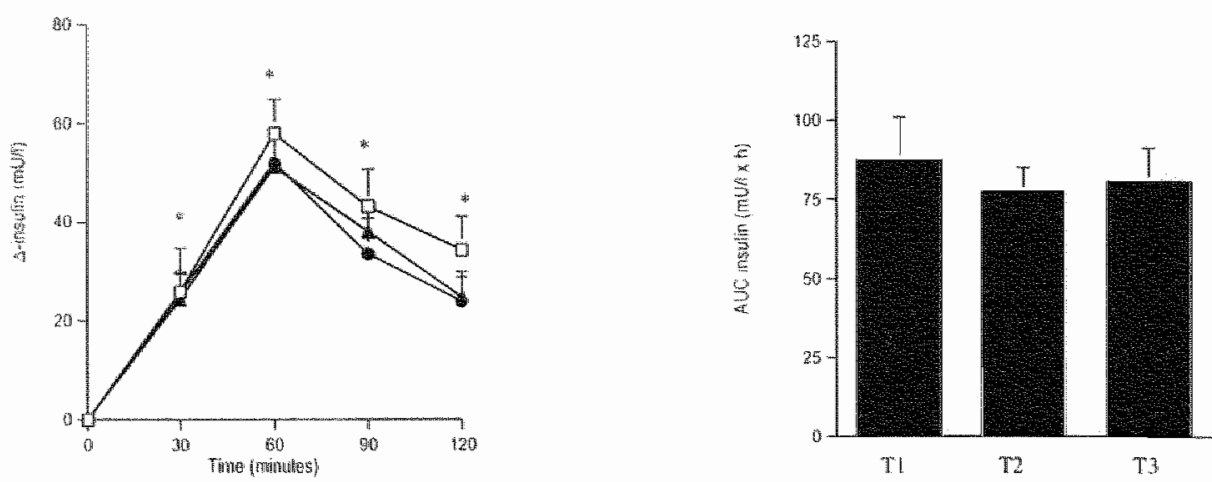
$3 \mathrm{C}$

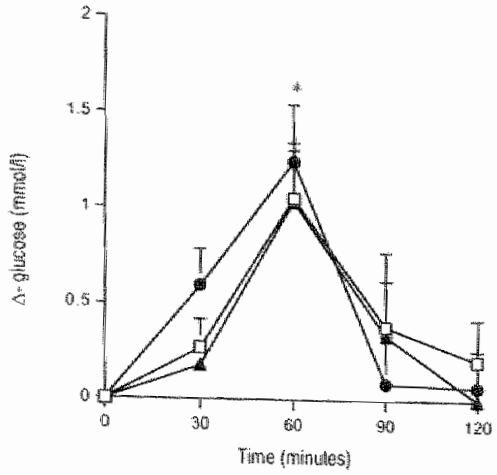

$3 \mathrm{D}$

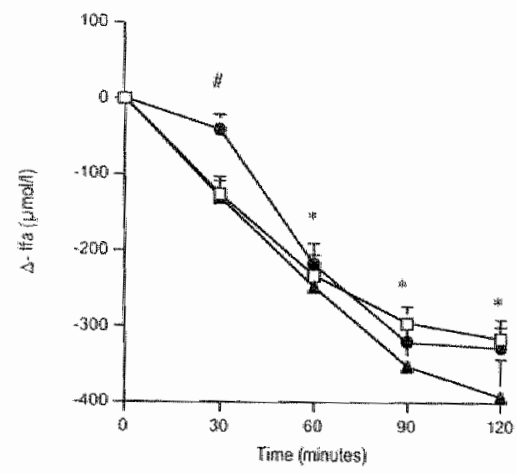

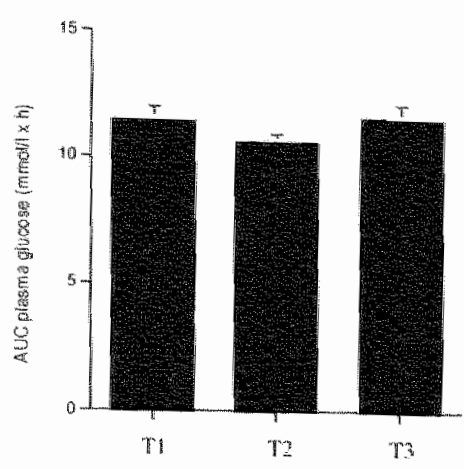

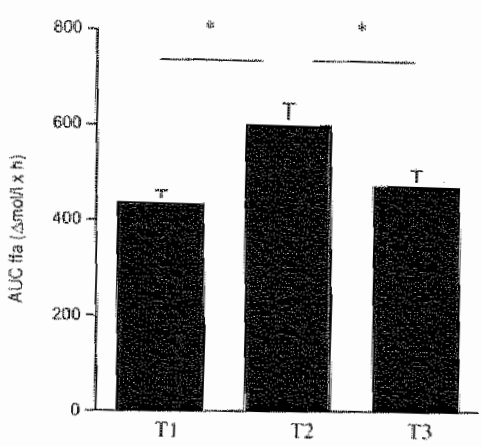

Figure 3 B-D. Plasma concentrations of insulin (3B), glucose (3C) and free fatty acids (3D) after ingestion of a standard breakfast before weight loss, after weight loss and after weight maintenance. Data are presented as mearis \pm SEM.

Left panel: Plasma concentrations expressed as change from the fasting sample at time point $O(A)$ before weight loss (squares), after weight loss (triangles) and after weight maintenance (circles).

* significantly different concentrations compared to fasting concentrations at o minutes after ingestion of a standard breakfast before weight 1055, after weight loss and after welght maintenance. $P<0.05$

\# significant difference compared to baseline plasma concentrations after weight maintenance compared to before weight loss and after weight loss. $P<0.05$

Right panel: Area under the curve (ALC) calculated as incremental ALC $\times 2 \mathrm{~h}$ before weight loss (T1), after weight loss (T2) and after weight maintenance (T3).

* significantly different at $P<0.05$ 
Table 2. Appetite ratings of 32 subjects ( 23 women; 9 men) before weight loss, after weight loss and after weight maintenance. Values are means \pm sem. Statistical significance was determined by ANOVA for repeated measures.

\begin{tabular}{|c|c|c|c|c|c|c|c|c|c|c|}
\hline & \multirow{2}{*}{$\begin{array}{c}\text { time } \\
\text { (minthes) }\end{array}$} & \multicolumn{3}{|c|}{ before weight 055} & \multicolumn{3}{|c|}{ ather weight loss } & \multicolumn{3}{|c|}{$\begin{array}{c}\text { after } \\
\text { weight mainkentance }\end{array}$} \\
\hline \multirow{5}{*}{$\begin{array}{l}\text { Hurger } \\
\text { (mitiv VAS) }\end{array}$} & & 24.37 & \pm & 3.7 & 23.8 & \pm & 39 & 33.2 & \pm & 3.9 \\
\hline & 30 & 9.03 & \pm & 2.7 & 6.9 & t & 5.7 & 6.7 & \pm & 1.8 \\
\hline & 60 & 9.22 & \pm & 2.3 & 5.7 & \pm & 1.6 & 9.9 & \pm & 2.2 \\
\hline & 90 & 10.2 & \pm & 27 & 6.1 & t & 1.0 & 11.6 & \pm & 1.6 \\
\hline & 120 & 14,48 & \pm & 3.6 & $8.8^{3 / 2}$ & \pm & 1.4 & 14.33 & \pm & 2.6 \\
\hline \multirow{5}{*}{$\begin{array}{c}\text { Sutiety } \\
\text { (mom WAS) }\end{array}$} & 0 & 31,33 & 1 & 4.3 & 34.1 & + & 33 & 30.86 & \pm & 38 \\
\hline & 30 & 72.38 & I & 39 & 69.95 & \pm & 5.7 & 79.36 & \pm & 3.4 \\
\hline & 60 & 69.14 & \pm & 4.6 & 72.37 & $t$ & 4.3 & 75.72 & \pm & 3.8 \\
\hline & 90 & 69.04 & + & 4.2 & 75.5 & \pm & 2.9 & $\$ 7.0$ & \pm & 4.1 \\
\hline & 120 & 63.57 & \pm & 4.7 & 69.7 & \pm & 4.1 & 61.55 & \pm & 4.5 \\
\hline
\end{tabular}

* significantliy different compared to betore weight loss at $P=0.03$.

\section{Appetite ratings}

Hunger ratings were not different between T1, T2 and T3 at baseline, at 30,60 and 90 minutes. Hunger scores decreased after breakfast at T1, T2 and T3. The decrease in hunger was significantly different at 120 minutes $(P=0.03)$ between $T 1$ and $T 2$ with lower hunger ratings after weight loss compared to before weight loss (Table 2).

Satiety ratings increased after breakfast compared to fasted ratings at T1, T2 and T3 and stayed elevated compared to the fasted ratings throughout the two hours of measurement. No differences between T1, T2 and T3 were observed over time (Table 2). Appetite ratings were not related to plasma GLP-1 concentrations.

\section{Discussion}

The present study shows a tendency of decreased plasma GLP-1 concentrations after modest weight loss in overweight obese subjects. After a weight maintenance period of three months GLP-1 concentrations rebound to a level similar to before weight loss. After weight loss not only fasting GLP-1 concentrations seemed to be decreased compared to before weight loss, but it appears that nutrient-stimulated GLP-1 release was disturbed after weight loss as well.

This observation might be an effect of the semi-solid VLED that the subjects followed during weight loss. A study comparing a liquid and a solid test meal in healthy normalweight subjects revealed a difference in gastric-emptying time, but not in small-bowel transit time for a liquid and a solid test meal (26). Altered gastric emptying rates, and increased proximal absorption rates of a liquid test meal in obese subjects (27), possibly resulting in less food reaching the distal intestine, are suggested as a possible explanation for decreased GLP-1 release (28). Thus, the absorption rate of the semisolid VLED in the presence of a negative energy balance might have lead to the decrease of GLP-1 secretion after weight loss in the overweight/ obese subjects. It 
needs to be taken into consideration that the reported results in the present study allso might be due to a decreased stimulation of the L-cells. Peptide $Y$ (PYY) is a peptide colocalized with GLP-1 in the L-cells of the gut. GLP-1 infusion studies showed significantly decreased PYY concentrations as a response to GLP-1 infusion, giving evidence that L-cell secretion is regulated in part by GLP-1 itself through negative feedback regulation $(29,30)$. Since in those studies GLP 1 concentrations were elevated to supraphysiological levels (30), the question remains in how far the results apply to rather a low range of physiological GLP-1 concentrations in the present study.

During the weight maintenance period subjects appeared to have stable body weight. This might have been achieved since the body weight lost can be described as modest, but in accordance with reports from other weight lass studies $(31,32)$

Surprisingly, after the three months weight maintenance period GLP-1 concentrations were rebounded back to a level comparable to before weight loss. The decrease of GLP1 secretion after weight loss might be due to a negative energy balance and may suggest that GLP-1 might play a role as a neuroendocrine factor signaling energy deficiency.

The overall pattern of GLP-1 release during $T 1, T 2$ and $T 3$, is following the biphasic pattern, that has been described before (33). GLP-1 release has been reported as attenuated in obese subjects compared to normal-weight subjects (12). This observation has been explained by increased DPP-IV activity for example (34). However, based upon the literature on DPP-IV activity in obese subjects, where abnomally increased DPP-IV activity could be observed in the obese even after substantial weight loss, it seems unlikely that altered DPP-IV activity is an explanation for different GLP-1 release at T1, T3 and T2 in the present study

Due to the negative energy balance during weight loss, free fatty acid concentrations were increased after weight loss compared to before weight loss. An increase in plasma non-esterified fatty acids has been found to inhibit carbohydrate-mediated GLP-1 secretion $(12,35)$, so that increased plasma free fatty acids after weight loss in the current study, might in part contribute to decreased GLP-1 secretion after the standard breakfast.

As expected, the RQ measured after a VLED was reduced (32), indicating increased fat oxidation. RQ was increased again after three months weight maintenance. REE aS a function of FFM did not change over time. Since the main determinant of REE is FFM (36) and FFM did not change over time either, this result is not surprising. Subjects mainly lost fat mass, as can be seen in the significant reduction in percentage fat mass. Weight lost during the VLED consisting mainly of fat mass seems to be favorable for the prevention of weight regain, and the result is in line with studies showing that weight regain was slower, when body weight regained consisted of a greater FFM $(37,38)$.

During a weight maintenance period subjects usually regain weight $(32,39)$. Subjects in the current study did not regain weight significantly during weight maintenance. Part of an explanation for this might be either individual motivation or the weather (40). The summer 2003 was an exceptionally warm one and June was with $17.8^{\circ}$ Celsius the 
warmest June since 1901. Subjects had their weight maintenance period in the months between April and July 2003.

Another important factor in successful weight maintenance is the restraint status of the subjects, which was increased significantly after weight loss and stayed increased after weight maintenance. It has been shown, that on the individual level, differences in successful weight maintenance after an energy restriction period are related to increases in cognitive restrained eating behavior during energy restriction phase $(39,41,42)$. This was supported by a decrease in disinhibition and hunger during weight loss and weight maintenance.

Differences in hunger and satiety ratings were observed at only one timepoint after weight loss compared to before weight loss, an observation that is similar to reports from other studies before (32). Ratings were not different after the weight maintenance period either. Again, this might be due to the weather or could be explained by less energy requirements due to weight loss.

Evaluating the hunger and satiety ratings as well as the blood parameters it is important to mention that the size of the test meal was the same at every occasion, although energy requirements changed. This is a procedure similar to other dietary induced weight loss studies (44). It is unlikely that this had an effect on GLP-1 concentrations, since if at all an increased GLP-1 release would have been expected due to more energy relative to requirements after weight loss compared to before weight loss.

No relationship between satiety ratings and GLP-1 concentrations were observed in the present study. Decrease in hunger ratings was not related to the increase in GLP-1 concentrations after weight maintenance. Both rather seem to reflect a new state of energy balance achieved.

In conclusion mutrient stimulated GLP-1 release was decreased after weight loss, but rebounded to a level similar to before weight loss after a weight maintenance period. The rebound in nutrient stimulated GLP-1 release makes it likely that the absence of nutrient stimulated GLP-1 release after weight loss is transient and might be due to a negative energy balance.

\section{Acknowledgements}

Supported by Novartis Consumer Health Ltd, Nyon, Switzerland \& Novartis Pharmaceuticals, Basel, Switzerland and Summit, USA. 


\section{References}

1. Seidell JC. Obesity, insulin resistance and diabetes--a worldwide epidemic. $\mathrm{Br} J$ Nutr 2000;83 Suppl 1:55-8.

2. Pi-Sunyer FX. The obesity epidemic: pathophysiology and consequences of obesity. Obes Res 2002;10 Suppl 2:97S-1045.

3. Sowers JR. Obesity as a cardiovascular risk factor. Am J Med 2003;115 Suppl $8 \mathrm{~A}: 37 \mathrm{~S}-41 \mathrm{~S}$.

4. Manson $\mathrm{JE}_{r}$ Willett $\mathrm{WC}_{\mathrm{r}}$ Stampfer $\mathrm{MJ}$, et al. Body weight and mortality among women. N Engl I Med 1995;333:677-85.

5. Van Gaal LF, Wauters MA, De Leeuw IH. The beneficial effects of modest weight loss on cardiovascular risk factors. Int $J$ Obes Relat Metab Disord 1.997;21 Suppl 1:S5-9.

6. Blundell JE, Lawton CL, Hill AJ. Mechanisms of appetite control and their abnormalities in obese patients. Horm Res 1993;39:72-6.

7. Blundell JE, Näslund E. Glucagon-ilke peptide-1, satiety and appetite control. Br J Nutr 1999;81:259-60.

8. Holst J]. Glucagonlike peptide 1: a newly discovered gastrointestinal hormone. Gastroenterology 1994;107:1848-55.

9. Näslund $E_{*}$ Barkeling $B$, King $N_{x}$ et al. Energy intake and appetite are suppressed by glucagon-like peptide-1 (GLP-1) in obese men. Int J Obes Relat Metab Disord 1999;23:304-11.

10. Flint A, Raben A, Astrup A, Holst J]. Glucagon-like peptide 1 promotes satiety and suppresses energy intake in humans. J Clin Invest 1998;101:515-20.

11. Fukase $\mathbb{N}$, Igarashi $M$, Takahashi $H_{x}$ et al. Hypersecretion of truncated glucagon-like peptide-1 and glastric inhibitory polypeptide in obese patients. Diabet Med 1993;10:44-9.

12. Ranganath LR, Beety JM, Morgan LM, Wright JW, Howland $R$, Marks V. Attenuated GLP-1 secretion in obesity: cause or consequence? Gut $1996 ; 38: 916-9$.

13. Verdich $C$, Toubro $S$, Buemarn B, Lysgard-Madsen J, Holst J], Astrup A. The role of postprandial releases of insulin and incretin hormones in meal-induced satiety-effect of obesity and weight reduction. Int I Obes Relat Metab Disord 2001;25:1206-14.

14. Cigaina V, Hirschberg AL. Gastric pacing for morbid obesity: plasma levels of gastrointestinal peptides and leptin. Obes Res 2003;11:1456-62.

15.

16. WHO. Obesity: preventing and managing the global epidemic. Geneva: WHO, 1998.

Raben A, Tagliabue A, Astrup A. The reproducibility of subjective appetite scores. Br I Nutr 1995;73:517-30. 
17. Schoeller DA, van Santen $\mathbb{E}$, Peterson DW, Dietz $W$, Jaspan J, Klein PD. Total body water measurement in humans with 180 and $2 \mathrm{H}$ labeled water. Am J Clin Nutr 1980;33:2686-93.

18. van Marken Lichtenbelt WD, Westerterp KR, Wouters L. Deuterium dilution as a method for determining total body water: effect of test protocol and sampling time. Br J Nutr 1994;72:491-7.

19. Siri. The cross composition of the body. Adv Biol Med Physial 1956;4:239-280.

20. Schoffelen PF, Westerterp KR, Saris WH, Ten Hoor F. A dual-respiration chamber system with automated calibration. J Appl Physiol 1997:83:2064-72.

21. Weir JB. New methods for calculating metabolic rate with special reference to protein metabolism. Nutrition [classical article] 1949;6:213-221.

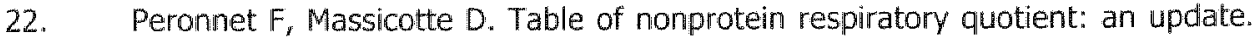
Can J Sport Sci 1991;16:23-9.

23. Sturkard AJ, Messick $S$. The three-factor eating quiestionnaire to measure dietary restraint, disinhibition and hunger. J Psychosom Res 1985;29:71-83.

24. Westerterp-Plantenga MS, Rolland V, Wilson SA, Westerterp KR. Satiety related to $24 \mathrm{~h}$ diet-induced thermogenesis during high protein/carbohydrate vs high fat diets measured in a respiration chamber. Eur $J$ Clin Nutr 1999;53:495-502.

25. Nathan DM, Schreiber $E$, Fogel $H_{s}$ Mojsov $S_{j}$ Habener JF. Insulinotropic action of glucagonlike peptide-1-(7-37) in diabetic and nondiabetic subjects. Diabetes Care $1992 ; 15: 270-6$.

26. Bennink R, Peeters $M$, Van den Maegdenbergh $V_{r}$ et al. Evaluation of smallbowel transit for solid and liquid test meal in healthy men and women. Eur 3 Nucl Med 1999;26:1560-6.

27. Wisen 0 , Johansson C. Gastrointestinal function in obesity: motility, secretion, and absorption following a liquid test meal, Metabolism 1992;41:390-5.

28. Vilsboll $T$, Krarup $T$, Sonne J, et al. Incretin secretion in relation to meal size and body weight in healthy subjects and people with type 1 and type 2 diabetes mellitus. J Cin Endocrinol Metab 2003;88:2706-13.

29. Hansen L, Hartmann $B$, Mineo $H$, Holst J]. Glucagon-like peptide-1 secretion is influenced by perfusate glucose concentration and by a feedback mechanism involving somatostatin in isolated perfused porcine illeum. Regul Pept 2004; 118:11-8.

30. Nầslund E, Bogefors 1, Skogar S, et al. GLP-1 slows solid gastric emptying and inhibits insulin, glucagon, and PYy release in humans. Am J Physiol 1999;277:R910-6.

31. Kovacs EM, Lejeune MP, Nijs I, Westerterp-Plantenga MS. Effects of green tea on weight maintenance after body-weight loss. Br J Nutr 2004;91:431-7.

32. Lejeune MP, Kovacs EM, Westerterp-Plantenga MS. Effect of capsaicin on substrate oxidation and weight maintenance after modest body-weight loss in human subjects. Br J Nutr 2003;90:651-59. 
33. Hermann $C_{*}$ Göke R, Richter $G$, Fehmann $H C$, Arnold R, Göke B. Glucagon-like peptide-1 and glucose-dependent insulin-releasing polypeptide plasma levels in response to nutrients. Digestion $1995 ; 56: 117-26$.

34. Lugari $R$, Dei Cas A, Ugolotti $D$, et al. Glucagon-like peptide 1 (GLP-1) secretion and plasma dipeptidyl peptidase IV (DPP-IV) activity in morbidly obese patients undergoing biliopancreatic diversion. Morm Metab Res 2004;36:111-5.

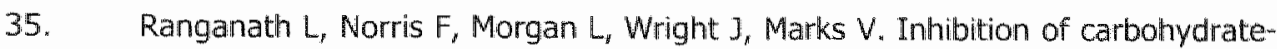
mediated glucagon-like peptide-1 (7-36)amide secretion by circulating nonesterified fatty acids. Clin Sci (Lond) 1999:96:335-42.

36. Ravussin E, Bogardus C. Relationship of genetics, age, and physical fitness to daily energy expenditure and fuel utilization. Am J Cin Nutr 1989;49:968-75.

37. Pasman WJ Saris WH, Muls E, Vansant G, Westerterp-Plantenga MS. Effect of exercise training on long-term weight maintenance in weight-reduced men. Metabolism 1999;48:15-21.

38. Westerterp-Plantenga MS, Lejeune MP, Nijs I, van Ooijen M, Kovacs EM. High protein intake sustains weight maintenance after body weight loss in humans. Int 1 Obes Relat Metab Disord 2004:28:57-64.

39. Lejeune MP, Van Aggel-Leijssen DP, Van Baak MA, Westerterp-Plantenga MS. Effects of dietary restraint vs exercise during weight maintenance in obese men. Eur J Clin Nutr 2003;57:1338 44.

40. Plasqui $G$, Kester $A D$, Westerterp $K R$. Seasonal variation in sileeping metabolic rate, thyroid activity, and leptin. Am J Physiol Endocrinol Metab 2003:285:E33843.

41. Westerterp-Plantenga MS, Kempen KP, Saris WH. Determinants of weight: maintenance in women after diet-induced weight reduction. Int $J$ Obes Relat Metab Disord 1998;22:1-6.

42. Pekkarinen $T$, Takala $I$, Mustajoki P. Two year maintenance of weight loss after a VLCD and behavioural therapy for obesity: correlation to the scores of questionnaires measuring eating behaviour. Int 7 Obes Relat Metab Disord $1996 ; 20: 332-7$.

43. Clark MM, Marcus BH, Pera $V$, Niaura RS. Changes in eating inventory scores following obesity treatment. Int I Eat Disord 1994;15:401-5. 



\section{Chapter 8}

\section{General Discussion}


The research presented in this thesis focused on the irvestigation of both endogenous GLP.1 stimulation and effects of GLP-1 stimulation in lean and obese subjects. First galactose as a non-glucose carbohydrate in combination with guar gum as a fiber has been assessed concerning its ability to stimulate GLP-1 release. As a second stimulus for GLP-1 release physical activity has been investigated. Physical activity as well as galactose and guar gum as a nutrient combination were shown to stimulate GLP-1 release in lean subjects. Secondly, it has been assessed whether GLP-1 release can be triggered by the same nutrient combination, respectively physical activity in overweight obese subjects. As for the stimulation with galactose and guar gum, no differences were observed between lean and obese subjects concerning GLP-1 release. Physical activity only stimulated GLP-1 release after a period of madest weight loss in the overweight obese subjects.

Thirdly, parameters were investigated that might influence GLP-1 dynamics. Particularly gender was found to be a major determinant of GLP-1 release in lean subjects in one of the studies.

Furthermore the effects of weight loss and weight maintenance on GLP-1 release have been examined. Weight loss was shown to improve sensitivity of GLP-1 release to physical activity and to stimulation by nutrients, yet only after a weight maintenance period when a new point of energy balance had developed. Otherwise, weight loss induced by a very-low-energy-diet, initially led to decreased GLP-1 rellease and diminished sensitivity.

\section{Stimulation of GLP-1 release}

GLP-1 is released into the circulation after a meal (1-3). Macronutrients have been tested distinctively in their potential to stimulate GLP-1 release. As far as protein it has been found that GLP-1 secretion is stimulated, when protein is part of a mixed meal, but protein alone did not consistently increase GLP-1 release in humans $(2,4,5)$. GLP-1 is increased by the ingestion of mixed fats or triglycerides in humans $(2,6)$.

Carbohydrates, especially glucose, are a sufficient stimulus for GLP 1 secretion (2-5).

This thesis focused on non-glucose carbohydrates and their ability to stimulate GLP-1 release. With respect to obesity and diabetes non-glucose carbohydrates such as galactose may stimulate GLP-1 release sufficiently with a lower glycaemic index (11).

\section{Carbohydrates}

Oral glucose has been shown to stimulate GLP-1 release consistently $(2,4)$. It has been suggested, that the effect of oral carbohydrates on gut hormone release may vary between different monosaccharides (7). The monosaccharide that was investigated in the studies of this thesis was galactose in combination with guar gum.

The release of GLP-1 from the ileum requires sodium (2), implicating a role for the brush-border sodium/glucose co-transporter in the effect of glucose on GLP-1 release 
(8). Other sugars that utilize the same co-transporter as glucose for the absorption across the intestimal epithelium such as galactose, are expected to stimulate GLP-1 release as well (2). Not much is known about the effect of galactose on GLP-1 secretion. The results of the present studies, particularly described in Chapter 2 demonstrate that galactose, when combined with fiber such as guar gum, is a potent stimullus for GLP-1 release in lean subjects. The area under the curve for GLP-1 concentrations after ingestion of galactose/ guar gum was not significantly different compared to glucose/ guar gum; both showed stronger GLP-1 release in comparison to the single nutrient or to water.

With respect to diabetes and obesity, galactose seems to be an interesting ingredient. Oral galactose was shown to increase insulin concentrations most likely due to an incretin effect. That means that galactose affects insulin concentrations via GLP-1 or GIP, the two major incretins in men (9). Galactose also has a lower glycemic index compared to glucose, which is thought to be beneficial with respect to the risk for obesity, type 2 diabetes and cardiovascular disease $(10,11)$.

It has been suggested, that sugars using a different mechanism of transport compared to glucose, such as fructose and lactose do not to stimulate GLP-1 release (12).

Fructose has been investigated concerning its ability to stimulate GLP-1 release. Effects. of fructose on GLP-1 secretion are contradictory. While no difference between fructose and glucose has been observed concerning the stimulation of GLP $1(13,14)$, other results show a smaller GLP-1 release in response to fructose as compared to glucose ( 7 , 15). Because of the positive effects on insulin release, glucose concentrations and the utilization of the same co-transporter as glucose, galactose was used as one nutrient in the studies described in this thesis, when it was the intention to investigate nutrient stimulated GLP-1 release.

\section{Fiber}

Observations on the effect of fiber alone on GLP-1 release are conflicting. Results from animal studies show an increase in GLP-1 concentrations along with the consumption of fiber $(16,17)$. A human study revealed no effect of 1.79 physillium on $G L P-1$ concentrations compared to a control condition (18). In the present studies guar gum has been used as a fiber component. Guar gum is a polysaccharide, which on contact with water forms a highly viscous gel (19).

The addition of guar gum has been shown to delay absorption of a meal, delay small bowel transit time and to prolong the contact between nutrients and small intestinal epithelium (20). The intention for the studies presented in this thesis was to use the properties of guar gum in order to enhance and extend the GLP-1 stimulation caused by galactose. The results of chapter 2 show that galactose in combination with guar gum led to GLP-1 concentrations that were higher than concentrations evoked by galactose alone. In comparison with other results on the effect of fiber on GLP-1 release(18), guar gum in combination with a nutrient such as galactose increased GLP-1 release. The 
underlying mechanism maly be an increased contact of galacose with receptors in the small intestine due to the properties of guar gum.

\section{Physical activity}

Nutrient stimulation is not the only mechanism to regulate GLP-1 release, since the GLP-1 releasing cells are located mainly in the distal part of the intestine and the early peak of GLP-1 secretion occurs before nutrients reach the distal ileum $(21,22)$. Therefore it is believed that GLP.1 release is triggered by putative humoral mediators, like i.e. gastrointestinal polypeptide (GIP), which are released when nutrients are present in the upper intestine and by stimulation of the autonomic nervous system (23).

Meal-induced activation of the sympathetic nervous system has been mentioned as a potential factor to account for the early secretion of GLP-1 (24). There is evidence that release of peptide $Y Y$ (PYY), a peptide that is co-synthesized with GLP-1 in the intestinal $L$ cells as well as co-secreted with GLP-1 in response to ingestion of mixed meals is affected by the sympathetic nervous system $(25,26)$. Until now the effect of sympathetic stimullation on GLP-1 release has only been investigated in animal or cell line studies (27-29).

Only one study has investigated the effect of physical activity on GLP-1 concentrations and other gastrointestinal peptides (30). In that study marathon runners were investigated concerning their GLP-1 concentrations during a race. Significantly increased concentrations were reported post-race, but mechanisms remained unclear.

In Chapter 4 the results on GLP-1 release after stimulation by means of physical activity are reported. Indeed, increased GLP-1 concentrations after physical activity compared to rest were observed in lean subjects and in obese subjects after modest weight loss. Subjects were in a fasted state. Physical activity is known to increase norepinephrine concentrations by two- to six-fold depending on the intensity (31), thus we may speculate that the increase in GLP-1 release is related to activation of the sympathetic nervous system. Stimulation of adrenergic pathways mediates the inhibition $(32,33)$ of gastrointestinal motility by GLP-1 $(29,34)$. Colonic sympathetic afferents controlling the gastroduodenal area have been described and as a consequence, a GLP-1 action on these fibers which could activate an ileal brake mechanism has been suggested $(29,34)$. Furthermore, GLP-1 receptor stimulation was shown to increase blood pressure and heart rate (35). Taken together, GLP-1 release during physical activity may be due to a decrease in splanchnic blood flow, which may lead to gut ischaemia. Gastrointestinal hormones may be released in conditions where increased blood flow is needed ( 30 ).

The results presented in this thesis show that not only endurance, but also daily physical activity increased GLP.1 concentrations, which may be either related to catecholamine concentrations or to gut ischaemia, or both in lean subjects. This novel result supports the suggestion of a mediating role for the GLP-1 system in multiple stress responses (36). 


\section{Parameters of importance for the stimulation of GLP-1 release}

\section{GLP-1 release and age}

Aging is associated with decreased appetite and food intake $(37,38)$. The causes for this so called anorexia of aging are unknown but are likely to be multifactorial, possibly including changes in gastrointestinal peptides associated with hunger and satiety (39). Differences in GLP-1 concentrations in relation to age hardly have been investigated.

Age related differences have been found for Cholecystokinin (CCK), after indraduodenal glucose or lipid infusion, but not for GLP-1 or PYY concentrations (39). CCK concentrations appeared to be higher in older compared to younger subjects as a result of higher baseline values and a greater increase from baseline during lipid infusion. Chapter 5 reports on a group of subjects significantly different ages showing no difference in fasted or postprandial GLP-1 concentrations, similar to the observations by Macintosh et al. (39). However, due to their study design, no clear conclusions on agerelated difference after oral or intragastric ingestion of nutrients could be drawn after intraduodenal infusions of lipid or carbohydrate (39). Another study by Ranganath et al. found significantly increased GLP-1 concentrations in older subjects compared to younger subjects after administration of oral glucose (40). Results of Chapter 5 are due to oral ingestion and show no age-related difference in GLP-1 release. Different from Ranganath et al. (40) active GLP-1 (7-36 amide) was measured in the studies of this thesis. The immunoassay Ranganath et al. (40) used does not reliably differentiate between active GLP-1 (7-36 amide) and the inactive metabolite GLP-1 ( $9-36$ amide). If older subjects would indeed have inappropriate accumulation of active GLP-1 concentrations, this should lead to lower glucose and higher insulin responses, which have not been observed in the older subjects. Comparing our findings with those from Ranganath et al. (40) it is likely that older subjects might have increased total GLP-1 concentrations but not active GLP-1 concentrations. Nevertheless this would raise the question whether age might be related to progressive receptor insensitivity for the GL.P-1 receptors. To our knowledge this has not been investigated yet.

Thusfar, based on the results presented in Chapter 5 and the results from Macintosli et al. (39) age seems to affect other gastrointestinal hormones like CCK rather than GLP-1 and it seems unlikely that changes in circulating GLP-1 concentrations contribute to the reduced appetite accompanying normal aging.

\section{GLP-1 release and weight status}

GLP-1 concentrations appear to be affected by weight status. Results on how GLP-1 concentrations differ in obese subjects compared to normal-weight subjects are contradictory. One study found a hypersecretion of GLP-1 in the obese after a glucose challenge (41). GLP-1 has been shown to be strongly insullinotropic (3). It has been suggested that an exaggerated "incretin" factor - GLP-1-might play a pathophysiological role in obesity (41) and it seems possible, that an increased secretion of GLP-1 
contributes to hyperinsulinaemia in obese patients. Similar results have been reported for an obese group of African-Americans $(42,43)$. Higher fasting as well as higher stimulated GLP 1 concentrations were observed after an oral glucose challenge, possibly contributing to a higher prevalence of hyperinsulinaemia-related disorders in AfricanAmericans.

Most of the studies executed in Caucasian subjects show attenuated GLP-1 concentrations in the obese compared to normal-weight controls $(44,45)$. It has been shown that hyperglycaemia, a feature of obesity, due to a condition of either insulin resistance or insulin deficiency could induce a progressive desensitization of intestinal $L$ cells with a consequent peptide falure response to stimulation (46). Another explanation for attenuated GLP-1 concentration in obesity is the observation that GLP- 1 degradation by the enzyme DPP-IV is accelerated compared to lean subjects, leading to the attenuated GLP-1 concentrations. Furthermore higher pllasma levels of free fatty acids in obesity have been mentioned as a possible reason for lower GLP-1 concentrations in obese subjects (45).

Results of Chapter 5 show no differences in baseline GLP-1 concentrations when comparing lean and obese subjects. However, weight status appeared to affect GLP-1 sensitivity to nutrient ingestion rather than baseline concentrations, since stimulated GLP-1 concentrations were different between lean and obese subjects after ingestion of water and a standard breakfast. When water was replaced with galactose/ guar gum instead, the difference between the groups disappeared, showing a sensitivity in the obese to a stronger trigger, resulting in a similar GLP-1 release as in the lean subjects. Free fatty acid concentrations were not different between obese and lean subjects in the study of chapter 5 . The results of the studies in this thesis suggest that attenuated baseline GLP-1 concentrations do not yet occur in subjects in a class 1 stadium of obesity and that the difference between lean and obese subjects in nutrient-stimulated GLP-1 concentrations is related to the strength of the nutrient stimulus.

\section{GLP-1 and weight loss}

Since GLP 1 concentrations have been described as attenuated in obesity $(44,45,47)$, it is relevant to investigate how GLP-1 concentrations may change with weight loss. The effect of weight loss on GLP-1 concentrations has been mainly investigated after weight loss induced by surgery (jejunoileal bypass (48), gastric bypass (49) or gastric pacing (50)). Bypass surgeries have in common that parts of the gastrointestinal tract are connected by bypassing others, such as parts of the stomach or the duodenum. With gastric pacing a gastric stimulator system is implanted to provide electrical stimulation of the stomach (50). With surgically induced weight loss it is difficult to evaluate whether changes in peptide hormones are due to weight loss or result from a manipulated stimulation of secretory cells due to surgery. Two surgically induced weight loss studies report improved GLP-1 concentrations in relation to either subjects own baseline (51) or compared to a control group (48). For the latter one the question remains, whether 
baseline concentrations differed between the treatment and the control groups before surgery and whether GLP-1 concentrations in the weight loss group improved compared to their own baseline.

Chapter 6 shows initially decreased GLP-1 concentrations after weight loss in a group of obese subjects (BMI 30.3), probably caused by the VLED induced lack of nutrient stimulation. These results confirm the observations concerning the effect of gastric pacing on gastrointestinal hormone concentrations (50). GLP-1 concentrations were decreased after gastric pacing induced weight loss. Since GLP-1 is released in response to wagal nerve stimulation, a decreased vagal tone due to gastric pacing has been considered as a possible explanation for decreased gastrointestinal hormone secretion after weight loss (50). The mechanisms are not fully understood yet, but either vagal depression or excessive stimulation may play a role in decreased GLP-1 concentrations. after weight loss (50). Only one study investigated the effect of diet induced weight loss on GLP-1 concentrations (52). Another study induced weight loss pharmacologically with Orlistat (53).

When GLP-1 concentrations were investigated after dietary induced weight loss (52), improved GLP-1 concentrations have been reported compared to before weight loss, although the reported increase in GLP-1 release was not statistically significant. This seems to contradict the findings of decreased GLP-1 concentrations after weight loss reported in this thesis. The most striking difference between the study presented in this thesis and other studies that investigated effect of weight loss on GLP- $\mathbb{1}$ concentrations, is the duration of the weight loss period and the time between baseline measurement and measurements after weight loss. Verdich et al. (52) investigated subjects after six months of weight loss, while subjects in the present thesis were imvestigated after six weeks of weight loss with a VLED.

In addition to decreased baseline GLP-1 concentrations, meal-induced postprandial GLP1 concentrations after weight loss also failed to modify (Chapter 6). Lugari et all. (51) reported similar results after surgically induced weight loss. The group of subjects investigated in this thesis showed meal induced sensitivity before weight 105s, which is most likely due to a lack of nutrients stimulating GLP-1 release associated with weight loss caused by the VLED.

The suggestion of an initial decrease in GLP-1 concentrations due to a VLED and the importance of the duration of the weight loss period is supported by the rebounded meal induced GLP-1 concentrations to a level similar to before weight loss, after a weight maintenance period (Chapter 7). Subjects from those studies that report improved GLP-1 concentrations after weight loss (52), may be adjusted to a new set-point of energy balance at the time of re-investigation and may have passed the decrease in hormones already.

Ghrelin, an orexigenic hormone that seems to play a role in the regulation of hunger and satiety has been given much attention lately conceming its concentrations before and after weight loss. Ghrelin appears to be inversely related to GLP-1 secretion and ghrelin and GLP-1 seem to have opposite effects on satiety $(54,55)$. 
Diet-induced weight loss was shown to increase plasma ghrelin concentrations, while gastric bypass surgery suppressed ghrein concentrations (49). This may be explained by the possible role of ghrelin in fat oxidation (56). Suppressed ghrelin concentrations seem to be the effect of enhanced fat oxidation, which is stronger after gastric bypass surgery than after diet-induced weight loss (56). In addition decreased ghrelin levels after surgery may be caused by the surgical technique that is applied, as recently shown for bariatric surgery (57). Ghrelin concentrations were only decreased after Roux- en -Y gastric bypass, yet not after gastric banding and biliopancreatic diversion.

Taken together the results on initially decreased GLP-1 concentrations after weight loss in a group of obese subjects and a subsequent rebound in GLP-1 concentrations after a weight maintenance period up to a level similar to concentrations before weight loss (Chapter 7) are not necessarily contradicting observations by Cigaina et al (50), who reported decreased GLP-1 concentrations after weight loss, nor by verdich et al (52), who reported silghtly increased GLP-1 concentrations after six months of gradual weight loss.

In our studies GLP-1 concentrations rebounded while significant weight loss was maintained during weight maintenance, indicating an improved sensitivity in obese subjects after weight loss. Improved sensitivity due to weight loss is supported by the results in chapter 4 , where modest weight lloss caused sensitivity to activity induced GLP. 1 release. The results show that a clear conclusion on the effects of weight loss has to imply the final effect when weight stabilization is reached.

\section{GLP-1 and gender}

The relationship between gender and GLP-1 rellease has not explicitly been studied before. In Chapter 3 a clear relationship between gender and GLP-1 release was observed. The effect of increased GLP-1 concentrations after ingestion of galactose/ guar gum and breakfast compared to water and breakfast was almost exclusively observed in female subjects. (Chapter 3)

GLP-1 release was positively related to \%body fat and negatively with fat free mass respectively. Since women in the present experiment (Chapter 3) had significantly more body fat and less fat free mass than men, body composition seems to be an explaining factor for the gender related difference in GLP-1 release. Leptin and insulin are released in direct proportion to body fat as well (58). One other study reported similar results concerning the difference between men and women in GLP-1 release (59). Vaag et al. (59) reported thigher values in women for GLP-1, GIP, glucose and insulin concentrations after a glucose challenge. Glucose and insulin concentrations were not different for men and women in our study, although, due to the insulinotropic action of GLP-1, higher insulin concentrations and lower glucose concentrations would be expected for women. Since we stimulated GLP-1 endogenously in healthy subjects with a difference in peak concentrations of about 5 pmol/I between men and women, the effect of GLP-1 on 
insulin and gllucose concentrations supposively is less pronounced in our group of subjects.

Body fat content is highly correlated with circulating leptin concentrations (60). Recently it has been shown that leptin significantly stimulated GLP-1 secretion in vitro and in vivo and leptin resistance in mice was associated with impaired GLP-1 release (61).

Therefore different leptin concentrations due to differences in body fat mass are a likely explanation for the difference in GLP-1 concentrations.

GLP-1 and leptin exert counteregulatory actions in the periphery, but centrally actions overlap. While GLP-1 simulates insulin biosynthesis, leptin inhibits glucose-dependent insulin release in the endocrine pancreas (62). In ordel to create a homeostatic condition women would have to show higher plasma GLP-1 concentrations due to higher circulating leptin levels.

Takery together the present results show that gender may be a determinant of GLP-1 concentrations due to different body fat mass. There is evidence that leptin as a hormonal indicator of body fat is involved in GLP-1 secretion and contributes to higher plasma concentrations in women.

\section{Effects of GLP-1 release on satiety}

It has been stated that the primary cause of obesity lays in the control of appetite (63). Energy balance is regulated very precisely, although daily energy intake is highly variable (64).

Long-term and short-term hormonal signals from adipose tissue and the gastrointestinal tract act in concert to regulate feeding behavior and body weight regulation.

Long-term signals have different functions than the short-term regulators. Insulin and leptin are considered to be long-term regulators of energy homeostasis that are activated in proportion to both adipose stores and the amount of energy consumed over a prolonged period of time to regulate food intake and energy expenditure in order to keep body adiposity relatively constant and to maintain energy homeostasis.

In contrast to the long term signals, short-term signals can be overridden by the longterm signals and are not primary determinants of body adiposity (65).

Short-term signals like GLP-1, CCK or PYr primarily act as deterininants of satiety to limit the size of individual meals and to sustain the intermeal-interval (65).

This thesis focuses on the effect of GLP-1 as a short-term satiety regulator. Findings on GLP-1 as a short-term satiety regulating peptide are contradictory $(66,67)$. Studies that found an effect on satiety mostly have been applying GLP-1 infusions in supraphysiological doses (68-70). One study investigated the paradigm of endogenous GLP-1 stimulation with an energy fixed meal like it is described in this thesis (52). Subjects had a sandwich based standard breakfast, and meal related GLP-1 release was investigated before and after a weight loss period. Hunger and satiety was assessed before and after the test meal with visual analog scales. Only weak correlations were reported for GLP-1 release and subjective appetite ratings in that study. The results of 
chapter 3 and chapter 5 show a relationship between GLP-1 release and satiety in normal-weight subjects yet not in obese subjects, when GLP-1 was stimulated endogenously by a standard meal. Taken together, the question remains whether the pharmacological effect of GLP-1 on satiety and food intake is always clearly present as a physiological effect. In Chapter 3 a relationship between the increase in GLP-1 and the increase in satiety at 60 and 90 minutes in the water and breakfast condition was described. In Chapter 5 a relationship for the area under the curve in the galactose/ guar gum and breakfast condition and GLP-1 was found for the lean subjects. The relationship between GLP-1 and satiety in this thesis is also less pronounced as with exogenous supraphysiologicall GLP-1 infusions (68-70). GLP-1 has been shown to even induce nausea when administered in higher doses (71). Furthermore, there is evidence that GLP-1 might be involved in the development of taste aversion and that the anorexic actions may partially be caused by the activation of hypothalamic stress pathways (7274). Thus, the effect of GLP-1 an appetite in the studies using exogenous pharmacological doses of GLP-1 might be an effect exceeding satiety, resulting in nausea, respectively taiste aversion.

Results of chapter 5 , chapter 6 and chapter 7 show that the relationship between GLP-1 and satiety does not appear in the obese subjects.

Since no differences in basal GLP-1 concentrations between lean and obese subjects were observed, lower satiety ratings in the obese group might be rather an effect of a disturbed perception of a physiological feedback. Other hormones that are involved in the regulation of hunger and satiety i.e. ghrelin or CCK might play a role as well.

The suppressing effect of exogenous CCK administration on food intake in humans was first described by Kissilleff et al. (75). Pharmacological doses of CCK8 decreased intake of a liquid meal in humans (75). That the pharmacological effect of CCK on satiety in humans may not always be clearly present as a physiological effect is supported by other authors (76). Studies on CCK have been reviewed and the conclusion was drawn that central CCK plays a role in the control of food intake, yet peripheral endogenous CCK is not a major satiety factor (77).

Results on GLP-1 are similar to the results on CCK. Clear central effects of GLP-1 on food intake have been reported in animal studies (78). When human subjects are investigated it appears that pharmacological doses of GLP-1 are necessary to show a clear relationship between GLP-1 release and satiety and food intake (66). Based on the results presented in this thesis GLP-1 appears to have some effect on satiety (Chapter 3 and 5) yet cannot be seen as the major satiety factor when stimulated endogenously in lean subjects and should be further investigated in combination with other satiety factors. 


\section{Practical relevance of GLP-1}

Based on the actions of GLP-1 that have been described, GLP-1 became interesting for the treatment of nom-insulin-dependent Diabetes Mellitus (NIDDM). NIDDM is characterized by an increase in basal glucose concentrations and exaggerated postprandial glucose excursions, induced by a combination of beta-cell dysfunction and impaired insulin sensitivity (79). NIDDM patients, who are often obese, share a lot of features with obese subjects and obese subjects in turn are at high risk to develop NIDDM.

GLP-1 is considered as a potential treatment in NIDDM and obesity especially because of its insulinotropic potency and the effect on food intake. Different from GIP, which has lost most of its insulinotropic activities in NIDDM (80), GLP-1 still appears to stimulate insulin release in these subjects (1). In contrast to other insulinotropic agents, i.e. sulfonylureas, GLP-1 acts fully glucose-dependent, thus prevents hypoglycaemia (81). A significant relationship between the increase in GLP-1 and the increase in insulin was observed in the lean subjects from Chapter 3 , but not in the obese subjects in Chapter 6 (Figure 1). This result suggests that the incretin effect is present in lean subjects when GLP-1 is stimulated endogenously, yet concentrations are not sufficient for causing an effect in obese subjects. Physiologically stimulated GLP-1 concentrations may be too low to show an effect in obese subjects. However, the addition of guar gum that has been shown to lower insulin concentrations (82) limits conclusions about the effect of GLP-1 on insulin release. Different from the water and breakfast condition, a relationship between GLP-1 and insulin was observed in the guar gum and breakfast condition. Guar gum may interfere with the actions of GLP-1 on insulin release by delaying nutrient absorption and slowing access to the absorptive epithelium (82).

The effect of GLP-1 on satiety and food intake has been discussed before. There is a body of evidence showing that GLP-1 plays a role in satiety and body weight loss when administered exogenously and in high doses $(66,68,83)$. The question remains whether the effect of GLP-1 on satiety and body weight may be transitory or persists during long. term treatment as well $((84)$. To date, work dealing with this research question came to contradictory results.

In animal as well as in human studies effects on hunger and prospective food consumption (85) or leeduced food intake (86) were observed for the duration of GLP-1 administration, but no effects on total food consumption after a longer period of time (86) or during an ad libitum lunch five hours after GLP-1 infusions respectively were reported (85). The results described in this thesis suggest a short-term role of GLP-1 in satiety. After endogenous GLP-1 stimulation with different nutrients initiall differences in satiety were observed, yet no differences were observed in ad libitum food intake four hours later (Chapter 1). 

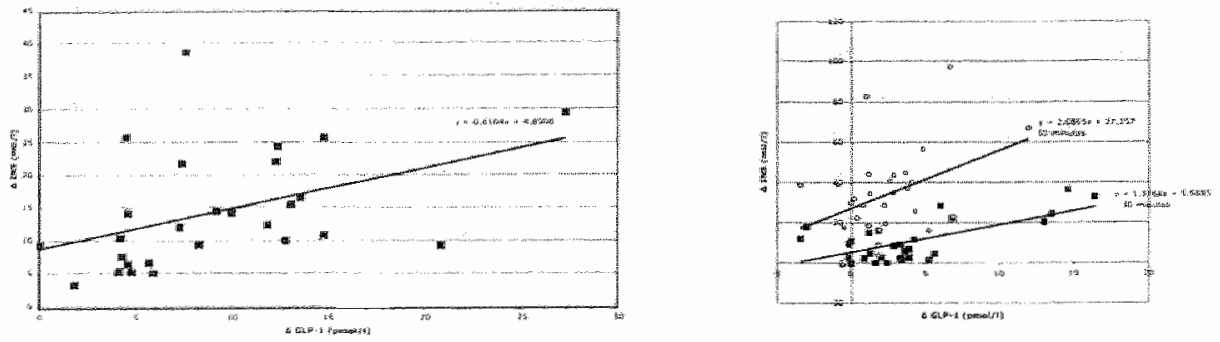

Figure 1. Increase in insulin is significantly related to the increase in GLP-1 concentrations in 30 normal-weight subjects at 30 minutes $\left(R^{2}=0.17 ; \rho=0.02\right)$ after ingestion of a galactose guar gum preload and a standard breakfast (left side figure) and at $30\left(R^{2}=0.43 ; p=0.0001\right.$ ) and 60 minutes $\left(R^{2}=0.15 ; p=0.03\right)$ after ingestion of water in combination with the same standard breakfast (right side figure).

Other groups have reported reduced body weight after long-term sustained treatment with GLP-1 (87).

Taken together, it appears that GLP-1 plasma concentrations need to be maintained elevated constantly for long-term effects. That raises the question about a decrease in postsynaptic receptor sensitivilty and adaption (tachyphylaxis). No occurrence of tachyphylaxis has been reported for short-term investigations (88), but not much is known about long-term effects yet.

Results from chapter 5 show that satiety ratings differed between lean and obese subjects despite similar GLP.1 concentrations in the water and breakfast conditions. This would give evidence to the suggestion of receptor insensitivity or that pharmacologica! doses are needed to see effects of GLP-1 on satiety in obese subjects.

Another problem for the therapeutic suitability of GLP-1 in addition to finding the appropriate dosage, is its short half-life time. Most of the peptide is cleaved in mbetween two minutes after administration at the N-terminus and thereby yielding the biologically inactive fragment GLP-1 ( 9 - 36 amide). When plasma concentrations are measured, like described in this thesis, peptidase inhibitors are used to inhibit degradation.

For practical use of GLP-1 this thesis revealed that weight loss programs should be combined with increased physical activity in order to improve GLP-1 sensitivity, thus contributing to metabolic fitness. Both, activity and weight loss increase sensitivity for GLP-1 release in obese subjects.

Pharmacologically, GLP-1 may be potent as a therapeutic agent in NIDDM and obesity when administered in high doses steady state in order to maintain constantly elevated plasma concentrations. Furthermore suitable modes of administration are needed to prevent early degradation. 


\section{Implications for future research}

This thesis has demonstrated that galactose and guar gum is an effective nutrient combination for endogenous stimulation of GLP-1 release. This nutrient combination is very specific and has been applied through all the experiments in the same dosage.

For therapeutic purpose of enhancing GLP-1 release endagenously in diabetes and obesity it is important to evaluate more nutrients with a low glycaemic index to prevent: hyperglycaemia and still have sufficient GLP-1 release. Otherwise only exogenous GLP-1 application seems useful in this disease area, which is accompanied by diverse shortcomings.

Suitable modes of GLP-1 application need to be evaluated. Since the peptide is inactivated immediately by gastric acid it cannot be ingested orally. A problem with intravenous or subcutaneous injection is the short half mlife time of GLP-1 $(89,90)$. Therefore another approach is to inhibit the degradation of GLP-1 by DPP-IV or Use analogues of the peptide that have extended half-lives (91).

Due to the current state of development of these modes of GLP-1 application it is important to further evaluate the possibilities of endogenous GLP-1 stimulation, not only for treatment, but also for prevention.

More research is needed to investigate the effect of the stimulation of GLP-1 in physiological concentrations to draw finall conclusions on the effect of GLP-1 on satiety. Studies in humans are mostly investigating the effect of exogenously administered supraphysiological doses of GLP-1 $(66,68,69)$. Since it has been shown that the GLP-1 system is related to anxiety and plays a role in stress responses (36), the effect on satiety might be mediated by these circuits rather than being a direct effect. It is not clear yet, whether GLP-1 specifically acts on inhibitory feeding centers in the brain to evoke satiety or rather is a mediator of aversive stimuli (35). Taste aversion has been reported in response to agents that serve visceral illness such as lithium chloride (92) and central as well as pheripheral GLP-1 receptor agonist were found to increase blood pressure and heart rate (35). These models can be described as internal stressors and have been defined as interoceptive stress (93). Interoceptive stress may be mediated by central GLP 1 systems (74).

We have shown a stimulation of GLP-1 release by physical activity. Our study is one of the very few reports on the relationship between physical activity and GLP-1 release. More work needs to be done to elucidate the mechanism for that relationship. Taken together our results and the described possible role for GLP-1 in the mediation of interoceptive stress the question remains, whether GLP-1 release during physical activity is a cause or a consequence in the regulation of sympathetic outflow.

This thesis shows that decreased GLP-1 concentrations after weight loss are transient and rebound after a weight maintenance period. The present results and the results from the literature $(48,52)$ show, that the timepoint of investigation after weight loss seems to play a critical role for the interpretation of the results. Although GLP-1 sensitivity was improved after weight maintenance, future research is needed to clarify 
the decrease in GLP-1 concentrations and the impaired GLP-1 release after a nutrient stimulus after weight loss.

\section{Conclusions}

From the results presented in this thesis and the results from the literature severall conclusions can be drawn.

- In addition to nutrients, physical activity is a suitable way to stimulate GLP-1 release and increase GLP-1 plasma concentrations.

- Results on GLP-1 concentrations need to be analyzed for gender differences, since differences in body fat, fat free mass and related hormones appear to affect GLP-1 concentrations.

- Weight loss decreases GLP-1 concentrations transiently, yet increases the overall sensitivity for GLP-1 release in the longer term

- Basal GLP-1 concentrations are not different between lean and modestly obese subjects, but stimulated GLP-1 release is different depending on the stimulus that is used.

- Weight loss affects the sensitivity for GLP-1 release in modestly obese subjects.

- Pharmacologicall effects of GLP-1, which appear to correlate with satiety and food intake are not always clearly present as physiological effects in humans.

- For increasing GLP-1 release endogenously and therapeutic use, weight loss and activity should be combined. 


\section{References}

1. Gutniak $M$, Ørskov $\left.C_{\text {, Holst }}\right]$ J, Ahren $B$, Efendic $S$. Antidiabetogenic effect of glucagon-like peptide-1 (7-36)amide in normal subjects and patients with diabetes mellitus. N Engl J Med 1992;326:1316-22.

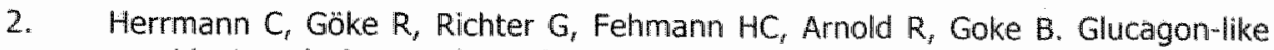
peptide-1 and glucose-dependent insulin-releasing polypeptide plasma levels in response to nutrients. Digestion 1995;56:117-26.

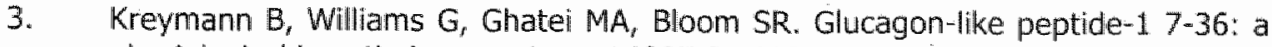
physiological incretin in man. Lancet $1987 ; 2: 1300-4$.

4. Elliott RM, Morgan LM, Tredger JA, Deacon S, Wright J, Marks V. Glucagon-like peptide-1 (7-36)amide and glucose-dependent insulinotropic polypeptide secretion in response to nutrient ingestion in man: acute post-prandial and 24-h secretion patterns. J Endocrinal 1993; 138:159-66.

5. Layer P, Holst J], Grandt D, Goebell H. Ileal release of glucagon-like peptide-1 (GLP-1). Association with inhibition of gastric acid secretion in humans. Dig Dis Sci 1995;40:1074-82.

6. Roberge INN, Brubaker PL. Regulation of intestinal proglucagon-derived peptide secretion by glucose-dependent insulinotropic peptide in a novel enteroendocrine loop. Endocrinology 1993;133:233-40.

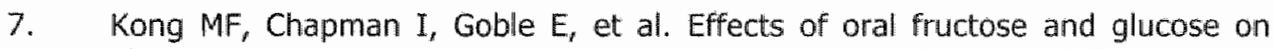
plasma GLP-1 and appetite in normal subjects. Peptides 1999;20:545-51.

8. Kieffer T], Habener JF. The glucagon-like peptides. Endocr Rev 1999;20:876-913.

9. Ercan $N$, Nuttall FQ, Gannon $M C$, Redmon JB, Sheridan KJ. Effects of glucose, galactose, and lactose ingestion on the plasma glucose and insulin response in persons with non-insulin-dependent diabetes melitus. Metabolism 1993;42:1560-7.

10. Ebbeling $C B$, Leidig $M M_{*}$, Sinclair $K B$, Hangen JP, Ludwig DS. A reduced-glycemic load diet in the treatment of adolescent obesity. Arch Pediatr Adolesc Med $2003 ; 157: 773-9$.

11. Ludwig DS. The glycemic index: physiological mechanisms relating to obesity, diabetes, and cardiovascular disease. Jama 2002;287:2414-23.

12. Shima $K$, Suda $T$, Nishimoto $K$, Yoshimoto $S$. Relationship between molecular structures of sugars and their ability to stimulate the release of glucagon-like peptide-1 from canine lieal loops. Acta Endocrinol (Copenh) 1990;123:464-70.

13. Rayner CK, Park HS, Wishart JM, Kong M, Doran SM, Horowitz M. Effects of intraduodenal glucose and fructose on antropyloric motility and appetite in healthy humans. Am I Physiol Regul Integr Comp Physiol 2000;278:R360-6.

14. Vozzo R, Baker B, Wittert GA, et al. Glycemic, hormone, and appetite responses to monosaccharide ingestion in patients with type 2 diabetes. Metabolism 2002; $51: 949-57$.

15. Horowitz $M$, Cunningham $\mathrm{KM}$, Wishart $3 \mathrm{M}$, Jones $\mathrm{KL}$, Read $\mathrm{NW}$. The effect of short-term dietary supplementation with glucose on gastric emptying of glucose and fructose and oral glucose tolerance in normal subjects. Diabetologia $1996 ; 39: 481-6$. 
16. Massimino SP, McBurney MI, Field CJ, et al. Fermentable dietary fiber increases GLP 1 secretion and improves glucose homeostasis despite increased intestinal glucose transport capacity in healthy dogs. I Nutr 1998; 128:1786-93.

17. Reimer RA, McBurney MI. Dietary fiber modulates intestinal proglucagon messenger ribonucleic acid and postprandial secretion of glucagon-like peptide-1 and insulin in rats. Endocrinology $1996 ; 137: 3948-56$.

18. Frost GS, Brynes AE, Dhillo WS, Bloom SR, McBurney MI. The effects of fiber enrichment of pasta and fat content on glastric emptying, GLP-1, glucose, and insulin responses to a meal. Eur J Clin Nutr 2003; 57:293-8.

19. Todd PA, Benfleld P, Goa KL. Guar gum. A review of its pharmacological properties, and use as a dietary adjunct in hypercholesterolaemia. Drugs $1990 ; 39: 917-28$.

20. French SJ, Read NW. Effect of guar gum on hunger and satiety after meals of differing fat content: relationship with gastric emptying. Am I Clin Nutr $1994 ; 59: 87-91$.

21. Anini $Y$, Hansotia $T$, Brubaker $P L$. Muscarinic receptors control postprandial release of glucagon-like peptide-1: in vivo and in vitro studies in rats. Endocrinologr 2002;143:2420-6.

22. Herrmann-Rinke C, Vöge A, Hess M, Göke B. Regulation of glucagon-like peptide1 secretion from rat ileum by neurotransmitters and peptides. I Endocrinol $1995 ; 147: 25-31$.

23. Herrmann-Rinke C, Horsch D, McGregor GP, Göke B. Galanin is a potent inhibitor of glucagon-like peptide-1 secretion from rat ileum. Peptides 1996;17:571-6.

24. Plaisancie $P$, Bernard $C$, Chayvialle JA, Cuber JC. Regulation of glucagon-like peptide-1-(7-36) amide secretion by intestinal neurotransmitters and hormones in the isolated vascularly perfused rat colon. Endocrinology $1994 ; 135: 2398-403$.

25. Adrian TE, Ferri GL, Bacarese-Hamilton AJ, Fuessl HS, Pollak JM, Bloom SR. Human distribution and release of a putative new gut hormone, peptide $Y$. Gastroenterology 1985;89:1070-7.

26. Dumoulin $V$, Dakka $T$, Plaisancie $P$, Chayvialle JA, Cuber JC. Regulation of glucagon-like peptide-1-(7-36) amide, peptide $Y$, and neurotensin secretion by neurotransmitters and gut hormones in the isolated vascularly perfused rat ileum. Endocrinology 1995;136:5182-8.

27. Claustre J, Brechet $S$, Plaisancie P, Chaywialle JA, Cuber JC. Stimulatory effect of beta-adrenergic agonists on ileal $L$ cell secretion and modulation by alphaadrenergic activation. J Endocrinol 1999;162:271-8.

28. Chap $Z$, Okuda $Y$, Pena J, Fleld JB. Beta-adrenergic stimulation contributes to incretin effect in conscious dogs. Am J Physiol 1991;261:E58-65.

29. Giralt $M$, Vergara P. Sympathetic pathways mediate GLP-1 actions in the gastrointestinal tract of the rat. Regur Pept 1998;74:19-25. 
30. O'Connor AM, Jahnston CF, Buchanan KD, Boreham C, Trinick TR, Riddoch CJ. Circulating gastrointestinal hormone changes in marathon running. Int I Sports Med 1995; 16:283-7.

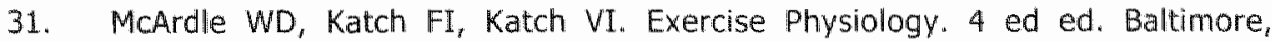
Maryland: Williams \& Wilkins, 1996.

32. Tolessa T, Gutniak M, Holst JJ, Efendic $S_{r}$ Hellström PM. Inhibitory effect of glucagon-like peptide-1 on small bowel motility. Fasting but not fed motility inhibited via nitric oxide independently of insulin end somatostatin. J Cin Invest $1998 ; 102: 764-74$.

33. Drucker DJ. Biological actions and therapeutic potential of the glucagon-like peptides. Gastroenterology $2002 ; 122: 531-44$.

34. Giralt M, vergara P. Glucagonlike peptide-1 (GLP-1) participation in ileal brake induced by intraluminal peptones in rat. Dig Dis SCi 1999;44:322-9.

35. Yamamoto $H$, Lee CE, Marcus $I N$, et all. Glucagon-like peptide-1 receptor stimulation increases blood pressure and heart rate and activates autonomic regulatory neurons. J Clin Invest $2002 ; 110: 43-52$.

36. Kinzig KP, D'Alessio DA, Herman JP, et al. CNS glucagon-like peptide-1 receptors mediate endocrine and anxiety responses to interoceptive and psychogenic stressors. J Neurasci 2003;23:6163-70.

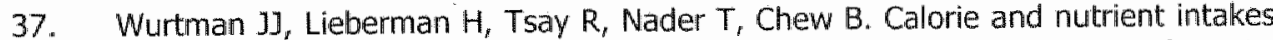
of elderly and young subjects measured under identical conditions. I Gerontol $1.988 ; 43: B 174-80$.

38. Forbes GB, Reina JC. Adult lean body mass declines with age: some longitudinal observations. Metabolism 1970;19:653-63.

39. MacIntosh $\mathrm{CG}_{*}$ Andrews JM, Jones $\mathrm{KL}_{\text {, }}$ et al. Effects of age on concentrations of plasma cholecystokinin, glucagon-like peptide 1 , and peptide $Y Y$ and their relation to appetite and pyloric motility. Am J Clin Nutr 1999;69:999-1006.

40. Ranganath L, Sedgwick I, Morgan L, Wright J, Marks V. The ageing entero-insular axis. Diabetologia 1998;41:1309-13.

41. Fukase $\mathbb{N}$, Igarashi $M$, Takahashi $H$, et al. Hypersecretion of truncated glucagonlike peptide-1 and gastric inhibitory polypeptide in obese patients. Diabet Med $1993 ; 10: 44-9$.

42. Velasquez-Mieyer PA, Cowan PA, Umplerrez GE, Lustig RH, Cashion AK, Burghen GA. Racial differences in glucagon-like peptide-1 (GLP-1) concentrations and insulin dynamics during oral glucose tolerance test in obese subjects. Int $J$ Obes Relat Metab Disord 2003; 27:1359-64.

43. Velasquez-Mieyer PA, Umpierrez GE, Lustig RH, et al. Race affects insulin and GLP-1 secretion and response to a long-acting somatostatin analogue in obese adults. Int 3 Obes Relat Metab Disord 2004:28:330-3.

44. Ranganath LR, Beety JM, Morgan LM, Wright JW, Howland R, Marks V. Attenuated GLP-1 secretion in obesity: cause or consequence? Gut 1996;38:916-9. 
45. Ranganath $L$, Norris $F$, Morgan L, Wright J, Marks $V$. Inhibition of carbohydratemediated glucagon-like peptide-1 (7-36)amide secretion by circulating nonesterified fatty acids. Clin Sci (Lond) $1999 ; 96: 335-42$.

46. Lugari $R_{*}$ Dell'Anna $C_{*}$ Ugolotti $D_{\text {, }}$ et al. Effect of nutrient ingestion on glucagonlike peptide 1 (7-36 amide) secretion in human type 1 and type 2 diabetes. Horm Metab Res 2000;32:424-8.

47. Ranganath $L$, Norris F, Morgan L, Wright J, Marks $V$. The effect of circulating nonesterified fatty acids on the entero-insular axis. Eur J Clin Invest 1999;29:27-32.

48. Näslund $E_{1}$ Gryback $P$, Hellström PM, et al. Gastrointestinal hormones and gastric emptying 20 years after jejunoileal bypass for massive obesity. Int $J$ Obes Relat Metab Disord 1997;21:387-92.

49. Cummings DE, Weigle DS, Frayo RS, et al. Plasma ghrelin levels after dietinduced weight loss or gastric bypass surgery. N Engl J Med 2002;346:1623-30.

50. Cigaina V, Hirschberg AL. Gastric pacing for morbid obesity: plasma levels of gastrointestinal peptides and leptin. Obes Res 2003;11:1456-62,

51. Lugari $R$, Dei Cas A, Ugolotti D, ett al. Glucagon-like peptide 1 (GLP-1) secretion and plasma dipeptidyl peptidase IV (DPP-IV) activity in morbidly obese patients undergoing biliopancreatic diversion. Horm Metab Res 2004; 36:111-5.

52. Verdich C, Toubro S, Buemann B, Lysgard Madsen J, Juul Holst J, Astrup A. The role of postprandial releases of insulin and incretin hormones in meal-induced satiety--effect of obesity and weight reduction. Int 3 Obes Relat Metab Disord 2001:25:1206-14.

53. Damci $T$, Yalin 5 , Balci $H_{\text {, }}$ et al. Orlistat augments postprandial increases in glucagon-like peptide 1 in obese type 2 diabetic patients. Diabetes Care 2004:27:1077-80.

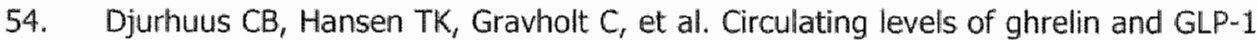
are inversely related during glucose ingestion. Horm Metab Res 2002;34:411-3.

55. Djurhuus CB, Hansen TK, Holst JJ, Schmitz O. Feast or famine - are GLP-1 and ghrelin secretion intertwined? Horm Metab Res 2002;34:353-4.

56. Wortley KE, Anderson KD, Garcia K, et al. Genetic deletion of ghrelin does not decrease food intake but influences metabolic fuel preference. Proc Nat Acad Sci U S A 2004; 101:8227\%32.

57. Fruhbeck $G_{*}$ Diez-Caballero $A_{*}$ Gil $M J$, et al. The decrease in plasma ghrelin concentrations following bariatric surgery depends on the functional integrity of the fundus, Obes Surg 2004;14:606-12.

58. Clegg DJ, Riedy CA, Smith KA, Benoit SC, Woods SC. Differential sensitivity to central leptin and insulin in male and female rats. Diabetes $2003 ; 52: 682-7$.

59. Vaag AA, Holst Jj, Volund A, Beck-Nielsen HB. Gut incretin hormones in identical twins discordant for non-insulin-dependent diabetes mellitus (NIDDM)--evidence for decreased glucagon-like peptide 1 secretion during oral glucose ingestion in NIDDM twins. Eur J Endocrinol 1996;135:425-32. 
60. Friedman JM, Halaas JL. Leptin and the regulation of body weight in mammals. Nature $1998 ; 395: 763-70$.

61. Anini $Y$, Brubaker PL. Role of leptin in the regulation of glucagon-like peptide-1 secretion. Diabetes $2003 ; 52: 252-9$.

62. Scrocchi LA, Hill ME, Saleh $]_{x}$ Perkins $B$, Drucker DJ. Elimimation of glucagon-like peptide IR signaling does not modify weight gain and islet adaptation in mice with combined disruption of leptin and GLP-1 action. Diabetes 2000;49:1552-60.

63. Blundell JE, Lawton CL, Hill AJ. Mechanisms of appetite control and their abnormalities in obese patients. Horm Res 1993;39 Suppl 3:72-6.

64. Neary NM, Goldstone AP, Bloom SR. Appetite regulation: from the gut to the hypothalamus. Clin Endocrinol (Oxf) 2004;60:153-60.

65. Havel PJ. Peripheral signals conveying metabolic information to the brain: shortterm and long-term regulation of food intake and energy homeostasis. Exp Biol Med (Maywood) 2001;226:963-77.

66. Flint A, Raben A, Astrup A, Holst 3]. Glucagon-like peptide 1 promotes satiety and suppresses energy intake in humans. J Clin Invest 1998;101:515-20.

67. Long SJ, Sutton JA, Amaee WB, et al. No effect of glucagon-like peptide-1 on short-term satiety and energy intake in man. Br J Nutr 1999;81:273-9.

68. Gutzwiller JP, Drewe J, Göke B, et al. Glucagon-like peptide-1 promotes satiety and reduces food intake in patients with diabetes mellitus type 2. Am I Physiol $1999 ; 276: \mathrm{R} 1541-4$.

69. Näslund $E$, Barkeling $B$, King $N$, et al. Energy intake and appetite are suppressed by glucagon-like peptide-1 (GLP-1) in obese men. Int $J$ Obes Relat Metab Disord 1999:23:304-11.

70. Näslund E, Gutniak M, Skogar S, Rössner S, Hellström PMi. Glucagon-like peptide 1 increases the period of postprandial satiety and slows gastric emptying in obese men. Am J Clin Nutr 1998;68:525-30.

71. Ritzel R, Orskov C, Holst 1], Nauck MA. Pharmacokinetic, insulinotropic, and glucagonostatic properties of GLP-1 [7-36 amide] after subcutaneous injection in healthy volunteers. Dose-response-relationships. Diabetologia 1995;38;720-5.

72. Thiele TE, Seeley $R]_{*}$ DAlessio $D$, et al. Central infusion of glucagon-like peptide1-(7-36) amide (GLP-1) receptor antagonist attenuates lithium chloride-induced c-Fos induction in rat brainstem. Brain Res 1998;801:164-70.

73. Thiele TE, Van Dijk $G$, Campfield $L A$, et al. Central infusion of GLP-1, but not leptin, produces conditioned taste aversions in rats. Am J Physiol 1997;272:R726-30.

74. Rinaman L. Interoceptive stress activates glucagon-like peptide-1 neurons that project to the hypothalamus. Am J Physiol 1999;277:R582-90.

75. Kissileff HR, Pi-Sunyer FX, Thornton J, Smith GP. C-terminal octapeptide of cholecystokinin decreases food intake in man. Am J Clin Nutr 1981;34:154-60.

76. Schick RR, Schusdziarra V. Mossner J, et al. Effect of CCK on food intake in man: physiological or pharmacological effect? Z Gastroenterol 1991;29:53-8. 
77. Baldwin BA, Parrott RF, Ebenezer IS. Food for thought: a critique on the hypothesis that endogenous cholecystokinin acts as a physiological satiety factor. Prog Neurobiol $1998 ; 55: 477-507$.

78. Tang-Christensen M, Larsen PJ, Goke $R$, et al. Central administration of GLP-1-(736) amide imhibits food and water intake in rats. Am J Physiol 1996;271:R848-56.

79. Defronzo RA. Lilly lecture 1987. The triumvirate: beta-cell, muscle, liver. A collusion responsible for NIDDM. Diabetes 1988;37:667-87.

80. Nauck $M A_{\text {, }}$ Bartels $E_{f}$ Orskov $C$, Ebert $R$, Creutzeldt $W$. Additive insulinotropic effects of exogenous synthetic human gastric inhibitory polypeptide and glucagonlike peptide-1-(7-36) amide infused at near-physiological insulinotropic hormone and glucose concentrations. J Clin Endocrinol Metab 1993;76:912-7.

81. Vilsboll $T$, Kranup $T$, Madsbad 5 , Holst J]. No reactive hypoglycaemia in Type 2 diabetic patients after subcutaneous administration of GLP-1 and intravenous glucose. Diabet Med 2001;18:144-9.

82. Lavin JH, Read NW. The effect on hunger and satiety of slowing the absorption of glucose: relationship with gastric emptying and postprandial blood glucose and insulin responses. Appetite 1995;25:89-96.

83. Turton $M D$, O'Shea D, Gunn I, et al. A role for glucagon-like peptide-1 in the central regulation of feeding. Nature 1996;379:69-72.

84. Meier 1], Gallwitz B, Schmidt WE, Nauck MA. Gucagon-like peptide 1 as a regulator of food intake and body weight: therapeutic perspectives. Eur I Pharmacol 2002;440:269-79.

85. Flint A, Raben A, Ersboll AK, Holst J], Astrup A. The effect of physiological levels of glucagon-like peptide-1 an appetite, gastric emptying, energy and substrate metabolism in obesity. Int J Obes Relat Metab Disord 2001;25:781-92.

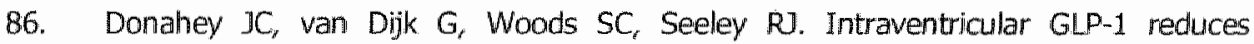
short-but not long-term food intake or body weight in lean and obese rats. Brain Res 1998;779:75-83.

87. Meeran $K_{r}$ O'Shea $D$, Edwards $C M$, et al. Repeated intracerebroventricular administration of glucagon-like peptide-1-(7-36) amide or exendin-(9-39) alters body weight in the rat. Endocrinology 1999; 140:244-50.

88. Nauck MA, Wollschlager $D$, Werner $J$, et al. Effects of subcutaneous glucagon-like peptide 1 (GLP-1 [7-36 amide]) in patients with NIDDM. Diabetologia $1996 ; 39: 1546-53$.

89. Deacon CF, Nauck MA, Toft-Nielsen M, Pridal $L$, Willms B, Holst J]. Both subcutaneously and intravenously administered glucagon-like peptide $I$ are rapidy degraded from the NH2-terminus in type II diabetic patients and in healthy subjects. Diabetes $1995 ; 44: 1126-31$.

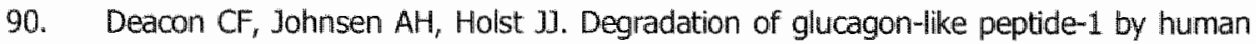
plasma in vitro yields an $\mathrm{N}$-terminally truncated peptide that is a major endogenous metabolite in vivo. I Clin Endocrinol Metab 1995;80:952-7. 
91. Edwards CM, Stanley SA, Davis R, et al. Exendin-4 reduces fasting and postprandial glucose and decreases energy intake in healthy volunteers. Am J Physiol Endocrinol Metab 2001;281:E155-61.

92. Seeley RJ, Blake $K_{r}$ Rushing PA, et al. The role of CNS glucagon-like peptide-1 (736) amide receptors in mediating the visceral illness effects of lithium chloride $]$ Neurosci 2000;20:1616-21.

93. Sawchenko $\mathrm{PE}, \mathrm{Li} H \mathrm{H}$, Ericsson A. Circuits and mechanisms governing hypothalamic responses to stress: a tale of two paradigms. Prog Brain Res 2000;122:61-78. 



\section{Summary}

During the last decades the prevalence of obesity dramatically increased. Weight gain occurs when energy intake is increased or energy expenditure is decreased. Acute and long-term food intake and energy balance are regulated through distinct, but interacting mechanisms, such as neural and hormonal signals. Hormonal signals are for example gastrointestinal hormones that are released by the intestinal L cells, like peptide $Y Y$ 3-36 or glucagon-like peptide 1 (GLP-1) that are released in response to mutrient sensing in the intestine. Those hormones have peripheral as well as central effects in areas that are supposed to be involved in the sensation of hunger and satiety. Via such actions the hormones mentioned are expected to play a role in both the frequency and amount of energy intake. For a hormone like GLP-1, that is believed to be irvolved in the regulation of hunger and satiety it has been suggested that basal concentrations as well as the release in response to a meal are decreased in overweight and obese subjects compared to normall-weight subjects. This has been considered a cause for the development of obesity. However, most of the work showing clear relationships between these gastrointestinal hormones and satiety were executed with exogenous hormone application in supraphysiological doses. The research described in this thesis focused on one gastrointestinal peptide in particular, namely GLP-1.

One approach for the therapeutic us of GLP-1 is to enhance its endogenous release, in order to avolid compliance issues that are related to the necessary injections of peptide hormones. Therefore different ways to stimulate GLP-1 release endogenously in normalweight as well as in overweight and obese subjects were investigated as well as the effect of gender on these findings. Furthermore, the effects of weight loss and weight maintenance on GLP-1 release were explored. In addition it was investigated whether endogenously stimulated GLP-1 release affects satiety sensations in subjects with different weight status.

GLP- 1 is believed to play a role in the regulation of food intake and satiety, but also functions as an incretin. Incretins stimulate insulin release and improve glucose tolerance and thereby GLP-1 presently is discussed as a target peptide for the treatment of type II diabetes. With regard to nutrients, carbohydrates, especially glucose, was shown to stimulate GLP-1. With respect to the role of GLP-1 for diabetes and obesity another carbohydrate than glucose, i.e. galactose and the ability to stimulate GLP-1. release has been tested in the present thesis. Soluble viscous fiber (modified guar gum) is believed to increase the contact of carbohydrates with receptors in the small intestine. Therefore a study was performed where galactose in combination with guar gum was tested as a potential stimulus for GLP-1 release.

In combination with guar gum galactose stimulated GLP-1 release in a manner similar to glucose in combination with guar gum. All tested nutrient combinations showed a relationship between GLP-1 release and satiety after 30 and 120 minutes of ingestion. After finding the combination of galactose and guar gum effective in stimulating GLP-1, the mixture was combined with a standard breakfast. The effect of the galactose with 
guar gum and breakfast combination was significantly more effective in stimulating GLP1 release than breakfast alone. The effect on GLP-1 release has been analyzed for men and women separately. Body fat was the most discriminative variable between men and women in the experiment and was significantly related to GLP-1 release in women. Since leptin is an adiposity signal that is secreted in direct proportion to the amount of body fat stored in the adipocytes and since in animal as well as in human studies leptin was shown to stimulate GLP-1 release, leptin may be a possible explanation for the gender related difference in GLP-1 release. Furthermore the increase in satiety was related to the increase in GLP-1 release at 60 and 90 minutes after ingestion, independent of gender and only present when the breakfast was combined with water instead of galactose and guar gum.

GLP-1 receptor stimulation also has been showin to play a role in the physiological adaption to a stressor by increasing blood pressure and heart rate. As an alternative to nutrients GLP-1 release was stimulated with physical activity as a physiological stressor. Most of the work investigating the effect of stress, activity and the nervous system on GLP-1. release has been done in animals and cell lines. In this thesis it is shown that physical activity stimulates GLP-1 release in lean subjects and in overweight and obese subjects, yet only after modest weight lloss suggesting a role of body weight for GLP-1 sensitivity.

Since weight status seemed to be important for GLP-1 release, the role of body weight was further investigated. Comparing a normal-weight group with an overweight and obese group concerning their GLP-1 release after a nutrient trigger, it was observed that: weight status did not affect GLP-1 release after the galactose with guar gum and breakfast combination. When breakfast was combined with water instead of the galactose and guar gum mixture, the overweiglit and obese group had significantly lower GLP-1 release compared to the normal-weight group, indicating that stimulated GLP-1 release is different for different weight categories depending on the stimulus that is used for triggering the release of the peptide. To further cllarify the impact of weight status on GLP-1 release a weight loss experiment with a subsequent weight maintenance period was executed. Since GLP-1 release has been suggested to gradually improve with weight loss and was indeed increased after modest weight loss in the experiment with physical activity, a six-week very-low-energy diet (VLED) was applied to a group of obese subjects. Unexpectedly, GLP-1 release initially was decreased after substantial weight loss and was not triggered anymore by the galactose with guar gum and breakfast combination. However, after a subsequent weight maintenance period of three months, GLP-1 release rebounded to a level comparable to before weight loss. Satiety ratings were not related to GLP-1 release in these subjects neither before weight loss, nor after weight loss or weight maintenance.

In conclusion, it was found that a galactose with guar gum mixture alone, as well as in combination with a standard breakfast was effective in stimulating GLP-1 release in lean and obese subjects. In lean subjects, replacement of the galactose with guar gum mixture by water in combination with the same breakfast showed significantly increased GLP-1 release compared to obese subjects, indicating a slightly lower sensitivity for 
GLP-1 release in the obese, depending on the nutrient challenge that is used. However, the stimulus-related difference in GLP-1 release in the obese was not mirrored in their subjective satiety sensations. That leads to the suggestion that a disturbance of appropriate perception of the satiety feedback rather than a disturbed feedback itself might contribute to obesicy.

In addition to the nutrient combination physical activity was found to be a GLP-1 stimulus as well, yet depending on the weight status of the subjects, leading to the conclusion that attenuated GLP-1 release in the obese may be reversible and might be rather an effect than a cause of obesity. However, in the presence of a negative energy balance, after significant weight loss, GLP-1 release was blunted and decreased compared to before weight loss. The rebound of GLP-1 release to a llevel similar to before weight loss after a subsequent weight maintenance period though leads to the conclusion that the effects of our weight loss experiment on GLP-1 release are transient. 


\section{Samenvatting}




\section{Samenvatting}

De prevalentie van overgewicht en obesitas is in de Westerse welvaartsmaatschappij de latste decennia drastisch gestegen. Gewichtstoename is het resultaat van een positieve energlebalans, weroorzaakt door een verhoogde energie-inname en/of een verlaagd energiegebruik.

Neurale en hormonale signalen reguleren de energiebalans, en met name de energieinname op korte en lange termijn. Hormonale signalen zijn bijwoorbeeld gastrointestinale hormonen, zoals peptide YY3-36 (PYY3-36), en glucagon-like peptide 1 (GLP1) die afgegeven worden door intestinale L-cellen. Deze hormonen worden in de dunne darm vrijgemaakt wanneer daar nutriënten aanwezig zijn. Genoemde hormonen hebben zowel perifere als centrale effecten die betrokken blijken te zijn bij de signalering van honger en verzadiging. Alszodanig dragen deze hormonen bij aan de maaltijd-frequentie en de totale energie-inname. Voor GLP-1 is er enige evidentie dat niet alleen de basale concentratie, maar ook de afgifte na een maaltijd verlaagd is bij overgewichtige/obese ten opzichte van normaal-gewichtige individuen. Op deze manier zou het een rol kunnen spelen bij het ontstaan van obesitas. De relatie tussen deze hormonen en verzadiging is echter alleen aangetoond bij studies die met een exogene toediening van hormonen in supra-fysiologische doseringen gewerkt hebben.

Het onderzoek beschreven in dit proefschrift richt zich op een gastro-intestinaal peptide in het bijzonder, namelijk GLP-1. Om complicaties, die aan de exogene toediening van GLP-1 zijn gekoppeld te voorkomen, dient ten behoeve wan mogelijk therapeutisch gebruik, de GLP-1 afgifte endogeen gestimuleerd te worden. Verschillende mogelijkheden om de GLP-1 afgifte in normaal-gewichtige en obese individuen endogeen te stimuleren zijn onderzocht, evenals het mogelijke effect van geslachtsverschil hierop en het effect van gewichtsverlies en gewichtsbehoud. Tevens werd de relatie tussen GLP-1 afgifte en verzadiging bij proefpersonen met een verschillend uitgangsgewicht onderzocht.

GLP-1 zou niet alleen een rol spelen bij de regulatie van de voedsel-inname en werzadiging, maar wordt ook geacht te functioneren als 'incretine'. Incretinen zijn hormonen die de insuline afgifte op een glucose afhankejike manier stimuleren en de glucose tolerantie verbeteren. Daarom staat GLP-1 tegenwoordig ook in de belangstelling als een target peptide voor de behandeling van type II diabetes.

Voor nutriënten is aangetoond dat koolhydraten, met name glucose, de GLP-1 afgifte stimuleren. Gezien de rol van GLP-1 afgifte bij obesitas en diabetes werd in dit proefschrift tevens een ander koolhydrate dan glucose op het vermogen om de GLP-1 afgifte te bevorderen onderzocht, te weten gallactose.

Van oplosbare, visceuze woedingsvezels zoals guar gum wordt verondersteld dat ze het contact van koolhydraten met receptoren in de dunne darm verlengen. Om die reden is in de beschreven experimenten galactose met guar gum gecombineerd als potentiele stimulus woor GLP-1 afgifte. In het eerste experiment bleek de combinatie van guar gum en galactose de GLP-1 afgifte op een vergelijkbare manier te stimuleren als glucose in 
combinatie met guar gum. Alle nutriënten die in dit experiment werden getest toonden een relatje van GLP-1 afgifte met verzadiging op 30 en 120 minuten na inname van het drankje.

Nadat de combinatie van galactose en guar gum als effectief voor de stimulering van de GLP-1 afgifte was vastgesteld, werd deze gecombineerd met een standaard ontbijt. De combinatie van galactose en guar gum met een ontbijt leidde tot een significant hogere GLP-1 afgifte dan het ontbijt in combinatie met water. Wit de analyse van het effect van galactose en guar gum met ontbijt op GLP-1 afgifte apart voor mannen en vrouwen bleek dat vrouwen significant hogere GLP-1 afgiften als reactie op de voedselinname lieten zien dan mannen. Lichaamsvet was de meest bepalende parameter voor het verschil tussen mannen en vrouwen en bleek bij vrouwen significant gerelateerd te zijn aan de toename in GLP-1 afgifte.

In dit werband is het hormoon leptine relevant, dat geproduceerd wordt in relatie tot de hoeveelheid lichaamswet. Hiervan is al eerder aangetoond dat het de GLP-1 afgifte stimuleert. Het effect van leptine zou dus een verklaring voor het geslachts-gerelateerde verschil in GLP-1 afgifte kunnen zijn. Tevens werd in dit experiment een verband gevonden tussen de GLP-1-afgifte en verzadiging op 60 en 90 minuten na de maaltijd. Dit effect was onafhankelijk van geslacht aamwezig wanneer het ontbijt met water werd gecombineerd.

GLP-1 receptor stimulatie wordt werondersteld een rol te spelen in de fysiologische aanpassing aan stress, met name door verhoging van de bloeddruk en de hartslag. Als alternatief voor nutriënten werd GLP-1 afgifte onderzocht na stimulatie met een fysiologische stressor, te weten fysieke activiteit. De meeste experimenten die effecten van stress, activiteit en het zenuwstelsel op GLP-1 onderzoeken, hebben dit in cel-ijnen of dier-experimenten gedaan. In dit proefschrift werd aangetoond dat fysieke activiteit de GLP-1 afgifte in normaal-gewichtige en in overgewichtige/obese individuen na een bescheiden gewichtswerlies bevordert. Dit is een indicatie dat lichaamsgewicht een rol speelt bij GLP-1 gevoeligheid.

Omdat gewichtsstatus een rol blijkt te spelen bij de GLP-1 afgifte is het onderzoek in dit proefschrift tevens op de rol van lichaamsgewicht gericht. Uit vergelijking van de GLP-1 afgifte bij de overgewichtige/obese groep met die van de normaal-gewichtige groep, bleek dat er geen verschil was bij een sterke trigger zoals galactose met guar gum in combinatie met een ontbijt, maar wel bij een normale trigger, zoals wanneer het ontbijt met water gecombineerd werd. De overgewichtige groep had dan een lagere GLP-1 afgifte. Dit leidt tot de conclusie, dat gewichtsstatus belangrijk is in relatie tot de trigger die ter stimulatie van de peptide gebruikt wordt.

Om de invloed van gewichtsstatus op GLP-1 verder te verhelderen, is een experiment met gewichtsverlies en een aansluitende gewichtsbehoud fase uitgevoerd. Er wordt verondersteld dat GLP-1 afgifte gradueel verbetert tijdens gewichtsverlies wat inderdaad ook bleek uit het beschreven experiment met fysieke activiteit.

Een zeer laag energetisch dieet werd gedurende zes weken aan de proefpersonen aangeboden, om gewichtsverlies te induceren. Onverwacht bleek de GLP-1 afgifte na gewichtverlies gedaald te zijn en bleek deze ook niet meer door de combinatie wan 
galactose, guar gum en ontbijt gestimuleerd te kunnen worden. Na een daarop volgende gewichtsbehoud fase wan drie maanden waren de GLP-1 concentraties terug op een niveau vergelijkbaar met de uitgangswaarden van voor het gewichtsverlies, terwijl de proefpersonen niet significant waren aangekomen. Verzadiging en GLP-1 afgifte waren zowel voor gewichtsverlies, na gewichtsverlies of na gewichtsbehoud in deze groep niet gerelateerd.

Concluderend kan gesteld worden dat galactose met guar gum alleen zowel als in combinatie met een ontbijt effectief was in het stimuleren van de GLP-1 afgifte in normaal-gewichtige, in overgewichtige en obese individuen.

Normalal-gewichtige individuen gaven echter een significant verhoogde GLP-1 afgifte ten opzichte van de overgewichtige en obese individuen te zien wanneer enkel een ontbijt met water werd aangeboden. Dit kan als een indicatie gezien worden voor een verlaagde gevoeligheid voor GLP-1 afgifte in overgewichtige en obese individuen, afhankelik van de trigger die gebruikt is. Het stimullus- afhankelijke verschil in GLP-1. afgifte bij de overgewichtigen en obesen werd niet weerspiegeld in subjectieve verzadigingsgevoelens. Dit leidde tot de conclusie dat een verstoorde perceptie van de fysiologische feedback van verzadiging meer bijdraagt aan het ontstaan van obesitas, dan een verstoorde fysiologische feedback zelf.

Naast de werkzame nutriënten combinatie die in dit proefschrift voor het stimuleren van GLP-1. vastgesteld is, is ook fysieke activiteit een effectieve manier voor thet stimuleren wan GLP.1 gebleken. Omdat dit afhankelijk was van gewichtsstatus kan worden geconcludeerd dat verlaagde GLP-1 afgifte in overgewichtige en obese individuen reversibel zou kunnen zijn en eerder een gevolg dan een oorzaak van overgewicht en obesitas is.

Dit was echter niet van toepassing op een toestand van negatieve energie balans, omdat: de GLP-1 afgifte na gewichtswerlies significant werlaagd was ten opzichte van voor het gewichtsverlies en ook door de effectieve nutrienntencombinatie niet meer stimulieerbaar bleek te zijn. Na een gewichtbehoud fase was de GLP-1 afgifte weer vergellikbaar met de afgifte van voor het gewichtsverlies, wat tot de conclusie leidt dat het effect van gewichtsverlies op GLP-1 afgifte en concentraties van voorbijgaande aard is. 


\section{Zusammenfassung}




\section{Zusammenfassung}

Während der letzten Jahrzehnte hat die Prävalenz der Adipositas dramatisch zugenommen. Gewichtszunahme kann zum einen Resultat übermäBiger Energiezufuhr und/oder zum anderen unzureichenden Energieverbrauchs sein. Die akute, aber auch die Energieaufnahme über einen längeren Zeitraum, sowie die Energiebalance sind durch werschiedene Mechanismen geregelt, die in ständiger Interaktion miteinander stehen. Zu diesen Mechanismen gehören zum Beisplel neurale und endokrinologische Signale, die Informationen über Hunger und Sättigung vermitteln. Zu den endokrinogischen Signalen gehören unter anderen Hormone, sowie Peptide YY 3-36 ader Glucagon-like Peptide 1 (GLP-1), die von sogenannten L-Zellen im Dünndarm abgegeben werden, sobald dieser mit Nährstoffen in Berührung kommt. Diese Hormone haben sowohl periphäre als auch zentrale Effekte. Die zentralen Effekte können lokalisiert werden in Gerhimarealen, von denen bekannt ist, das sie in die Regulation von Hunger und Sättigung involviert sind. Von GLP-1 nimmt man an, daß sowohl basale Konzentrationen wie auch die Abgabe nach einer Mahlzeit, bei übergewichtigen und adipösen Menschen niedriger sind als bei normalgewichtigen Personen. Dies wird spekulativ als eine mögliche Ursache für die Enstehung von Übergewicht diskutiert.

GLP-1. wird gesehen als einer der Hormone, die subjektiv Sättigung vermitteln "Bisher haben Studien, die eine deutliche Beziehung zwischen gastrointestinalen Hormonen und Sättigung nachweisen konnten jedoch leider vorwiegend mit exogener Hormonapplikation in supra-physiologischer Dosierung operiert. Die Studien, die in dieser Arbeit beschrieben sind, konzentrieren sich auf die endogene Stimulation eines Hormones, nämlich GLP-1 in normal- und übergewichtien Versuchspersonen. Der Versuch der endogenen Stimulation won Peptidhormonen ist besonders interessant, durch 'Compliance'-Probleme, die für den Patieten mit deir Injektionen von Peptidhormonen verbunden sind. Im weiteren Verlauf wurde untersucht, ob Geschlechtsunterschiede bestehen hinsichtlich der Abgabe von GLP-1 und welchen Einfluß Gewichtsabnahme, sowie eine anschlieBende Gewichtsstabilisationsphase auf GLP-1 Spiegel haben. In allen Experimenten wurde ausserdem untersucht, ob GLP-1 in Bezlehung mit dem subjektiven Erleben von Sättigung steht und wenn ja, wie dies möglicherweise durch Gewichtsstatus beeinflußt ist. Neben einer Funktion in der Regulation von Hunger und Sättigung wird GLP-1 auch eine Rolle als Incretin zugesprochen. Incretine stimulieren die Insulinabgabe und verbessern die Glukosetoleranz, Darum wird GLP-1 augenblicklich auch als ein Target Peptid für die Behandlung von Typ 2 Diabetes diskutiert und untersucht.

Es konnte bereits gezeigt werden daB Kohlenhydrate, besonders Glukose, besonders potente GLP-1 Stirnulatoren sind. Entsprechend der Rolle die GLP-1 für die Behandlung von Diabetes und Übergewicht potentiell spielen kann, erscheint es nötig andere Kohlehydrate, mit niedrigerem glycămischen Index in ihrem Potential für die Stimulation der GLP-1 Abgabe zu testen. Im Besonderen setzen sich die hier beschriebenen Studien mit dem Effect won Galaktose auf die GLP-1 Abgabe auseinander. Galaktose wurde dabei 
kombiniert mit Guar Gum, einem Ballaststoff, von dem man annimmt, daB er zu einem verlängerten Kontakt von Kohlehydraten mit Rezeptoren des Dünndarmes beitrầgt und so zu einer vermehrten Abgabe gastrointestinaler Hormone füht. In Kombination mit Guar Gum stimulierte Galaktose GLP-1 in ähnlichen Konzentrationen wie Glukose in Kombination mit Guar Gum. Unabhängig von der getesteten Nährstoffkombination konnte eine Beziehung zwischen GLP-1 und Sättigung 30 und 120 Minuten nach Nahrungsaufnahme gefunden werden.

Nachdem die Kombination von Galaktose und Guar Gum sich als effektiv herausgestellt hatten, wurde diese Mixtur mit einem Standard-Frühstück kombiniert. Die Supplementierung des Frühstücks durch die Mixtur führte zu einer Verbesserung der GLP-1 Abgabe, die größer war, als aufgrund der zusätzlich aufgenommenen Energie erwartet worden war. Dies ergab sich aus einem Vergleich mit dem Effekt des Frühstüicks in Kombination mit Wasser anstelle der Galaktose - Guar Gum Mixtur. Anschließend wurden die Ergebnisse getrennt für Männer und Frauen analyslert. Die Ergebnisse zeigten, daB beinahe ausschließlich die Frauen zu dern Effekt der Mahlzeit in Kombination mit Galaktose und Guar Gum auf die GLP-1 Abgabe beitrugen, verglichen mit der Kombination des Frühstücks mit Wasser. Körperfett war die am stärksten diskriminierende Variable zwischen den Männern und Frauen des Experiments und signifikant korreliert mit der GLP-1 Abgabe für die Frauen. Leptin ist ein Hormon, das in direkter Proportion zum Körperfett, das in den Adipozyten gespeichert ist, abgegeben wird. Durch Tier- und Humanexperimente ist nachgewiesen, daß Leptin die Abgabe von GLP-1 stimuliert. Diese Ergebnisse machen die unterschiedlichen Leptinkonzentrationen von Männern und Frauen zu einem potentiellen Erklärungsansatz für geschlechtsspezifisch Unterschiede in der GLP-1 Abgabe.

Eine Beziehung zwischen GLP-1 und Sättigung konnte 60 und 90 Minuten nach Nahrungsaufnalhme gefunden werden. Dieser war jedoch geschlechtsunabhängig und nur present, wenn des Frühstück mit Wasser kombiniert war, nicht nach Supplementation mit Galaktose und Guar Gum.

GLP-1 Rezeptor Stimulation spielt eine Rolle bei der physiologischen Anpassung and einen Stressor, durch Blutdruck und Herzrate zu erhöhen. Alternativ zu den Nährstoffen, die in den beschrieben Experimenten getested wurden, wurde ausserdem Aktivität als ein pysiologischer Stressor angewendet und in seinem Potential für die GLP- 1 Stimulation untersucht. Arbeiten, die bisher den Zusammenhang von StreB, Nervensystem und GLP-1 dokumentiert haben, wurden in tiertexperimentellen- oder Zellstudien durchgefuhrt. Die hier beschriebene Studie zeigt, daß die GLP-1 Abgabe durch Aktivität stimuliert wird. Dieser Effekt war jedoch Gewichts-Status abhängig und konnte in schlanken Versuchspersonen, aber auch in übergewichtigen Versuchspersonen, jedoch nur nach mäßiger Gewichtsreduktion, gefunden werden. Diese Ergebnis suggeriert eine Rolle von Gewicht und Gewichts-Status fü GLP-1 Sensitivität. In den folgenden Experimenten wurde darum diese Rolle weiter untersucht. Der Vergleich einer normalgewichtigen Gruppe mit einer überewictigen Gruppe ergab keinen Unterschied, weder in basalen noch in stimulienten GLP-1 Konzentrationen zwischen diesen beiden Gruppen, wenn das Standard Frühstück in Kombimation mit 
Galaktose und Guar Gum konsumiert wurde. Ein signifikanter Unterschied zwischen den Gruppen konnte jedoch festgestellt werden, wenn Galaktose und Guar Gum durch Wasser ersetzt wurden.

Dieses Ergebnis zeigt, daB Gewichtsstatus möglicherweise nur in Abhängigkeit vom trigger, der verwendet wird, eine Rolle spielt. Um den Einfluß von Gewichtsstatus weiter zu kären wurde im Folgenden ein Gewichtsreduktionsexperiment durchgefuhrt mit eimer anschließenden Gewichtsstabilisationsphase. Da andere Arbeiten bereits eine graduelle Verbesserung der GLP-1 Abgabe mit zunehmender Gewichtsabnahme suggerierten, waren unsere Ergebnisse uberraschend in dem Sinne, daB nach Gewichtsreduktion die GLP-1 Abgabe nicht nur niedriger war als vor der Gewichtsreduktion, sondern auch nicht mehr stimullierbar durch die bewährte Nährstffkombination. Nach einer anschlieBenden Gewichtsstabilisationsphase jedoch waren GLP-1 Konzentrationen ähnlich den Ausgangswerten vor Gewichtsreduktion, obwohl die untersuchte Gruppe nicht signifikant an Gewicht zugenommen hatte. Ein Hinweis auf eine verbesserte GLP-1 Sensitivität.

Zusammenfassend kann festgehalten werden, daß Galaktose in Verbindung mit Guar Gum, sowie kombiniert mit einem Standard Frühstück die GLP-1 Abgabe in schlanken, aber auch in übergewichtigen Versuchspersonen effizient stimuliert. Ein Unteschied zwischen den beiden Gruppen mit unterschiedlichem Gewichts-Status wurde nur gefunden, wenn Galaktose und Guar Gum durch Wasser ersetzt wurden. Ein Ergebnis, das, abhängig vom Trigger, auf eine leicht erniedrigte GLP-1 Sensitivität bei Übergewichtigen hindeutet. Der Stimulus-abhängige Unterschied in der GLP-1 Abgabe bei den beiden untersuchten Gruppen konnte nicht zurückgefunden worden in der subjektiven Sättigung. Dieses Ergebnis weist darauf hin, daß möglicherweise nicht das physiologische feedback, sondern die Perzeption dieses Feedbacks verstört ist in der Gruppe der LIbergewichtigen, was einen Beitrag zu der Entstehung von Adipositas beitragen könnte. Neben einer effizienten Nährstoffkombination wurde auch Aktivität als effizient fur die GLP-1 Stimulation gefunden. Dies war jedoch abhängig won GewichtsStatus, was zu der Schlubfolgerung führit, das das emiedrigte GLP-1 Niveau bel Adipösen rewersibel ist und eher ein Effekt als eine Ursache der Adipositas darstellt.

In eienem Zustand der negativen Energiebalnce haben sich GLP-1 Konzentrationen als ermiedrigt und nicht mehr stimulierbar herausgestellt. Ein Befund der sich jedoch als vorübergehend herausgestallt hat nach Gewichtsstabilisation. 
Dankwoord 


\section{Dankwoord}

"If adventures do not befall a young lady in her own village she must seek them abroad" (Jane Austen)

I thought the Netherlands would be a good place for that. When I started my Ph.D. period in Maastricht, I started out in 'English' and so I will complete that "adventure' in the same language as I started it, in "English".

Margriet, you are the one I want to express my thanks to first. You took the "risk' of hiring a psychologist for one of your most biological' projects, not only a psychalogist but also from Germany. You had trust in me and supported me so much, not only in work related ways, but also when my car was torn apart, my floor was ruined and I remember the wonderful dinners you fixed (potatoes just like at home) and the many invitations. Thank you and I hope I could give you something in return.

Klaas, in addition to being involved in the invitations mentioned above I want to thank you for sharpening my view on scientific language as my promotor and writing scientific papers instead of novels. It certainly contributed significantly to shaping the scientific parts of my personality.

Tjerk, thank you for contributing by reading and correcting my manuscripts and making important suggestions that helped the publishing process.

I am thankful to Prof. Dr. R. Mensink, Prof. Dr. W. Langhans, Prof. Dr. P. v. d. Brandt, Prof. Dr. A. Scheurink and Prof. Dr. M. v. Meyenfeldt for their time and effort to critically evaluate this thesis. Wolfgang, dir besonderen Dank für deine Unterstützung über die Jahre.

Manuela and Neeltje, I want to thank you for all the help, not only work related, and support over the last four years. Manuela, with you I certainly had the perfect roommate at work but also at meetings. You never asked where I came from, when I was home and still had a rose for me on my pillow. I am glad I still have the songs we sang on a CD. And if I sometimes had doubts about how to continue, I can say 'mensen als jullie, daar doe je het soms voor".

Lydia en Nathalle, thanks for being my friends and 'running mates'. The talks we had helped to clear my mind and finding new motivation. Together with Marieke, we had many "dinners" helpful in putting things into perspective. Lydia, what would I have done without you sharing the experience of weird phone calls at certain times, ending up on rolls when long distance relationships seem the most stupid thing a person can have and the advice that it's sometimes just better to call each other instead of bothering others.

Annemiek, Astrid, Diane, Freddy, Guy, Kristel, Marieke and Mirjam completing the 'third floor club". With you and our coffee rounds the days always began well. You always had an open ear, when things didn't work out the way they should and after a walk to our kitchen the world always looked a little brighter than before. Even if it only was that Guy hit the cup with a piece of sugar again. 
Joan and Jos, thanks for all the work (all the endless analyses) and help I had from you, not only workwise. Your opinions and our conversations always were a helpful connection to "the real world" and you made the long and early hours easier. Jos, I still didn't manage to find a german wife for you, but I keeplooking. Ik ben blij, dat ik het "he duitser' op de gang nog een tijdje mag meemaken.

Claudia, Larissa and Ilona, without you things would not run as smoothly as they do. Thanks for all the work you did and claudia special thanks for sharing a little 'mindtravelling' once in a while. That felt as refreshing as being on a real vacation.

Loek and Paul, thank you both for solwing all the 'emergencies' so unconventionally and quick. This is a chance to say that you were not only appreciated when problems had to be solved, although it sometimes must look like that for you.

Joost "du siehst aber auch wieder echt gut aus" and Freddy, thank you for helping a lot with this thesis. Kathleen, thank you all the corrections and and comments on almost all my manuscript.

Marco, thank you for helping me with my first steps in a foreign country. Annemarie and Marieke (I think of you whenever $\mathbb{I}$ listen to my $\mathrm{CD}$ 'introduction to the dutch music' and still appreciate that you 'forced" me to watch the Andre Hazes video. One cannot live in the Netherlands without the "mentality basics' you and Marieke taught me). Antoine (je zult een geweldige papa worden), Arienne, Berber, Chantal, Edwin, Ellen, Elke, Eva, Gijs, Hanneke, Ilse (thanks for the duets you sang with me), Jochum, Johan, Joris, Kaatje, Kristof, Luc, Mandy, Marja, Marleen and Marleen, Myriam, Nils, Patrick, Ping, Ralph, Reinout, Rene, Roy, Stefan, Ward and Wouter, thank you all for your help, collaboration and making work days good days. Michiel, thank you for telling me what is important once in a while.

Petra and Gabby, thank you for sharing time and 'time-outs' in het 'rookers hok' the first years.

Johan and Juanita, thank you for your help as my students. It was a pleasure working with you and you were an incredible help for the studies.

Chris, you were a special person for me from the beginning. Thank you for so much that would take too much room to mention.

Ron, Sjoerd, Ruud and Geranda. Best house-mates one can wish for. Ronnie, sjoerd, thanks for being 'my family' and firiends through thick and thin during that time in Maastricht.

Guy and Marieke, thank you for standing behind me during the defense of this thesis. I wanted you for that since you did that "standing behind" me many times before during the last four years already and I thought you did an amazing job.

Ute, Ferdi, Tina und Marco. Danke für die Zeit, die Unterstützung und den Mut, den inr mir die letzten vier Jahre gegeben habt. Hagen, danke, daß du so ein klasse Bruder bist.

Louis, you brought me to one of the very few places where I feel 'at home'. I hope that we can meet, connect and share that place for a long time. 
Acki, Du hast die meiste Zeit dieser vier Jahre an meiner Seite, vor und hinter mir gestanden. Du hast meine Freude getelt und Tränen getrocknet. Du bist mein 'soulmate, einzigartig, nicht ersetzbar und das wirst du auch nie sein. Danke für alles.

Esther und Nicki, ihr seid die zwei Diamanten, die ich in meinem Samtkästchen mit mir trage. Mehr als eine Freundschaft, unbeschreiblich und besonders. Ich weiss nicht, was ich ohne euch machen würde. Ihr seid der wertwollste Schatz, den ich 'besitze'. Danke.

Mama und $\mathbf{P a p a}$, auch wern ihr manchmal nicht versteht was ich für komische Ideen habe, habt ihr mich immer vorbehaltios unterstützt. DaB ich jetzt hier stehe, habe ich euch zu verdanken. 


\section{Publications}

\section{Full papers}

Adam, T.C.M. \& Westerterp-Plantenga. Nutrient stimulated GLP-1 release in normalweight men and women. Hormone and Metabolic Research (In Press)

Adam, T.C.M. \& Westerterp-Plantenga. Activity induced GLP-1 release in lean and obese subjects. Physiology \& Behavior (In Press)

Adam, T.C.M. \& Westerterp-Plantenga. GLP 1 release and satiety after a nutrient challenge in normal weight and obese subjects.

British Journal of Nutrition (In Press)

Adam, T.C.M., Jocken, J. \& Westerterp-Plantenga. Decreased GLP-1 release after weight loss in obese subjects. Submitted for publication 2004

Adam, T.C.M. \& Westerterp-Plantenga. Nutrient stimulated GLP-1 release after bodyweight loss and weight maintenance in humans. Submitted for publication 2004.

Hughes T.E., Westerterp-Plantenga M.S. \& Adam T.C.M. (2004) Nutritional compositions comprising a non-glucose carbohydrate or pectine and soluble fiber. In wO 2004/022074 A1. Patent

\section{Published abstracts}

Adam, TCM \& Westerterp-Plantenga, MS (2002). Moderate exercise stimulates GLP-1 release in healthy, normal-weight subjects.

Appetite 39(1): 62 .

Adam, TCM \& Westerterp-Plantenga, MS (2003). Long-term effect of physical activity induced weight-loss on GLP-1 release in overweight subjects.

Appetite 40(3): 314 .

Adam, TCM \& Westerterp-Plantenga, MS (2004). GLP-1 release and satiety after a nutrient chanllenge in normal-weight and modestly obese subjects.

International Journal of Obesity 28(Suppl.1): 167.

Adam, TCM \& Westerterp.Plantenga, MS (2004). Effect of weight lass on GLP-1 release in modestly obese subjects.

International Journal of Obesity 28(Suppl.1): 175.

Adam, TCM \& WesterterpmPlantenga, MS (2004). GLP=1 release in obese subjects before and after weight loss and weight maintenance.

International Journal of Obesity 28(Suppl.1): 175. 


\section{Curriculum vitae}




\section{Curriculum vitae}

Tanja Comella Maria Adam was born on 11 January 1974 in Andernach, Germany. She completed secondary school in Bad Neuenahr Ahrweiler in 1993.

In the same year she started her academic education at the Trier University, Germany, where she studied Psychology. As part of her training she completed a four months internship at the Psychosomatic Clinic Roseneck in Germany and a three months internship at the Columbia University, New York at the Obesity Research Center. She graduated in 2000 .

In the same year she started her Ph.D. research "Glucagon-like Peptide 1(GLP-1) stimulation in relation to body weight" at the Department of Human Biology, Maastricht University. Her research was mainly focused on finding different ways to endogenously stimulate GLP-1 release in subjects with different weight status, as well as the effects on satiety and changes in body weight. The research performed during this period is described in this thesis. In November 2004 she started her postdoctoral fellowship at the Department of Human Biology, Maastricht University, which will partly take place at the Department of Heaith Sciences at the University of California, San Francisco. 
Wohlan denn, Herz, nimm Abschied und gesunde!

(Herman Hesse, "Stufen") 